DYNAMICS OF THE EQUATORIAL UNDERCURRENT AND ITS TERMINATION

by

Sophie Huguette Claire Wacongne

Doctorat $3^{e}$ cycle en "Physique des Liquides"

Université Paris 6, France (1980)

Maîtrise, Université Paris 6, France (1977)

SUBMITTED IN PARTIAL FULFILLMENT OF THE REQUIREMENTS FOR

THE DEGREE OF DOCTOR OF PHILOSOPHY

at the

Massachusetts Institute of Technology

and the

Woods Hole Oceanographic Institution

January 1988

(C) Sophie Wacongne 1988

The author hereby grants to MIT permission to reproduce and to distribute copies of this thesis document in whole or in part

Signature of the Author

Joint Program In Oceanography, Massachusetts

Institute of Technology - Woods Hole Oceanographic Institution

Certified by:

Mark Cane

Philip Richardson...

Thesis Supervisors

Accepted by:

Doseph Pedlosky

Chairman, Joint Committee for Physical Oceapography

Massachusetts Institute of Technology - Woods Hote

Oceanographic Institution 
2 


\title{
DYNAMICS OF THE EQUATORIAL UNDERCURRENT AND ITS TERMINATION
}

\author{
by $S$. Wacongne
}

submitted in January 1988 in partial fulfillment of the requirements for the Degree of Doctor of Philosophy in Physical Oceanography.

\section{ABSTRACT}

This study focuses on the zonal weakening, eastern termination and seasonal variations of the Atlantic equatorial undercurrent (EUC). The main and most original contribution of the dissertation is a detailed analysis of the Atlantic EUC simulated by Philander and Pacanowski's (1986)general circulation model (GCM), which provides a novel description of the dynamical regimes governing various regions of a noni inear stratified undercurrent.

Only in a narrow deep western region of the simulation does one find an approximately inertial regime corresponding to zonal acceleration. El sewhere frictional processes cannot be ignored. The bulk of the mid-basin model EUC terminates in the overlying westward surface flow while only a small fraction (the deeper more inertial layers) terminates at the eastern coast. In agreement with observations, a robust feature of the GCM not present in simpler models is the apparent migration of the EUC core from above the thermocline in the west to below it in the east. In the GCM, this happens because the eastward flow is eroded more efficiently by vertical friction above the base of the thermocline than by lateral friction at greater depths. This mechanism is a plausible one for the observed EUC. A scale analysis using a depth scale which decreases with distance eastwards predicts the model zonal transition between western inertial and eastern inertio-frictional regimes. Historical and recent observations and simple models of the equatorial and coastal eastern undercurrents are reviewed, and a new analys is of current measurements in the eastern equatorial Atlantic is presented. Although the measurements are inadequate for definitive conclusions, they suggest that Lukas' (1981) claim of a spring surge of the Pacific EUC to the eastern coast and a seasonal branching of the EUC into a coastal southeastward undercurrent may also hold for the Atlantic ocean. To improve the agreement between observed and modelled strength of the eastern undercurrent, it is suggested that the eddy coefficient of horizontal mixing should be reduced in future GCM simulations.

Thes is supervisors:

Mark Cane, Doherty Senior Scientist, Adjunct Associate Professor in Geological Siences, Visiting Professor at the Center for Meteorology and Physical Oceanography at M.I.T.

Philip Richardson, Associate Scientist, Physical Oceanography, W.H.O.I. 


\section{ACKNOWLEDGEMENTS}

To some degree, the completion of this dissertation has undoubtedly been an exciting motivating and enjoyable scientific experience. It would be unfair however not to mention that it also involved draining struggles with dead ends, with changes of focus, with misunderstandings, and with the "spirit of the deadl ine".

I therefore wish to insist on my deep gratitude to Mark Cane, Phil Richardson and George Philander not only for their guidance but also for their constant heart warming display of optimism and confidence. I attribute my perseverance to the combined effect of their always positive attitude, the affectionate support of my officemates, housemates and other friends and relatives, the balancing presence of Kevin, and shear obstinacy on my part, for all of which I am very thankful.

I also thank Paola Rizzoli, John Toole and Joe Pedlosky for the time they spent at giving me valuable detailed comments on my dissertation. Paola and John deserve extra thanks for their patience and goodheartedness at committee meetings, and Joe for the excellent job he did at tempering any undue excess of optimism along the way.

I am pleased and grateful that Nick Fofonoff agreed to chair my thesis defense, and I have to acknowledge the help I received from my self appointed "anti advisor" Bill Schmitz towards keeping my sense of humor alive.

I am indebted to Bruno Voituriez and Boer Piton who let me use their Gulf of Guinea profiler current meter data, and to Jean-Jacques Lechauve and Daniel Corre who prepared the tapes. I am deeply indebted to Ron Pacanowski who provided the model data that I analysed and kind$1 y$ helped me decipher the model code and the GFDL computer 1anguage, and to Mary Hunt who adapted the tape decoding software provided by Steve Hankin. I am also forever indebted to Mary Ann Lukas who typed and edited most of my dissertation as if it was fun, and I thank Jayne Doucette who drafted some of the figures.

My interaction with the scientists involved in the SEQUAL/FOCAL program has been instructive in many ways and very motivating, and I thank them all for having made me feel at ease in their company. Repeated encouragements from Ed Sarachik and conversations with Eli Katz and Christian Col in were specially appreciated.

Finally I wish to thank the Joint Program for having given me the opportunity to spend several years among the American oceanographic community, pursue my education and meet the great people I met, and I thank the staff of M.I.T.'s International Students Office for their helpfulness and efficiency.

Special thoughts went to Melissa, Joyce and Betsy during the writing of this thesis.

This work was supported by NSF grants OCE 82-14771, OCE82-08744 and OCE85-14885. 
TABLE OF CONTENTS

Introduction

p. 11

Chapter 1:OBSERVATIONAL AND THEORETICAL REVIEW

p. 15

1.1 Wind forcing over the tropics

p. 16

1.2 Simplest explanations for the existence of steady

p. 20 eastward flow within the equatorial thermocline

1.2.1 Zonal pressure gradient forcing

1.2. 2 Conservation of vorticity

1.2.3 Driving by upwelling

1.3 Observations of the equatorial zonal pressure gradient p. 26 (or of the longitudinal structure of the dynamic topography)

1.3.1 Seasonal variations of the equatorial $Z P G$ in the Atlantic

1.3.2 Seasonal variations of the equatorial $Z P G$ in the Pacific

1.3.3 Seasonal variations of the equatorial $Z P G$ in the Indian Ocean

1.4 Observational basis for a relationship between EUC and p. 40 ZPG

1.4.1 Zonal circulation

1.4.1.1 Atlantic undercurrent

1.4.1.2 Pacific undercurrent

1.4.2 Meridional circulation

1.4.2.1 Observations in the Pacific Ocean

1.4.2.2 Observations in the Atlantic Ocean

1.4.3 EUC eastern termination

1.5 The system of governing equations at the equator

p. 65 
1.6 Review of EUC models

p. 73

1.6.1 Steady mode1s

1.6.1.1 Layer models

1.6.1.2 Continuously stratified models

1.6.2 Time-dependent models

Chapter 2: EASTERN TERMINATION OF THE EQUATORIAL UNDERCURRENT p.101

2.1 Eastern termination of the Pacific EUC p.102

2.2 Eastern termination of the Atlantic EUC p.114

2.3 Current meter measurements in the eastern Gul $f$ of $\quad$.137 Guinea

2.4 Seasonal variations of the EUC at $4^{\circ} \mathrm{W} \quad$ p.151

2.5 Coastal undercurrent off the coast of Gabon p.174

$\begin{array}{lll}2.6 \text { Conclusion } & \text { p.187 }\end{array}$

Chapter 3: DYNAMICS OF A SIMULATED EQUATOR IAL UNDERCURRENT p.195

3.1 Basic features of the model p.196

3.2 Description of the simulated circulation p.200

3.2.1 Annual mean

3.2.2 Time dependence

3.3 Dynamical analysis of the general circulation model p.220

3.3.1 Zonal evolution of the annually averaged zonal momentum balance (ZMB) along the equator

3.3.2 Meridional structure of the annually averaged ZMB at various 1 ongitudes

3.3.3 Time evolution of the ZMB at $0^{\circ} \mathrm{N} 25^{\circ} \mathrm{W}$

Chapter 4: PERFORMANCE OF THE GENERAL CIRCULATION MODEL p .283

IN SIMULATING ATLANTIC OBSERVATIONS

$\begin{array}{ll}4.1 \text { The SEQUAL run } & \text { p.289 }\end{array}$

$\begin{array}{ll}4.2 \text { The half climatology run } & \text { p.299 }\end{array}$

4. 3 Discussion p.299

4.4 Possible ways to improve the simulation p.306 
Chapter 5: DISCUSSION OF THE EQUATORIAL UNDERCURRENT DYNAMICS SIMULATED BY THE GENERAL CIRCULATION MODEL

5.1 Comparison between the dynamical regimes simulated p. 310 by the GCM and by simpler models 5.1.1 Charney's (1960) nonl inear frictional EUC 5.1.2 Pediosky's (1987) purely inertial EUC 5.1.3 Veronis' (1960) nonlinear frictional stratified EUC

5.2 Vertical scales relevant for the dynamical regimes p.317 simulated by the GCM

5.3 Conceptual model of an $x$-dependent upper undercurrent p.324 5.3.1 Input from scale analysis

5.3.2 Simulation of a zonal transition between regimes under zonally uniform easterly wind forcing

5.4 Justification for a deep undercurrent in the simulation

References

Appendix I: MERIDIONAL STRUCTURE OF THE FLOW AND OF THE ZONAL P. 353 MOMENTUM BALANCE SIMULATED BY THE GENERAL CIRCULATION MODEL 
à Catherine 
INTRODUCTION

The equatorial undercurrent (EUC) is a swift narrow subsurface jet found in the equatorial Pacific and Atlantic thermocline (and in the Indian Ocean thermocline on a seasonal basis) below predominantly westward surface flow. This current has been the object of many observational and theoretical studies over the last forty years which resulted in an abundant literature on observations and theoretical justifications of the undercurrent existence. The following questions related to the dynamics of the EUC are however still unanswered. How does the EUC form in the western equatorial oceans and how does it terminate in the east? What is the zonal evolution of the system? How do EUC speed and transport depend upon the forcing? (Why is the Pacific EUC stronger than the Atlantic EUC, given southeasterlies of similar magnitude over both basins?) How does the EUC vary on seasonal and interannual time scales?

This thesis contributes elements of answers to some of these questions, through two distinct studies. The first, observational, is aimed at determining whether presently available velocity measurements in the Gulf of Guinea (eastern equatorial Atlantic) confirm the circulation pattern for the EUC termination inferred from indirect methods. Special attention is given to a southeastward branching of the EUC into a poleward coastal undercurrent. While it is demonstrated that the spatial and temporal distribution of the velocity measurements is inadequate to allow for definitive conclusions, two partial conclusions can be made. First the analysis of unpublished moored profiler current meter measurements off Gabon and Congo presented in this thesis provides the first statistically significant estimate of a mean poleward undercurrent (possibly seasonal) above the shelf break. Second the various 
velocity measurements reviewed in the eastern equatorial Pacific and At1antic do not contradict Lukas'(1981) hypothesis of a seasonal surge of eastern EUC waters leading to a direct seasonal branching of the EUC into the coastal southeastward undercurrent near the longitude where the equator meets the eastern boundary.

The second study proposes a possible balance of zonal forces for a nonlinear stratified EUC. The results are obtained from the diagnostic analysis of a climatologically forced general circulation model (GCM) of the tropical Atlantic (Philander and Pacanowski, 1986a). No complete theory of a nonlinear stratified undercurrent is presently available, and no set of measurements yields estimates of all dynamical terms at one time. Thus the appropriate set of approximations one should use to study the dynamics of the observed EUC is not conclusively determined. However, that the core of the EUC is generally found in the thermocline suggests the importance of stratification. Further, both direct measurements and order of magnitude estimates point to the importance of the advective terms in the zonal momentum equation. On the other hand, theoretical studies have shown that virtually any combination of terms from the zonal momentum balance can result in an eastward subsurface flow under realistic forcing, even in a homogeneous layer. The approach undertaken in this dissertation was thus a logical step: start with the flow simulated by a model able to reproduce most of the physical processes expected to play a role at the equator, and reconstitute the dynamical balances within the simulated flow. The simulated flow is thus described in detail, the terms of the zonal momentum balance are computed, several regions of simplified dynamical regimes are identified and the relevance to the real ocean is discussed. This somewhat novel approach is found powerful and promising for the study of other oceanic processes with comparably rich dynamics.

The most robust feature of the EUC zonal evolution in both the observations and the simulation is shown to be a relative eastward diving of the EUC core from above the (deep) western thermocline to 
bel ow the (shallow) eastern thermocline. Simpler models of the undercurrent have so far been unable to simulate this feature, justifying our analysis of the GCM. The reason for the apparent crossing of the thermocline by the EUC in the model can be traced to differential dissipation on the upper and lower layers of the undercurrent: the eastward momentum of the upper layers is dissipated at a fast rate by vigorous vertical friction against the overlying westward flow, while the eastward momentum of the lower layers is dissipated at a slow rate by weak lateral friction. Even though there is in the west more eastward momentum above than below the base of the thermocline, the upper momentum is discarded faster along the EUC eastward course and the vertical profiles in the east eventually exhibit more eastward momentum below than above the base of the thermocline. We suggest that this is a plausible mechanism for the apparent crossing of the thermocline by the observed undercurrent.

A simple scale argument applied to the upper undercurrent can explain the zonal transition between the inertial and the eastern frictional regimes identified in the GCM simulation. It is argued that a proper depth scale for the upper undercurrent must decrease from west to east as does the thermocline depth. Therefore a longitude can exist at which the decreasing depth scale of the inertial regime becomes comparable to the depth scale of the overlying frictional sublayer (directly forced by the imposed wind stress), and past which the two regimes merge into one.

The dissertation is organized as follows:

Chapter 1 presents a review of observations and theories of the EUC of relevance to its zonal and temporal variations, focusing on the possible role of zonal pressure gradient variations in forcing EUC variations. 
Chapter 2 concentrates on the EUC termination in the eastern equatorial Pacific and Atlantic oceans and presents a new analysis of data bearing on the question of the connection of the Atlantic EUC to a poleward undercurrent off Gabon and to the EUC seasonality at $4 \% \mathrm{~W}$.

Chapter 3 contains the diagnostic analysis of the Atlantic EUC simulated by the Philander and Pacanowski's GCM and the description of the zonal, meridional, vertical and temporal structure of the model zonal momentum balance.

Chapter 4 analyses the performance of the GCM in simulating real

Atlantic observations and proposes parameter changes which may improve the agreement between the two.

Chapter 5 offers a more conceptual interpretation of the dynamical regimes identitied in the GCM simulation. These regimes are compared to the predictions of steady models and a new simple conceptual model of an upper $x$-dependent EUC is built, which provides a visual illustration of the zonal transition between western inertial and eastern frictional regimes. 
Chapter 1. OBSERVATIONAL AND THEORETICAL REVIEW

This chapter discusses basic concepts for the existence of the equatorial undercurrent and reviews current knowledge of $i$ ts 1 arge scale zonal evolution based on available observations and model predictions. Observational and theoretical evidence for a relationship between the zonal structure of the EUC and that of the wind stress forcing (via basin-wide pressure gradients and local upwelling) is specially investigated.

For general reviews of equatorial and undercurrent measurements and dynamics, the reader is referred to Arthur (1960), Montgomery (1962), Philander (1973), Gi11 (1975), Moore and Philander (1977), O'Brien (1979), Philander (1980), Leetmaa, McCreary and Moore (1981), Cane and Sarachik (1983), Knox and Anderson (1985), McPhaden (1986), and Eriksen and Katz (1987). 


\subsection{Wind forcing over the tropics}

The main wind system over the tropical Atlantic and Pacific Oceans are the Southeast trades, which converge towards the Northeast trades, meeting them at the intertropical convergence zone (ITCZ), located on average north of the equator. In both oceans, this regime becomes a southwest monsoon over the easternmost basin. The dynamical forcing is therefore neither symmetrical with respect to the equator nor uniform with longitude. On seasonal time scales, the ITCZ migrates meridionally, creating in the central equatorial Atlantic and Pacific a pattern of strongest winds during boreal summer when the ITCZ lies at its northernmost position, a secondary maximum during austral summer when it reaches south of the equator, and weakest winds in early spring, with a secondary minimum in late fall. Climatological wind stress fields were computed for example by Wyrtki and Meyers (1976) for the Pacific Ocean, and by Hellerman and Rosenstein (1983) for the world oceans.

The main differences in the wind fields of the tropical Atlantic and Pacific are found in their structure with longitude (Figure 1) and in the relative importance of their interannual and seasonal variations. Over the Atlantic ocean, the mean zonal wind stress, from westerly off the African coast, grows more and more easterly towards the west, and reaches a peak near $40^{\circ} \mathrm{W}$, very close to the Brazilian coast. Over the Pacific 0cean, which is between two and three times as wide as the Atlantic, the mean wind stress is again, from westerly off the coasts of Ecuador, more and more easterly towards the west, but it peaks around $150^{\circ} \mathrm{W}$, i.e. at about the center of the basin, and decreases further west to westerly off Indonesia. Part of the year, westerly winds are observed over much of the western Pacific. If one compares only the zonal wind stress over the Atlantic and the eastern Pacific, longitudinal patterns are actually very similar. Differences occur in the ranges of variation of the zonal wind stress with time: seasonal changes have similar amplitudes in the eastern Atlantic and the easternmost Pacific, but they are 1 arger in the western Atlantic 10.5 to 1.0 dynes $/ \mathrm{cm}^{2}$ ) than in the central Pacific $\left(0.5\right.$ to 0.8 dynes $\left./ \mathrm{cm}^{2}\right)$. 

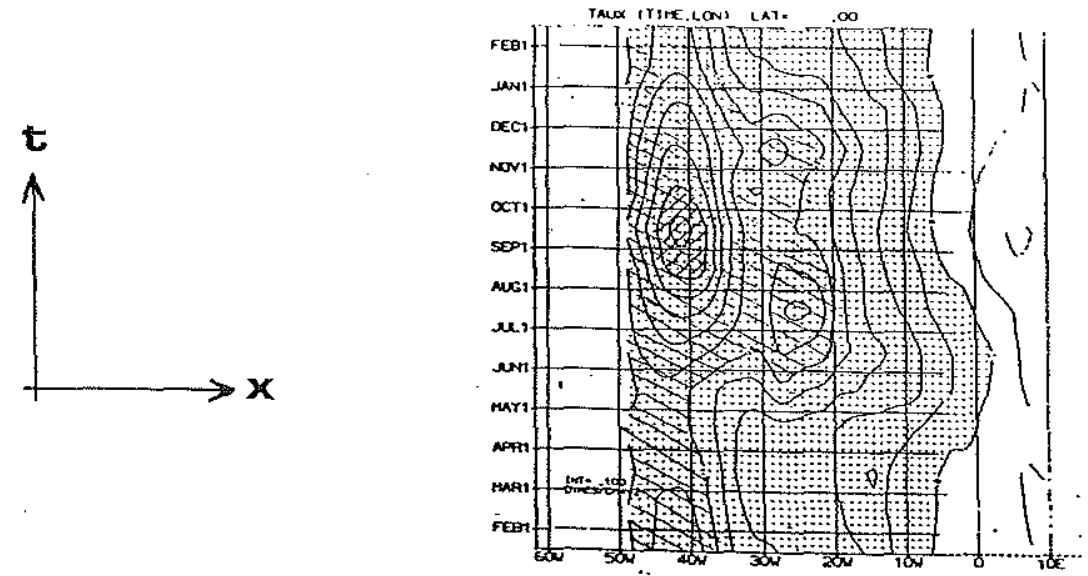

a

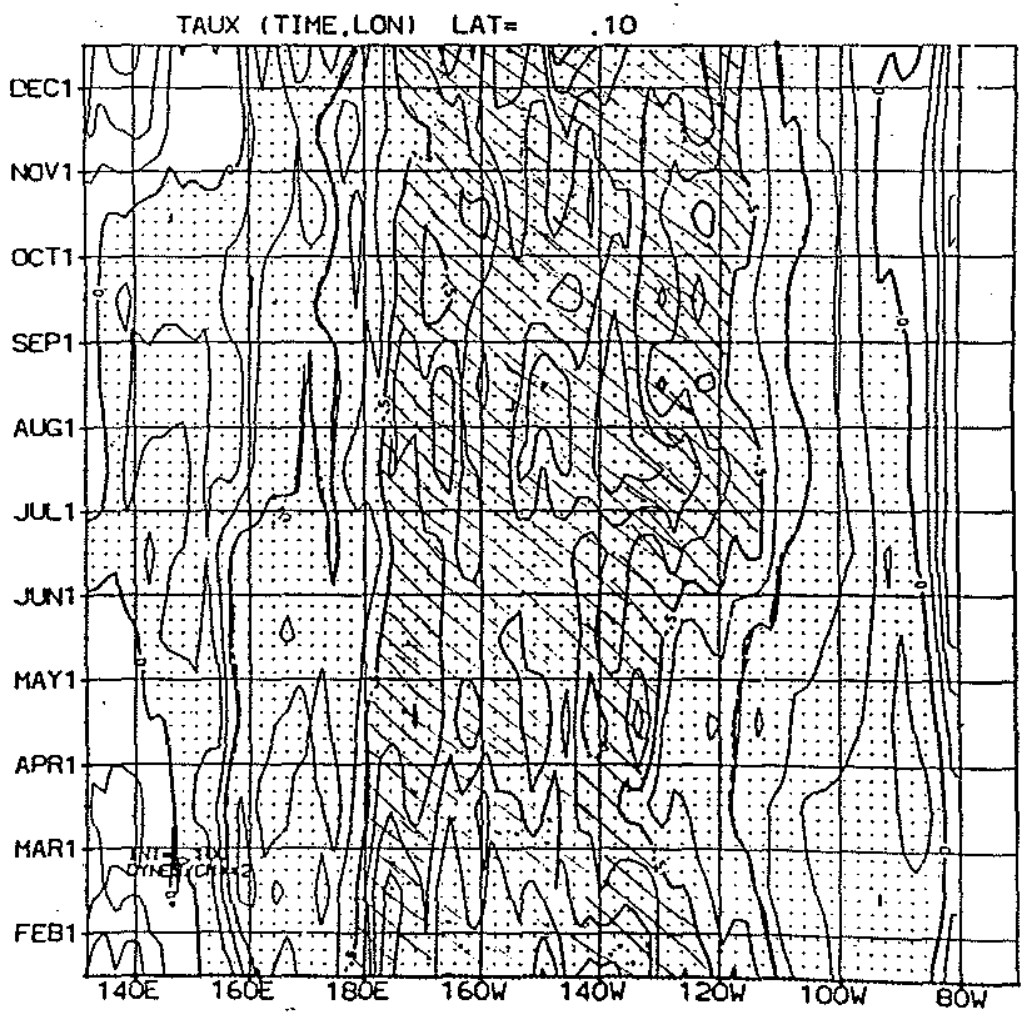

b

Figure 1: Longitude-time plots of the Hellerman and Rosenstein (1983) zonal wind stress at the equator over (a) the Atlantic Ocean; (b) the Pacific 0cean. Easterlies are dotted; values larger than -0.5 dynes $/ \mathrm{cm}^{2}$ (in absolute value) are cross-hatched. (Philander and Pacanowski, personal communication). 
Also, while the Atlantic seasonal signal is more annual (one extremum per year) in the west, more semi-annual (two extrema per year) in the center and the east (due to the tilt of the ITCZ), the Pacific seasonal signal is more annual at the easternmost and westernmost longitudes, and more semi-annual at the center of the basin. Finally, interannual wind variations have been observed over both the equatorial Pacific, where they have been intensively investigated in connection with El Nino events (Wyrtki, 1975), and the equatorial Atlantic (Picaut et al., 1984). In both cases, interannual variations affect more the central or western 1ongitudes than the eastern ones. Their amplitude is, however, larger in the central and western Pacific (where they can dominate the seasonal signal) than in the western Atlantic.

The situation over the tropical Indian ocean is drastically different. Each year, southwest winds dominate the atmospheric circulation during boreal summer and globally switch to the northeast for a few months during boreal winter (Wyrtki, 1973). Only then is the wind stress field similar to that over the other two equatorial oceans, with however a northerly rather than a southerly component and a more complicated zonal structure (easterlies are confined to the western part of the basin only).

Steady easterlies blowing over a meridionally bounded tropical ocean have two main effects on the surface water: (1) to pile it up towards the western boundary along the equator, creating an eastward zonal pressure gradient (ZPG) force which acts against the wind stress, (2) to drive it polewards through Ekman divergence, creating upwelling at the equator to replenish mass. The presence of a southerly wind component introduces a meridional asymmetry: surface waters are driven northwards across the equator and a convergence (divergence) appears north (south) of it at the latitude of transition with the offequatorial eastward (westward) Ekman transport. [In the simplest case of an $\mathrm{x}$-independent southerly wind, the ocean response is also $\mathrm{x}-$ independent (away from meridional boundaries) and the convergence and divergence north and south of the equator are purely meridional (Cromwe11, 1953). Their existence does not require nonl inearities.] 
The latitudes of convergence and divergence constitute dynamical boundaries onto which a meridional tilt of the sea surface slope gets anchored, upwards to the north, corresponding to a southward pressure gradient force which opposes the southerly wind stress. The combined effect of the easterly and southerly components of the wind is therefore to create a southeastward pressure gradient force at the equator and to displace the region of divergence south of the equator. As the winds change, so do the surface ZPG, the upwelling rate, and presumably the equatorial circulation as a whole. But the way in which the adjustment takes place depends on the magnitude and the rapidity of the changes in the wind stress since these changes affect the Ekman flow and thus the upwelling rate instantly, but they affect the ZPG on a longer time scale as adjustment of the density field requires propagation and reflections of equatorial waves (section 1.6.2).

\subsection{Simplest explanations for the existence of steady eastward flow within the equatorial thermocline \\ The earliest models of a steady EUC are based on three} main ideas: zonal pressure gradient forcing, conservation of vorticity and driving by upwelling.

\subsubsection{Zonal pressure_gradient forcing}

Since the Coriol is force becomes zero at the equator, no deflection occurs there, and zonal flow is expected to be driven by zonal forces. Accordingly, the EUC has been described as a compensation current flowing "downhill" below a frictionally driven westward surface flow. The implicit assumption is made that the vertical decay scale of westward stress due to the local wind is less than that of the eastward ZPG force set up basinwide by the easterlies which accumulate water at the western boundary of the ocean. (That the frictional stresses would become negligible at shallower depths than the ZPG force is an empirical fact at higher latitudes where theories of a thermally 
driven inviscid interior are very successful; however frictional effects may reach deeper at the equator where penetration scales are difficult to predict a priori). In a stratified ocean with a sharp thermocline, one expects pressure gradients to weaken rapidly with depth through baroclinic adjustment and to become negligible below the thermocline, and one expects motion below the thermocline to be much weaker than motion above, with the EUC confined at levels of net eastward force. The importance of the equatorial ZPG was first stressed by Montgomery and Palmen in 1940, in connection with the dynamics of the North Equatorial Countercurrent (NECC). Their arguments apply more convincingly to the EUC, as the deflecting force present at the latitude of the NECC vanishes at the equator, simplifying the reasoning. Thus, in a baroclinic system forced by steady easterlies, the expected vertical profile of $\left(-p_{x}\right)$ is maximum (and positive) at the surface. In other words, the ZPG forcing exists (with weakening amp1itude) from the surface down to some level in or below the thermocline, and its tendency is to drive the corresponding water column eastwards in a surface-intensified jet. Only because of the presence of the stress-driven surface westward flow (which sets up the opposing ZPG) does the "undercurrent" have a subsurface core. If the local winds, after establishing the ZPG, were to disappear temporarily, then on time scales short compared to the relaxation of the density field, the maximum eastward flow would indeed be found at the surface (Philander, 1973).

A similar argument applies to the meridional flow: with the southerly component of the wind stress driving frictionally a northern component of flow and creating a positive meridional surface slope across the equator, water at subsurface levels is expected to be driven southwards by the resulting meridional pressure gradient force, rationalizing the often observed slight southern shift of the EUC core. [During the 1982-84 FOCAL program, for example, six out of the nine cruises show such a shift near $25^{\circ} \mathrm{W}$ (Hénin, Hisard and Piton, 1986)]. 


\subsubsection{Conservation_of vorticity}

Looking at meridional sections of water properties in the central equatorial Pacific, Cromwell (1953) found evidence for equatorial upwelling, which he related to surface Ekman divergence off the equator. Using isentropic analysis, he then deduced a pattern of meridional circulation consisting of divergent flow at the surface, upwelling at the equator, and convergent flow in the thermocline, to be superimposed on any existing zonal flow.

Using an idealization of Cromwe11's meridional circulation, symmetrical with respect to the equator, Fofonoff and Montgomery (1955) showed that conservation of absolute vorticity implied a nonlinear transformation of the subsurface equatorward flow into eastward flow at the equator. As the authors pointed out, an eastward $Z P G$ force is still needed in that model to account for "the gain of eastward momentum by the water flowing towards the equator"; this is better understood in terms of gain of angular momentum, as explained by Cane (1980). Consider a steady frictionless horizontal system where $x$-gradients other than $p_{x}$ are negligible compared to y-gradients, and call $y_{0}$ the latitude from which water originates; the equations of conservation of momentum and vorticity reduce to:

$$
\begin{aligned}
& d u / d t-f v=\left(u_{y}-\beta y\right) v=-p_{x} / \rho \\
& d(f+\zeta) / d t=-v\left(u_{y}-\beta y\right)_{y}=0
\end{aligned}
$$

So:

$u_{y}-\beta y=-p_{x} /(\rho v)=-\beta y_{0}$, assuming $u_{y}\left(y_{0}\right)=0$,

$u_{y}=\beta y-p_{x} /(\rho v)=\beta\left(y-y_{0}\right)$

and, at $y=0$ :

$u(0)=-\beta y_{0}^{2} / 2+\int_{y_{0}}^{0}\left(-p_{x}\right) /(\rho v) d y=+\beta_{0}{ }^{2} / 2$, assuming $u\left(y_{0}\right)=0$.

Without a positive ZPG force $\left(-p_{x}\right)$, the angular momentum $\left(u_{y}-\beta y\right)$ would be conserved and the flow at the equator would be westwards [cf 
Hide's (1969) theorem according to which the winds at the equator cannot be westeriy]. Furthermore, it is because of the existence of a negative $\mathrm{p}_{x}$ in and above the thermocline that an equatorward return flow of Cromwe11's meridional circulation occurs and that it occurs geostrophically throughout these levels (rather than in some bottom frictional 1ayer), making the vorticity conservation argument relevant to the EUC. So one obtains the surprising result that the velocity of the EUC does not depend on the magnitude of the ZPG which forces it, but only on the latitude of origin of the meridional flow.

In terms of predicting $u(0)$ though, this result is more conceptual than practical, since it shifts the problem to that of predicting $y_{0}$. Furthermore, given $y_{0}$, one only gets an order of magnitude estimate for $u(0)$, since, rigourously, the above integration is not valid all the way to the equator where, in a steady state, friction is needed to remove the discontinuity in $u_{y}$, i.e. to "smear" out the unrealistic cusp that the above nonlinear solution develops. In order to satisfy $u_{y}=0$ at $y=0$, the approximation of the zonal momentum equation used above must break down within some equatorial boundary layer. More dynamical terms are needed to balance $p_{x}$, and the flow may no longer be considered two-dimensional and conservative. The case of a homogeneous ocean was treated accordingly by Charney (1960) and Charney and Spiegel (1971). Finally, saying that $u(0)$ does not depend on $p_{x}$ is not saying that $u(0)$ is independent of the wind forcing al together: if one estimates $y_{0}$ as the latitude of transition between 1 inear tropical regime and nonlinear equatorial regime, dimensional analysis for a homogeneous ocean gives a dependence of $y_{0}$, and therefore of $[u(0)]^{1 / 2}$, on $\tau^{2 / 5}$ according to Charney and Spiegel (1971), and Cane (1979), or on $\tau^{1 / 8}$ according to Pedlosky (1987) [cf section 5.1.2].

\subsubsection{Driving by upwe 11 ing}

On a meridional section, isopycnals display a vertical spreading equatorwards, with meridional slopes off the equator consistent with geostrophic eastward flow. Thus the presence of the EUC can 
be anticipated by geostrophic arguments (Yoshida, 1959) and the problem is to explain the meridional structure of density. Yoshida uses steady linear frictional dynamics in a stratified ocean to explain this meridional structure in analogy with coastal upwelling: isopycnals are deformed by the subsurface convergence and equatorial upwelling necessary to compensate the surface divergence caused by the easterlies, with upward advection of density balanced by downward diffusion. Subsurface convergence in turn may be due to equatorward flow in the central basin, according to Cromwell's meridional circulation, or to downstream deceleration of the EUC itself as it approaches the eastern boundary.

As Yoshida's ocean is viscous, meridional convergence needs not be geostrophic, and it might seem that his mechanism would generate an EUC independently of any ZPG. At closer look however, his argument may explain the upward sloping of the upper isopycnals equatorwards, but not the downward sloping of the lower ones. The change of sign of the slope is necessary for the existence of a subsurface eastward jet: according to the thermal wind equations, the upper region of spreading corresponds to a negative $u_{z}$, the lower region to a positive $u_{z}$. The simple equations used by Yoshida simulate an interesting surface poleward flow which peaks slightly off the equator and which tends to Ekman's solution at higher latitudes, and a surface-intensified zonal jet centered at the equator in the direction of the wind $\left(u_{z}<0\right)$. In the absence of ZPG, no eastward subsurface maximum is simulated unless artificial boundary conditions are imposed. But if a negative ZPG is present, it may become possible for $u_{z}$ to change sign with depth, and we are back to the case of ZPG forcing. Neglecting lateral friction, the steady linear zonal momentum balance (ZMB) reduces to:

$-\beta y v=-p_{X} / \rho+\left(v u_{z}\right)^{*}$

At the equator, if there is no $Z P G$ :

$\left(v u_{z}\right)_{z}=0$, with $v u_{z}=\tau^{(x)}$ at $z=0$

and so:

$v u_{z}=\tau^{(x)}<0$ for all $z$. 
If now there is a negative $Z P G$, i.e. a positive $Z P G$ force:

$-\left(v u_{z}\right)_{z}=-p_{x} / \rho$,

$v u_{z}=\tau(x)+\int_{z}^{0}\left(-p_{x} / \rho\right) d z$

Since $\tau^{(x)}<0$ and $\int_{z}^{0}\left(-p_{x} / p\right) d z>0$,

$v u_{z}$ increases (as $|z|$ increases) from the negative value it has at the surface, and becomes positive below the depth $D$ defined by:

$\int_{-D}^{0}\left(-p_{x} / \rho\right) d z=-\tau(x)$

provided that the variations of $p_{x}$ with $z$ make this definition possible. In this model it would be the subsurface eastward flow at the equator which, with the help of some lateral diffusion of momentum, creates the downward sloping of the lower isopycnals by geostrophic mass adjustment.

The ZPG and the vorticity conservation arguments reviewed above are not only the simplest but to date the only explanations for the existence of eastward momentum at the equator. Through the years, models of equatorial dynamics have tried to isolate the roles of stratification, nonlinearities, lateral versus vertical friction, global versus local forcing, and have been studied intensively to see how a steady state is reached when winds are switched on over an ocean basin initially at rest. They have not introduced al together new physical mechanisms for the EUC. Dimensional analysis and order of magnitude estimates indicate that a11 terms of the ZMB may be important at the equator. Their relative importance however is likely to change with depth and stratification, so that it may be possible to define distinct dynamical regimes over various depth ranges. Models which incorporate only some of the terms may then be representative of only some regimes. For instance, it is quite conceivable that, given an EUC whose core 
lies in the thermocline, dynamics such as those of the Charney's (1960) constant density nonlinear mode1 apply to the upper layers of the current (within the relatively well mixed surface 1ayer), while the mechanism of convergent equatorward flow, driven eastwards at the equator where $p_{x}$ is no longer balanced by the Coriolis force, apply to the lower layers imbedded in the thermocline.

Before discussing the predictions of more elaborate models in section 1.6, we will first review actual observations of the equatorial ZPG (1.3) and, when possible, relate them to observations of the meridional circulation and of the state of the EUC (1.4). Since we are interested in the large scale zonal evolution of the EUC, we will be more interested in estimates of the large scale than of the local equatorial ZPG.

\subsection{Observations of the equatorial ZPG (or of the longitudinal structure of the dynamic topography)}

After an early discussion by Arthur (1960), measurements of the ZPG have been reported, for the Pacific by Knauss (1966), Lemasson and Piton (1968), Tsuchiya (1979), Meyers (1979), Halpern (1980), Leetmaa and Spain (1981), Mangum and Hayes (1984), Bryden and Brady (1985) and Lukas (1986), for the Atlantic by Katz et al. (1977), Lass et al. (1983), Arnault (1984), Merle and Arnault (1985), Weisberg and Weingartner (1986), Katz et a1. (1986), and Hisard and Hénin (1987), for the Indian ocean by Taft and Knauss (1967) and Eriksen (1979). The case of the Indian ocean will be considered separately in the following, because of the extraordinary seasonality of the wind system there.

In both the equatorial Atlantic and Pacific oceans, directly measured sea levels (e.g. from sea level gauges at Pacific islands) are reported to be higher in the west on average. An upward slope of the thermocline to the east is observed, consistent with an upward slope of the sea surface to the west if one assumes small motions below the thermocline (two-layer approximation). Because of the large intensity of the currents above and in the thermocline, 
located around $150 \mathrm{~m}$ in the central Pacific, around $75 \mathrm{~m}$ in the central Atlantic, dynamic topography relative to a deeper level (typically chosen between $500 \mathrm{db}$ and $1000 \mathrm{db}$ ) is likely to represent pressure adequately, as long as one is not concerned with the deep circulation. Rebert et al. (1985) compared sea level gauge measurements to hydrographic data at several locations within the tropical Pacific Ocean. They checked that, between $15^{\circ} \mathrm{N}$ and $15^{\circ} \mathrm{S}$, a good correlation exists between directly measured sea levels and the dynamic topography of the sea surface relative to $400 \mathrm{~m}$.

When referenced to a deep level, pressure indeed decreases from west to east in the western and central equatorial Atlantic and Pacific. A typical order of magnitude for the surface $Z P G$ force is $5 \times 10^{-7} \mathrm{~m} \mathrm{~s}^{-2}$ (or equivalently $5 \times 10^{-5} \mathrm{dyn}^{-1}$ ) in the central basin of both oceans. The zonal slope however quickly flattens with depth as mass readjusts baroclinicly. In the Pacific ocean, Lemasson and Piton (1968) show that, for the period November 1964 to March 1965, the slope of the dynamic height anomaly relative to $700 \mathrm{db}$ is mostly flat at $200 \mathrm{db}$ along the equator (Figure 2a). A similar result is reported by Knauss (1966) who presents dynamic height relative to $1000 \mathrm{db}$ along the equator for the May 1958 Dolphin Expedition. In the Atlantic, Merle and Arnault (1985) show similarly a vanishing slope at $200 \mathrm{~m}$ of the annual mean relative to $500 \mathrm{db}$ averaged between $2^{\circ} \mathrm{N}$ and $2^{\circ} \mathrm{S}$ (Figure $2 \mathrm{~b}$ ). These results indicate, in agreement with local vertical profiles of $p_{x}$ reported for instance by Arthur (1960), Mangum and Hayes (1984) and Bryden and Brady (1985), that the ZPG becomes negligibly small shortly below the core of the EUC, as reviewed also in Weisberg and Weingartner (1986). (Then, according to Arthur's simple steady linear stratified model used at the end of section 1.2, the source for the eastward momentum still present in the region of no, or even slightly reversed, ZPG below the thermocline can be just downward diffusion from the core above).

Another feature apparent on the zonal sections of Figure 2 is the eastern reversa] of the surface $Z P G$, in regions of southwest monsoons in both oceans [i.e. east of about $10^{\circ} \mathrm{W}$ in the Atlantic and 
$90^{\circ} \mathrm{W}$ in the Pacific]. This has been suspected of slowing down the EUC (Knauss, 1966; Rinkel et al., 1966; Hi sard, 1973). The reversal however does not appear to reach deep below the surface and, at the levels of eastward flow, one sees more of a gradual decrease of the slope with longitude than a sudden change at a given longitude.

\subsubsection{Seasonal_variations of the equatorial ZPG in the Atlantic}

Seasonal variations of the ZPG in connection with seasonal variations of the zonal wind stress have been studied mostly in the equatorial Atlantic, using data from global experiments such as GATE (early to late summer 1974), FGGE (part of the Global Weather Experiment, August 1978 to March 1980), and SEQUAL/FOCAL (fall 1982 to fa11 1984).

Katz et a1. (1977) analysed the GATE data and, combining them with earlier observations from the experiments EQUALANT I (MarchApril 1963) and EQUALANT II (August-September 1963), found evidence for a seasonal cycle of the ZPG in phase with the seasonal cycle of the zonal wind stress, i.e. minimum in the spring when the ITCZ 1 ies closest to the equator, and maximum in early fall, after the ITCZ migrated to its northernmost location. The vertical integral of the $Z P G$, which is the quantity that one wishes to compare to the surface stress $\tau^{(x)}$ (cf section 1.2), was approximated by the value of $p_{x}$ at $50 \mathrm{db}$ (relative to $500 \mathrm{db}$ ), i.e. close to the EUC core depth, multiplied by a depth of $100 \mathrm{~m}$; a linear fit was computed through the data points west of $10^{\circ} \mathrm{W}$, reducing the field of ZPG to one value, which was then compared to a zonal average of the zonal wind stress. A similar analysis was performed from the FGGE data, confirming the pattern of lower ZPG in the spring, higher ZPG in the fall, and suggesting that these variations follow similar changes in the wind stress by one to two months (Lass et a1., 1983). A longitudinal variation was also noted in the western and central parts of the basin, attributed to a similar longitudinal variation in the wind, towards larger absolute values in the west. 


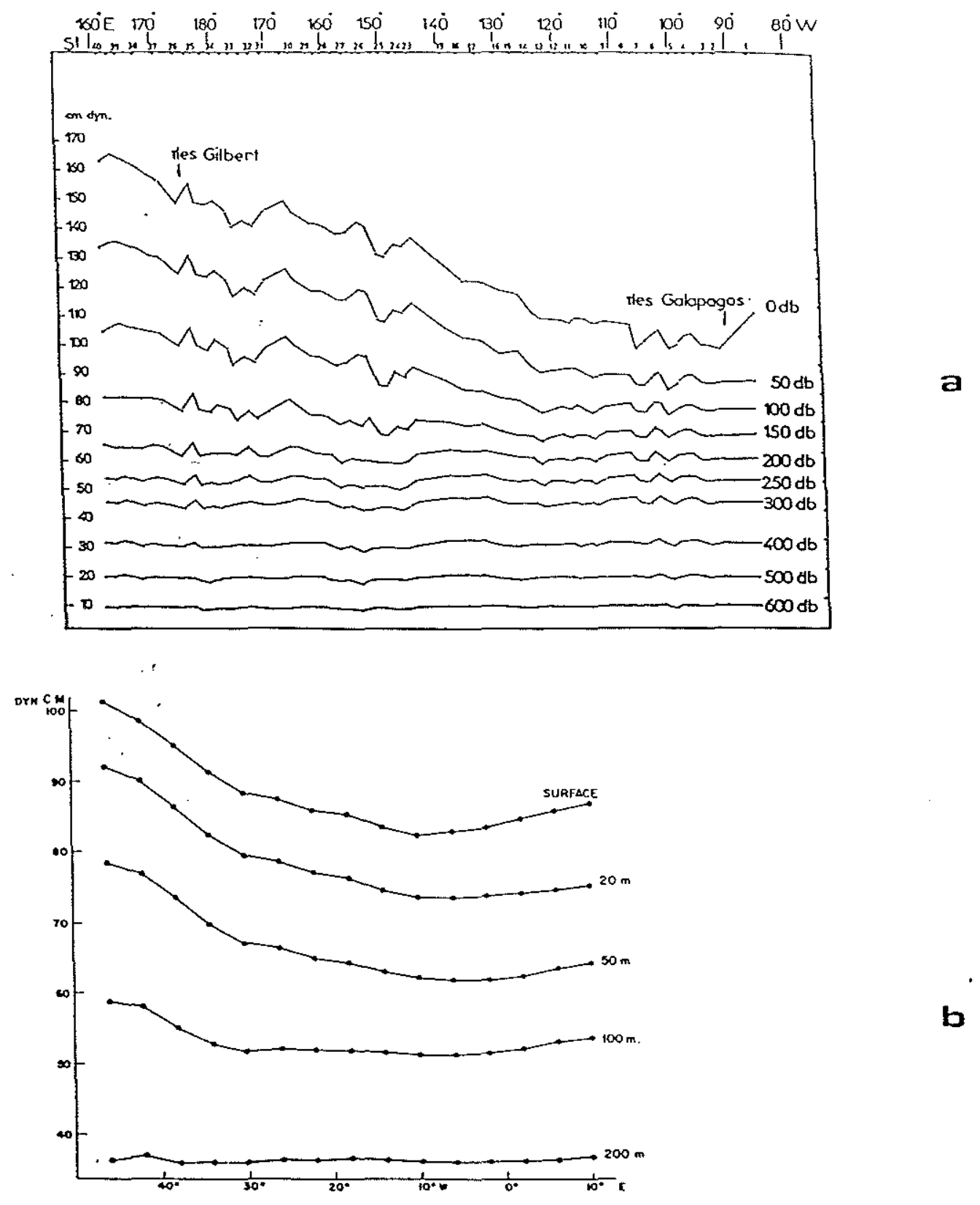

Figure 2: Equatorial sections of the dynamic topography (a) relative to $700 \mathrm{db}$ in the Pacific Ocean (November 1964-March 1965; Lemasson and Piton, 1968); (b) relative to $500 \mathrm{db}$ in the Atlantic Ocean (annual mean averaged between $2^{\circ} \mathrm{N}$ and $2^{\circ} \mathrm{S}$; Merle and Arnault, 1985). Note that at mid-basin, the EUC core is found around $120 \mathrm{~m}$ in the Pacific, around $80 \mathrm{~m}$ in the Atlantic. 
Results from the SEQUAL/FOCAL progam are presented in three papers. Katz et a1. (1986) describe the variations in sea surface slope from combined measurements using hydrographic stations, pressure gauges and inverted echo-sounders (Figure $3 a$ ). On a seasonal cycle similar to the one observed before, an interannual variation is superimposed: during the boreal winter of 1983-1984, an almost complete relaxation of eastward wind stress occurred in the central basin, accompanied by a levelling off of the sea surface to the west and a strong rise against the African coast; through 1984, the zonal wind stress remained lower than in 1983, with however a larger surface ZPG west of the Gulf of Guinea. Ten to fifteen days was the estimated time for the build up of the surface ZPG in response to the onset of the south-east winds.

Weisberg and Weingartner (1986) study how the sloping isopycnals reduce the surface ZPG by computing time series of the heat content between the surface and various depths using moored temperature data along the equator, and by forming zonal differences between pairs of these time series, taking the risk of aliasing spatial into temporal variations. According to their analysis, during periods of rapidly changing easterlies, the differentiated heat content experiences a rapid variation of one sign followed by a slow variation of the opposite sign; their interpretation is that the variations "overshoot their intended equilibrium and then gradually relax towards it". They also argue that the baroclinic response is zonally inhomogeneous and that its vertical structure varies with time.

Finally, Hisard and Hénin (1987) summarize measurements of the ZPG at 0 and $50 \mathrm{db}$ relative to $500 \mathrm{db}$ from the hydrographic data. The ZPG at $50 \mathrm{db}$ is seen to vary mostly in phase with the surface gradient, with, as expected, a weaker slope at $50 \mathrm{db}$, except in winter 1983 and, more strikingly, in winter 1984, when the value at depth exceeded the (lower than usual) surface value (Figure $3 b$ ). Unlike continuously sampled data from the echo-sounders or the moored temperature sensors, these hydrographic data poorly resolve variations in time, and the 1 ack of synopticity of the measurements may introduce an error in 
the zonal differencing. However, Hisard and Henin argue that they observe a $1 \mathrm{ag}$ of the order of two months between $Z P G$ and $\tau^{(x)}:$ ZPG force at $23^{\circ} \mathrm{W}$ and easterly wind stress at $40^{\circ} \mathrm{W}$ are both maximum in the fall and they both weaken in the winter, but the ZPG appears to reach $i$ ts minimum and to start building back up before the winds reach their own minimum and reintensify. According to Katz et a1. (1986), the echo-sounder signal does not reproduce such an early reintensification of the zonal slope in January 1984, but there is no echo-sounder data to compare to the estimate from hydrography in January 1983. Hisard and Hénin's interpretation of their data differs from the interpretation published in Katz et al. (1986): according to Hisard and Hénin, the maximum zonal slope and hence ZPG force estimated from the 1983 hydrographic casts occured in October (based on two data points only) while, in Katz et al., it is represented as occuring in July, and being followed by a weaker value in 0ctober in agreement with the echo-sounder signal. However, Hisard and Hénin's description of their data is not unlike Weisberg and Weingartner's "overshooting" argument, and their observation of a larger zonal slope at depth than at the surface in winter 1983 and 1984 agrees with Weisberg and Weingartner's suggestion that "subsurface gradients may not be in phase with those at the surface during a period of weak and variable winds". The question of the time 1 ag with the wind obviously requires some clarification, as not only do estimates of the date of the maximum zonal slope differ, but also the onset date appears to vary with longitude.

Hisard and Hénin also report measurements in the Gulf of Guinea (eastern equatorial Atlantic), showing variations with time of the intensity of the ZPG reversal and of its penetration at $50 \mathrm{db}$. Previous estimates based on climatological hydrographic data are presented in Arnault (1984) for each month of the year. East of about $5^{\circ} \mathrm{W}$ in February-March and in September, when the westerly component of the south-west monsoon is most intense, the zonal slope of the equatorial dynamic height field at various depths relative to $500 \mathrm{db}$ exhibits its largest upward slope towards the coast. In June, the slope in the Gulf 


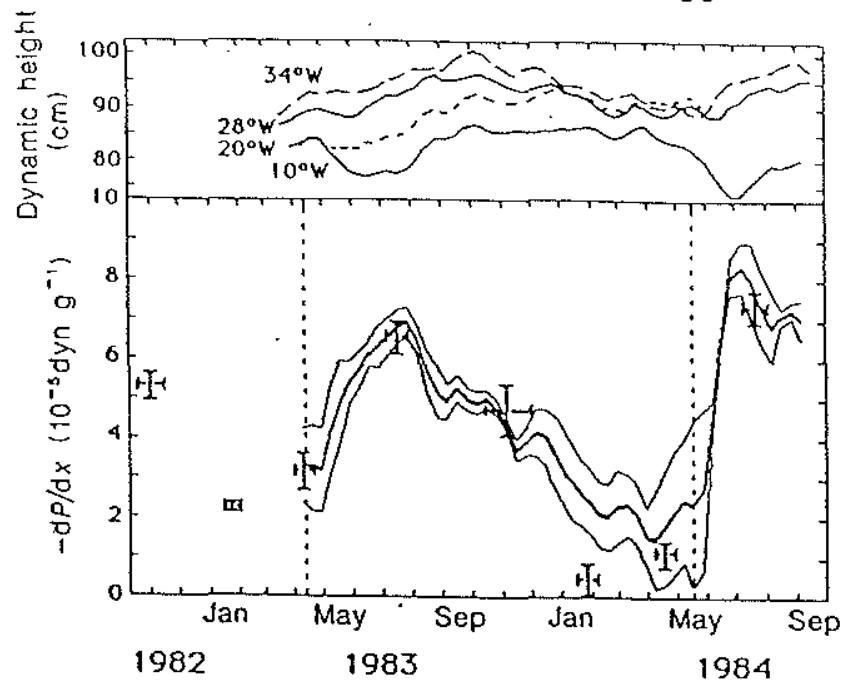

a

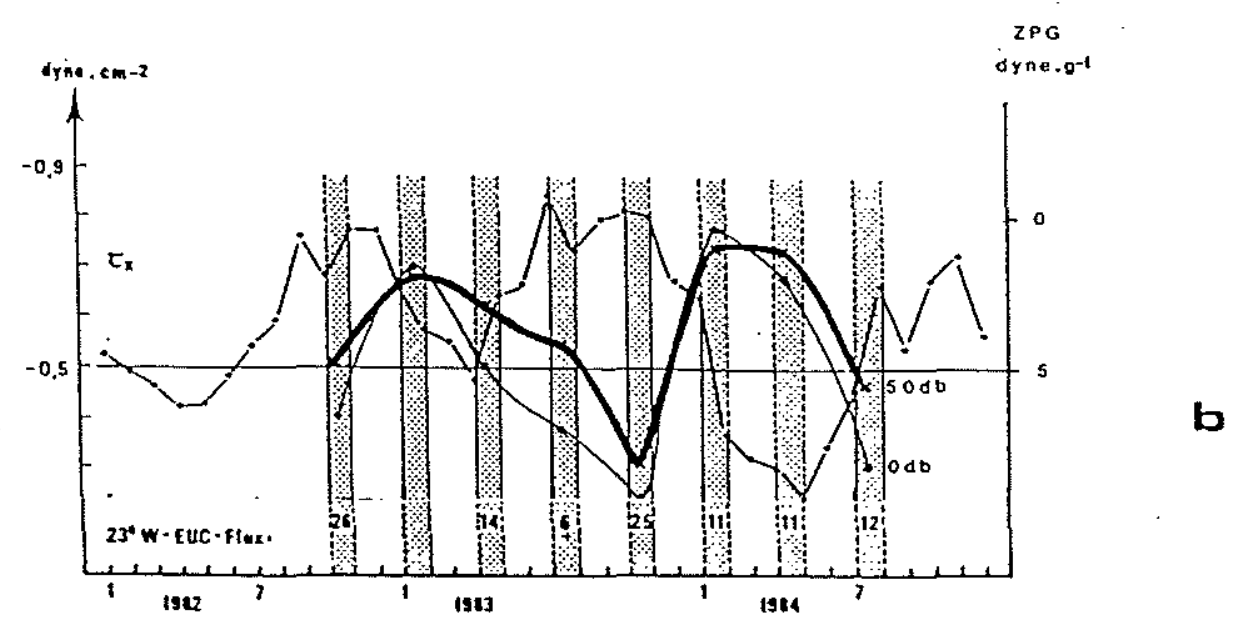

Figure 3: Time evolution of zonal pressure gradient estimates along the equator during SEQUAL/FOCAL.

a) Dynamic height (upper panel) and zonal pressure gradient force $-p_{x}$ (lower panel) between $34^{\circ} \mathrm{W}$ and $10 \mathrm{~W}$ from four inverted echo sounders. Points with error bars are from the hydrocast data (compare with b). Dashed lines indicate the time of onset of the southeast tradewind. (Katz et al., 1986). b) Thick and thin continuous lines link the point estimates of the zonal pressure gradient $+p_{x}$ at respectively 0 -dbar and 50-dbar relative to 500 dbar deduced from the hydrographic sections (compare with a). The interrupted line represents the monthly averaged zonal wind stress at $40^{\circ} \mathrm{W}$ during 1982-1984. Vertical dotted bands indicate the time of the cruises, and numbers at the bottom represent estimates of the EUC transport during these cruises. (Hisard and Hénin, 1987). 
of Guinea is negative as it is in the western and central basin. A secondary minimum of the positive slope occurs in winter. Qualitatively, such a sequence is observed by Hisard and Hénin between fall 1982 and summer 1983, but 1984 shows a reversed cycle: an unusually large eastern reversal of the otherwise negative zonal slope of dynamic height during winter 1984, no reversal during spring 1984 and a reversal similar to the one of fall 1982 in summer 1984. Again, the signal is not very well resolved in time and the quantitative determinations of the zonal slope and of the longitude of the reversal are somewhat subjective. Nevertheless these results illustrate how the anomalous character of 1984 was emphasized in the eastern basin, where substantially warmer and more saline waters accumulated during the early months of the year (Hisard et al., 1986).

In summary, it seems established that the ZPG field of the central and eastern equatorial Atlantic ocean varies seasonally and interannually in response to variations on similar time scales of the zonal wind stress. However, the time 1 ag between the changes in the wind and those in the ZPG is not firmly established (estimates range from one week to two months and opinions differ on what to use as a measure of "the wind"), and there are indications that the baroclinic mass adjustment varies in time in such a fashion that variations of the ZPG at depth (in particular at the levels of the EUC) do not necessarily mimic those at the surface.

\subsubsection{Seasonal variations of the equatorial ZPG in the Pacific}

In the huge equatorial Pacific basin, no observational program has had both the zonal and temporal coverage necessary for a reliable determination of either the annual average or the seasonal variations of the ZPG as a function of depth and longitude. The closest to a climatology of the sea surface slope is given by Meyers (1979), who studies the annual variation in the 1ongitudinal structure of the depth of the $14^{\circ} \mathrm{C}$-isotherm (located below the thermocline) as a proxy for that of the depth of the thermocline $i t s e l f$, and argues that they mirror adequately the changes in sea level in the central and western 
portions of the basin (cf Wyrtki, 1984). As seen on Figure 4a, the zonal slope of the $14^{\circ} \mathrm{C}$-i sotherm is steepest year-round between $170^{\circ} \mathrm{W}$ and $110^{\circ}, W$ (in reasonable agreement with the pattern of zonal windstress with longitude of Figure 1), with larger positive values in August to 0ctober, smaller positive values in May to July and small scale undulations between January and May. The amplitude of the seasonal variations about the annual mean is small however and does not seem to reflect the semi-annual character of the local wind variations. West of $170^{\circ} \mathrm{W}$ and east of $110^{\circ} \mathrm{W}$, the slope is less but experiences larger seasonal changes and can reverse sign. Variations west of $170^{\circ} \mathrm{W}$ are almost out of phase with those in the central portion of the ocean, but compatible with variations in the local winds (Figure 1), with maximum slopes in May-June, negligible or slightly negative slopes in october-December. East of $110^{\circ} \mathrm{W}$, the maximum slope reversal takes place between June and August, while positive values of the order of the ones observed in the center of the basin are found between December and March. These eastern variations in the depth of the $14^{\circ} \mathrm{C}$-isotherm may not mirror similar variations in sea level and surface $Z P G$, but again they are consistent with the variations in local winds shown on Figure 1. (Given the mixed character of the quantities compared, time lags of a couple of months are probably not significant.)

In a direct study of the seasonal cycle of the equatorial $Z P G$ in the easternmost Pacific (120 $\mathrm{W}-95^{\circ} \mathrm{W}$; Tsuchiya, 1979), geopotential anomalies with respect to $500 \mathrm{db}$ are computed at 0,50 and $100 \mathrm{db}$, showing as expected a uniform decrease of the zonal gradients with depth. Lower values in the spring coincide with weak easterlies (or westerlies) and higher values in the summer with strong easterlies. Zonal coverage however is not very good and errors are 1 arge.

Halpern (1980) argues after Philander (1979) that variations in the zonal slope of the Pacific thermocline should actually be negligible on seasonal time scales and therefore computes a mean surface ZPG for the eastern equatorial Pacific using a single XBT section made between 23 April and 2 May 1979 from $153^{\circ} \mathrm{W}$ to $110^{\circ} \mathrm{W}$ along the equator. His subsequent rough estimate of the vertical integral of 


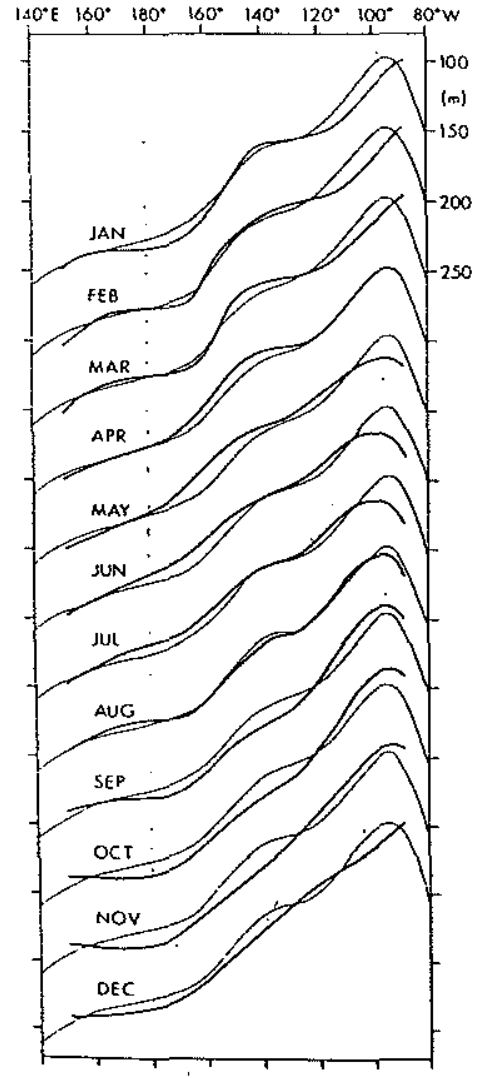

a
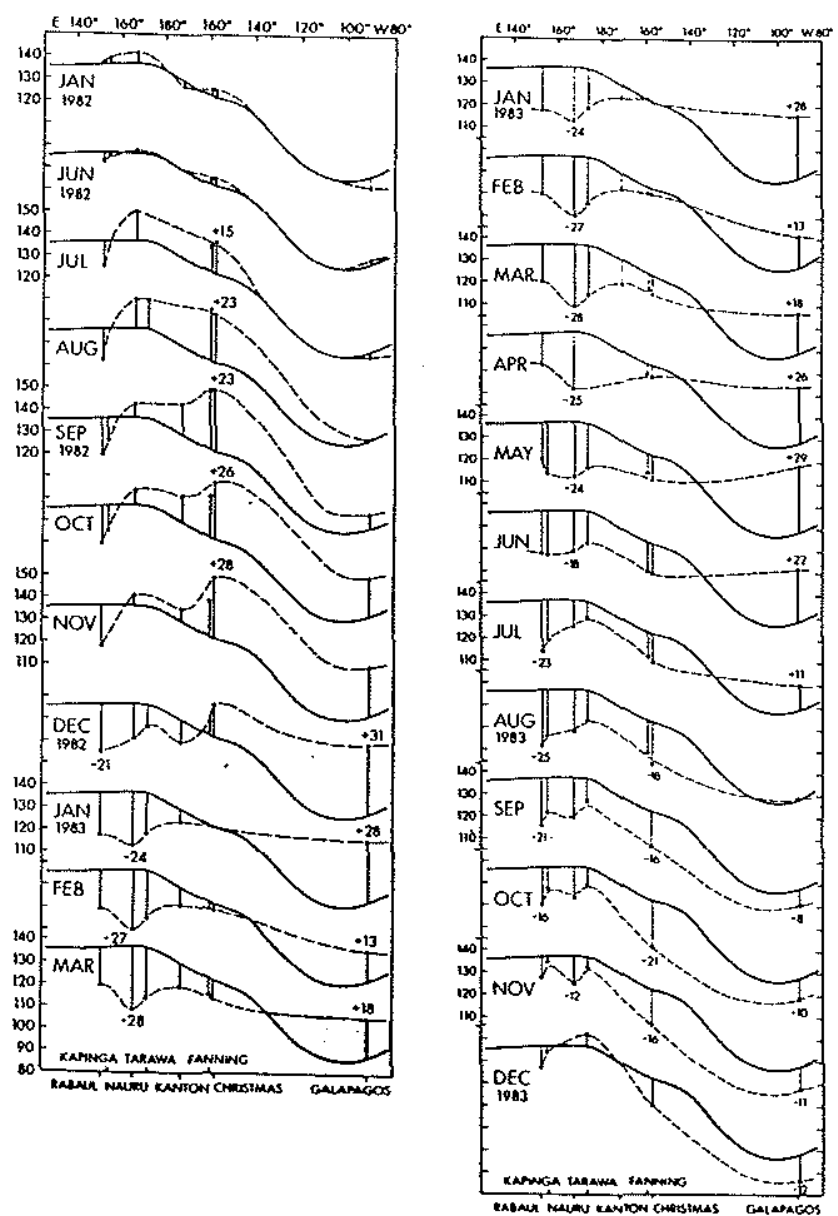

b

Figure 4: Indirect evidence of zonal pressure gradient variations along the equator in the Pacific.

a) Seasonal scales: climatology of the depth of the $14^{\circ} \mathrm{C}$ isotherm [annual mean (]ight line) and monthly means (heavy 1ines)]. (Meyers, 1979).

b) Interannual scales: sea surface slope during the 1982-1983 El Niño. Monthly values of directly observed sea level deviations (dashed lines) are superimposed on the main topography of the sea surface relative to $500 \mathrm{db}$ (continuous line) (Wyrtki, 1984). 
$\mathrm{p}_{\mathrm{x}} / \mathrm{\rho}$ comes out about twice as 1 arge as the zonal wind stress measured during the cruise and averaged between $153^{\circ} \mathrm{W}$ and $120^{\circ} \mathrm{W}$; he concludes that the vertical integrals of other terms of the ZMB have to be included, in particular that of $w_{z}$. Mangum and Hayes (1984) computed a time mean vertical profile of ZPG over the same region by differentiating CTD data collected at $150^{\circ} \mathrm{W}$ and $110^{\circ} \mathrm{W}$ between 1979 and 1981. They found the same surface value as Halpern; but their vertical integral from 0 to $200 \mathrm{~m}$ comes out very close to the mean climatological wind stress between $150^{\circ} \mathrm{W}$ and $110^{\circ} \mathrm{W}$. When they compare instantaneous estimates of $p_{x}$ profiles to their mean vertical profile, they find important deviations, especially in April of both years, but warn that, rather than representing a seasonal variation in the global slope between $150^{\circ} \mathrm{W}$ and $110^{\circ} \mathrm{W}$, these deviations are due to the passage at one of the longitudes of wave-like propagating pulses with zonal scales much shorter than the distance between the sections.

At interannual scales, ZPG variations in the equatorial Pacific are more spectacular than at seasonal scales. This is illustrated by Firing et a1. (1983) and by Wyrtki (1984) who report a global relaxation of the sea surface slope along the equator towards the end of 1982, in connection with the strong 1982-1983 El Niño event. Large scale slope reversals are also documented over the western equatorial Pacific (Figure 4b; Wyrtki, 1984). These are important observations since they coincide with the first ever observed "disappearance" of the EUC (section 1.4).

In summary, seasonal variations in the Pacific equatorial ZPG seem to have smaller amplitudes and more zonal structure than those in the Atlantic. Apparently, there is a better correlation with the seasonal variations in the zonal wind stress in the east and the west than in the center of the Pacific basin; however, documentation of that correlation is worse than for the Atlantic. Spatially confined propagating disturbances which complicate the interpretation of zonal differentiations have been observed. Finally, the most global and dramatic changes in the ZPG seem to occur on interannual scales in association with El Niño events. 
1.3.3 Seasonal_variations of the equatorial $Z \mathbf{P G}$ in the Indian Ocean

The best observations of the longitudinal and vertical structure of the equatorial ZPG in the Indian 0cean are reported by Taft and Knauss (1967) and by Eriksen (1979). The first LUSIAD section (Taft and Knauss, 1967) was occupied in July 1962 during the main southwest monsoon: the $0 \mathrm{db} / 400 \mathrm{db}$ pressure surface slopes up to the east (westward ZPG force) almost monotonically over the full zonal extent of the basin, $45^{\circ} \mathrm{E}$ to $95^{\circ} \mathrm{E}$, and the slope weakens but remains positive with depth (Figure $5 \mathrm{a}$ ). The pattern agrees with one's expectation of the effect of quasi-steady westerlies blowing over a bounded equatorial basin and leading to an accumulation of surface waters in the east. The second LUSIAD section was occupied in March-Apri1 1963, at the end of the period of northeasterly winds over the western part of the basin. Contrary to expectations this time, the $0 \mathrm{db} / 400 \mathrm{db}$ pressure surface still sloped up to the east, with however a value reduced to about one half the July value. Deeper pressure surfaces however all sloped down to the east, indicating an eastward ZPG force (Figure $5 \mathrm{~b}$ ). This is not the equilibrium response to quasi-steady easterlies, rather the pattern probably reflects an on-going adjustment to the switch from southwesterlies to northeasterlies, and measurements at similar periods of different years would probably reveal various stages of adjustment. The zonal section discussed by Eriksen (1979) was occupied in December 1976-January 1977, again during the southwest monsoon. As in the July 1962 section, pressure increases to the east, with a considerably larger slope than in 1962.

\subsection{Observational basis for a relationship between EUC and ZPG}

As pointed out in section 1.2, the existence of a negative ZPG seems essential to that of both the zonal and meridional components of the steady equatorial circulation, but how the actual value of the subsurface maximum of eastward velocity is determined, and how the intensity and spatial structure of the circulation should respond to temporal changes in the fields of wind stress and ZPG force is not 


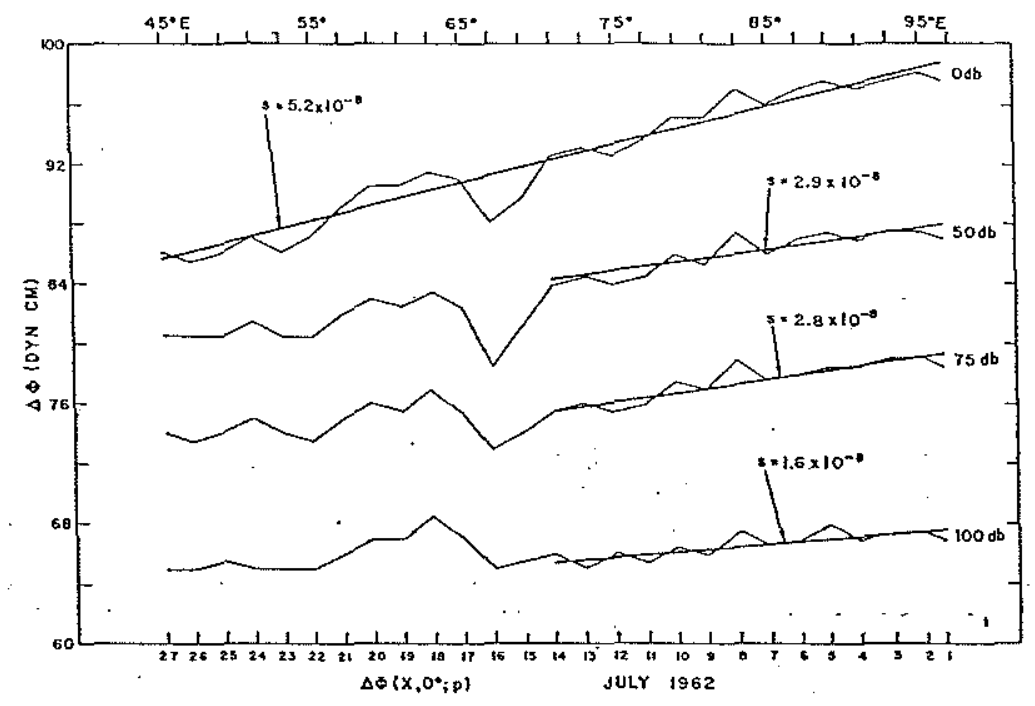

Longitudinal distribution of geopotential anomaly $(\Delta \Phi)$ of selected isobaric surfaces $(0,50,75,100 \mathrm{db})$ along the equator relative to $400 \mathrm{db}$ (July $1-22,1962$ ). The zero point of the values of the geopotential anomaly has been adjusted so that all four isobaric surfaces can be couveniently represented. Linear regression equations fitted to the data ( $s=$ slope) are shonin by the heavy lines.

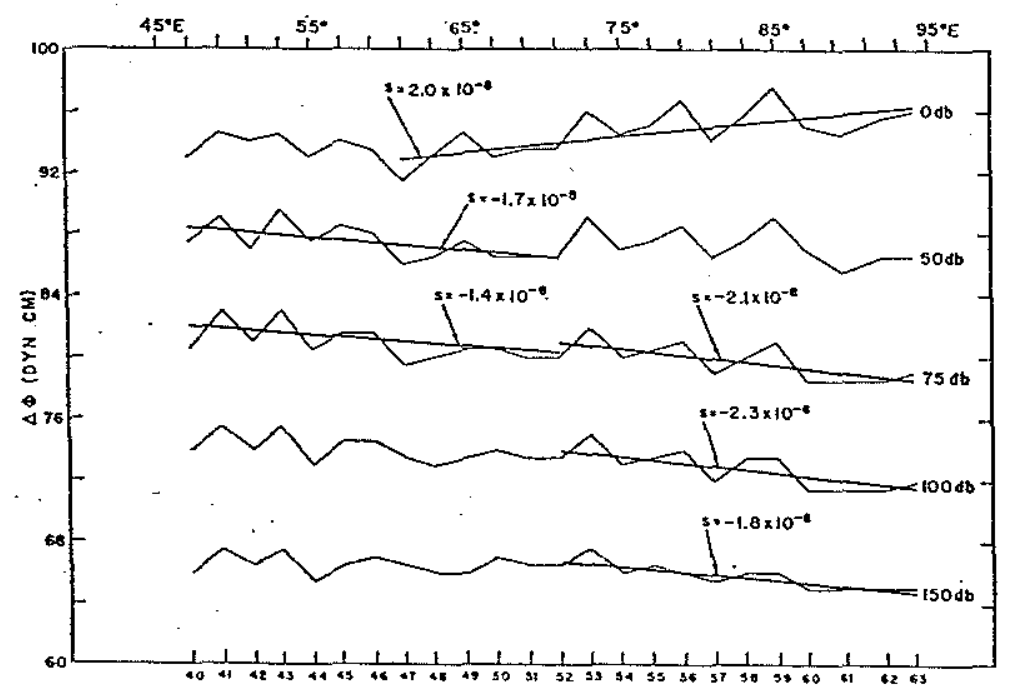
$\Delta \odot(x, 0 * p)$ MARCH - APRIL 1963

Longitudinal distribution of geopotential anomaly $(\Lambda \$)$ of selected isolsuric surfaces $(0,50,75,100,150 \mathrm{db})$ along tle equator relatire to $400 \mathrm{db}$ (Afarch 24-April 10, 1963). The zero point of the values of the geopotential anomnly has been sdjusted so that all five isobaric sero point of the values of the geopotential anomnly has been sdjugted 80 that all five isobaric are shown by the heary lines.

Figure 5: Equatorial sections of dynamic height relative to $400 \mathrm{db}$ in the Indian 0cean (a) during the main southwest monsoon; (b) at the end of the period of northeasterly winds (Taft and Knauss, 1967). 
clear. In an attempt to clarify such relationships between the fields of velocity and mass at the equator, the present section reviews measurements of the equatorial circulation in reference to the ZPG estimates presented in section 1.3.

\subsubsection{Zonal circulation}

Before becoming more specific, it is worth mentioning several general observations. The most spectacular one comes from the Indian Ocean and was last reviewed in detail by Knox and Anderson (1985). Only in spring (i.e. at the end of the northeast monsoon when one expects a negative ZPG to have developed) has a persistent basinwide subsurface core of eastward flow similar to the Atlantic and Pacific undercurrents been observed along the equator. The observations reported in section 1.3.3 confirm the existence of an eastward ZPG force at the levels of eastward flow in March-April 1963. At other times, flow in the thermocline appears uncorrelated with the sign of $p_{x}$. Rather, it changes direction in phase with the surface flow and winds, suggesting direct frictional driving as in an unbounded basin (Knox, 1976; Cane, 1980).

Another general observation suggestive of a tight link between the EUC and the field of density is the vertical location of the maximum eastward velocity core in both the Pacific and the Atlantic. The core is typically in the thermocline and slopes up with it from west to east. The vertical extent of the region of positive ZPG force shrinks accordingly (but see section 1.4.3). Note that, because of the sloping of the core with longitude, a region of zonal convergence $\left(u_{x}<0\right)$ and positive inertial force $\left(-u_{x}\right)$ exists below the core. This force, along with the downward diffusion of eastward momentum from the core already mentioned at the beginning of section 1.3, may be of importance in driving the eastward flow still present at depths where the ZPG force itself has become negligible.

A crude comparison between the Pacific and the Atlantic undercurrents illustrates however the complicated character of the EUC/ $Z P G$ relationship. While the mean ZPG has comparable surface values in 
both oceans, the Pacific EUC reaches speeds considerably larger than the Atlantic EUC (typically $1.5 \mathrm{~m} / \mathrm{s}$ versus $1.0 \mathrm{~m} / \mathrm{s}$ ). U1timately, this may be related to the difference in size of the two oceans which, given a similar sea surface slope, allows for a deeper thermocline in the western Pacific than in the western Atlantic. The influence of the wind, on another hand, presumably penetrates down to similar levels in both basins no matter their size. In the western Pacific thermocline then, the waters of the EUC start their eastward and upward course better sheltered from the retarding influence of the surface westward stress than they do in the western Atlantic thermocline. Thus, they may be subjected to a larger net eastward acceleration over a wider longitudinal range, therefore reaching higher velocities.

The differences in the longitudinal structure and in the scales of temporal variations of the winds over the Pacific and the Atlantic 0ceans may also play a part in determining the speed of the undercurrents, and the question requires further clarification. That the two oceans adjust somewhat differently is illustrated by a comparison of the seasonal and interannual variations in their respective undercurrents. In section 1.3, it was argued that seasonal variations in the ZPG in response to changes in the winds had less amplitude in the Pacific than in the Atlantic. The EUC however seems to exhibit a clearer seasonal cycle at $140^{\circ} \mathrm{W}$ in the central Pacific (Figure 8a), than at $28^{\circ} \mathrm{W}$ in the central Atlantic (Figure $7 \mathrm{~b}$ ).

On an interannual basis now, the presence or absence of EUC west of $160^{\circ}$ W during the 1982-83 El Niño appears well correlated with the sign of the ZPG (Halpern, 1987a). However, while the Pacific EUC is reported to have "disappeared" at $110^{\circ}, \mathrm{W}$ and $95^{\circ}, \mathrm{W}$ at the end of 1982 when the sea surface slope was abnormally flat east of $170^{\circ} \mathrm{W}$ (Halpern, 1987a), an Atlantic EUC was still observed at the beginning of 1984 when eastward wind stress and sea surface appeared totally relaxed (Katz et a1., 1986). A similar observation of the persistence of the Atlantic EUC during low winds and in the absence of a significant ZPG force both at the surface and at the core depth was also made during the boreal spring of 1963 (EQUALANT), as reported by Katz et a1. (1977). 
One does not in fact expect a direct correlation between the EUC core speed and the value of the ZPG either at the core or at the surface, as discussed in section 1.2. Dynamically, it seems more promising to investigate how the wind and the vertical integral of the ZPG affect the equatorial transport. As will be seen in section 1.6.2, models of the time varying equatorial circulation relate the establishment of the $Z P G$ to the reflection of low frequency 1 inear waves at the basin boundaries and predict time lags between changes in the wind, the current system and the ZPG field. How nonlinearities modify that response, as changes in the equatorial upwelling are induced, which in turn change the term of vertical advection of zonal momentum, is illustrated by Cane (1980). Available observations do not however permit quantitative tests of elaborate predictions, and one only hopes to be able to check for tendencies.

\subsubsection{Atlantic undercurrent}

Studies were performed in the equatorial Atlantic, using the FGGE data (Katz et a1., 1981; Katz and Garzoli, 1982; Lass et a1., 1983), and the SEQUAL/FOCAL data (Hi sard and Henin, 1987). Rather than estimate the total equatorial transport between the surface and a given depth, those studies choose to isolate the volume transport of the EUC itself, defined as the eastward velocity flux within the $0.20 \mathrm{~m} / \mathrm{s}$ isotach and above $200 \mathrm{~m}$ or $500 \mathrm{~m}$. (Velocities were measured using a profiling current meter referenced to the flow at $500 \mathrm{~m}$ ). Also, rather than deal with a vertical integral of the ZPG force, they consider the values of the $Z P G$ at the $0 \mathrm{db} / 500 \mathrm{db}$ and $50 \mathrm{db} / 500 \mathrm{db}$ surfaces, or time series of the thermocline displacements. Meridional averaging is used to reduce the observational noise.

Measurements from the Global Weather Experiment (FGGE, August 1978 to March 1980) were combined into one time series of the seasonal cycle of the EUC volume transport between $25^{\circ} \mathrm{W}$ and $33^{\circ} \mathrm{W}$ (Katz et a1., 1981). The resulting plot shows a maximum transport around March and a minimum around June (Figure 6b), and strikingly resembles a similarly combined plot of the near-surface zonal current (Figure 6c): 
eastwards in March following the relaxation of the easterlies (Figure $6 a)$, and westwards in July following their reintensification (Katz and Garzoli, 1982). In fact, the large March increase in EUC transport is shown to be caused more by the reversal of the surface layers, and hence an increase of the area of eastward flow, than by an acceleration of the EUC core. [The amplitude of the seasonal variation of the total transport (velocity integrated up to the ocean surface) would be larger than that of the EUC alone, since it would be comparable in March when the surface flow is eastwards, but less in boreal summer when the surface flow is westwards.] On the contrary, we have seen that the ZPG force varies from weaker in the spring to stronger in the fall, as the density field adjusts to the new values of the dynamical forcing.

What the FGGE observations suggest is therefore an essentially frictional (instantaneous) response of the central equatorial Atlantic to the rather sharp seasonal changes in the wind forcing. As argued in section 1.2, the existence of a negative ZPG is fundamental for explaining the occurence of subsurface eastward flow year round and that of the eastward surge of the surface layers lor "surfacing of the EUC", as it is often called somewhat ambiguously), when the weakening of the easterlies leaves the positive ZPG force temporarily unbalanced. Nonetheless, the seasonal variations of the ZPG would oppose the observed variations of the transport and thus appear to be of secondary importance.

Measurements from the SEQUAL/FOCAL experiments do not really confirm the annual cycle in zonal transport from the FGGE data analysis. Let us first consider estimates of the EUC transport made at $23^{\circ}$ W using, as for the FGGE data, meridional sections of profiler current meter measurements (Hisard and Hénin, 1987). With only four cruises a year, roughly in January, April, July and 0ctober, the March EUC surge of Figure $6 \mathrm{~b}$, if any, is not resolved. The only suggestion from these observations is for lower values of the EUC transport in July and higher values in 0ctober (Figure $7 \mathrm{a}$ ). The other measurements available are time series of temperature and zonal velocity measured at $0^{\circ} \mathrm{N} 28^{\circ} \mathrm{W}$ at $10,50,75,100,150$ and $200 \mathrm{~m}$ between February 1983 and 


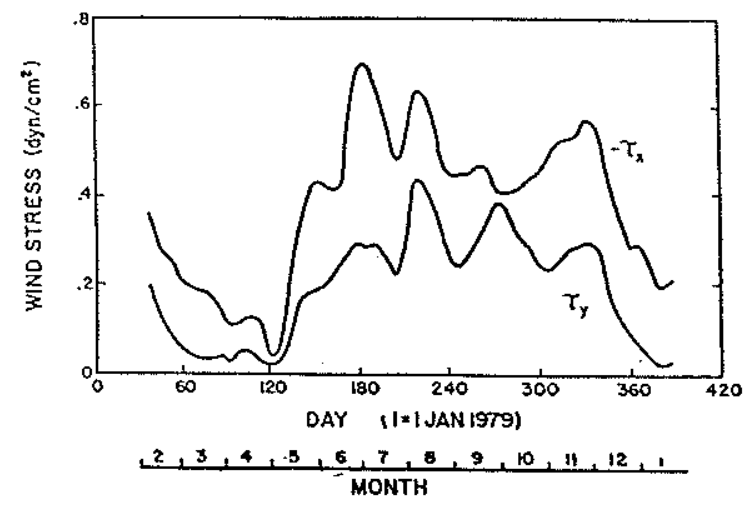

a

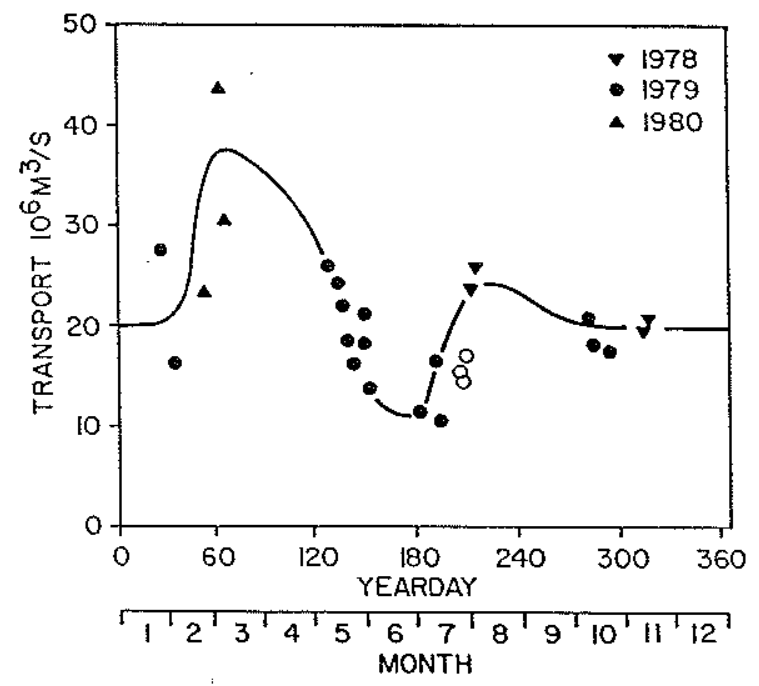

$\mathbf{b}$

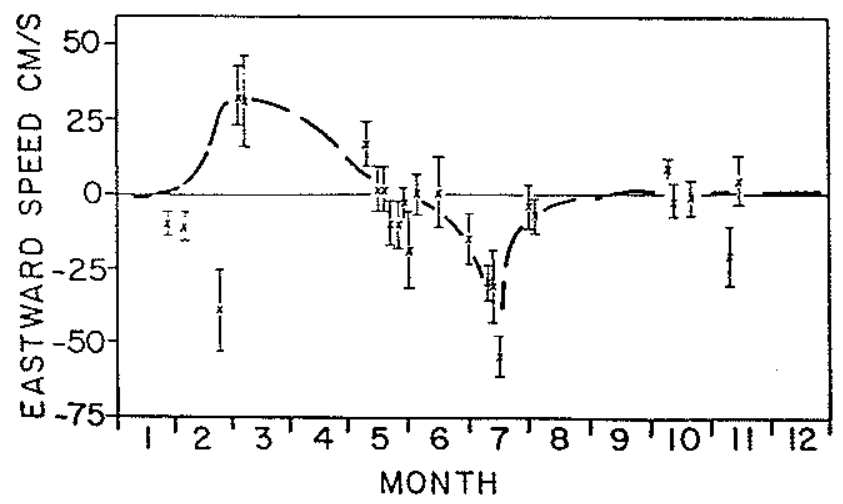

c

Figure 6: Winds (a), equatorial undercurrent transport (b), and nearsurface zonal current (c) from the Global Weather Experiment (Katz and Garzoli, 1982). 


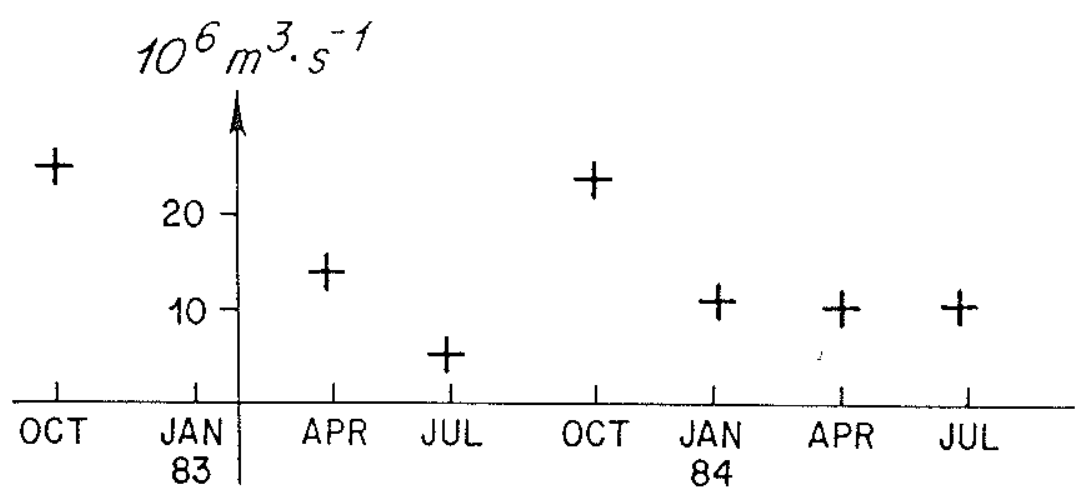

a
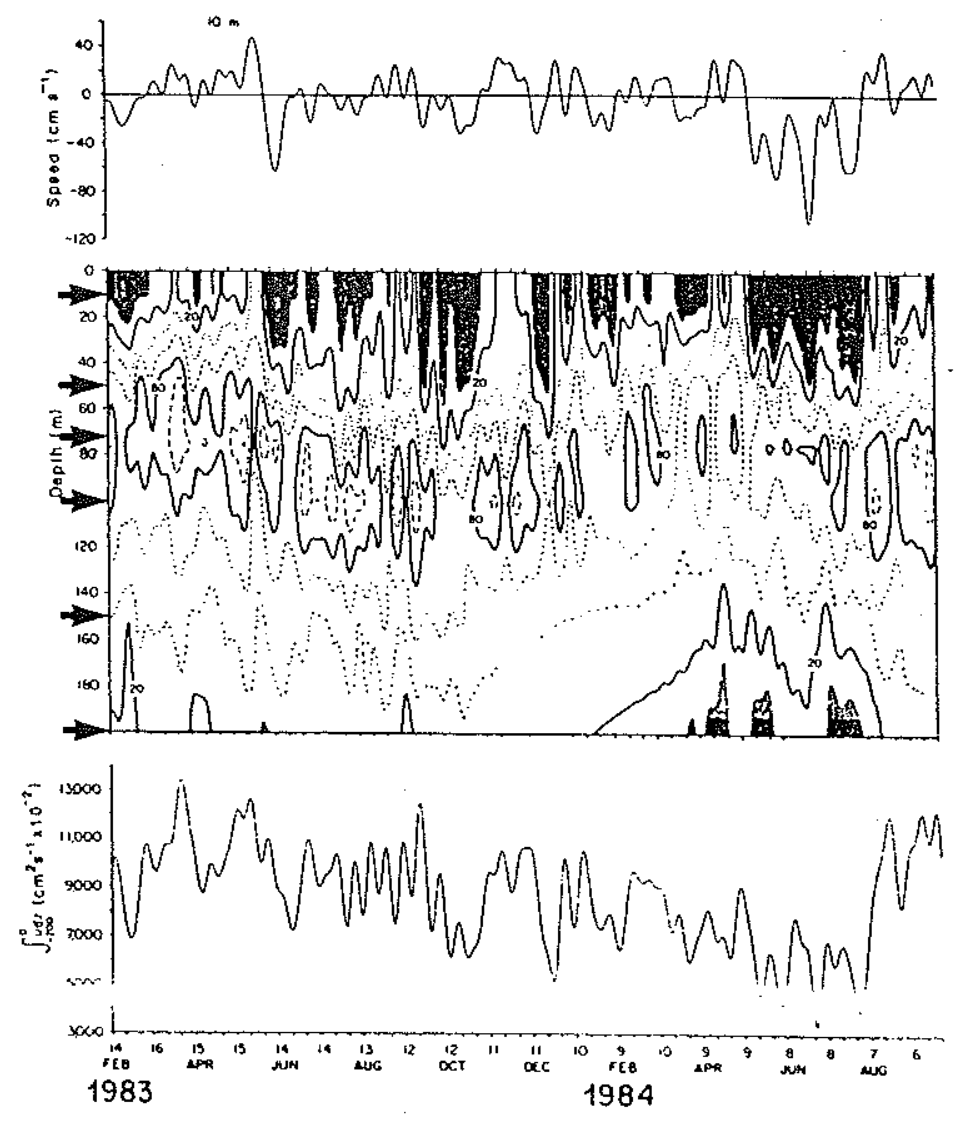

b

Figure 7: Estimates of EUC velocity and transport in the central Atlantic during SEQUAL/FOCAL.

a) EUC transport at $23^{\circ} \mathrm{W}$, from profiler current meter sections. Velocity is referenced to $500 \mathrm{~m}$ and integrated within the $20 \mathrm{~cm} / \mathrm{s}$ isotach. The plot is drawn from the numbers of Figure $3 \mathrm{~b}$ above (Hisard and Hénin, 1987).

b) Time series of speed at $10 \mathrm{~m}$, zonal velocity above $200 \mathrm{~m}$ and $0-200 \mathrm{~m}$ zonal transport per unit width at $28^{\circ} \mathrm{W}$, from moored current meters. Measurement levels are added on the left (Weisberg and Col in, 1986). 
September 1984 (Weisberg and Colin, 1984). The advantage of these data is that they are continuous in time, disadvantages are that the vertical resolution is poor, and that temporary meridional migrations of the equatorial system, if they occur, are aliased and complicate the interpretation of the data in terms of simple physical models. The seasonal signal evidenced by this data set is a tendency for the eastward subsurface core to be closer to the surface in the spring, deeper in the fall (Figure 7b), mimicking similar vertical displacements of the temperature field. Figure $7 b$ shows variations in the surface and subsurface zonal velocity fields $\left(0.60 \mathrm{~m} / \mathrm{s}<u_{\max }<1.00 \mathrm{~m} / \mathrm{s}\right)$ and in the vertically integrated zonal velocity above $200 \mathrm{~m}$, but no clear seasonal trend can be seen, apart from a tendency for the surface current to be stronger towards the west in June. In particular there is no clear indication of the lower EUC transport in July 1983 or of the higher one in October 1983 suggested by Hisard and Hénin.

Given the very anomalous character of 1984, it is probably reasonable to compare only the 1983 SEQUAL/FOCAL data to the FGGE data. From the lowest panel of Figure $7 \mathrm{~b}$, one may conceivably argue for higher values of the $0-200 \mathrm{~m}$ vertically integrated zonal velocity in the spring and lower values in the summer. And one may also argue that the spring is the time of the year when the surface flow is most consistently towards the east. But while we expected the variation of the total transport per unit width above $200 \mathrm{~m}$ to be more contrasted than that of the EUC transport alone since it included the surface westward flow, it is in fact weak, and transition periods are i11-defined. 0ther time series of temperature and zonal velocity are available at $0^{\circ} \mathrm{N} 4^{\circ} \mathrm{W}$ at $10,35,60,85$ and $110 \mathrm{~m}$ (Weisberg and Col in, 1986). The tendency for the velocity field to describe vertical displacements in phase with the temperature field is much less marked than at $28^{\circ} \mathrm{W}$. Surface flow to the east occurs around February when, in 1983, it combines with increased subsurface flow to yield a maximum vertically integrated transport, more clearly distinct from the lower values observed the rest of the year than at $28^{\circ} \mathrm{W}$. 
If the seasonal cycle suggested after $F G G E$ is not ruled out by the SEQUAL/FOCAL observations, it is therefore not strongly supported either. Note that if the variability of the velocity field observed in Weisberg and Colin's presentation is not an artifact of their sampling technique (caused by aliasing of spatial displacements of the EUC core), then one cannot expect an "instantaneous" profiler current meter section to be representative of the "seasonal state" of the zonal velocity field, and progress in the observational determination of the seasonal cycle of the equatorial circulation may require the use of time series from meridional arrays of moored current meter profilers.

To summarize the above discussion of the seasonal variations of the circulation in the equatorial Atlantic, there is some evidence for higher eastward transport in the spring, due more to the reversal of the surface current than to an increase of the subsurface flow. The data do not provide evidence for a correlation between changes in the vertical profiles of eastward current and ZPG on a seasonal scale, but do provide some on an interannual scale (weakening of the subsurface eastward flow in spring 1984).

\subsubsection{Pacific undercurrent}

Long term moored current meter measurements have also been made in the central Pacific $\left(0^{\circ} \mathrm{N} 140^{\circ}, W\right)$ and in the eastern Pacific $\left(0^{\circ} \mathrm{N} 110^{\circ} \mathrm{W}\right)$, mostly during the NORPAX and EPOCS experiments. A timedepth contour plot of the zonal velocity at $0^{\circ} \mathrm{N} 140^{\circ} \mathrm{W}$ between May 1983 and August 1985 (Figure 8a, Halpern, unpublished) shows in late spring of each year, following the winter weakening of the climatological easterlies (Figure 1), a reversal of the surface current towards the east, as well as a clear intensification of the subsurface eastward flow $\left(0.9 \mathrm{~m} / \mathrm{s}<u_{\max }<1.40 \mathrm{~m} / \mathrm{s}\right)$. The presence of a secondary maximum of the EUC, along with a relative minimum of the surface westward flow, is suggested around December, following the secondary weakening of the climatological easterlies in late summer-early fall. That the variations in zonal transport and wind stress in the central Pacific both 


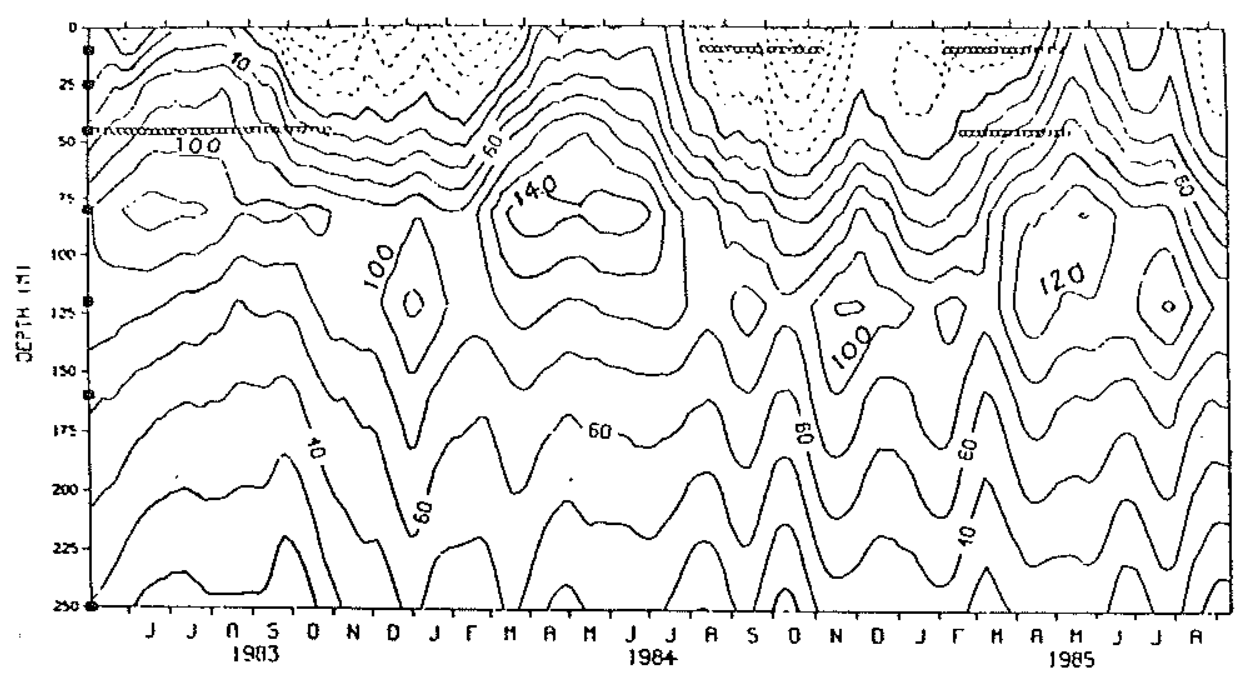

a

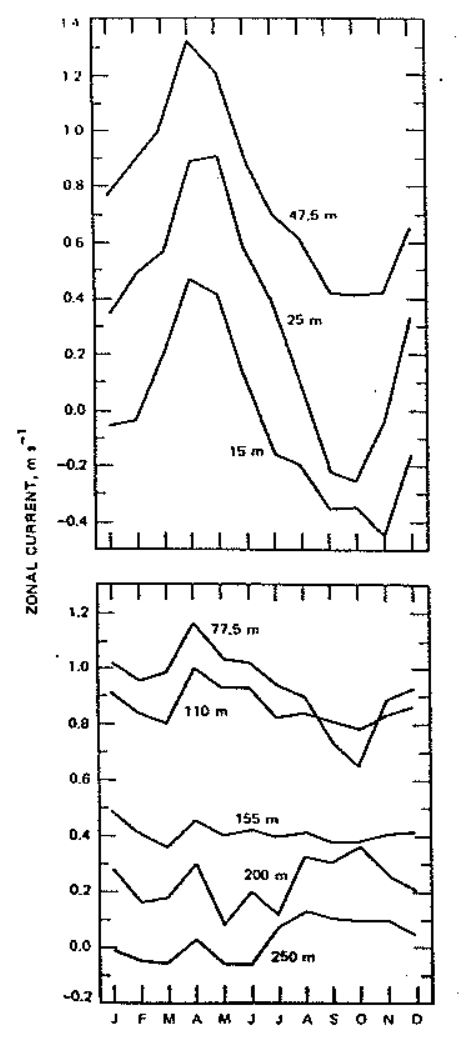

b

Figure 8: EUC velocity in the central and eastern Pacific. (a) At $0^{\circ} \mathrm{N} / 140^{\circ} \mathrm{W}$ from current meters moored between June 1983 and August 1985 (Halpern, unpublished); (b) at $0^{\circ} \mathrm{N} / 110^{\circ} \mathrm{W}$ using monthly mean zonal currents from the "non El Niño" current meter measurements of the 1980-85 period (Haldern. 1987b). 
have a semi-annual character, while the variations in the ZPG are weak and seem more annual (section 1.3.2) again suggests that the seasonal changes in the ZPG are of secondary importance.

Combining "non El Niño" measurements of the zonal velocity from the periods March 1980-July 1982 and August 1983-September 1985 at $0^{\circ} \mathrm{N} 110^{\circ} \mathrm{W}$, Halpern (1987b) constructed mean seasonal cycles of the zonal flow at depths around 15,25, 50,75,110,150, 200 and $250 \mathrm{~m}$ (Figure $8 \mathrm{~b}$ ). At that longitude, the variations in the zonal wind stress are more annual: minimum easterlies are around Apri1, maximum around July (Figure 1). Large eastward surface current and maximum EUC core velocity (near $77.5 \mathrm{~m}$ ) are observed around Apri1-May, 1arge westward surface current and minimum EUC around 0ctober, roughly out of phase with reported variations of ZPG in that region (section 1.3.2). Again the response appears mostly forced by the local winds.

In conclusion, both in the equatorial Atlantic and Pacific Oceans the main physical mechanism for changing the zonal transport on a seasonal basis appears to be downhill acceleration of the flow at times when the easterlies weaken and temporarily fail to balance the eastward ZPG force; effects of changes in the amplitude of the ZPG force itself are not properly resolved by the available data and seem of secondary importance. There is too much uncertainty in the pub1 ished measurements to clearly determine values for time lags between seasonal changes in the wind, the EUC zonal transport and the ZPG. Seasonal changes in the EUC velocity appear to have larger amplitudes in the Pacific than in the Atlantic 0cean, but the difference is difficult to quantify since the 1983 time series from the SEQUAL/FOCAL moorings may not represent the climatology. Changes in the ZPG seem to directly influence the EUC on longer (interannual) time scales. Why an apparently similar relaxation of the sea surface would provoke the "disappearance" of the eastern Pacific EUC during the 1982-1983 E1 Niño, but only a weakening of the Atlantic EUC in 1984 or 1963 is not clear. 


\subsubsection{Meridional circulation}

In the simple conceptual model of section 1.2, one visualizes water parcels driven equatorwards below poleward Ekman flow to some transitional latitude by the off-equatorial Coriolis force associated with the ZPG $\left(p_{x}<0\right)$, then driven eastwards by the ZPG force itself, as well as upwards by the equatorial upwelling. In the presence of a southerly wind stress component, a meridional pressure gradient force is created as well (equatorwards of the latitudes marking the transition to geostrophic flow) which drives southward flow across the equator below a frictionally driven northward flow; the degree of meridional asymmetry (or how much $v$ differs from zero at $0^{\circ} \mathrm{N}$ ) depends on the amplitude of $\tau^{(y)}$. Because the 1 ine of zero wind stress curl coincides with the ITCZ and lies on average north of the equator, the curl tends to be negative at the equator (Hellerman and Rosenstein, 1983), and a net southward Sverdrup transport across the equator results, at least in the eastern part of both the Pacific (Meyers, 1980; Joyce, 1988a) and the Atlantic (Joyce, 1988b). Changes in the meridional circulation with space and time are expected to occur, as the ratio of southerly to easterly wind stress increases with increasing longitude, and as the strength of the southeasterlies at a given longitude varies with time. Where $x$-gradients of the surface and subsurface currents are negligible, changes in $v$ and $w$ should be closely related since $w$ is largely determined by $v_{y}$ through continuity.

Unfortunately, there are no observations available for a direct test of this meridional pattern and its variability. A few time series of $v$ have been obtained from moorings at or very close to the equator. Reliable meridional sections of $v$ are however not usually available since simultaneous long time series are needed to resolve time variability; sections drawn from instantaneous profiler current meter can in fact be misleading. Equatorward tongues of tracer (salinity) in the upper ocean have been viewed as indirect evidence for the meridional convergence. As for $w$, attempts at direct estimates are extremely rare, and vertical motion is typically inferred from the 
displacement of isolines of conservative quantities or from the equation of continuity.

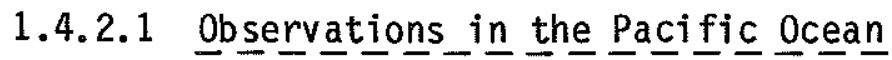

Observations from 1961 hinting at convergent meridional

flow towards the Cromwell current (Pacific EUC) are reported by Knauss (1966). More modern data from moorings in the equatorial Pacific near $152^{\circ} \mathrm{W}$ and $110^{\circ} \mathrm{W}$ taken between 1979 and 1981 are discussed by Halpern and Freitag (1987), Halpern (1986), Bryden, Brady and Halpern (1986). Moorings occupied triangular arrays: two were $3 / 4^{\circ}$ north and south of the equator, the third one was on the equator $1.5^{\circ}$ to the east of the first two. Vertical profiles of the meridional divergence are obtained at both longitudes by differencing with latitude the time-averaged north-south velocities measured at the off-equatorial moorings. The meridional flow is found strongly divergent in the upper layers and convergent at depth as expected of the effects of an easterly wind component. At $110^{\circ} \mathrm{W}$, the profiles suggest that the meridional flow is northwards at the surface and southwards at subsurface levels with orders of magnitude around $10 \mathrm{~cm} / \mathrm{s}$. These directions agree with expectations of the effects of a southerly component of wind stress. At $152^{\circ} \mathrm{W}$, the tendency is on the contrary for southward surface flow and northward subsurface flow, but the currents are also weaker and may not be significantly different from zero.

Using a fourth equatorial mooring near $110^{\circ} \mathrm{W}, \mathrm{Halpern}$ and Freitag (1987) attempted to compute a time series of the vertical profile of the zonal divergence as well, and to combine it with that of the vertical profile of the meridional divergence to obtain a time series of the vertical velocity (integrated vertically from zero at the surface). The results are not very convincing because the error on $w$, which they attribute mostly to $u_{x}$, is as large or larger than $w$ itself. Bryden, Brady and Halpern (1986) obtain mean vertical profiles of $u_{x}, v_{y}$ and $w$ between $152^{\circ} \mathrm{W}$ and $110^{\circ} \mathrm{W}, 0^{\circ} 40^{\prime} \mathrm{N}$ and $0^{\circ} 40^{\prime} \mathrm{S}$, by combining the time-averaged velocity fields at both locations (Figure 9a). 
The horizontal divergence is shown to be mostly meridional in the upper layers, but equally zonal and meridional at the depths where $u_{x}$ is negative due to the upward slope of the EUC core to the east and to the weakening of the EUC between the two longitudes. The resulting mean vertical velocity reaches a maximum of $3.5 \times 10^{-5} \mathrm{~m} / \mathrm{s}(3 \mathrm{~m} / \mathrm{dy})$ around $75 \mathrm{~m}$ and decreases below; by $250 \mathrm{~m}$, where the mean zonal velocity becomes very close to zero, $w$ is still computed to be positive, but it is probably not significant. Given the vertical spacing of the current meters, the location of the maximum cannot be accurately determined, but it is worth noting that, in a general sense, the mean vertical profile is fairly similar to the more noisy ones obtained by Halpern and Freitag.

Following the work of Wyrtki (1981), Bryden and Brady (1985) present another estimate of the mean vertical profile of $w$ at the equator between $150^{\circ} \mathrm{W}$ and $110^{\circ} \mathrm{W}$, based on the wind and density fields, i.e. using no direct measurements of the velocity field. Geostrophic zonal velocities are computed from time-averaged CTD sections, using the relations $\left(f u=-p_{y}\right)$ between $0.75^{\circ}$ and $5^{\circ}$, and $(B u=$ $-p_{y y}$ ) between $0.75^{\circ} \mathrm{S}$ and $0.75^{\circ} \mathrm{N}$ (cf section 1.5). Geostrophic meridional velocities are computed at $\pm 5^{\circ}$ latitude. Ekman flows are added in a surface slab layer, some adjustment is made to balance mass assuming that no exchange takes place through the $500 \mathrm{db}$ surface, and zonal and meridional divergences are calculated. The resulting vertical profile of $w$, set to zero at the surface and at $500 \mathrm{db}$, presents a maximum of $3 \times 10^{-5} \mathrm{~m} / \mathrm{s}$ around $75 \mathrm{~m}$ (Figure $9 \mathrm{~b}$ ), in striking similarity with the one computed from the time-averaged measurements of horizontal veloc$i$ ty. Further conclusions are that downwelling occurs through the lower layers of and below the EUC, and that there is negligible crossisotherm flow at the core of the EUC. Despite the disturbing number of hypotheses involved in that study, the fact that relatively little adjustment is required for the data to fit the assumed model, along with the fact that the resulting profiles of u compare fairly well with the time-averaged observed ones, give some confidence in the estimates of $w$. 

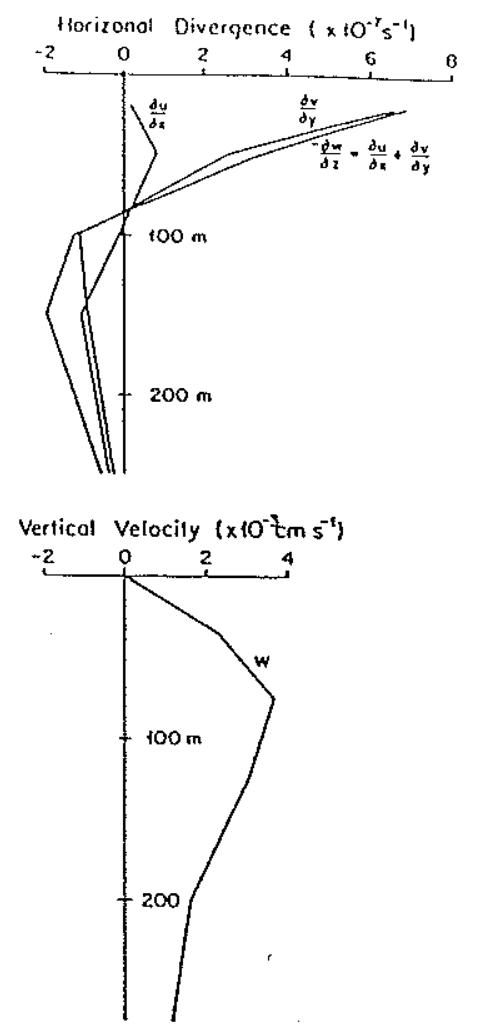

a

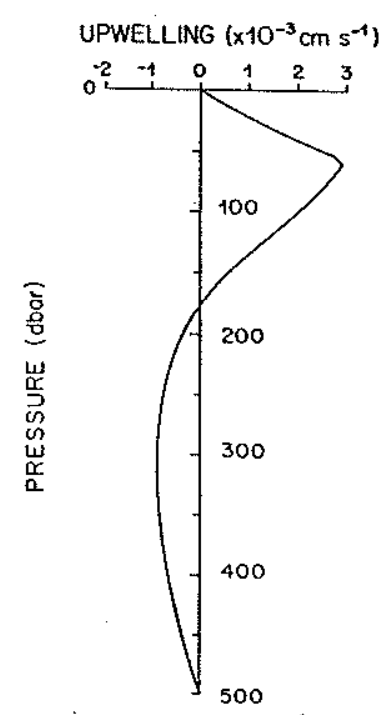

b

Figure 9: Estimates of vertical velocity in the Pacific using horizontal divergence (a) from the time-averaged velocity field measured at $152^{\circ} \mathrm{W}$ and $110^{\circ} \mathrm{W}, 0^{\circ} 40^{\prime} \mathrm{N}$ and $0^{\circ} 40^{\prime} \mathrm{S}$ (Bryden, Brady and Halpern, 1986); (b) from geostrophic velocities estimated at $150^{\circ} \mathrm{W}$ and $110^{\circ} \mathrm{W}, 5^{\circ} \mathrm{N}$ and $5^{\circ} \mathrm{S}$ (Bryden and Brady, 1985). 


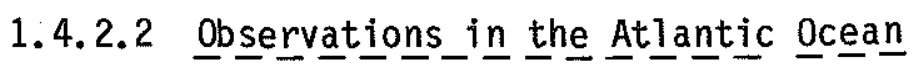

In the Atlantic ocean, most long-term measurements have been made as part of the SEQUAL/FOCAL experiment. The moored current meter data analysed so far are located at $0^{\circ} \mathrm{N} 28^{\circ} \mathrm{W}$ (Weisberg, Hickman, Tang and Weingartner, 1987) and at $6^{\circ} \mathrm{N} 28^{\circ} \mathrm{W}$ (Richardson and Reverdin, 1987). At $0^{\circ} \mathrm{N} 28^{\circ} \mathrm{W}$, the vertical profile of meridional velocity averaged over 2.7 years is indistinguishable from zero (within the 90 percent confidence interval) between 10 and $200 \mathrm{~m}$. At $6^{\circ} \mathrm{N} 28^{\circ} \mathrm{W}$, the mean meridional profile exhibits a distinct subsurface maximum of equatorward flow at about $50 \mathrm{~m}$ depth. It will be interesting to see similar profiles from moorings at intermediate latitudes in order to test for continuity of the equatorward subsurface flow. No estimate of the vertical velocity using the equation of mass conservation as in the equatorial Pacific ocean has yet been made.

Equatorial upwelling has been observed mostly through its effects: reduced sea surface temperature (SST) and higher levels of nutrients, especially noticeable in regions with a shallow thermocline, such as in the eastern part of the Pacific and Atlantic basins. In the Gulf of Guinea (eastern equatorial Atlantic) for instance, the seasonal occurrence of particularly cold and nutrient-rich surface waters has been attributed to enhanced upwelling due to the intensification of the meridional wind system (Voituriez, 1980b). This is not to say that there should necessarily be a tight correlation between changes in SST and vertical displacements of the thermocline. In fact, observations from SEQUAL/FOCAL i11ustrate many instances of low SST overlying a depressed thermocline. At $0^{\circ} \mathrm{N} 28^{\circ} \mathrm{W}$ for example, after the spring intensification of the easterlies, Weisberg and Colin (1986) describe a rapid shoaling of the thermocline and a simultaneous decrease of SST, followed by a deepening of the thermocline back to some stable equilibrium level while the SST remains low. After the winter relaxation of the easterlies, they describe a similar succession of events with the reverse sign: rapid deepening of the thermocline and warming of the surface waters, followed by a shoaling of the thermocline while the SST 
remains high. Presumably the intensification of the easterlies provokes a lasting intensification of the upwelling. On a short time scale, the enhanced upwelling in turn raises the isotherms. Then, on a longer time scale, increased vertical diffusion balances the increased upward advection, resulting in an apparent downward motion of the isotherms without a change of sign of the vertical velocity itself. So, because of vertical mixing at the equator, and because seasonal changes in air temperature are sma11, SST is probably a far better indicator of the upwelling intensity than vertical migrations of the thermocline, and estimates of $w$ based on the use of the equation of continuity are likely to be much more relevant than those based on any isoline displacement. Caution should be observed in regions where horizontal advection can also influence SST.

\subsubsection{EUUC eastern termination}

The subject of the termination of the EUC as it approaches the eastern boundary of the Pacific and Atlantic basins will be deve1oped in detail in chapter 2. In this section, we review the observations which could test the hypothesis of a relationship between the longitude and amplitude of the eastern ZPG reversal and the zonal penetration of the current.

If the ZPG force reverses from eastwards to westwards then the eastward flow, instead of being accelerated by the ZPG force, is retarded by it. Al so instead of driving an equatorward geostrophic flow, a westward ZPG drives a poleward one. Through such a process then, the EUC obviously looses both a source of momentum and a source of mass, and a downstream deceleration is expected to result. Accordingly, Knauss (1966) describes the Pacific EUC "breaking up" east of $95^{\circ} \mathrm{W}$ where the sign of the ZPG is reversed. The sources of eastward momentum downstream of the longitude of ZPG reversa1 are reduced to zonal inertia, and possibly downward diffusion of momentum if the surface flow reverses strongly enough to the east under the action of the westerlies. A11 this suggests indeed that the EUC will reach longitudes more or less close to the eastern coast depending on the 
longitude of the ZPG reversal and on the amplitude of that reversal. The relation between both can however be obscured if the ZPG reversal does not always reach the levels of the EUC, if other effects come into play simultaneously to slow down the EUC (such as southerlies-induced upwe11ing), or if upstream effects are important.

One would expect the very process of an eastward flow impinging on an eastern boundary to produce a region of high pressure which deflects the flow. The idea that is developed here is that the observed ZPG reversal is created independently by the reversal of the zonal winds, on a scale larger than that of such a "natural termination" (boundary layer), and that this ZPG reversal acts as an external forcing to retard the flow. To estimate the zonal length scale of such a boundary layer or, equivalently, the upstream distance at which the presence of the wall is felt, let us consider a zonal inertial jet impinging on a meridional wall. An inertial scale is $(U / \beta)^{1 / 2}$, which, for values of $U$ characteristic of the EUC, is of the order of $250 \mathrm{~km}$, or $2^{\circ}$. 1ongitude. By contrast, we have seen in section 1.3 that the sea surface, which on an annual average slopes downwards from the west, flattens and starts sloping upwards east of about $90^{\circ} \mathrm{W}$ in the Pacific, $10^{\circ} \mathrm{W}$ in the Atlantic (Figure 2). These longitudes are close to the longitudes at which a similar transition from southeasterly to southwesterly occurs in the zonal wind stress, i.e. at about $10^{\circ}$ from the coast in the Pacific, $20^{\circ}$, in the Atlantic. Since the longitude of the wind transition and the intensity of the southwest monsoon change with time (Figure 1), one expects the longitude of the sea surface slope reversal and its amplitude to vary accordingly. In particular, the vertical penetration of the $Z P G$ reversal, rather shallow in the examples of Figure 2, is likely to be deeper in the fall, when the westerlies are strong, than in the spring, when they are weak.

Simultaneous hydrographic and profiler current meter measurements from the FOCAL program are the best data available to investigate the relationship between eastern ZPG reversal and EUC penetration. They have however the same problem with time resolution in the Gulf of Guinea that they have further west: "instantaneous" sections 
four times a year. The zonal resolution is better though since sections were occupied at $10^{\circ} \mathrm{W}, 4^{\circ} \mathrm{W}, 1^{\circ} \mathrm{E}$ and $6^{\circ} \mathrm{E}$. The measurements suggest a semi-annual signal in the slope of the pressure surfaces east of $10^{\circ} \mathrm{W}$ reminiscent of the semi-annual character of the wind stress (section 1.1), but an annual signal in the penetration of the EUC (Hisard and Henin, 1987). The ZPG appears negative (i.e. EUC favourable as in the center of the basin) in winter 1983, summer 1983 and spring 1984, with most pronounced reversals observed in fal1 1982, winter 1984 and summer 1984. On the other hand, maximum penetration of the EUC is reported in winter 1983 and in winter and spring 1984. So the negative ZPG measured in winter 1983 and spring 1984 may have helped the EUC in penetrating further to the east at these times, but in winter 1984, the current was riding against a strong opposing gradient. Some progress will probably be made when the moored velocity and temperature data from $28^{\circ} \mathrm{W}, 24^{\circ} \mathrm{W}, 15^{\circ} \mathrm{W}$ and $4^{\circ} \mathrm{W}$ collected during SEQUAL/ FOCAL will be examined simultaneously. For the time being, given the uncertainties involved in determining the slope of the pressure surfaces and the intensity of the current, and given the poor resolution in time for estimating their extrema, the question is still unresolved. The indication of a more annual than semi-annual signal in the Atlantic EUC eastern penetration suggests that different mechanisms than the ZPG reversal may dominate the process of downstream deceleration of the EUC. The role of the summer upwelling will be investigated in section 2.4. The penetration of the EUC in the eastern Pacific was investigated by Lukas $(1981,1986)$. By contrast with the ideas presented above, he argues that $10 \mathrm{cal}$ wind effects and surface reversals of the ZPG do not penetrate deep enough to influence the subsurface eastward flow. Instead, the westward pressure gradient force which decelerates the flow zonally would be generated internally (cf section 2.1).

In both oceans, a large scale weakening of the EUC with distance eastwards takes place, and what terminates at the eastern boundary is only a fraction of the mid-basin undercurrent (chapter 4). 


\subsection{The system of governing equations at the equator}

The understanding of the time-dependent three-dimensional (3-D) circulation of a continuously stratified equatorial ocean has progressed by steps, as various simplifications were investigated to try and isolate dominant physical mechanisms. Analytic studies of the steady 3-D equatorial circulation and $i$ ts connection with the circulation at higher latitudes have produced scale estimates for the width of the equatorial region $(250 \mathrm{~km})$, the depth of the equatorial thermocline $(100 \mathrm{~m})$, and the magnitude of the zonal velocity $(1 \mathrm{~m} / \mathrm{s})$ as well as of the meridional and vertical flows, in reasonable agreement with available observations (Robinson, 1960; Philander, 1973b; Moore and

Phil ander, 1977; Pedlosky, 1987).

Using dimensional analysis, Robinson's and Philander's

studies have also derived an approximate system of equations for the steady equatorial circulation, which connects smoothly with extraequatorial geostrophic flow:

$$
\begin{aligned}
u u_{x}+v u_{y}+w u_{z}-\beta y v & =-p_{x} / \rho_{0}+\left(v u_{z}\right)_{z}+A_{M} \Delta u \\
\beta y u & =-p_{y} / \rho_{0} \\
p_{z} & =-\rho g \\
u_{x}+v_{y}+w_{z} & =0 \\
u_{\rho_{x}}+v_{\rho_{y}}+w_{z} & =\left(x \rho_{z}\right)+A_{D} \Delta \rho
\end{aligned}
$$

This system was also derived by Veronis (1960) from physical considerations at the equator independent of the circulation at higher latitudes. The assumption of symmetry with respect to the equator is usually made $\left(u_{y}=p_{y}=v=0\right.$ at $\left.y=0\right)$, with the idea that the effects due to the asymmetry are of secondary importance.

Estimates of the horizontal Coriol is term show that it is negligible in the zonal momentum equation at least in the upper equatorial 1ayers that we are studying here (Arthur, 1960; Knauss, 1966; Philander, 1971). The hydrostatic form of the vertical equation is used to relate pressure to the density field. Joyce et al. (1988) however argue that the neglect of the horizontal Coriolis term 
in the vertical equation may introduce a 10 percent error in the computation of the zonal flow using the geostrophic approximation of the meridional momentum equation. The argument requires further clarification since a spurious source of energy is introduced if one retains the horizontal Coriol is term in the vertical but not in the zonal momentum equation.

Recently, the geostrophic character of the meridional momentum balance was tested repeatedly in the central Pacific ocean using modern, high quality measurements (Hayes, 1982; Wyrtki, 1983; Lukas and Firing, 1984). Direct measurements of equatorial flow were compared to the flow deduced from the density field using the relations $\left(\beta y u=-p_{y} / \rho_{0}\right)$ slightly off the equator and $\left(\beta u=-p_{y y} / \rho_{0}\right)$ at the equator (and substituting dynamic height relative to $400 \mathrm{db}$ or $500 \mathrm{db}$ for $p$ ). Within measurement errors (which can be large for estimates of $p_{y y}$ ), the mean EUC (averaged over 6 months) was found indeed to be in semi-geostrophic balance (Figure 10a; Lukas and Firing, 1984; but see Joyce et a1., 1988). At shorter time scales, ageostrophic effects can dominate (Knauss, 1966). Four instantaneous geostrophic and measured velocity profiles from $110^{\circ} \mathrm{W}$ and $125^{\circ} \mathrm{W}$ compare reasonably well below the EUC core, but can differ significantly above the core (Figure 10b; Hayes, 1982). Joyce $(1988 \mathrm{a}, \mathrm{b})$ is investigating the role of $\tau^{(y)}$ in the meridional equation.

Since the work of Knauss (1966) which mostly produced orders of magnitude of some terms of the equatorial zonal momentum balance $(Z M B)$, the most complete attempts at estimating these terms have been made by Bryden and Brady (1985) and by Dillon, Moum, Chereskin and Caldwel1 (1988). Bryden and Brady computed a mean ZMB above $500 \mathrm{db}$ for the region $150^{\circ} \mathrm{W}-110^{\circ} \mathrm{W} / 0.75^{\circ} \mathrm{S}-0.75^{\circ} \mathrm{N}$, using estimates of the three components of velocity based on geostrophy, Ekman divergence and continuity (section 1.4.2), and calculating the ZPG force from the difference in dynamic height between $150^{\circ} \mathrm{W}$ and $110^{\circ} \mathrm{W}$. They find that the mean ZPG force is reduced to half of its surface value by the depth 

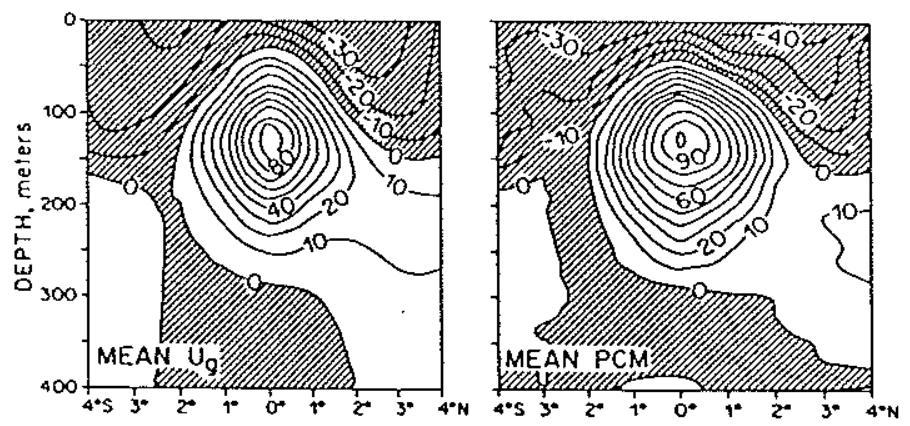

a

Comparison of geostrophic currents (left) computed from the mean pressure field of the NORPAX Hawaii-to-Tahiti Shuttle Experiment with the mean currents as measured by PCM during the experiment (right). Shaded portions indicate westward now. Units are $\mathrm{cm} \mathrm{s}^{-t}$.
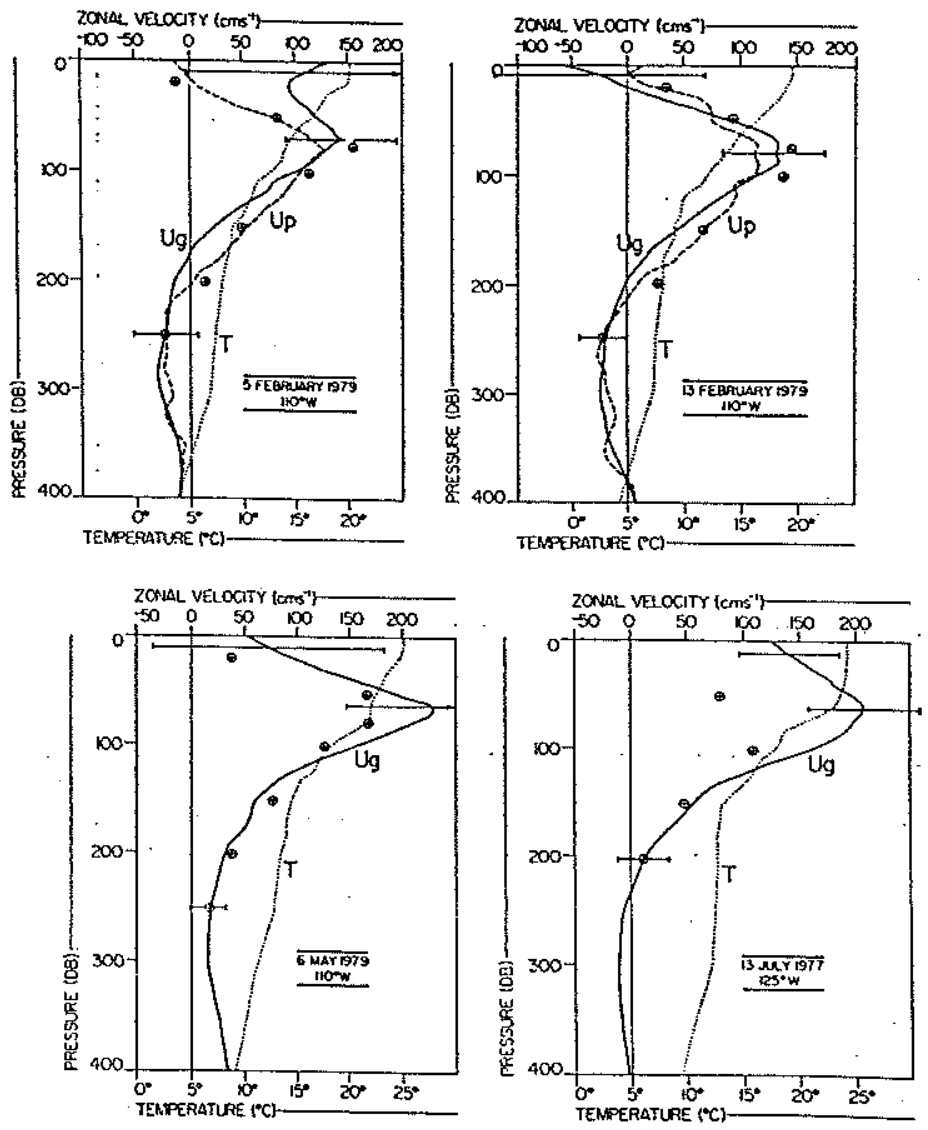

$\mathbf{b}$

Geostrophic and measured velocity profiles at $110 \mathrm{~W}$ and $125 \mathrm{~W}$. The geostrophic $\left(U_{v}\right.$, solid) and PCM ( $U_{v}$, dashed) velocities were referenced to the deepest moored current metsurement. Mtoored currents ( $(+)$ are duily averaged values. In February measured and conpuled currents were simultaneous, in May the moored Jata are from 1 May and in July from 10 suly. The dotted curve ( $n$ sbows the equatorial temperature profile.

Figure 10: Tests of semi-geostrophy in the equatorial Pacific (a) from mean current sections averaged over 16 months between $160^{\circ} \mathrm{W}$ and $150^{\circ} \mathrm{W}$ (Lukas and Firing, 1984); (b) from instantaneous profiles at $125^{\circ} \mathrm{W}$ and $110^{\circ} \mathrm{W}$ (Hayes, 1982). 
of the EUC core and becomes negligible slightly above the deep zerocrossing of the mean zonal velocity profile. The contributions from $\vec{u} \tilde{u}_{x}$ and $\tilde{w}_{z}$ are shown to partially cancel each other due to the upward slope of the EUC core to the east. The analysis disregards the term $\vec{v} \vec{u}_{y}$. The remainder $\left(\vec{u} \vec{u}_{x}+\vec{w}_{z}\right)$ is found to be negative at all depths and due mostiy to $\vec{w} \vec{u}_{z}$ above the EUC core and to $\vec{u} \vec{u}_{x}$ below. The average Coriolis term $(-\beta y \vec{v})$ vanishes by symmetry. The resulting imbalance between ZPG force and inertial terms becomes an estimate of the sum of the horizontal and vertical divergence of the zonal Reynolds stress (or terms of eddy mixing). These terms are found to be of the same order of magnitude as the mean ZPG throughout the 0-500 $\mathrm{m}$ water column, with substantial values well below the core of the EUC (Figure 11). An independent study of lateral mixing between $152^{\circ} \mathrm{W}$ and $110^{\circ} \mathrm{W}$ using estimates of the eddy momentum fluxes from direct current measurements confirms that order of magnitude estimate and suggests that the contribution of $-\left(\overline{\left(u^{\prime} u^{\prime}\right)_{x}}+\left(\overline{\left.\left.u^{\prime} v^{\prime}\right)_{y}\right)}\right.\right.$ to the total divergence of the zonal Reynolds stress is negative (decelerating) above and through the core, but positive (accelerating) further below (Bryden, Brady and Halpern, 1986).

In Bryden and Brady's study, all zonal derivatives are estimated by forming differences between time-averaged fields at $110^{\circ} \mathrm{W}$ and $150^{\circ} \mathrm{W}$. Terms which do not involve zonal differentiating are estimated at the two longitudes and averaged together. The resulting ZMB thus represents some average over the $150^{\circ} \mathrm{W}-110^{\circ} \mathrm{W}$ region. The question of longitude and time dependence of the ZMB is not addressed. If the dynamics change between the longitudes which bound the region under study, the depth to which substantial eddy fluxes are found by the above method may strongly depend on the size of the region. In other words there is a danger that zonal variations become aliased into eddy fluxes. Further errors may be introduced by neglecting asymmetries $\left(v u_{y}\right)$.

Bryden and Brady also present estimates of the terms of the vertically integrated mean ZMB. Uncertainty in the value of the wind stress makes it difficult to determine the exact percentage of 
$\tau^{(x)}$ which is balanced by the integral of the ZPG (the estimate lies between 65 and 80 percent). The interesting point is that the vertical integrals of $\bar{u} \bar{u}_{x}$ and $\bar{w} u_{z}$ appear to contribute significantiy and cannot be neglected as in Arthur's simple linear model (section 1.2).

Dillon et a1. (1988) attempted to construct a ZMB for the eastern equatorial Pacific by combining Bryden and Brady's estimates of $-\bar{p}_{x},-\vec{u} \bar{u}_{x}$ and $-\bar{w}_{z}$ for the $150^{\circ} \mathrm{w}-110^{\circ} \mathrm{W}$ region, Bryden, Brady and Halpern's estimate of $\left(\overline{\left(u^{\prime} u^{\prime}\right)_{x}}+\left(\overline{\left.u^{\prime} v^{\prime}\right)_{y}}\right)\right.$ for the same region, and Moum and Caldwe11's 1985-estimate of $\left(u^{\prime} w^{\prime}\right)_{z}$ from microstructure measurements made at $140^{\circ} \mathrm{W}$ during a 12 -days period in late fall 1984 . If the terms determined independently in this fashion are each representative of their time-averaged values within the $150^{\circ} \mathrm{W}-110^{\circ} \mathrm{W} / 0.75^{\circ} \mathrm{S}-0.75^{\circ} \mathrm{N}$ region, then their sum should be zero. Instead, when combining terms in three depth ranges, from 0 to $30 \mathrm{~m}, 30$ to $60 \mathrm{~m}$ and 60 to $90 \mathrm{~m}$, Dillon et a1. find large residuals, especially in the upper layer where the residual is five times larger than the ZPG itself. In my opinion, this result is not alarming since the data is not synoptic and therefore may not be consistent. Note in particular that the value of the wind stress measured during the experiment enters the ZMB averaged over the upper layer and weighs heavily on the residual. What is of some concern, however, is that, despite using a value of wind stress about twice as strong as the one used by Bryden and Brady, Moum and Caldwe11 find a much smaller depth of penetration of the stress effect. This raises questions about the accuracy of estimates of time mean vertical dissipation.

To summarize our observational knowledge of the ZMB in the equatorial region, it seems safe to say that the ZPG force is (1) globally the largest term (mostly balanced by dissipation); (2) essentially positive throughout the upper water column; and (3) largest at the surface and greatly reduced at the depth of the EUC core (becoming negligible or slighty negative in the lower layers of the undercurrent). The term $w u_{z}$ has a significant net contribution above the EUC core where the cross-isotherm flow is most important, and it tends to cancel part of the contribution of $u_{x}$ in the region of upward slope of the 


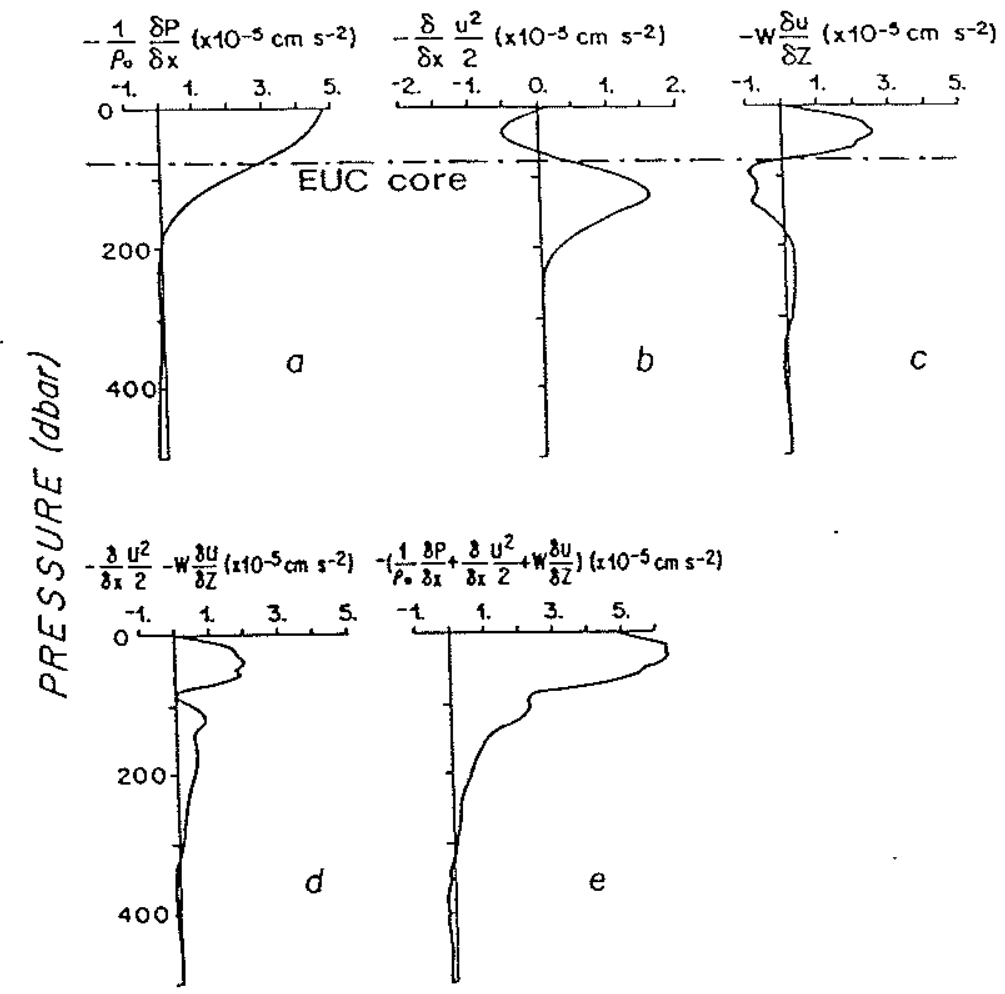

Vertical profiles of (a) zonal pressure gradient $-\left(1 / \rho_{0}\right) \partial P / \partial x$, (b) eastward advection of eastward momentum - $(\partial / \partial x)\left(u^{2} / 2\right)$, (c) vertical advection of castward momentum. $w(\partial u / \partial Z)$, (d) the sum of the eastward and vertical advection, and (e) the sum of zonal pressure gradient plus eastward and vertical advection.

Figure 11: Estimates of terms of the zonal momentum balance in the equatorial Pacific from mean hydrographic sections at $150^{\circ} \mathrm{W}$ and $110^{\circ} . \mathrm{W}$, and geostrophic estimates of the velocity field (Bryden and Brady, 1985). 
EUC core (another contribution to $u_{x}$ is the internal weakening of the undercurrent as it flows east). How deep the effect of these various forces penetrates is not well established. I suspect that, in Bryden and Brady's study, the depth extent of $u u_{x}$ may be overestimated compared to a typical mid-basin value, owing to the large zonal extent of the region used to compute $u_{x}$, and to the upward motion of the velocity core from west to east through the region. This would yield an overestimate of the depth extent of the eddy fluxes needed to balance it. The main questions that present observational studies have not addressed involve (1) the role of $\tau^{(y)}$ and of the associated asymmetries in the main ZMB $\left(v u_{y} \neq 0\right),(2)$ the way in which the vertical profile of the equatorial ZMB changes with longitude as the EUC weakens, (3) the way that profile changes with time, and (4) how the transition between the off equatorial geostrophic/Ekman regime and the equatorial one takes place.

\subsection{Review of EUC models}

Most conceptual models of the EUC do not address its $x$ dependence. They impose from the start that the dynamical forcing and al1 other fields except $p$ be independent of longitude, and they simulate a flow applicable to the we11-developed mid-basin regime far from meridional boundaries. Detailed reviews can be found by Gill (1975) and Moore and Philander (1977). The main lesson from these models is that there are many ways to simulate a steady subsurface eastward flow at the equator as we11 as some realistic features of the meridional circulation; in fact, there are as many ways as there are terms available to balance $p_{x}$ i.e. to limit the local acceleration of the flow down the pressure gradient. The following review begins with a few such $x$-independent models to illustrate differences with the $x$-dependent cases presented subsequently. All models use in some way the basic concepts introduced in section 1.2 


\subsubsection{Steady models}

\subsubsection{Layer models}

Consider a homogeneous equatorial layer, representing, if one approximates the thermocline by a density discontinuity, the relatively we11-mixed layer above it. A steady constant easterly wind forcing can create a subsurface eastward flow if $p_{x}$ is 1 inearly balanced by vertical friction, provided that the assumptions of zero zonal transport and zero bottom stress be applied. This is how Stommel (1960) obtains "the upper half of" an EUC. Subsurface eastward flow can also be created if $p_{x}$ is linearly balanced by large enough 1 ateral friction, in which case the effects of vertical friction are 1 imited to a surface Ekman layer of finite thickness (Gil1, 1971). In either case, the flow is independent of longitude, and a narrow boundary layer is required at meridional walls to close the circulation, by upwelling the waters of the eastward subsurface current into the westward surface current in the east, and downwelling the waters from the westward surface current into the eastward subsurface current in the west. If nonlinearities are included, a net convergence of eastward momentum at the equator is generated [the vertical integral of (uv) $y$ is negative], and a net eastward transport results, which requires westward return flow at slightly higher latitudes.

The unstratified nonlinear case with vertical friction and no-slip bottom boundary condition is treated by Charney and Spiegel (1971). Depending on the relative size of friction and nonlinearities, a more or less strong EUC is produced, with cusps at the equator in agreement with vorticity conservation by the meridional flow $\left(u_{y}=\right.$ $-\beta y_{0}$, section 1.2) and, for values of the parameters producing rea 1istic profiles of zonal velocity, there is upwelling above and downwelling below the core. If lateral friction is included as well with the assumption of zero bottom stress (McKee, 1970, as reviewed by Gill, 1975), cusps are smoothed out and, when friction and nonlinearities are equa1ly important, the EUC is in semi-geostrophic balance.

If now lateral friction is ignored, a no-slip boundary condition retained, but the assumption of $x$-independence of the velocity 
field relaxed (still keeping $\tau_{x}^{(x)}=0$ ), there exists a realistic range of parameters for which the effect of vertical friction can be limited to an upper sublayer on which the wind stress acts directly while the ZPG in the EUC layer below is balanced by zonal advection of zonal momentum (Cane, 1979a,b). In other words, the flow in the EUC layer behaves like an inertial jet, the average Bernoulli function is approximately conserved $\left(\left(p+u^{2} / 2\right) x=0\right)$, and the average zonal velocity increases with longitude (Figure $12 \mathrm{~b}$ ). Let $\mathrm{h}$ be the thickness of the EUC layer; the behaviour of the vertically integrated transport (hu) with longitude depends on the relative size of the variations of $u\left(u_{x}>0\right)$ and $h\left(h_{x}<0\right)$. In Cane's numerical simulation, $h_{x}$ (set by $\left.\tau^{(x)}\right)^{x}$ is small enough so that not only $u$ but also (hu) increase with $x$; only within a couple of degrees from the eastern coast are they abruptly reduced to zero. As seen in section 1.4.3, observations of the EUC, although imprecise, still strongly suggest that the weakening of the undercurrent towards the east occurs over a much broader range of longitudes. Accordingly, Cane argues that his model applies best to the western equatorial Pacific. In the eastern Pacific or Atlantic, either Cane's scaling breaks down and vertical friction cannot be ignored at the levels of subsurface eastward flow (because the thermocline becomes very shallow), or one of the following possibilities occurs: the assumption of no vertical exchange through the thermocline breaks down, the variations of $\psi^{(x)}$ with $x$ dominate the dynamics, or all such effects contribute.

Note also that, in Cane's model, the EUC is in semigeostrophic balance, and that two westward flows are found at about 2: latitude on either side, which receive water from the EUC in the narrow eastern termination corner and feed water into it along the rest of its course from the west. To rationalize the existence of these westward flows, Cane extends the vorticity argument of section 1.2.2: in the west, vorticity conservation explains that water parcels from latitude $y_{0}$ flow equatorwards and eastwards; similarly in the east, vorticity conservation explains that water parcels forced to flow polewards from 
the equator cannot pass latitude $y_{0}$ and have to recirculate westwards at $y_{0^{\circ}}$

A model of purely inertial EUC was developed by Pedlosky (1987). Pedlosky postulated that the EUC could be represented by an inertial homogeneous layer of density $\rho_{2}$ shielded from surface influences by an overlying layer of density $\rho_{1}$ (these two 1ayers lying on top of a motionless abyss as in the previous models). Since the detailed dynamics of the upper layer (not solved by the model) do not influence that of the undercurrent layer, the structure of Pedlosky's model is equivalent to Cane's. The circulation (solved in Pedlosky's model by conserving potential vorticity and Bernoulli function from an extra-equatorial latitude) is also similar in the two models: westward equatorward trajectories from the latitude of origin, eastward veering at the equator and downstream acceleration of the eastward flow. Thus, as for Cane's (1979) model, Pedlosky's probably applies best to the western "formation" regions of the Pacific and Atlantic equatorial undercurrents. This will be further developed in chapter 5 .

\subsubsection{Continuously_stratified models}

A nonlinear frictional stratified $\mathrm{x}$-independent undercurrent model was studied by Veronis (1960). This model addresses the question of the circulation which develops in a frictional stratified ocean when an eastward zonal pressure gradient and an easterly wind stress are imposed as surface boundary conditions. [The imposed ZPG (in practice a zonal gradient of sea surface temperature) represents the long-term effect of the easterly wind stress.] Stratification allows for baroclinic adjustment which reduces pressure gradients (in practice isotherms slope) with depth and may thus cause the confinement of the current system to the upper ocean. Veronis's analysis neglects lateral friction, zonal variations of the velocity field and meridional asymmetries and imposes a condition of vanishing velocity at great depth $(z>-\infty)$. The solution for the zonal velocity profile shows that it has an eastward subsurface maximum realistically located in the thermocline and that it slowly decreases below as the isotherms flatten 


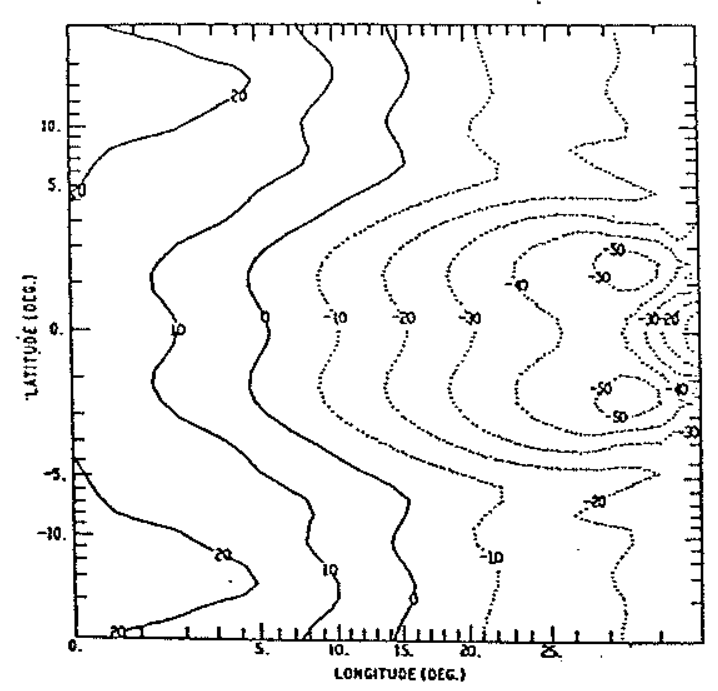

a

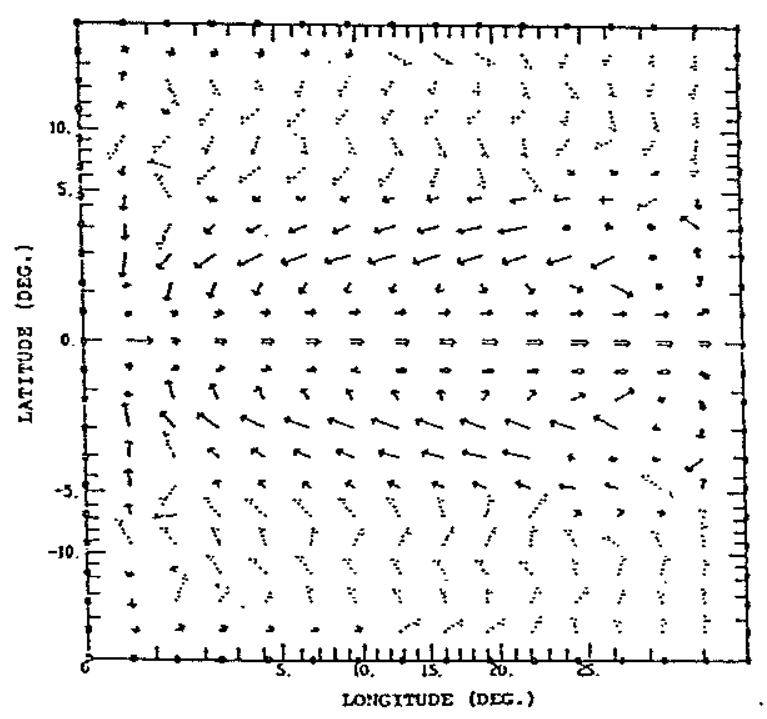

b

Figure 12: (a) Thickness of and (b) velocity in the equatoriat undercurrent layer of Cane's (1979b) model at day 398. 
with longitude. The depth scale deduced from this model will be discussed in chapter 5 .

Philander (1973b) treats the extreme case of pure thermal forcing: a negative zonal gradient of temperature is imposed as a surface boundary condition in the absence of wind stress (though the temperature gradient is understood as a long term effect of steady easterlies). The case is meant to apply either to the upper ocean when sustained winds die out leaving an unbalanced ZPG, or to the deeper ocean where motion is shielded from surface effects. (The meaning of a steady solution is a bit unclear though, since the mechanism for maintaining the surface gradient is eliminated in the absence of wind stress). The $x$-dependence is made implicit by the use of a similarity transformation, on the basis that, as the temperature structure varies with longitude, the current structure gets constrained in such a way that sections look similar except for some stretching of the meridional and vertical coordinates. With no opposing surface stress, the eastward flow extends to the surface. At the equator, the term of vertical friction is negligible throughout the water column, $p_{x}$ and the advective terms are important, but so is lateral friction (in contrast with Cane, 1979). It is shown that "the eastward equatorial current becomes slower, narrower and shallower", and that its transport (integrated meridionally as well as vertically) also decreases downstream. Downwelling occurs along the eastward path of the current, and a westward current returns mass and heat below. So the variation with longitude turns out to be the opposite of the one presented by Cane (1979). Dissipation (by lateral friction) appears to play a large role in slowing down the current. It is not clear to me how the $x$-dependence imposed on the dissipation coefficients themselves constrains the final solution.

Another $x$-dependent steady circulation is obtained by McCreary (1981), who also studies a continuously stratified ocean but goes back to linear viscid dynamics: stratification is linearized about a mean state $\mathrm{N}^{2}(\mathrm{z})$ independent on horizontal coordinates. An 
$x$-dependent dynamical forcing is imposed: a limited patch of easterlies isolated from the ocean boundaries, maximum at the center of the basin and tapering off in $x$ and $y$. It produces a similar zonal pattern of velocity: all three components have their largest amplitude towards the center of the wind patch, where the subsurface eastward core is also the shallowest (Figure 13). McCreary uses the formulation of linear equatorial waves (see section 1.6.2) but, instead of inviscid propagating waves, he considers waves which are damped away from their source region, i.e. away from the edges of the wind patch, in the direction of their group velocity. The flow pattern is thus described as an interference pattern set up by damped waves with group velocities in opposite directions. Dissipation is purely vertical, and special forms are adopted for the terms of diffusion of heat and momentum in order to retain the ability to expand solutions into sums of vertical normal modes as for the time-dependent 1 inear inviscid equations. Mixing coefficients are thus inversely proportional to the square of the Brundt-Väisälä frequency $N^{2}(z)$. Physically, this choice agrees with the expectation that more homogeneous regions are regions of more vigorous mixing. At the same time, one expects vigorous mixing to homogenize also the fine vertical structure of high-order modes, and that is not easy to reconcile with the representation of the solution in terms of independent modes damped individually without interacting with each other. Mccreary argues that the realistic zonal and meridional circulations simulated by the model when an $\mathrm{N}^{2}$-profile typical of the central equatorial Pacific is used are not very sensitive to his parameterization of the diffusion terms, even though it yields unrealistically large values of the eddy viscosity coefficient in the deep ocean. He also argues that nonlinearities (which, when estimated from the solution, can be of the same order of magnitude as the linear terms) would only play a secondary role, modifying the linear solution rather than generating an altogether different one. Being linear, viscid and continuously stratified, McCreary's model incorporates al1 the elements present in the simple arguments developed by Yoshida (1959) and Arthur (1960) and discussed 


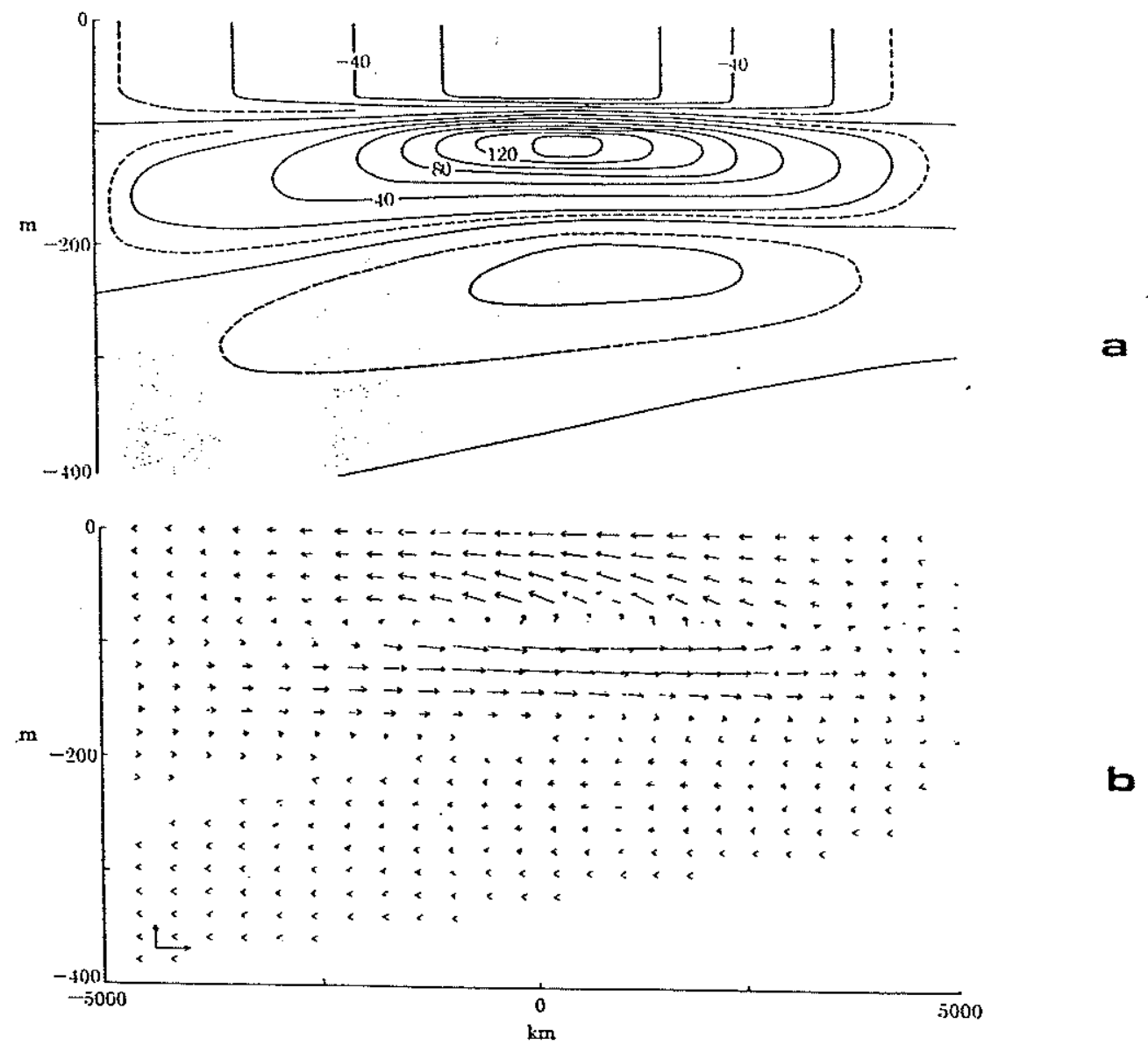

Calibration vectors in the lower left corner have amplitudes $0.005 \mathrm{~cm} / \mathrm{s}$ and $100 \mathrm{~cm} / \mathrm{s}$ in the vertical and horizontal directions, respectively.

Figure 13: Equatorial section from McCreary's (1981) linear stratified undercurrent model. (a) Zonal velocity contours; (b) vector plot of the zonal and vertical velocity fields. 
in section 1.2. The analysis of McCreary's model provides a dynamical explanation for the origin of $p_{x}$ and its role in changing the sign of $u_{z}$ at depth from the sign imposed by $\tau(x)$ at the surface. That analysis shows that the higher-order normal modes of the system, which are also the most strongly damped, tend to be, in McCreary's terminology, in "Yoshida balance", i.e. they reproduce the meridional circulation and simulate a surface-intensified zonal current in the direction of the wind; that current depends only on the local surface stress and does not extend beyond the forcing region. The lowest-order modes, by contrast, which are damped the 1east, tend to be in "Sverdrup balance", i.e. they create zonal baroclinic pressure gradients which balance the wind and settle the vertical structure of the system by bounding the amplitude of the surface flow and creating the eastward undercurrent; their characteristics depend on zonal integrals of the surface stress and their influence radiates beyond the forcing region.

Because the forcing in McCreary's model is limited to a bounded region of the ocean interior, that region is a distributed source of radiation. The meridional boundaries of the ocean basin itself are another source: if the energy radiated from the forcing area is not damped too quickly so that it reaches the 1 imits of the basin, it has to be reflected in the form of free damped waves with group velocity of the opposite sign in order to satisfy boundary conditions at the coasts. The influence of the ocean boundaries therefore clearly depends on their distance from the forcing region. In Mccreary's calculation, their presence is seen to weaken the westward surface flow appreciably and to intensify the EUC; they do not modify the vertical structure drastically though and are therefore not necessary for a steady EUC to be maintained as long as the forcing itself is bounded. (Meridional boundaries appear necessary however for a deeper slow westward flow to exist).

\subsubsection{Iime-dependent mode1 $\underline{\text { s }}$}

Time-dependent models have been developed to predict changes in the circulation and density field caused by changes in the 
wind forcing in order to interpret real observations. The analysis of these time-dependent models relies heavily on the theory of linear equatorial waves, which has been extensively reviewed in the literature (Moore and Philander 1977, for instance) and will therefore be only briefly summarized here, starting with the unforced problem. Given a main stratification independent of time and of the horizontal coordinates, it is possible to separate the vertical dependence of the system of unforced linear inviscid equations and to express its solutions as sums of a barotropic and a series of baroclinic normal modes. The vertical structure of these modes becomes more complicated (e.g more zero crossings of velocity), with slower speed, as their order increases. Once the vertical structure is separated, each mode individually satisfies the horizontal shallow water equations on an equatorial B-plane. At low frequencies (the case of interest for our study) the long-wave approximation can be made and the solutions reduce to two types of approximately non-dispersive meridional modes: a fast Kelvin wave trapped at the equator with eastward group velocity, and a series of long Rossby waves (the first of them slower than the Kelvin wave by a factor of 3 ) with westward group velocity. (Short Rossby waves with eastward group velocities are also excited at the western boundary, but their short wave length and slow speed trap them at the coast. In the presence of the slightest friction, they are damped and their effect on the interior circulation can be ignored).

For the forced problem, one needs the stratification to include a surface we11-mixed layer over which the wind stress acts as a body force. Provided that, like the rest of the stratification, the depth of that mixed layer is independent of time and space, the forcing can be projected onto the normal modes of the system, and each mode is thus individually forced. In McCreary's approach (section 1.6.1), time-dependence is replaced by friction, and the waves supported by the system decay rather than propagate away from their sources. Their meridional structure and group velocities are those of the inviscid free modes and the same terminology is used. 
Time-dependent models have been mostly used to study how a steady state develops after an abrupt switch-on or switch-off of the forcing, or how the ocean responds to periodic or more realistic forcing. In linear models, the adjustment process can be described in terms of wave radiations and reflections. Take for instance the case of a simple homogeneous rectangular equatorial ocean over which a steady uniform wind is suddenly switched-on from zero. In the wake of the directly excited waves and their reflections, a pressure gradient is built which acts towards balancing the applied stress. In a linear inviscid ocean, the final state is eventually a state of rest (except for gravity waves). The rapidity of the ocean response depends on the speed of the waves and on the size of the basin. Much of the adjustment occurs after the first eastward Kelvin wave front and the gravest westward Rossby wave front have propagated across the basin. For a $5000 \mathrm{~km}$ ocean (the order of magnitude of the equatorial Atlantic) and a stratification characteristic of the equatorial regions, that takes about 150 days (Cane, 1979).

If a physical process such as vertical dissipation or vertical advection creates a momentum exchange between the modes, then the spun-up state, instead of being the state of rest of the 1 inear inviscid solution, includes a permanent EUC. The way a viscid nonlinear equatorial ocean responds to the switch-on or the switch-off of simple wind patterns has been extensively studied by Cane (1979a,b), Philander and Pacanowski (1980), and Philander (1981). Philander and Pacanowksi used a multi-level numerical model with constant coefficients of eddy diffusivities in a $4800 \mathrm{~km}$ rectangular basin whose initial mean stratification is allowed to evolve. Nonlinear effects accelerate eastward jets, retard westward ones, and can reverse the direction of a westward surface current driven by switched-on easterlies (by upwelling eastward momentum from the underlying EUC). The wave fronts of the linear theory are still essential elements of the adjustment process (1ocal accelerations created in the early stages of the spin-up stop in their wake), but they can be modified by nonlinearities and dissipation, creating zonal homogeneities of interest here. 
Consider for instance the case of switched-on easterlies, homogeneous in longitude and in latitude. First if nonlinear effects are weaker than dissipative ones, a (somewhat damped) Rossby wave front does propagate away from the eastern boundary as a (somewhat damped) Kelvin wave front propagates away from the western boundary; the resulting vertically integrated eastward transport progressively diminishes as the eastern boundary is approached, and the water is returned by westward flows centered at about $3^{\circ}$, on either side of the equator; a western boundary layer closes the circulation (Figure 15 in Philander and Pacanowski 1980). On the other hand, if nonlinear effects are stronger, the Rossby wave front is prevented from propagating away from the eastern boundary by the opposing intensified eastward currents, and the inverse pattern obtains for the vertically integrated transport: progressively accelerating eastwards, as water converges from westward flows on either side of the equator; this time, an eastern boundary layer closes the circulation (Cane, 1979b; Figure $12 \mathrm{~b}$ above). Both cases are schematically represented on Figure 14 . In a situation where nonlinearities and dissipation are equally important, it is likely that the retarded pattern of Figure $14 \mathrm{a}$ applies more to the eastern part of the basin and the accelerated pattern of Figure $14 \mathrm{~b}$ more to the western part, the transitional longitude depending on how far from the eastern boundary the Rossby wave front is dissipated or overcome by opposing inertial effects. If the winds are confined to a limited zonal domain (1 ike in McCreary's 1981-steady simulation), wave fronts are excited at the edges of the forcing region and the above reasoning applies to the forced circulation, whose intensity diminishes with the zonal extent of the wind patch. The strength and zonal decay rate of the circulation east of the wind patch depends on the relative size of nonlinearities and dissipation acting on the free modes of the system and their eastern reflections.

If changes in the wind forcing are gradual rather than abrupt, for instance if the forcing is periodic with a period long compared to the adjustment scale (about 150 days for the $5000 \mathrm{~km}$ basin under consideration), wave propagation becomes hard to detect and the 


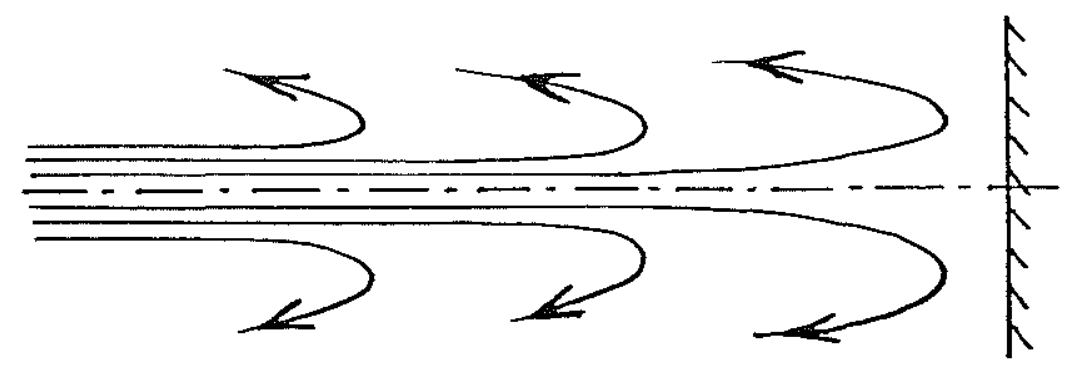

a

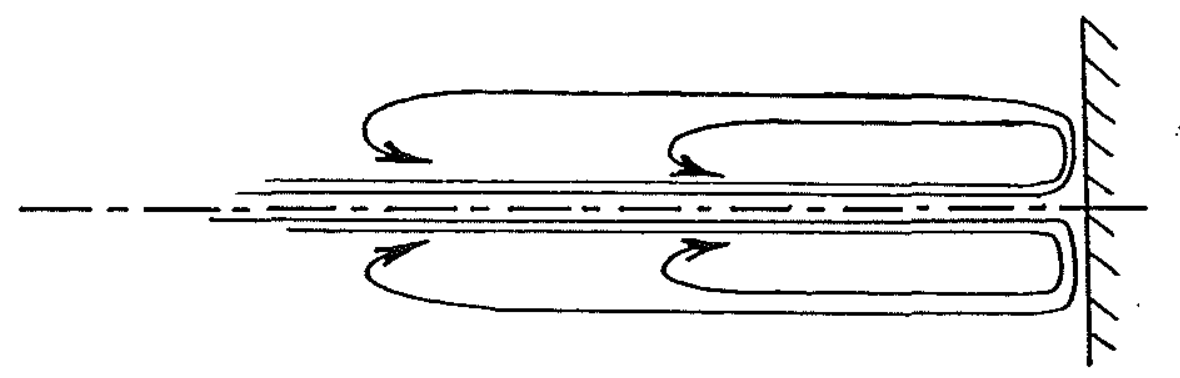

b

Figure 14: Schematic streamlines of the vertically integrated transport in the final state after switched on easterlies if

(a) nonlinear effects are weaker than dissipative effects;

(b) nonlinear effects are stronger than dissipative effects. 
response tends towards an equilibrium one. The effect of fluctuations of shorter periods was investigated by Philander and Pacanowski (1981). Their numerical results show that, for periods between 10 and 50 days, intense currents with large variability are generated in the surface layers while the variability at depth (below about $50 \mathrm{~m}$ ) is weaker. If the period of the forcing lies between 50 and 150 days, variability has a large amplitude both in the surface layers and in the thermocline. If the winds have a westward mean value (the best representation of the actual dynamical forcing), fluctuations with a period between 10 and 50 days cause a nonlinear intensification of the EUC (of the order of 15 percent in the example presented by Philander and Pacanowski), and the surface current reverses to eastwards when the easterlies weaken, because the ZPG becomes temporarily unbalanced just as in a sudden switch-off case. If the same winds have fluctuations of longer period, the pressure force has time to adjust, but the surface flow still reverses following the winds maximum, due this time to vertical advection of eastward momentum from the core of the EUC below (Figure 15a).

This description illustrates that with a complex realistic forcing where al1 such frequencies can be present simultaneously, virtually any time lag may exist between forcing, ZPG and current system. The only hope to interpret observations rests on one's ability to represent realistic forcing by drastically simplified patterns which would explain most of the ocean response. The observations reported by Katz et a1. (1977) of a ZPG roughly in phase with the wind stress (section 1.3.1) suggests an equilibrium response. But Katz and Garzoli (1982) were able to use the switch-off/switch-on simulations of Philander (1981) and Philander and Pacanowski (1980) to interpret the FGGE measurements as the response to a sudden weakening of the easter lies in January followed by the response to their sudden intensification in May. On the other hand, we saw above (Figure 15a) that the surface flow reversal following the maximum of the winds (probably the most robust observation of the FGGE period) could equally be part of the equilibrium response to low frequency varying easterlies. The recent wind measurements of the SEQUAL/FOCAL program tend to support 
the notion that, locally, the wind stress intensification is more event-like than gradual, as it appears to occur within a couple of weeks, rather than over a month or so as suggested by the climatology, which averages together years characterized by various wind onset dates. These measurements also reveal some zonal inhomogeneity in the way the onset takes place, and there still seems to be some controversy over how rapidly winds representative of larger zonal scales change. In any case, whether spun-up abruptly or periodically forced, models appear to predict more of a seasonal change in the EUC maximum velocity or vertically integrated eastward transport than observed during the same SEQUAL/FOCAL program. It is likely that the effect of wind f1uctuations of intermediate frequencies are in fact not negligible and that difficulties in interpreting observed time lags may be unavoidable. Finally, let us review the effects of a periodic wind stress with westward mean on the longitudinal structure of the ocean response, again from the simulations of Philander and Pacanowsk $i$ (1981). At periods between 50 and 150 days, mean currents have an impeding effect on the Rossby waves but not on the Kelvin wave. As a result, longitudinal differences develop: the response in the western part of the basin is closer to equilibrium than the response in the eastern part, zonal phase lags appear, and the location of the relative EUC maximum may switch from west to east during one cycle of the forcing. At periods longer than 150 days, these longitudinal differences become small. Figure 15 a shows the subsurface pattern of zonal velocity simulated with a spatially uniform wind with a westward mean value and a period of 200 days: the maximum EUC speed occurs in the eastern part of the basin, although not as close to the eastern coast as in Cane's (1979) nonlinear simulation (Figure 12b): the zonal deceleration in the east occurs over about $10^{\circ}$, longitude (versus $2^{\circ}$ in Cane's study), probably because friction at the EUC levels is not as small as in Cane's study compared to the nonlinear terms. When a wind with the same time dependence but confined to the central longitudes of the basin is applied, the forced region behaves similarly to the spatially uniform case. Figure 15b shows that, following the maximum easterlies, 

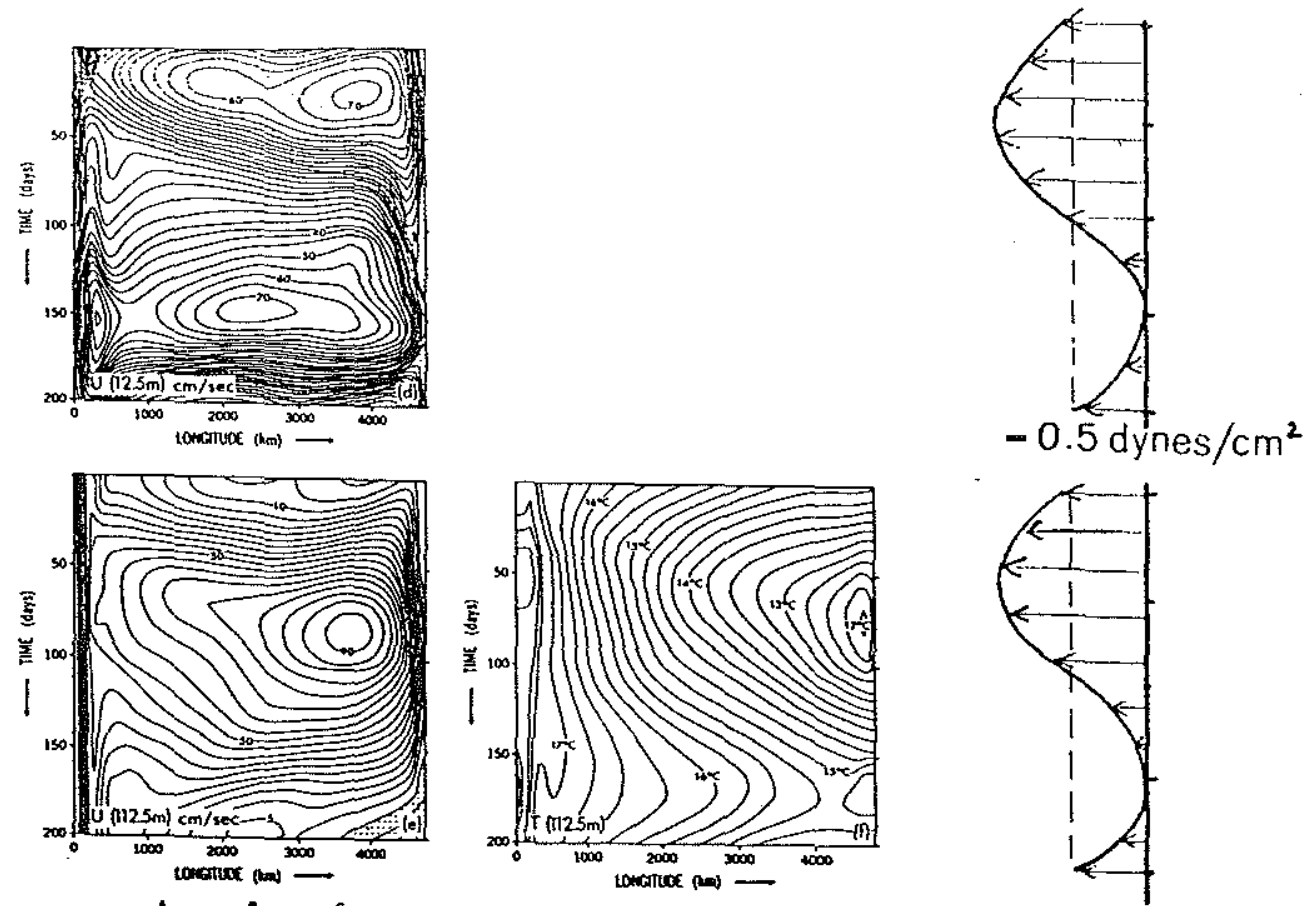

a
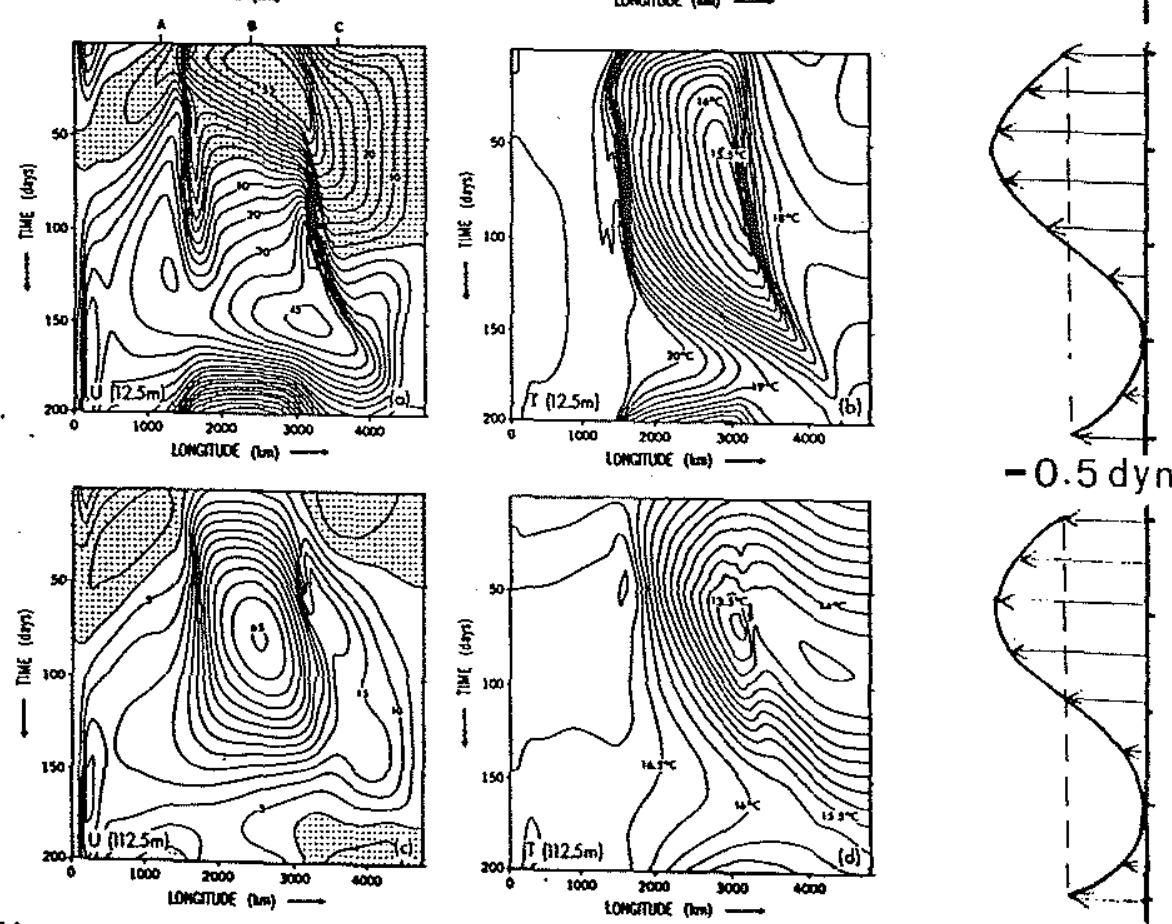

Figure 15: Longitude-time contours of equatorial velocity and temperature at $12.5 \mathrm{~m}$ and $112.5 \mathrm{~m}$ (1eft) in response to a periodic wind forcing wjth westward mean ( $r i g h t)$.

$$
\tau(x)=-0.5 H(x)[1+\sin (2 \pi t / P)] ; \quad P=200 \text { days. }
$$

a) Zonally uniform forcing: $H(x)=1$

b) Forcing concentrated near the center of the $5000 \mathrm{~km}$ basin:

$H(x)=0.5\{\tanh [(x-1600) / 120]-\tanh [(x-3200) / 120]\}$

(Philander and Pacanowski, 1981). 
the EUC is maximum at the center of the wind patch and that most of the zonal deceleration occurs within the forcing region. But some eastward flow is generated east and west of the forcing region as well, due to radiation and reflection of the free modes excited at its edges. Accordingly velocity maxima are reached later there than in the forced region.

To conclude this theoretical review and compare the effects of nonlinearities and friction on the zonal deceleration of the current to the effects of the zonal weakening of the wind stress itself, let us compare the runs of two numerical models of the seasonal equatorial Atlantic circulation forced by the same climatological monthly wind stress field (Hellerman and Rosenstein, 1983; Figure 1). The first is a continuously stratified viscid linear model close to a time-dependent version of McCreary's (1981), adapted by Tréguier and du Penhoat (1983) from the low frequency code originally written by Cane and Patton (1984) for one baroclinic mode. The second is a nonlinear layer-model developed by Schopf and Cane (1983).

Tréguier and du Penhoat's \$1983) model simulates a permanent EUC which, like McCreary's, has a reasonable width determined by the trapping scale of the baroclinic modes at the equator, and a rea1istic core depth and vertical extent. Because the model is linearized about a mean stratification independent of time and horizontal coordinates, the depth of the core does not change and its eastward shoaling is not reproduced. But its maximum zonal velocity and its transport (computed within the a $0.20 \mathrm{~m} / \mathrm{s}$ isotach between $2^{\circ} \mathrm{S}-2^{\circ} \mathrm{N}$ and $0-400 \mathrm{~m}$ ) do vary. The longitude-time pattern of the EUC maximum velocity simulated by Tréguier and du Penhoat's model is shown on Figure 16b. It is quite reminiscent of a similar plot of the zonal wind stress forcing (Figure 16a): in 0ctober for instance, the core velocity like the zonal wind stress is maximum near $40^{\circ} \mathrm{W}$ and progressively diminishes between $20^{\circ} \mathrm{W}$ and $0^{\circ} \mathrm{E}$. This similarity suggests that, with this forcing, the model ocean's response is close to an equilibrium response and that the 
weakening of the EUC with longitude is directly related to that of the zonal wind stress itself.

A comparison with transports measured during GATE in summer 1974 (Katz et a1., 1979, section 1.4.1.1) suggests that the model's EUC transport has the right order of magnitude in the central part of the basin but is too low in the eastern part. Also, EUC velocities at $5^{\circ}, \mathrm{W}$ and $0^{\circ} \mathrm{E}$ for example do not exceed 0.30 and $0.20 \mathrm{~m} / \mathrm{s}$ respectively during the simulated annual cycle while measured values at these longitudes usually exceed 0.50 and $0.40 \mathrm{~m} / \mathrm{s}$, respectively, and have been reported to reach $1 \mathrm{~m} / \mathrm{s}$ (sections 2.3 and 2.4). That the comparison is made between climatologically forced and instantaneously observed fields may explain part of the discrepancy, especially at periods of relatively rapid variations when a time lag between a given year and the mean may lead to substantial differences. Sti11, the data do suggest that the eastward penetration of the EUC is underestimated by the linear model. The time variation of the eastward transport simulated by the model in the central part of the basin is characterized by a minimum in May and a maximum in September. The model does not simulate a spring reversal of the surface current and an accompanying transport increase as reported by Katz et al., 1981 (section 1.4.1.1). This is not surprising since, given the smoothness of the wind stress variation (characteristic of a monthly climatology which eliminates high frequencies) and given the equilibrium character of the model's response, the only mechanism which could produce such a reversal is vertical advection of eastward momentum which, by definition is not included in a linear model.

Schopf and Cane's (1983) model has quite a different vertical structure from Tréguier and du Penhoat's (Figure 17a). Instead of being continuously stratified, Shopf and Cane's model is formed of two layers on top of a homogeneous motionless abyss and thus supports only two baroclinic modes. The upper layer is a turbulent we11-mixed 1ayer, homogeneous in currents as well as in temperature, over which wind stress and surface heating act. The lower layer is linearily stratified but permits no vertical shear; a mass flux is allowed 

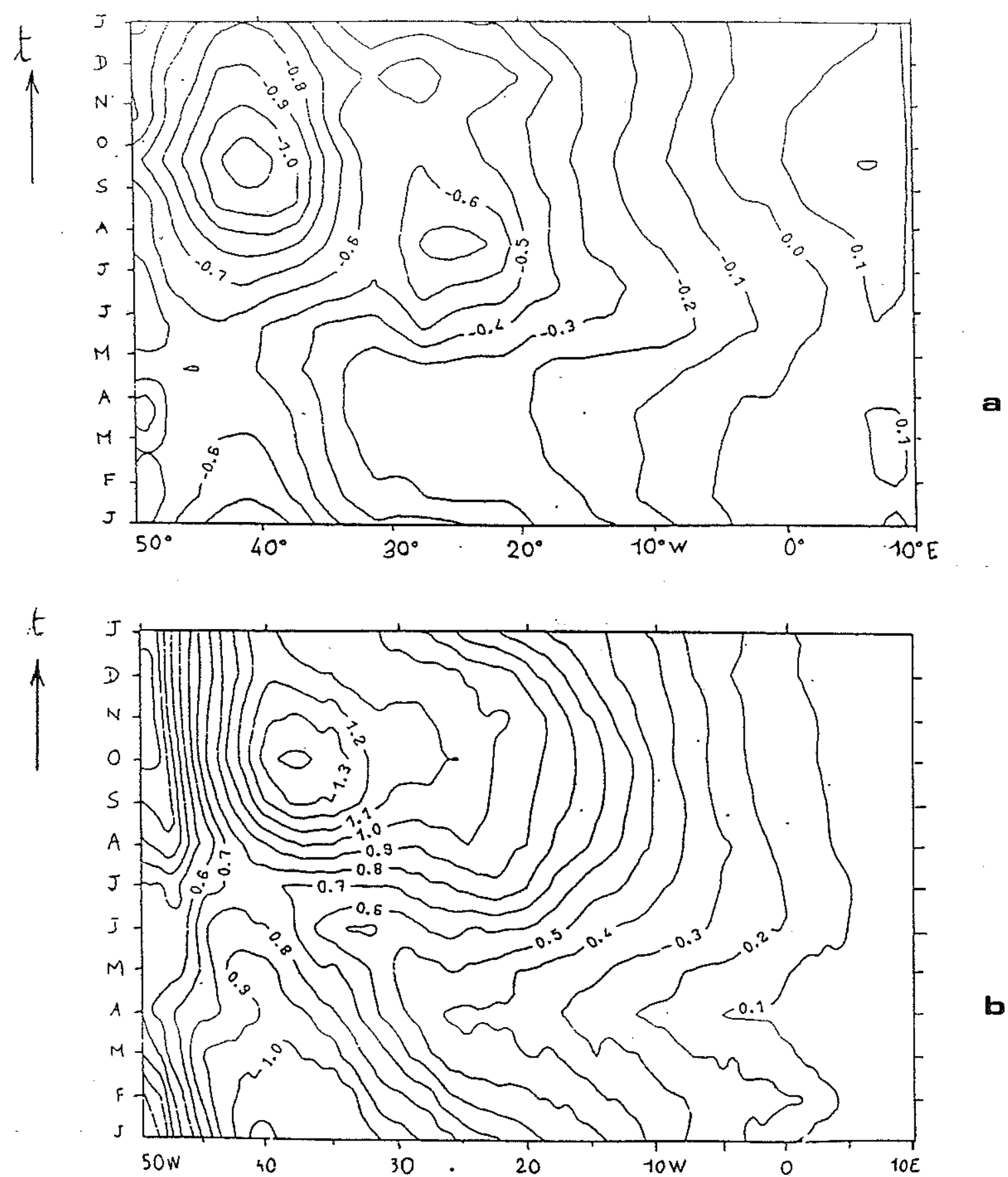

Figure 16: Longitude-time plots of (a) the Atlantic wind stress forcing (Hellerman and Rosenstein, 1983) and (b) the simulated EUC core velocity, from Tréguier and du Penhoat's (1983) linear stratified model. 

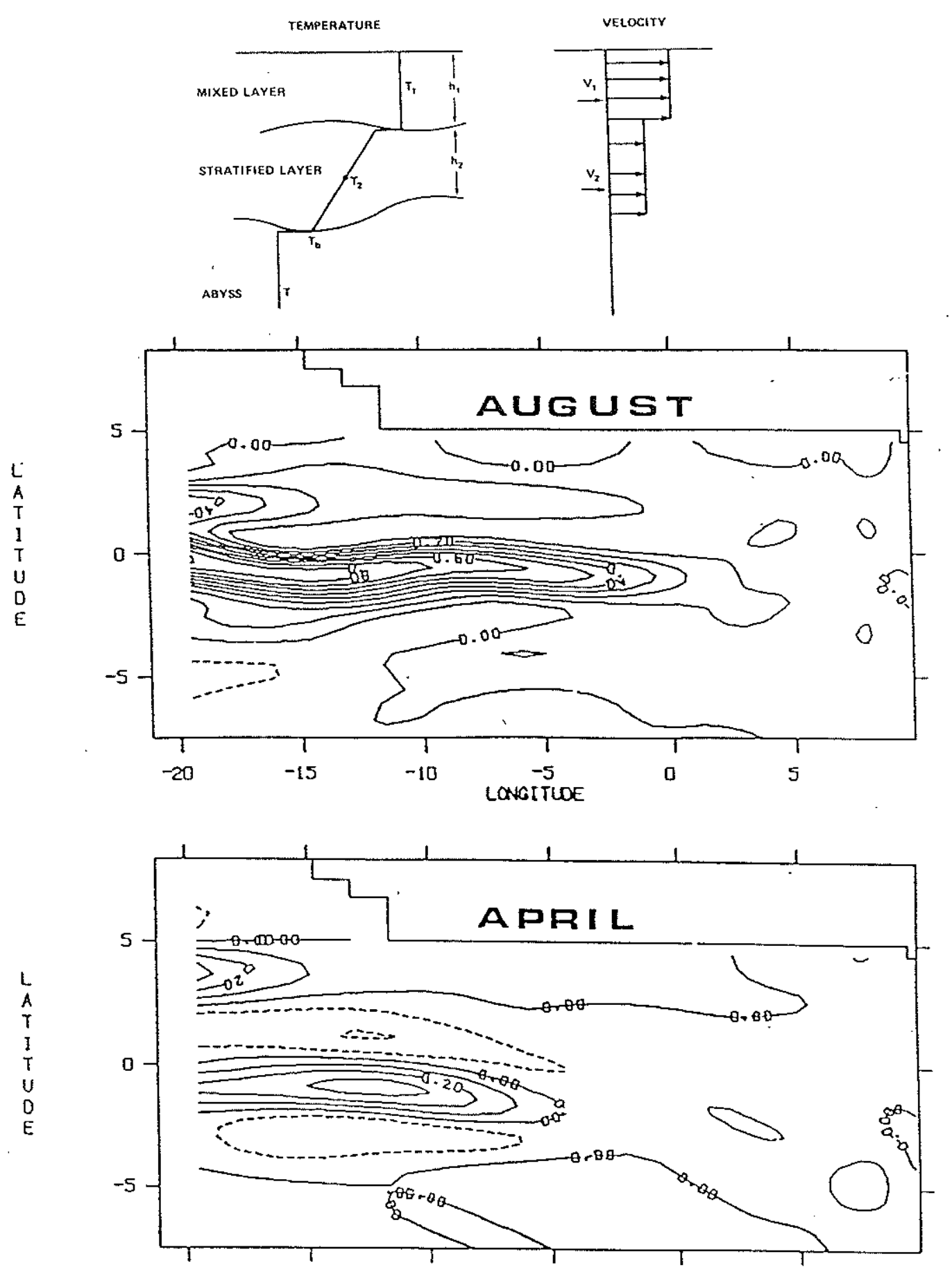

b

Figure 17: Simulation of the Atlantic EUC by Schopf and Cane's (1983) nonlinear model. The wind forcing is the same as on Figure 16.

a) Vertical structure of the model.

b) August and April horizontal contour plots of the zonal velocity in the stratified (EUC) layer of the model in the eastern half of the Atlantic basin. 
through its top while its base is treated as a material surface. The thicknesses of both layers are among the variables of the system and are therefore allowed to change with longitude and with time. Contrary to the models presented so far, there is no explicit vertical diffusion in the primitive equations which govern the lower layer, but the surface 1 ayer entrainment has an equivalent frictional effect. If the mixed layer depth is maintained constant and if both surface heating and internal temperature gradients are suppressed, the model becomes equivalent to Cane's (1979), which has separate formulations for inviscid vertical advection and diffusion. If, under these simplifications, it is forced by the same zonally uniform switched-on easterlies, it simulates in the lower layer a longitudinal pattern of velocity along the equator very similar to the one of Figure 12b or 14b: eastward velocity progressively increasing from west to east, and abruptly decreasing within two degrees of longitude from the eastern boundary. Consider now the case when the full mixed layer physics is included, surface heating is applied to maintain the stratification lotherwise quickly eroded by the strong vertical circulation) and the same zonally uniform easterlies are switched on. In the adjusted state, the eastward velocity in the lower layer again increases from west to east, but only over about the western third of the basin. It is then roughly constant over the rest of the equatorial section. The eastern decrease to zero is again abrupt and occurs within two or three degrees of $1 \mathrm{ong}-$ itude from the eastern boundary.

Consider finally Schopf and Cane's model adapted to the geometry of the tropical Atlantic ocean and forced by the climatological Hellerman and Rosenstein (1983) wind stress field. Figure 17b contrasts the response of the lower layer velocity in summer and spring over the eastern half of the basin. The weakening of the current is no longer as abrupt or confined to a narrow eastern boundary layer. As for Tréguier and du Penhoat's linear model, strength and eastward penetration of the EUC appear instead strongly correlated with the strength and eastward extent of the easterlies forcing the system. In order to compare further the EUC velocities simulated by both models, one needs 
to keep in mind that, due to the coarse vertical resolution of Schopf and Cane's model, the velocity of their simulated EUC (a vertical average over the lower layer thickness) underestimates what its core velocity would have been were the lower layer better resolved and able to support vertical shears. The EUC of the nonlinear run (Figure 17b) appears consistently stronger than that of the 1 inear run (Figure 16b), improving the comparison with observations. The large simulated seasonal variation however is not strongly supported by the data (section 1.4.1.1, and chapter 2).

The above observational and theoretical review suggests to me that the most likely cause for the gradually weakening EUC in the second half of its eastward course is gradual weakening of the wind stress forcing with longitude. The strength of the circulation still observed east of the region forced by the easterlies in the equatorial Atlantic points to the importance of nonlinear inertial effects, and it is possible that the effect of wind fluctuations with a period between 10 and 50 days, shown to cause a nonlinear intensification of the EUC in a $4800 \mathrm{~km}$ basin (Philander and Pacanowski, 1981), and absent in monthly climatologies, should be considered. 
101

Chapter 2. EASTERN TERMINATION OF THE EQUATORIAL UNDERCURRENT

Observations from both the Pacific and the Atlantic suggest that what is left of the eastward-flowing EUC veers southeastwards as it approaches the eastern boundary and possibly connects with a poleward coastal undercurrent. Some northward recirculation has al so been documented. These patterns have been mostly inferred from the study of hydrographic data. This chapter examines whether available direct current meter measurements confirm the patterns of eastern circulation obtained by indirect methods.

The (mostly hydrographic) observations supporting present assumptions on the eastern equatorial circulation are reviewed first along with a few poleward coastal undercurrent models. The observational contribution of this thesis to the question of the EUC termination in the Gulf of Guinea (eastern equatorial Atlantic) is presented next. It is mostly based on the analysis of historical profiler current meter data. Voituriez's (1984) case for a weakened EUC transport at $4^{\circ}, \mathrm{W}$ in the summer due to enhanced upwelling is revisited. New evidence for a poleward undercurrent along the coast of Gabon, with characteristics similar to those of the Peru-Chile undercurrent in the eastern Pacific, is found and discussed. 


\subsection{Eastern termination of the Pacific EUC}

Using hydrographic data from various expeditions in the eastern equatorial Pacific, Wyrtki $(1966,1967)$ constructed the circu1 ation pattern reproduced here as Figure 18, based on geostrophic transport estimates. Water from the EUC is shown to spread north and south before reaching the Galapagos Islands (located near $0^{\circ} \mathrm{N} 91^{\circ} \mathrm{W}$ ). Some EUC water appears to be integrated into the SEC at subsurface levels and to return westwards on both sides of the eastward core. Most is shown to flow southeastwards to the coast of Peru, upwell and return northwestwards as part of the surface SEC. A smaller portion is shown to branch northwards, upwe11 and return westwards with the surface NEC.

Lukas revisited the question of the Pacific EUC termination in 1981. Using again historical hydrographic data, he computed dynamic topography and traced features characteristic of the EUC core (Lukas, $1981 ; 1986)$. These features include the high salinity and high oxygen content generally associated with the core (see Figure 5 in Tsuchiya's monograph, 1968), and the $13^{\circ} \mathrm{C}$-thermostad generally found bel ow the core (Figure 19).

According to Lukas' study, the Pacific EUC terminates in the following manner. Over most of the year, the Galapagos Islands, located about $10^{\circ}$ of longitude off the coast of Ecuador, constitute a major obstacle to the eastward flow (already weaker than farther west). As a result, the EUC appears to adopt a southeastward course from the equatorial region west of the Galapagos directly to the coast of South Anerica at about $5^{\circ} \mathrm{S}$. Each spring however, an abrupt increase in the EUC transport and in the eastward advection seems to occur. High salinities can be traced around the Galapagos and along the equator to the eastern boundary and then southeastwards along the coast, suggesting that the EUC itself has adopted a new course: eastwards to the coast and then southeastwards along it.

Lukas explains this eastward surge as resulting from the eastward propagation of an equatorially-trapped downwelling (high pressure) feature with the characteristics of a Kelvin wave. As described in section 1.3.1, the mean pressure in the equatorial Pacific decreases 


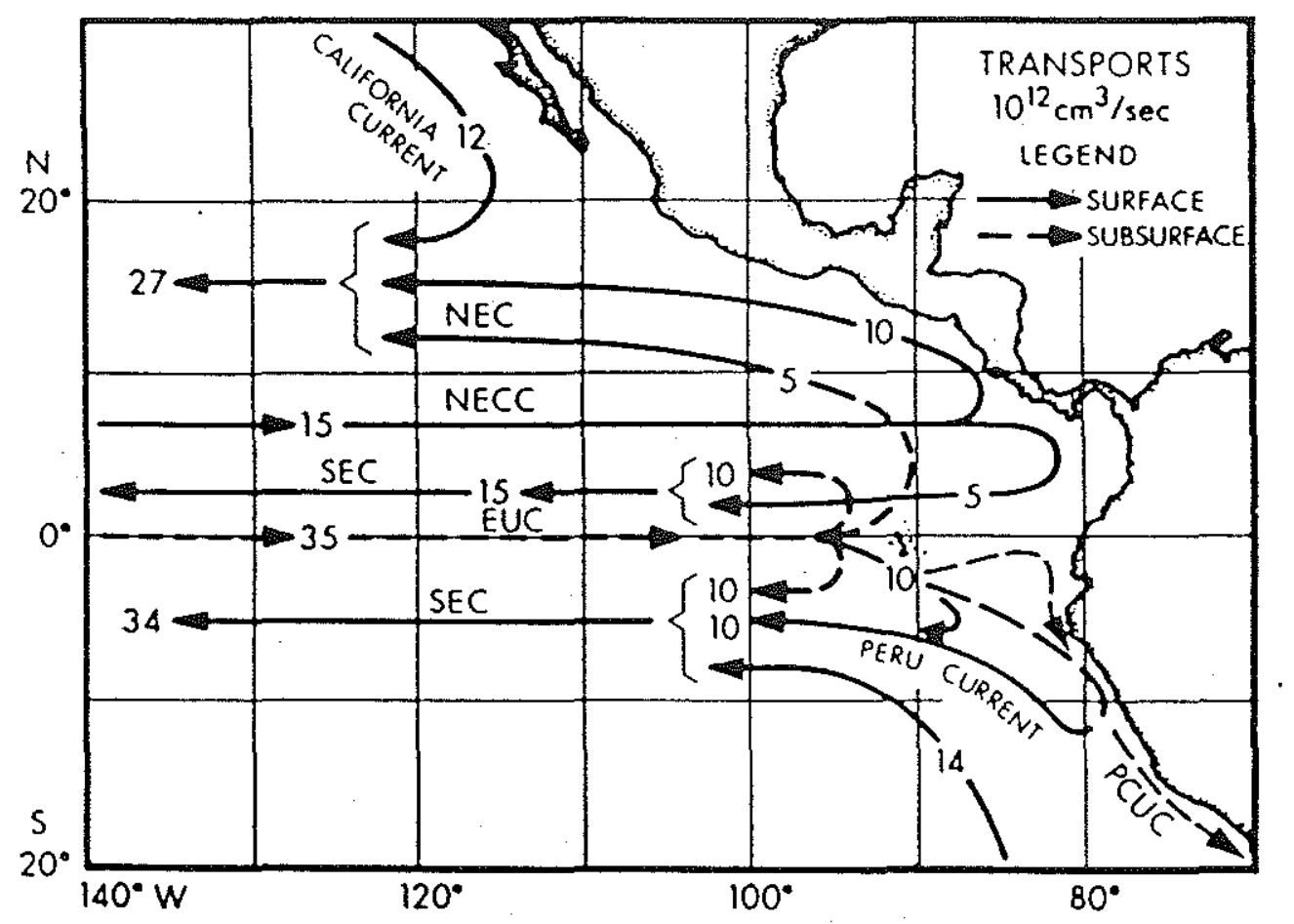

NEC North Equatorial Current

NECC North Equatorial Countercurrent

EUC Equatorial Undercurrent

SEC South Equatorial Current

Figure 18: Schematic circulation in the eastern equatorial Pacific 0cean. Numbers indicate estimates of the transport (in $10^{12} \mathrm{~cm}^{3} \mathrm{~s}^{-1}$ ) in the different branches during the period from June to December (Wyrtki, 1966). 
104 


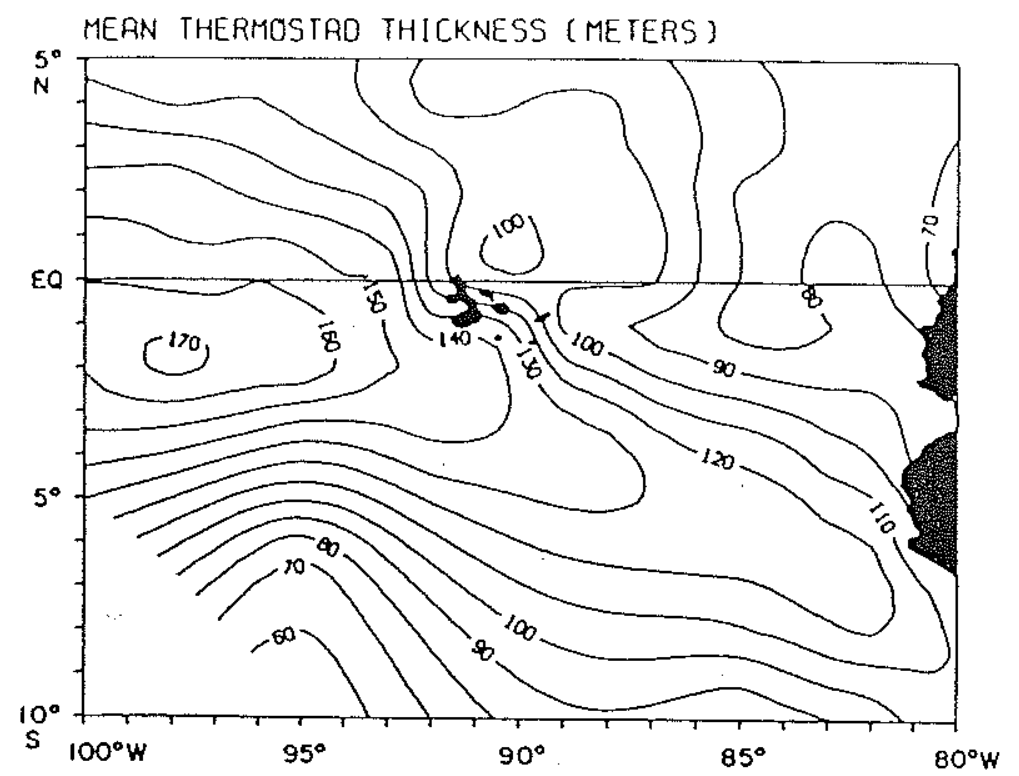

Mean thickness of the thermostad as defined by the vertical separation of the 160 and $180 \mathrm{cl} \mathrm{ton}^{-1}$ surfaces.

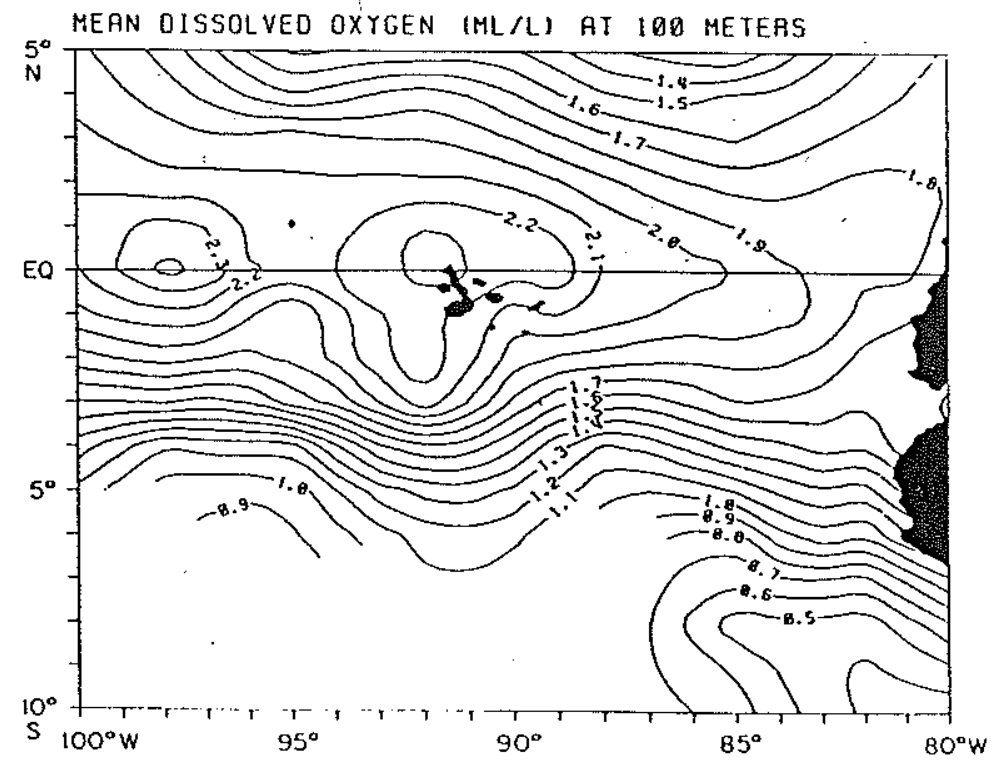

Mats of dissolved oxygen concentration at $100 \mathrm{~m}$.

Figure 19: Tracers of the EUC core in the eastern Pacific used by Lukas (1986). 
eastwards from the western boundary (positive ZPG force) until about $95^{\circ} \mathrm{W}$, then increases towards the eastern boundary (negative ZPG force). As the high pressure feature propagates into the region of positive ZPG of the eastern basin in the winter, the slope upstream of the feature is reversed, favoring a subsequent surge of eastward flow (Figure 20a). Lukas further argues that, close to the coast at $82^{\circ} \mathrm{W}$, the mean meridional dynamic topography is nearly flat at $75 \mathrm{~m}$ between 0 and $5^{\circ} \mathrm{s}$. But as the equatorially trapped high pressure feature described above reaches $82^{\circ} \mathrm{W}$ in the spring, a large slope is created between $0^{\circ}$ and $5^{\circ} \mathrm{S}$ (Figure 20b). This in turn forces a seasonal southward coastal flow, and the high salinity tongue observed along the coast at the same time can then be explained by southward advection. South of $5^{\circ} S$ where, according to Lukas, a southward pressure gradient force exists year round (Figure 20b), a poleward undercurrent, the Peru-Chile undercurrent, has been observed over the continental slope and shelf, its core between 50 and 100 m-depth (see for example Brockmann et al., 1980 and Brink et al., 1983). Alongshore velocities of the order of $0.15 \mathrm{~m} / \mathrm{s}$ were recorded and show large time variability dominated by 5-20 days barocl inic free coastal-trapped waves (Brink et al., 1983). Temperature, salinity and oxygen concentration of the coastal undercurrent appear to decrease downstream and to have an equatorial origin. This distribution of properties is actually what led earlier investigators to infer the existence of southward subsurface flow at the coast in the first place (Gunther, 1936).

According to Lukas' scenario then, the EUC generally leaves the equator at the Galapagos Islands and feeds the Peru-Chile undercurrent at about $5^{\circ} \mathrm{S}$. In the spring when the EUC is stronger, it passes the Islands, extends to the coast at the equator then deflects south. To our knowledge, presently available current meter measurements do not unambiguously confirm such a link between equatorial and coastal undercurrents. Long term current measurements at $0^{\circ} \mathrm{N} 110^{\circ} \mathrm{W}$ do show an intensification of the EUC in Apri1-May for non El Niño years (Figure 8b; Halpern, 1986). [Velocity measurements further east exist but consist either of instantaneous sections at $95^{\circ} \mathrm{W}$ and $85^{\circ} \mathrm{W}$ or 
of moored time series at $95^{\circ} \mathrm{W}$ during an $\mathrm{El}$ Nino event. They do not contradict the occurrence of a spring intensification of the EUC.] Current measurements at the coast, mostly made at $5^{\circ} \mathrm{S}$ and $15^{\circ} \mathrm{S}$, do not however resolve the seasonal variability of the coastal undercurrent (CUC). The longest time series so far were obtained during El Niño years at $15^{\circ} \mathrm{S}$ in 1976-77 and at $10^{\circ} \mathrm{S}$ in 1981-82 (Smith, 1983), and thus are more indicative of the interannual variability of the CUC. According to Smith's study, the onset of E1 Niño conditions at the coast (surface and subsurface warming) coincided with increased poleward flow in March-May 1976 and 0ctober-December 1982. Continuous current measurements at $0^{\circ} \mathrm{N} 110^{\circ} \mathrm{W}$ and $0^{\circ} 95^{\circ} \mathrm{W}$ (Halpern, 1987a,b) do not exhibit a fall intensification of the EUC but show that the EUC "disappeared" in January 1983. It may be that the $95^{\circ} \mathrm{W}$-time series at the equator missed an intensification of the EUC prior to its disappearance, since Mangum et a1. (1986) did observe a stronger than usual EUC core at $95^{\circ} \mathrm{W}$ in November 1982 , but centered at $0^{\circ} 30^{\prime} \mathrm{S}$ (Figure 21).

We saw earlier that the longitude of the Galapagos Islands coincides approximately with that of the reversal of the annual mean zonal winds (from easterlies to the west of the Islands to westerlies to the east). We also saw that southerlies create a sea surface set-up across the equator corresponding to a southward pressure gradient force. At a coast where zonal geostrophic flow can no longer balance such meridional pressure gradients, poleward flow can thus be forced below an equatorward flow frictionally driven in the direction of the wind. Furthermore, the end of the winter is a period of weaker southerlies (Leetmaa and Wilson, 1985). A relaxation of the southerlies could trigger an imbalance in the meridional pressure gradient resulting in increased southward flow.

Note however that one of the conclusions of Lukas' analysis is that local winds do not play a major role in the termination of the Pacific EUC. According to his description, the westward and poleward pressure gradient forces which decelerate the flow zonally and accelerate it meridionally are caused internally by the impingement of the 


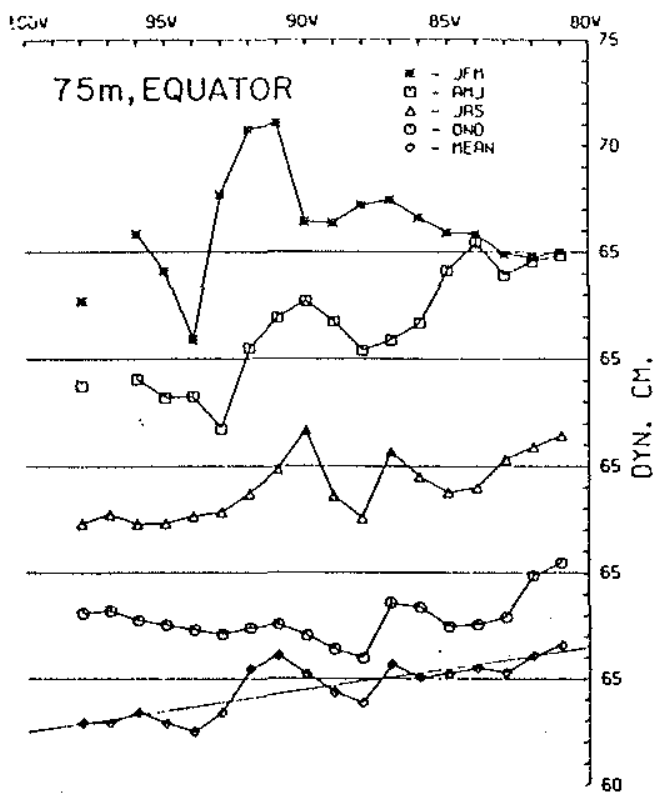

a

Seasonal and annual mean distribution of dynamic hejght of 75 dbar relative to 500 dhat along the eçutator. The solid line through the annuat mean is the least squares lit.

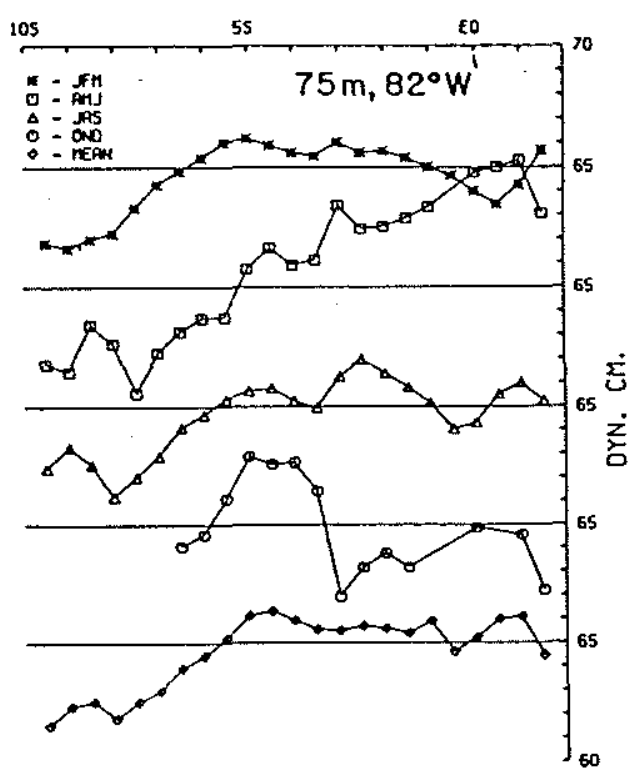

b

Seasonal and annual mean distribution of dynamic height of 75 dbar relative to $500 \mathrm{dbar}$ along $82^{\circ} \mathrm{W}$.

Figure 20: Zonal (a) and meridional (b) pressure distributions at the depth of the EUC in the eastern Pacific.

a. Along the equator.

b. At $82^{\circ} \mathrm{W}$.

(Lukas, 1986). 


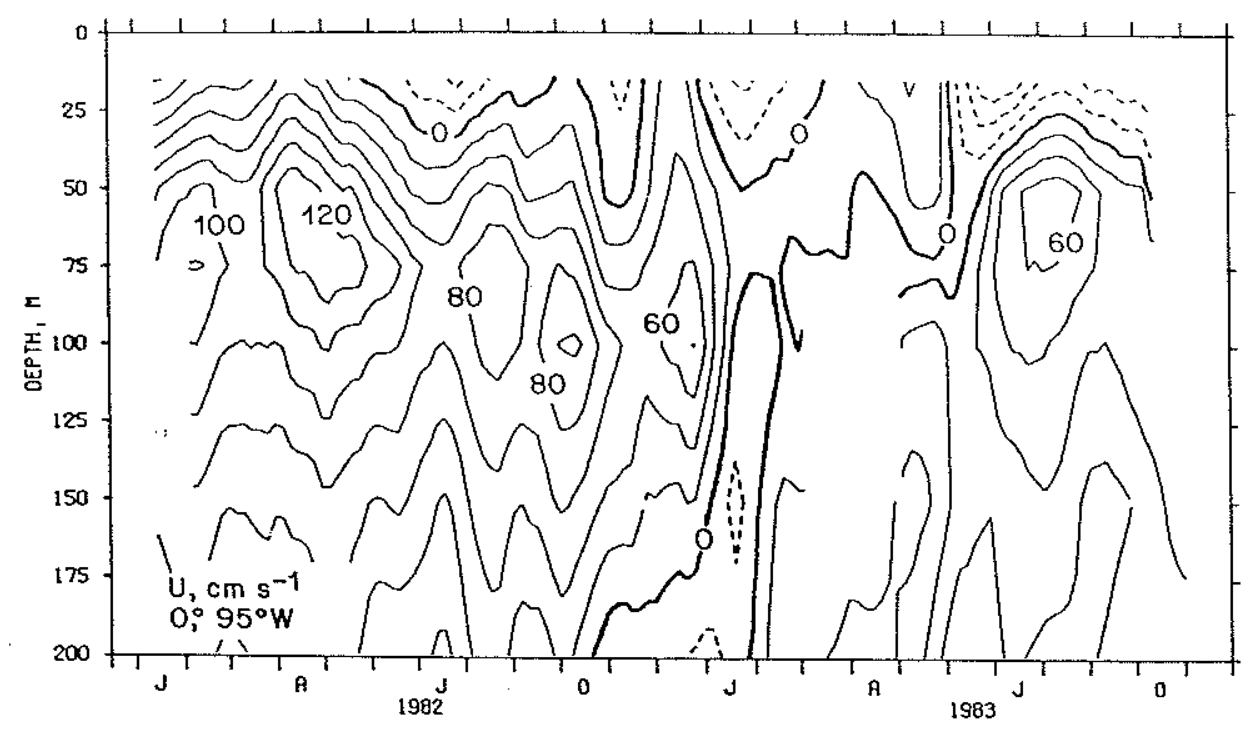

$\mathbf{a}$

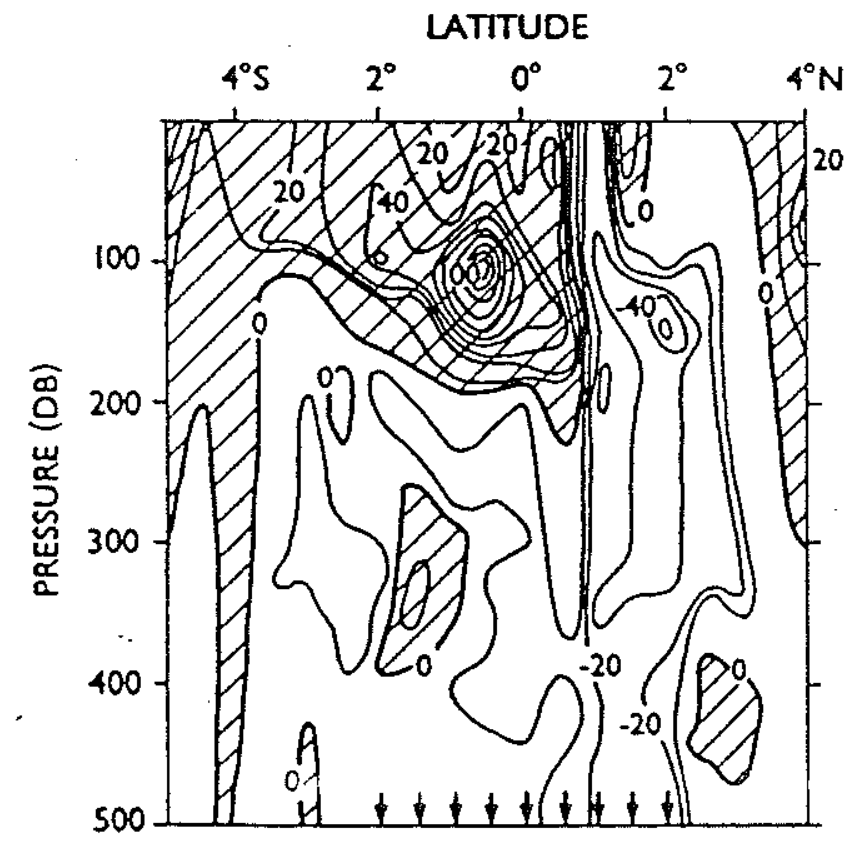

Figure 21: Zonal velocity measurements in the eastern equatorial Pacific at $95^{\circ} \mathrm{W}$ during the $1982-83$ El Niño.

a. Time-depth contour plot at $0^{\circ} \mathrm{N}$ from moored current meters at $15,50,75,100,150$ and $200 \mathrm{~m}$ (Halpern, 1984).

b. Meridional section in November 1982 based on TOPS velocity profiles at and equatorward of 2 and on geostrophic estimates relative to $500 \mathrm{db}$ poleward of $2^{\circ}$ (Mangum, Hayes and Toole, 1986). 
112 
EUC waters on the Galapagos Islands or of a remotely forced equatorial Kelvin wave on the eastern boundary. On the annual mean, Lukas (1981) does not observe a southward pressure gradient force below about $50 \mathrm{~m}$ between $0^{\circ} \mathrm{N}$ and $5^{\circ} \mathrm{S}$ at $82^{\circ} \mathrm{W}$. Furthermore he argues that timings are wrong to explain seasonal variations in the zonal pressure gradient along the equator and in the meridional pressure gradient along the coast by the seasonal variations in the zonal and meridional components of the local winds respectively.

Models simulating the coastal undercurrent on the other hand rely heavily on the existence of alongshore winds and opposing pressure gradients. In Yoshida's (1967) model of the circulation in the eastern tropical oceans, local winds are important because they cause local upwellings and subsequent meridional pressure gradients supporting zonal flow at the equator, and cross-shore pressure gradients supporting alongshore flow at the coast. In Mccreary's (1981) linear stratified model, the CUC is driven by a meridional pressure gradient force anchored at the edges of a patch of meridional wind stress. In Philander and Delecluse's (1983) mode1, the poleward CUC at the eastern coast is also driven by a poleward pressure gradient force. In their case, the pressure force which is created across the equator to oppose the northward wind stress becomes amplified at the coast since, with northward wind, downwelling (high pressure at the coast) is created north of the equator, and upwelling (10w pressure at the coast) is created south of the equator. Finally, in Rothstein's (1984) linear model, simulated EUC and CUC appear to be continuous, and agreement with Lukas' prediction is pointed out. But the model is forced by an idealized field of southeasterlies in which the coast coincides with the longitude at which $\tau^{(x)}$ goes to zero and $\tau^{(y)}$ is maximum. That choice makes it difficult to dissociate the role of the local winds from that of the coast itself in decelerating and deflecting the core of the EUC. 


\subsection{Eastern termination of the Atlantic EUC}

Figure 22, from Lemasson and Rebert (1973a), synthesizes their understanding of the mean surface and subsurface circulation in the Gulf of Guinea. It is based on a large number of prior observations of various nature scattered in space and time: surface current measurements, geostrophic transport estimates, tongues of high salinity and oxygen content, a few subsurface current measurements. Many observations in the region were made by the international community during the program EQUALANT (1963-1964). Since then, most have been taken during cruises out of Ivory Coast and Congo by the French agency O.R.S.T.O.M.

Figure 22 shows a predominantly northwestward surface circulation over a predominantly southeastward subsurface one, and presents many analogies with Figure 18 for the eastern Pacific. The two basins have similar geometries except for their northern boundary. The Sao Tome Island, around $0^{\circ} \mathrm{N} 7^{\circ} \mathrm{E}$, plays the role of the Galapagos Islands (although it is located $3^{\circ}$ of longitude off the coast rather than $10^{\circ}$ ). The Benguela Current is the equivalent of the Peru Current. As in Wyrtki's cartoon of the Pacific EUC (Figure 18), the Atlantic EUC is shown to veer southeastwards before Sao Tome and form a poleward coastal undercurrent. Some northward branching is also suggested. In contrast with Figure 18, Lemasson and Rebert also indicate the presence of two westward subsurface flows at and off the northern coast of the Gulf of Guinea below the surface eastward Guinea Current. Finally, they distinguish two distinct southeastward subsurface flows below the northwestward SEC south of the equator (see for instance Lemasson, 1975, and Molinari et al., 1981): the South Equatorial Undercurrent (SEUC) near $5^{\circ} \mathrm{S}$, and the South Equatorial Countercurrent (SECC) near $10^{\circ} \mathrm{S}$ (which occasionally has a surface signature as well). Subsurface countercurrents have also been observed in the eastern Pacific (Tsuchiya, 1968) al though their easternmost extension and fate is unclear.

Subsurface currents in the eastern equatorial Atlantic are in general associated with high salinities. No such water can be 


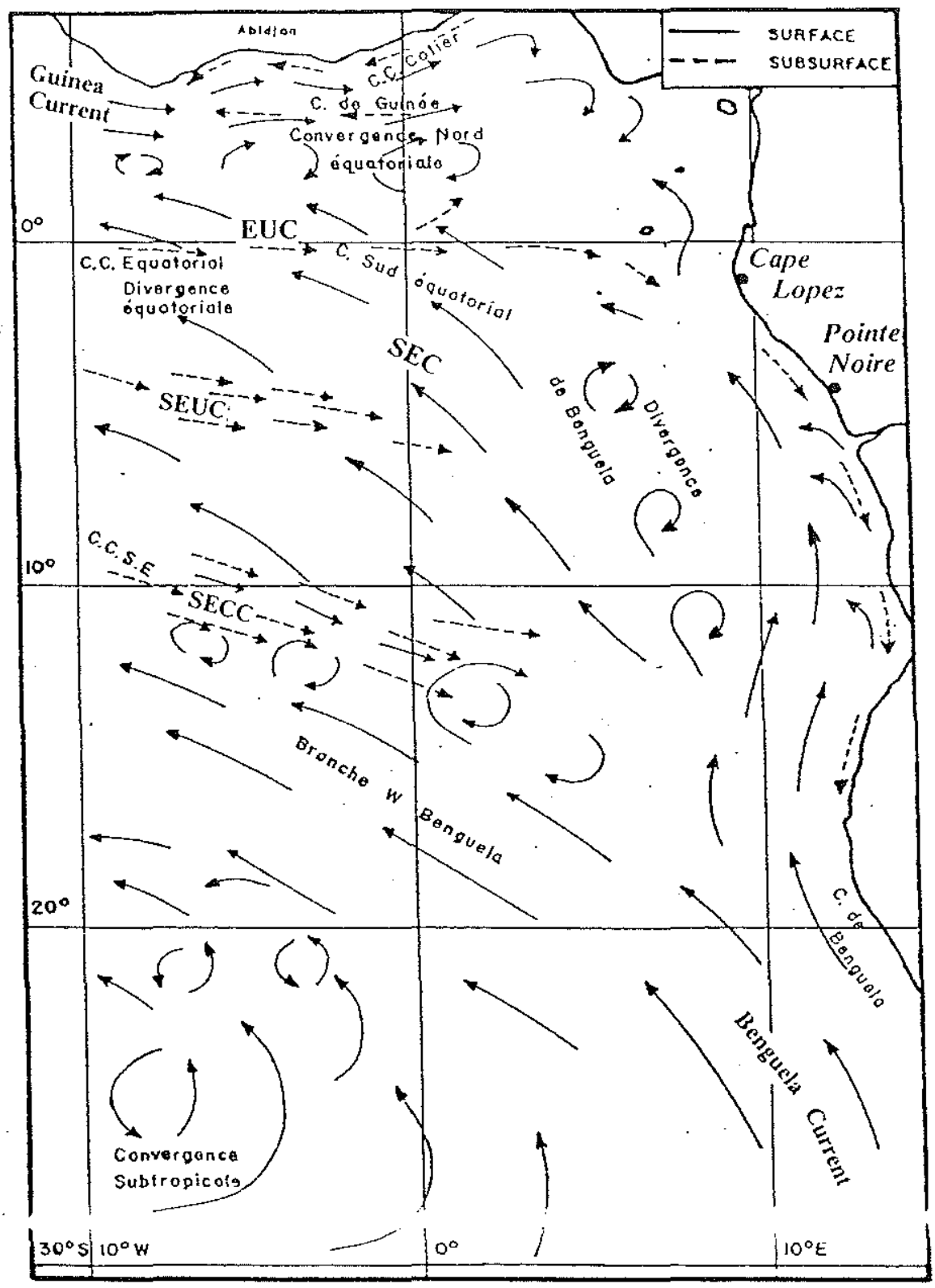

Figure 22: Schematic circulation in the eastern equatorial Atlantic 0cean (from Lemasson and Rebert, 1973a). 
formed within the Gulf of Guinea whose surface waters are on the contrary very fresh due to an excess of precipitation over evaporation and a large river runoff [from in particular the Niger River at $6^{\circ} \mathrm{E} 4^{\circ} 30^{\prime} \mathrm{N}$ and the Congo (Zaire) River at $12^{\circ} \mathrm{E} 6^{\circ} \mathrm{S}$ ]. High salinities thus appear to be advected into the Gulf of Guinea from the west via the eastward countercurrents (including the EUC), and from the south via the Benguela Current. Both current systems carry waters of subtropical origin (where surface salinities are high due to evaporation). In the case of the EUC, this water appears to have converged westwards towards the equator from higher latitudes before being advected eastwards (Figure 23; Khanaichenko, 1974).

There is agreement in the 1 iterature on the fact that the influence of the Benguel a Current $(B C)$ does not reach the equator, and that the source of the high coastal salinities observed between Cape Lopez $\left(0^{\circ} 30^{\prime} \mathrm{S} 10^{\circ} \mathrm{E}\right)$ and Pointe Noire $\left(5^{\circ} \mathrm{S} 12^{\circ} \mathrm{E}\right)$ (Figure 22) is the EUC. There is however no consensus over a southern 1 imit of EUC waters versus a northern limit of BC waters. Using TS curves, Wauthy (1977) traces EUC waters down to $13^{\circ} \mathrm{S}$, Gallardo (1981) mentions seasonal excursions of a coastal branch of the $\mathrm{BC}$ up to $5^{\circ} \mathrm{S}$, and Van Bennekom and Berger (1984) combine TS characteristics and $\mathrm{N}_{3}$ concentrations (1ower in the EUC, higher in the $B C$ ) to document a shallow zonal front of $\mathrm{BC}$ waters at $9^{\circ} \mathrm{E} 5^{\circ} \mathrm{S}$, i.e. off the continental shelf in front of the Congo River outflow. Further south, waters from the SECC may also contribute to the high coastal salinities. We will now examine how the salinity distributions have been used to infer circulation patterns. Given the uncertainty on the source of high salinities for the coastal region south of $5^{\circ} \mathrm{S}$, we will focus our attention on the region north of $5^{\circ} \mathrm{S}$.

The procedure of following tongues of high salinity and attributing them to direct advection by the EUC has been often used. In fact this constitutes most of the observational evidence for a southeastward branching of the EUC into a poleward coastal undercurrent off Gabon and for a northwestward connection between the EUC and the westward undercurrent off the northern coast of the Gulf of Guinea. 
Examples are shown on Figure 24 (Rinkel et al., 1966), Figure 25 (Hisard et a1., 1975) and Figure 26 [(a) Le Floch, 1970; and (b) Lemasson and Rebert, 1973b]. Additional observations are reported in Hisard and Morlière (1973), Kolesnikov et a1. (1971), Morlière et al. (1974), Khanaichenko (1974), Wauthy (1977), Piton, Montel and Gausi (1978), Piton, Besson and Esposito (1978). Distribution of dissolved oxygen on isanosteric surfaces has also been used to trace the EUC and the SEUC southeastwards (Hisard et a1., 1976; Piton, Besson and Esposito, 1978).

Khanaichenko (1974) justifies the use of the core layer technique for the study of the EUC trajectories (Figure 27) by arguing that the subsurface eastward flow remains confined between the isopycnals $\sigma_{t}=24$ and $\sigma_{t}=26$ and sheltered from local wind influences. With vertical mixing assumed negligible compared to lateral mixing on isopycnal surfaces, a tongue of conservative property suggests the existence of a component of the mean circulation along its axis. (With no diffusion at all, water mass properties would be exactly conserved along the flow trajectories, and isolines of property would coincide with trajectories).

There are various kinds of drawbacks to the core layer technique. That salinity is technically not a passive tracer appears minor compared to other problems and will be ignored. First there is an observational difficulty. Defining the property distribution itself involves contouring a set of scattered measurements which, typically, are poorly resolved in space and not simultaneous. The contouring operation thus tends to be quite subjective, relying on implicit assumptions of large spatial scales and small time variability. Figure 28 illustrates for example how the same subsurface salinity data from EQUALANT II (August-September 1963) were contoured differently by (a) Le Floch (1970) and (b) Neumann et a1. (1975). General patterns are fairly comparable, but the tongue-1ike structures drawn by Le Floch in the Gulf of Guinea appear to reflect his preconception that the high salinities observed there are of South Atlantic origin. 

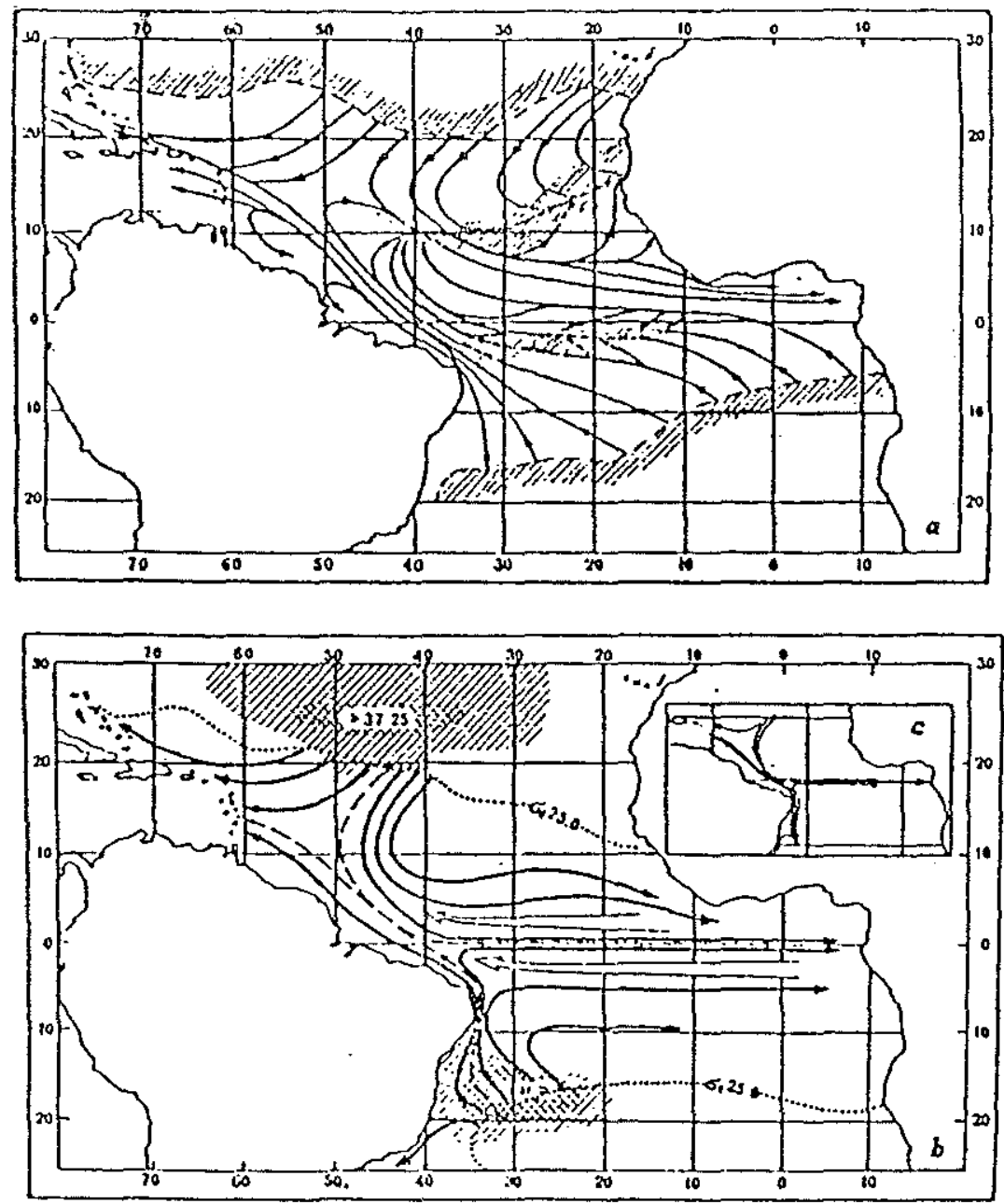

Transport of waters in subsurface layers of tropical zone in the Allantic Ocean.

$a-$ constructed by Defant on basis of salinity distribution [23]; $b$-constructed by author on basis of distribution of maximum salinity along isopycnal surface 25; $c$-deformed ficld of pressure in isopycnal surface 25 .

Figure 23: Origin of the salinity core associated with the Atlantic EUC, according to Khanaichenko (1974). 


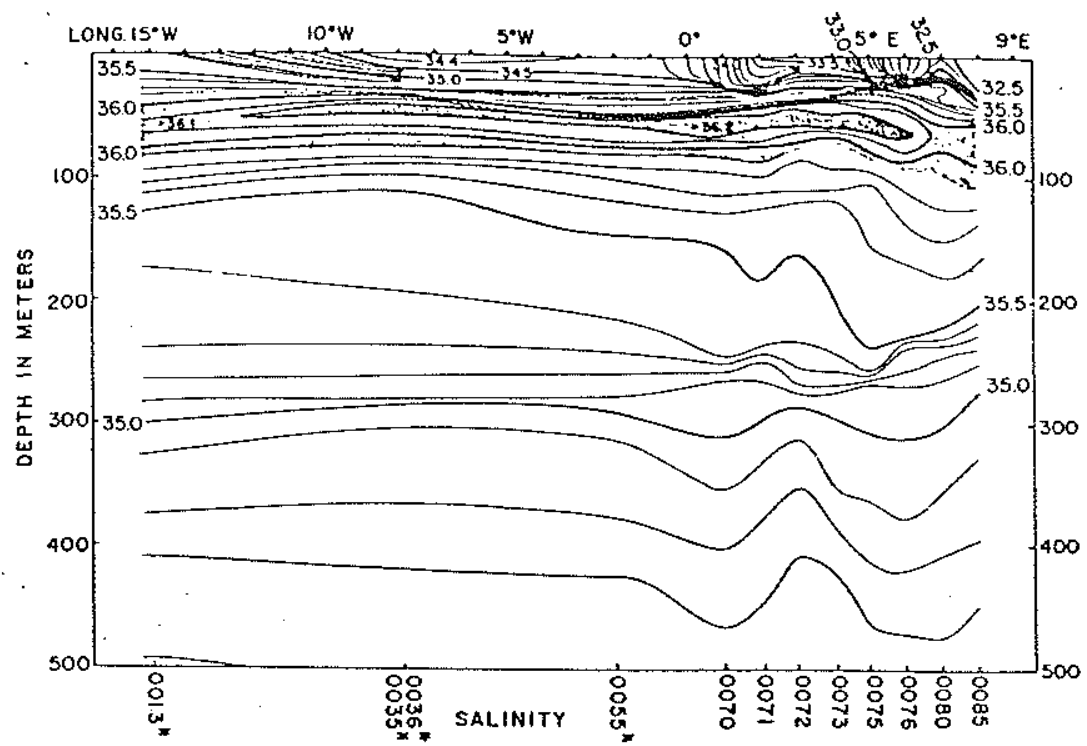

Salinity ection between $15^{\circ} \mathrm{W}$ and $8^{\circ} \mathrm{E}$ along the equator, March 10 to April 6 , 1964. Station numbers are given along bottom line of the section. Asterisks indicate data taken from vertical salinity sections along 15,8 , and $2 * \mathrm{~W}$.

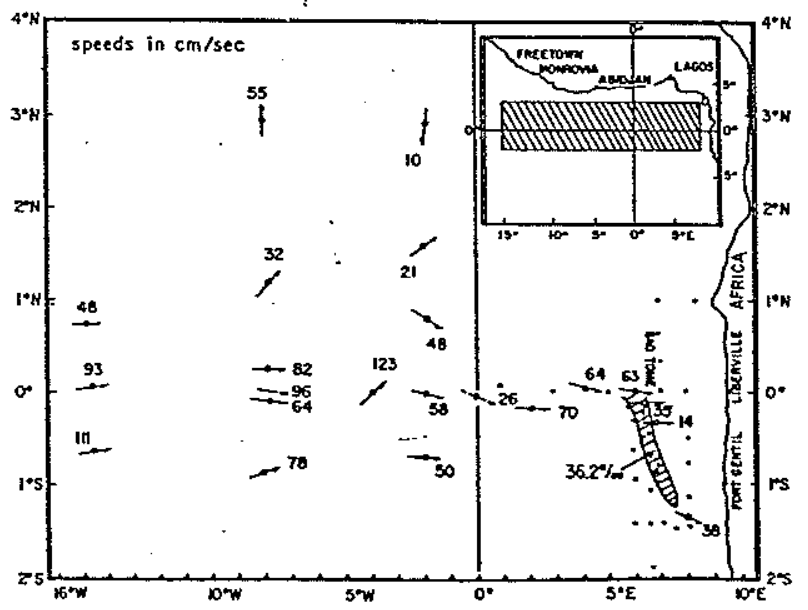

Results of current-drogue measurements at the depth of the salinity meximum in the equatorial repion betreen $15^{\circ} \mathrm{W}$ and $8^{\circ} \mathrm{V}$. Obsertations msde by R. V. Pillsbury are show by solid arrows and observations made by R. V. Geronimo by broken arrows. Direction of the arrows indicate a verage drift of the drogue duriog a tracking period of about 12 to 14 hours.
Average speed is given in $\mathrm{cm} / \mathrm{sec}$. Esst of $0^{*}$ longitude, oceanographic station locations sre Average speed is given in $\mathrm{cm} / \mathrm{sec}$. Esst of $0^{*}$ longitude, oceanographic station locations are
shown by dots. The hatched area indicates the southeastward extension of the high-salinity core (rith salinities in excess of 362 parts per thousand.) Insert shows location of survey area.

Figure 24: Tracing of the subsurface salinity maximum in the Gulf of Guinea (Rinkel et al., 1966). 


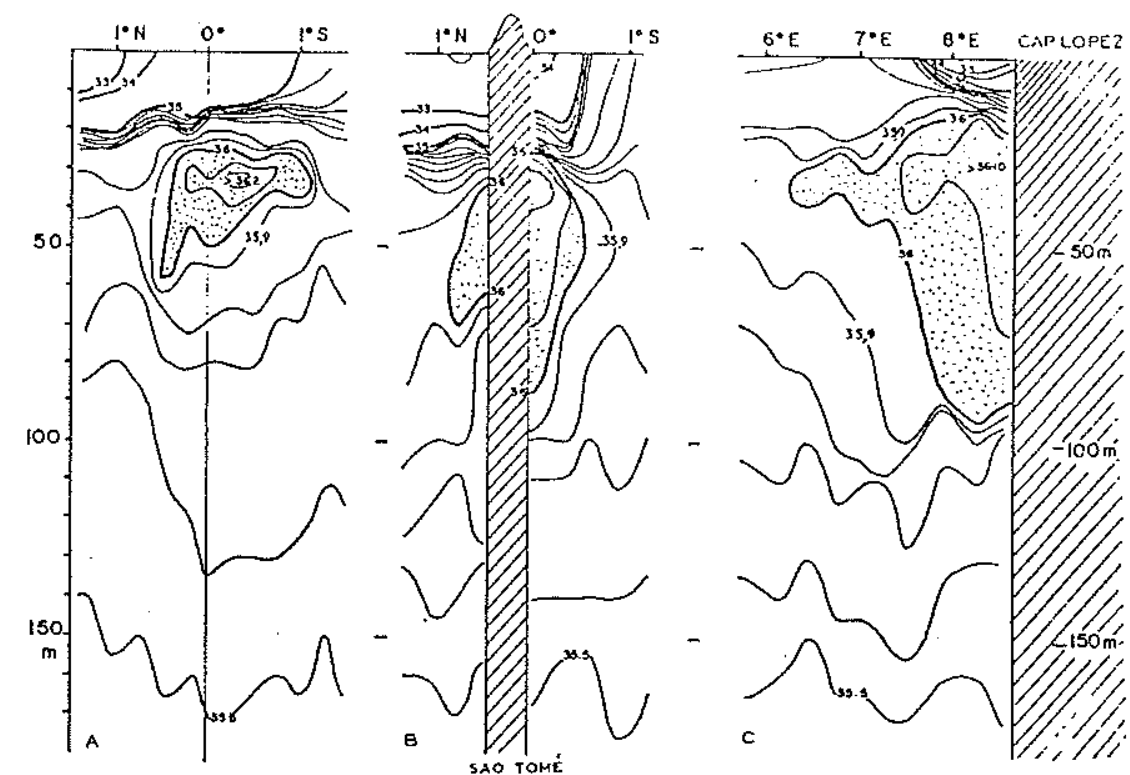

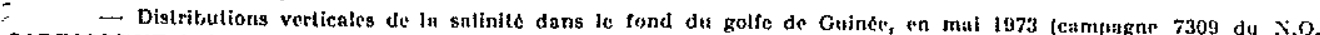

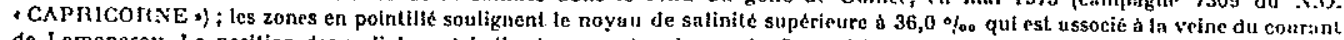
de Lomonosov. La position des radiales est indiquée en cartrische sur la figure $3 \mathrm{~b}$. Espacement des isohalines $0,5 \%$ \%
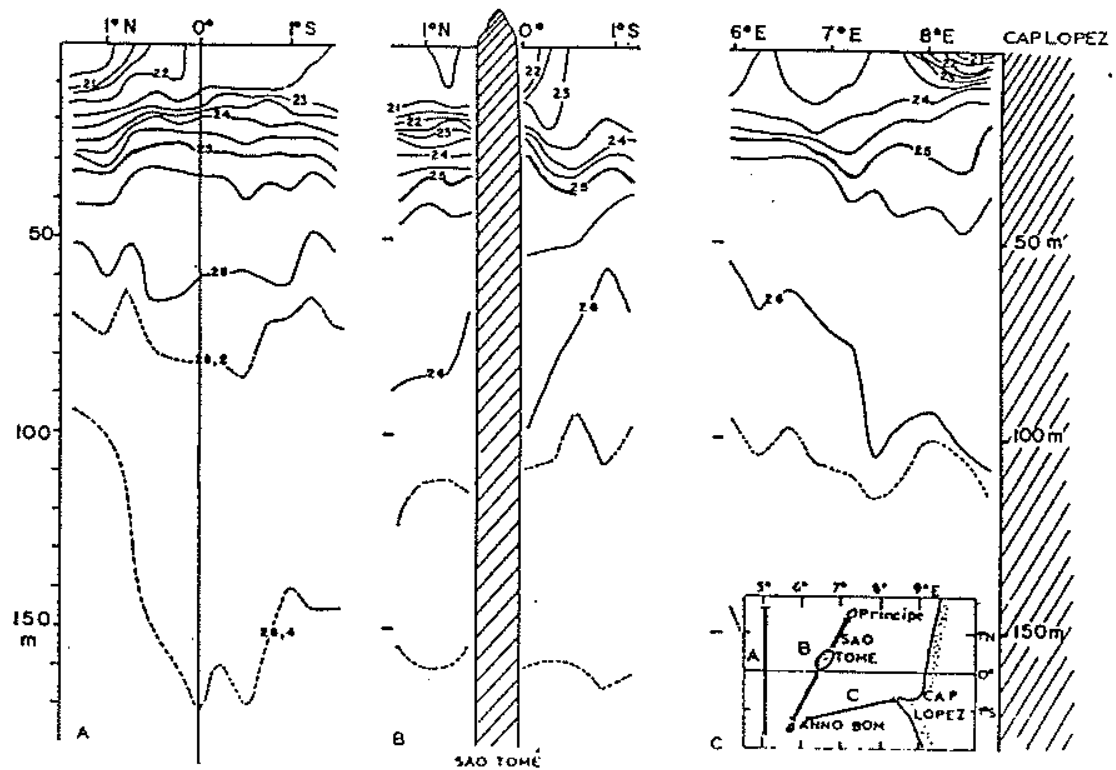

$\mathbf{b}$

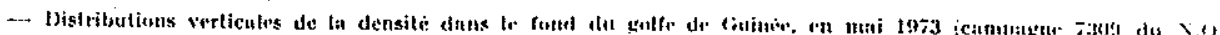

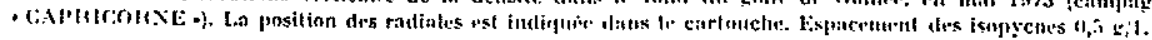

Figure 25: Vertical distributions of (a) salinity and (b) density in the easternmost Gulf of Guinea in May 1973. The location of the sections is indicated in the inset (Hisard et al., 1975). 


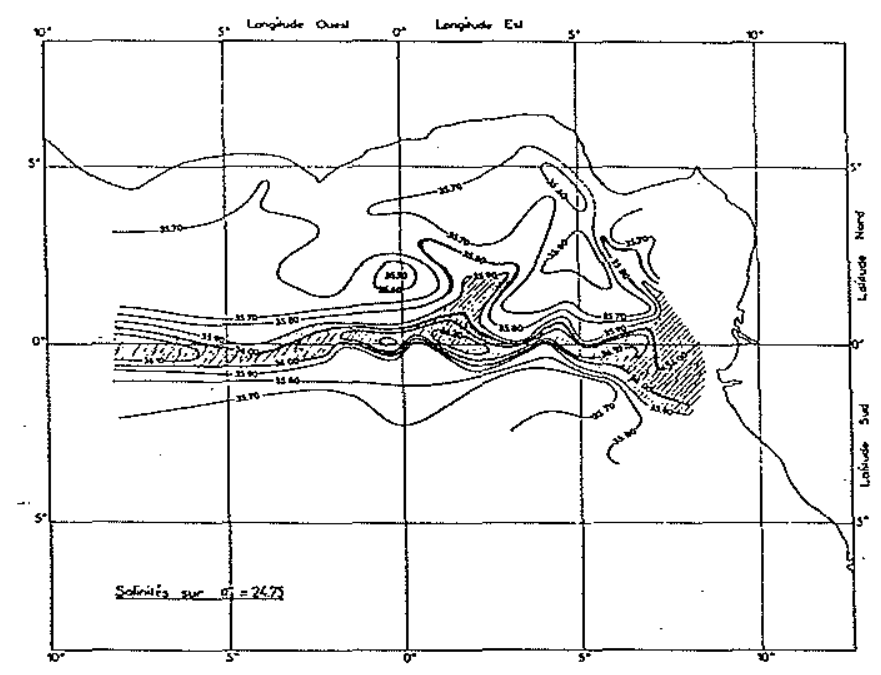

$\mathbf{a}$

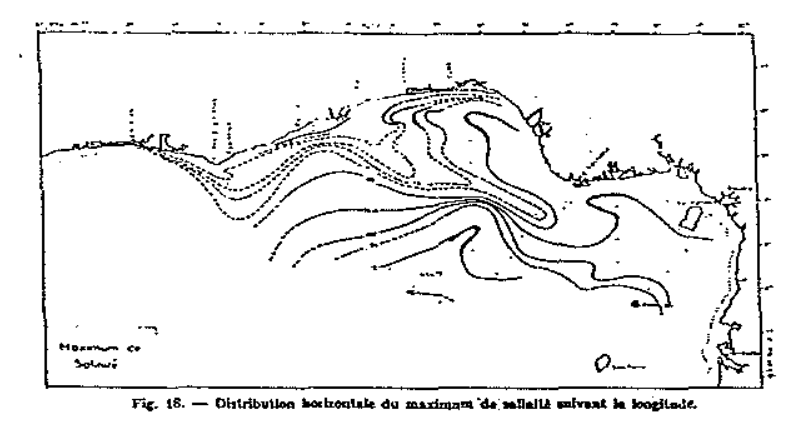

b

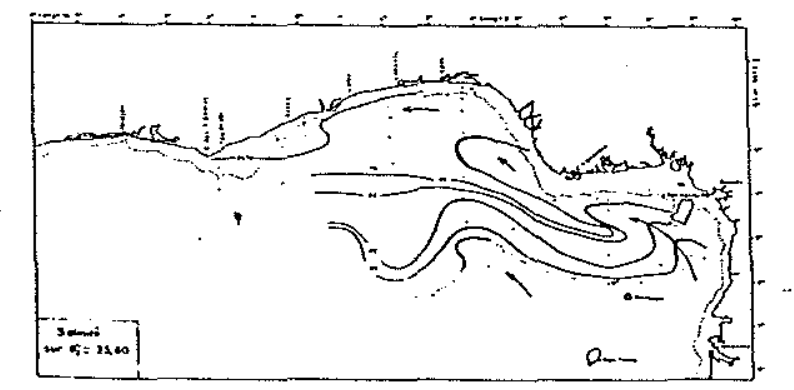

Figure 26: Tracing of subsurface salinity in the Bight of Biafra and the Bight of Benin (northeastern Gulf of Guinea).

a. On the surface $\sigma_{t}=24.75$ (Le Floch, 1970).

$b$. At the depth of the salinity maximum and on the surface $\sigma_{t}=25.60$ (Lemasson et al., 1973b). 


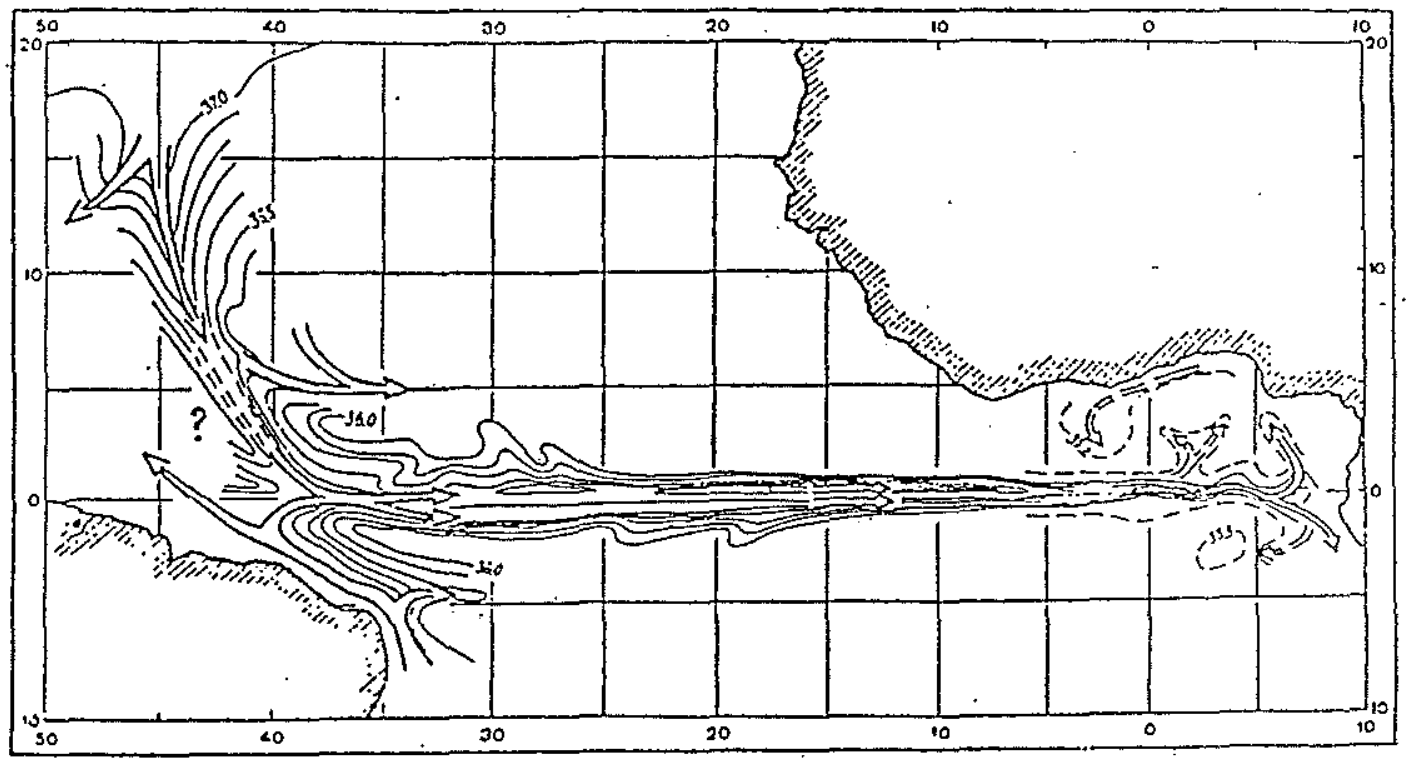

Lomonosov Current, its sources and termination in layer of maximum solinity.

Figure 27: Use of the core 1ayer method to determine the formation and termination of the Atlantic EUC (Khanaichenko, 1974). 


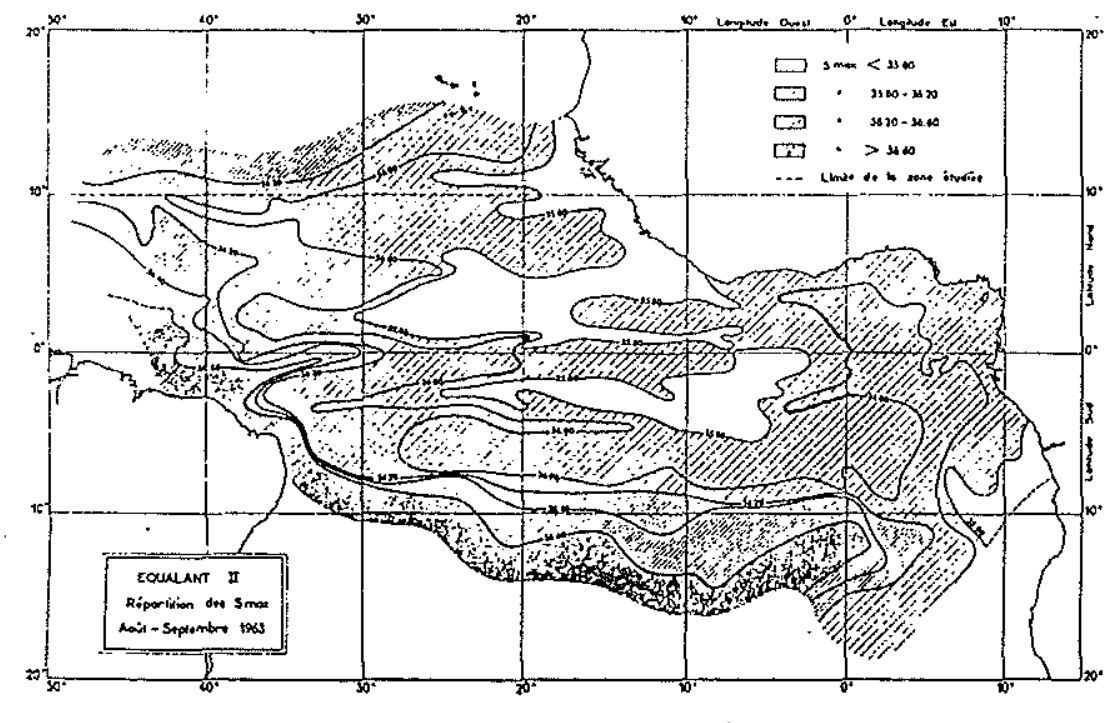

a

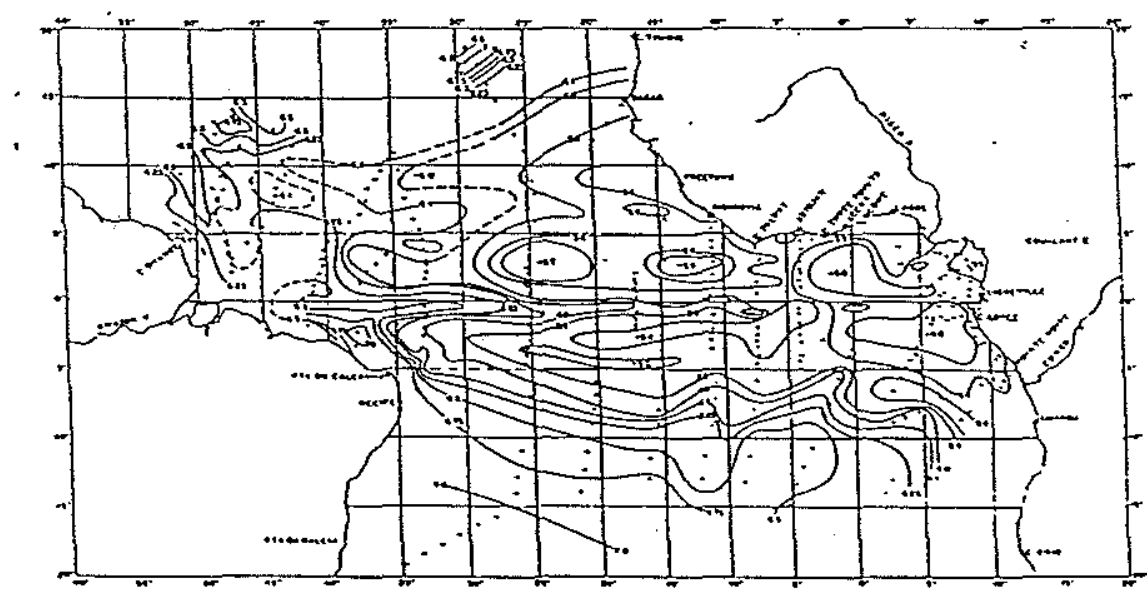

b

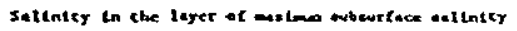

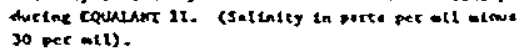

Figure 28: EQUALANT II subsurface sal inity maximum, according to (a) Le Floch (1970) and (b) Neuman et a1. (1975). 
Secondly, it has been often illustrated that, unless the effect of diffusion is very weak compared to that of advection (1arge Peclet number), the pattern of property distribution may bear little resemblance to that of the circulation, even in a well resolved twodimensional situation (see for instance the work done on the advectiondiffusion of the Mediterranean outflow, Richardson and Mooney, 1975; Hogg, 1987). Shear in the velocity may be mistaken for a veering of the flow, as illustrated on Figure 29 where the property field advected by a purely zonal shear flow $(U+\alpha y)$ is shown for various values of the shear at given zonal and meridional Peclet numbers (Pickart, 1987). Also temporal variations in the flow itself or the source of tracer are 1 ikely to produce misleading patterns. The general problem of how to invert a tracer field for velocity was recently discussed by Fiadeiro and Veronis (1984) and by Wunsch (1985). In the case of the midAtlantic EUC, the narrow tongue of high salinities weakening eastwards in the upper equatorial thermocline is thought to be formed by converging eastward flow. We saw that, by extension, the subsurface tonguelike high salinity structures found at the coasts of Gabon and Nigeria have been attributed to advection by southward and northward branches of the EUC respectively (Figure 27). It is just as conceivable, however, that the high salinity waters brought into the Gulf of Guinea by the EUC subsequently spread polewards without the need for advection by any well defined vein of current. This could happen because of a change in the meridional flow from converging to diverging, or simply because of weak velocities, small Peclet number and thus relatively larger lateral diffusion than farther west. The tongue-1ike character of the coastal distributions can then be due to convergence and maybe advection of the saline water mass by coastal dynamical processes independent from equatorial ones.

The last difficulty in applying the core layer method to trace the EUC into the Gulf of Guinea comes from the assumption of minimal vertical exchanges. The equator is a region of upwelling all year. The upwelling has a surface signature: the equator appears as a line of low temperature and high chlorophy 11 concentration, which 
implies that some vertical mixing occurs between the waters of the surface layer and those of at least the upper thermocline where the high salinity core is found. Indeed, Katz, Bruce and Petrie (1979) attribute the eastward loss of salt by the subsurface tongue between $28^{\circ} \mathrm{W}$ and $10^{\circ} \mathrm{W}$ to vertical mixing with the fresher SEC waters above. Moreover, the upwelling goes through a distinct seasonal cycle: it is maximum in boreal summer when the southeasterlies are maximum. In the Gulf of Guinea where the thermocline is shallow, the enhanced summer upwelling causes a spectacular drop of sea surface temperature along the line of maximum divergence (which, due to the southerly component of the wind, lies slightly south of the equator). At the same time, surface nitrate concentrations rise and the high salinity of the subsurface core drops. This has been documented in detail by Voituriez (1980a,b; 1981; 1983), based on repeated hydrographic stations along $4^{\circ} \mathrm{W}$ between 1971 and 1980 (Figure 30).

Voituriez (1983) points out that the subsurface salinity maximum in the Gulf of Guinea can disappear altogether during the summer, without a corresponding disappearance of the EUC velocity core (Hisard and Morlière, 1973). Rather than increased mixing with the surface waters, Voituriez describes a global upwelling of the whole hydrographic structure which brings the salinity maximum into the surface SEC, where it is advected westwards and quickly looses its identity. This constitutes a serious warning regarding prior inferences that the EUC itself would stop between $5^{\circ} \mathrm{W}$ and $0^{\circ} \mathrm{E}$ in the summer. Southerly winds over the eastern boundary of the Gulf of Guinea south of the equator and southwesterly winds over the northern boundary east of $0^{\circ} \mathrm{E}$ are also upwelling favourable. As at the equator, lower temperatures and higher salinities appear at the surface along these coasts during boreal summer, while subsurface salt concentrations presumably decrease. This again makes it hard to infer the limits of a corresponding advective flow.

This entire discussion points to the need for direct current measurements, not only along the equator and the coasts, but also in between, in order to estimate the respective roles played by 


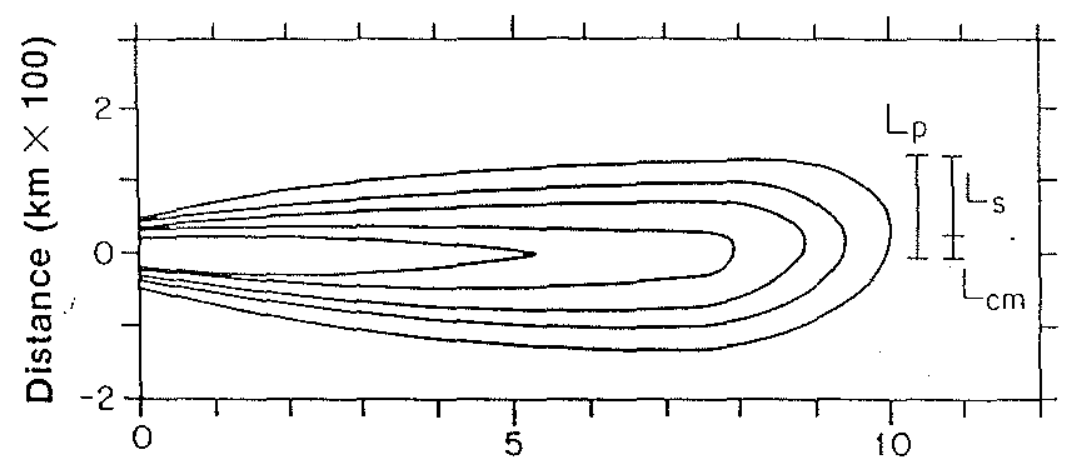

a

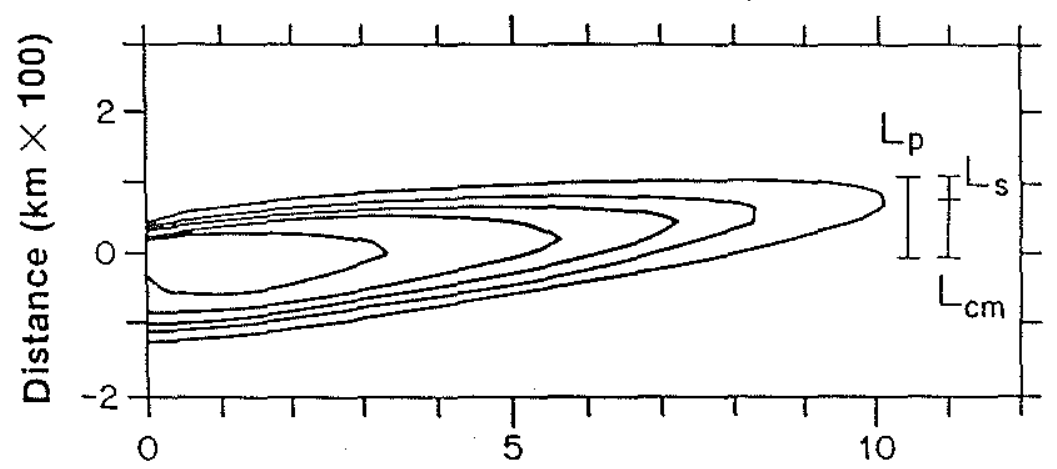

b

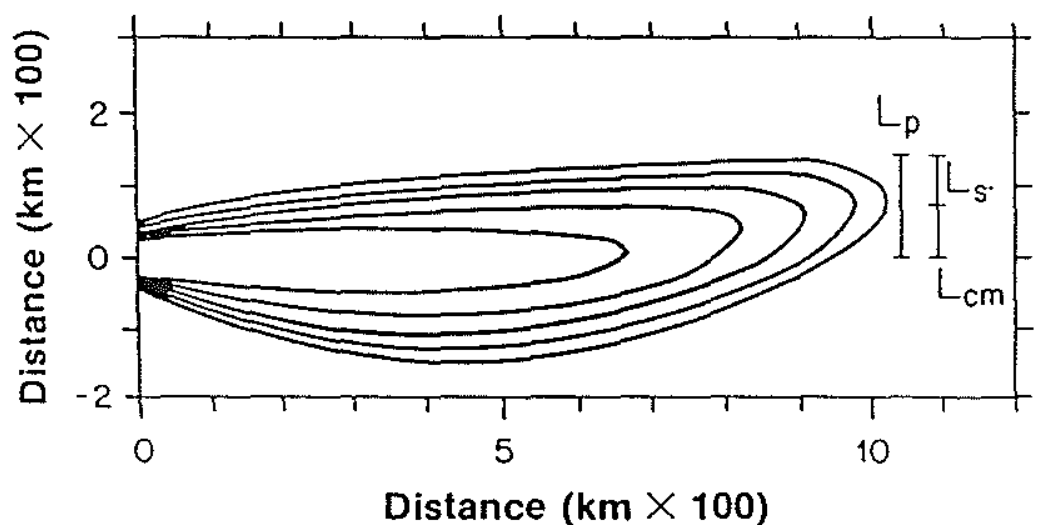

C

Figure 29: Advection of a property field by a purely zonal shear flow $(u+\alpha y)$ for various values of $\alpha$, illustrating (a) spreading, (b) migration, (c) a combination of spreading and migration. $L_{p}$ measures the cross-stream tracer penetration, $L_{c m}$ the displacement of the center of mass across streami ines, and $L_{S}$ the spreading of the tongue (Pickart, 1987). 

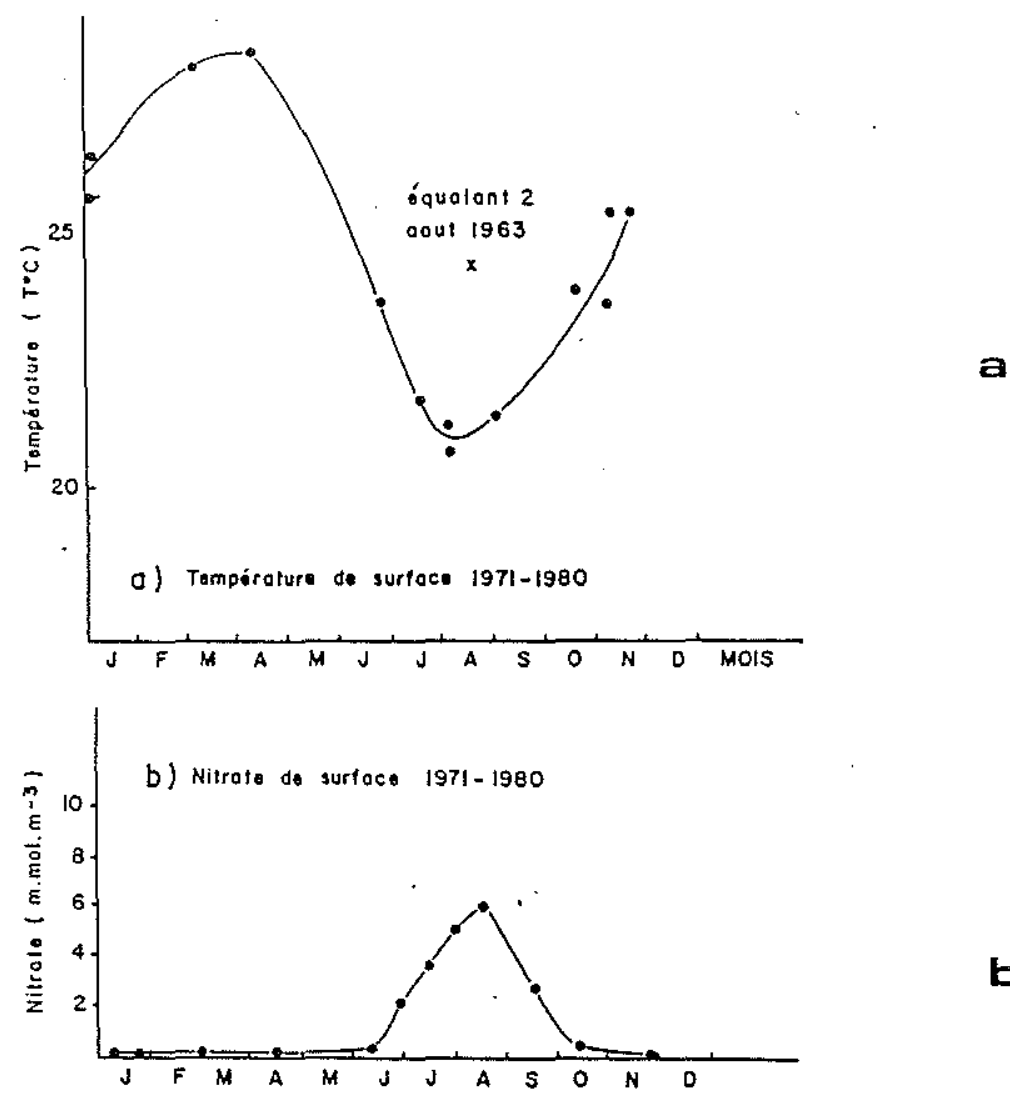

b

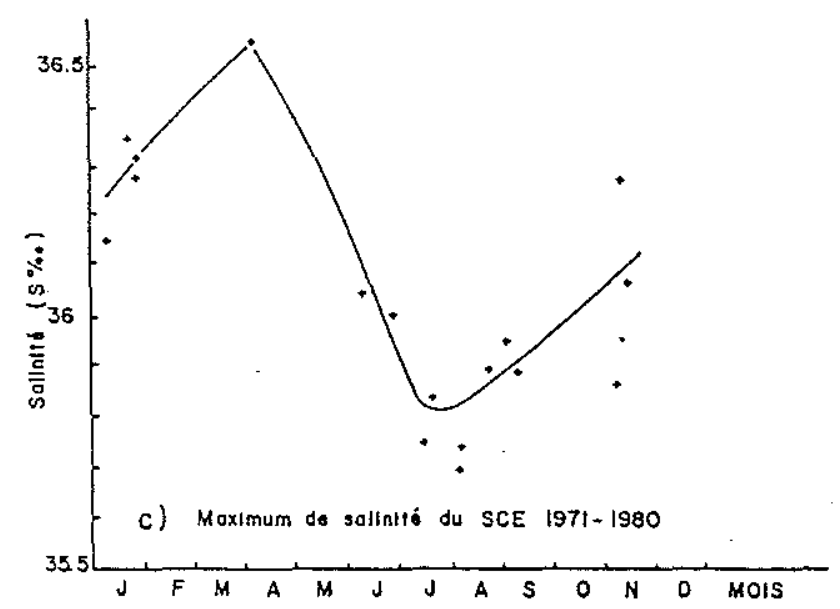

Figure 30: Seasonal variations of water properties at $4^{\circ} \mathrm{W}(1971-1980)$ a. minimum sea surface temperature between $0^{\circ} \mathrm{N}$ and $5^{\circ} \mathrm{S}$.

b. maximum surface nitrate concentration between $0^{\circ} \mathrm{N}$ and $5^{\circ} \mathrm{S}$. c. EUC maximum salinity.

(Voituriez, 1983). 
advection and diffusion in getting the saline subsurface water from the equator to the coasts. Existing current meter measurements in the Gulf of Guinea are reviewed in the following sections.

\subsection{Current meter measurements in the eastern Gulf of Guinea}

A number of velocity measurements have been made through the years within the eastern Atiantic EUC. While these measurements are too few to resolve seasonal variations unambiguously, they do provide order of magnitude estimates for the EUC maximum velocity: values around $0.75 \mathrm{~m} / \mathrm{s}$ have been often reported around $5^{\circ} \mathrm{W}$, and values larger than $0.30 \mathrm{~m} / \mathrm{s}$ around $5^{\circ} \mathrm{E}$ (this will be documented later in the section).

Al ong the northern coast of the Gulf of Guinea where subsurface westward tongues of high salinity have been reported (Figure 26), a subsurface westward flow centered around $4^{\circ} \mathrm{N}$ has been observed: the Guinea Countercurrent with core depth 50 to $150 \mathrm{~m}$ and core velocity 0.10 to $0.60 \mathrm{~m} / \mathrm{s}$. A distinct subsurface westward core trapped at the continental slope has also been reported: the Guinea Undercurrent. Both currents appear to be associated with high salinities (Lemasson and Rebert, 1973a,b).

At the eastern coast of the Gulf of Guinea south of the equator, where a southeastward subsurface tongue of high salinity has also been observed, velocity measurements published to date have mostly been made off Pointe Noire, along a section perpendicular to the coast between about $12^{\circ} \mathrm{E} 5^{\circ} \mathrm{S}$ and $9^{\circ} \mathrm{E} 6.5^{\circ} \mathrm{S}$ (Figure 22). Results from current meter measurements made between September 1967 and November 1969 are discussed by Gallardo (1981). Observations from the 1973-1976 period are presented in Guillerm (1981). Both studies report a predominance of south-southeastward flow (of order $0.30 \mathrm{~m} / \mathrm{s}$ ) through the year. The vertical and horizontal structure of the circulation is however complex and highly variable. The southward flow may be found off the continental slope or above the shelf or both and it may or may not be underneath north-northwestward flow. Furthermore, amplitudes undergo large changes. Subsurface high salinities can also be found both off the 
slope and above the shelf, although they seem more often centered off the slope.

Maxima of southward transport are noted in June (beginning of the upwelling season) and in the fall. It is not obvious that this is a reliable seasonal signal, however. In the experiment described by Guillerm (1981) the section was occupied less than once a month over three years, yielding twenty-one instantaneous vertical profiles of velocity between the coast and either $100 \mathrm{~km}$ or $350 \mathrm{~km}$ offshore. By considering these to be representative of the month or the season at which they were made, one implicitly assumes that higher frequency variability is negligible there. On the contrary, continuous time series of the velocity at station "Emeraude," off Pointe Noire over the continental shelf, show a succession of flow reversals at $40 \mathrm{~m}$ and no clear mean annual direction. Of course, the variability at the shelf may not be representative of the variability farther offshore, and fixed point measurements may alias spatial into temporal variability. Resolving both spatial and temporal variations of the alongshore circulation would probably require simultaneous long term measurements from closely spaced moorings along the cross-shore section.

Despite uncertainties on magnitudes and variability, most existing current measurements nevertheless indicate the presence, at least part of the time, of subsurface eastward flow at the equator around $5^{\circ} \mathrm{E}$, subsurface southeastward flow off the coast of Congo at $5^{\circ} \mathrm{S}$, and subsurface westward flow at the northern coast of the Gulf of Guinea east of $4^{\circ} \mathrm{W}$. Current measurements available so far thus do not rule out the assumption that the observed tongues of high salinity are at least partly advective.

Let us now investigate the question of a dynamical connection between equatorial and coastal currents. Onily one data set is available for that purpose. It was collected in May 1973 between $5^{\circ} \mathrm{E}$, $4^{\circ} \mathrm{S}$ and the coast of Africa during cruise 7309 of R.V. CAPRICORNE (Morlière, Hisard and Citeau, 1974). The cruise tracks were chosen so as to delimit a closed domain and estimate transports through its open 
sides and through various interior sections (Figure 31). The results do suggest continuity between the eastward EUC (reported to have a velocity as high as $0.90 \mathrm{~m} / \mathrm{s}$ at $5^{\circ} . \mathrm{E}$ ) and a southeastward flow located about $150 \mathrm{~km}$ off the Gabon coast. Most of the equatorial flow is described as going south of Sao Tome Island at $6.5^{\circ} \mathrm{E}$ and some as going north of it in agreement with the observed distribution of maximum salinity at similar levels. Continuity between the eastward SECC $\left(0.40 \mathrm{~m} / \mathrm{s}\right.$ at $\left.4^{\circ} \mathrm{S}\right)$ and a southeastward flow located at about $450 \mathrm{~km}$ from the Gabon coast is also suggested, again in agreement with the subsurface salinity distribution. Continuity is also claimed between the EUC and westward flow at about $3^{\circ} \mathrm{N}$ and $5^{\circ} \mathrm{E}$, but this is better supported by the subsurface salinity pattern than by the velocity measurements. Another observation from that cruise is the thickening of the subsurface salinity core at Sao Tome and at the African coast suggestive of the impingement of an inertial jet on a wall (Figure 25; Hisard, Citeau and Morlière, 1975).

Since those are the results of only one cruise made between May 9 and 29 in 1973, there is no way to know whether it is representative. Consider Figure 32 which recapitulates all the estimates published so far of the maximum velocity of the EUC near $1^{\circ}$.E and $6^{\circ} \mathrm{E}$. Crosses $(x)$ correspond to the most recent measurements from the 198284 FOCAL program (Hénin, Hisard and Piton, 1986), dots $\left({ }^{\circ}\right)$ indicate earlier measurements (Table 1). The $0.90 \mathrm{~m} / \mathrm{s}$ value of the EUC velocity in May 1973 is higher than any other measurement at $6^{\circ} \mathrm{E}$ (Figure 32b), al though rather high values were also reported in March 1969 at $4^{\circ} \mathrm{E}$ and $6^{\circ} \mathrm{E}[(\mathrm{b})$; Kolesnikov et al., 1971], and in February 1983 and May 1984 at $1^{\circ} \mathrm{E}[(\mathrm{a})$; Hénin et a1., 1986]. Note a1so the spectacular drop of velocity between $1^{\circ}$.E and $6^{\circ} . E$ in February 1983 (NICAL 2) and in May 1984 (NICAL 7).

Let us assume for now that the large values of the EUC maximum velocity on Figure 32 are not the result of some experimental error. Then the apparent discrepancy between measurements made at the same longitude and season but in different years, or between quasisimultaneous measurements taken $5^{\circ}$. of longitude apart, may be caused by 
the aliasing of a sharp eastward-propagating seasonal velocity pulse. A pulse with a $1 \mathrm{~m} / \mathrm{s}$ phase speed would take only one week to travel $5^{\circ}$ of longitude. During FOCAL, measurements along $1^{\circ} . \mathrm{E}$ and $6^{\circ} . \mathrm{E}$ were made about a week apart on average, but $6^{\circ} \mathrm{E}$ was visited first. So if the high velocity measured at $1^{\circ}$.E in February 1983 is the front of an eastward traveling pulse, it would not be observed at $6^{\circ} \mathrm{E}$ a week earlier. And if the pulse lasted less than three months, it could have been missed at $6^{\circ} \mathrm{E}$ altogether since next measurement is not made before May. The same reasoning may be applied to the high velocity measured at $1^{\circ} \mathrm{E}$ in May 1984. The fact that high velocities are encountered at $1^{\circ} \mathrm{E}$ in February 1983 and May 1984, and at 6 .E in March 1969 and May 1973 could then reflect interannual variability in the arrival of our hypothetical seasonal velocity pulse in the Gulf of Guinea. In favour of interannual anomaly is the fact that both 1973 and, to a greater extent, 1984 have been documented to be years of positive SST anomalies (reduced upwelling?) and increased precipitation (Merle, 1980; Hisard, 1980; Picaut et al., 1984; Philander, 1986).

We just reviewed the extent to which the direct velocity observations in the eastern Gulf of Guinea support the picture originally drawn on the basis of salt distribution of an asymmetric termination of the EUC into two coastal branches (Figure 27). Meridional sections of zonal velocity also reveal a feature of the circulation which is not predicted by tracing methods: the existence of substantial westward flows on both flanks of the EUC core. These flows may result from deep penetration of the surface SEC, or they may be distinct westward cores below the SEC. Their intensity and depth is not necessarily symmetrical with respect to the EUC core, and present observations do not provide information on their origin. Examples at $5^{\circ} \mathrm{W}$ and $1^{\circ} \mathrm{E}$ are reproduced on Figure 33 (Hisard et a1., 1976; Hénin et a1., 1986). Recall that, in Cane's (1979) model of a steady EUC forced by constant easterlies, no coastal flow is found at the eastern boundary beyond $2^{\circ}$. of latitude from the equator, but westward flows are simulated on the flanks of the model EUC: they return the eastward transport which impinges on the eastern boundary and contribute to the water which, in 


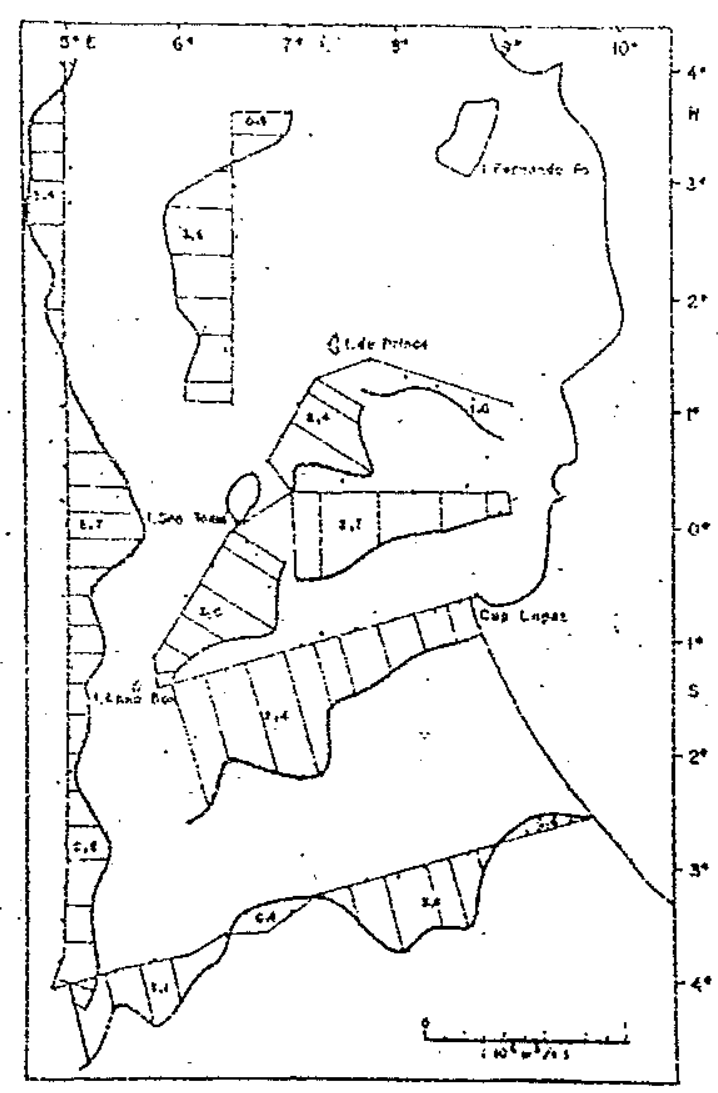

$\mathbf{a}$

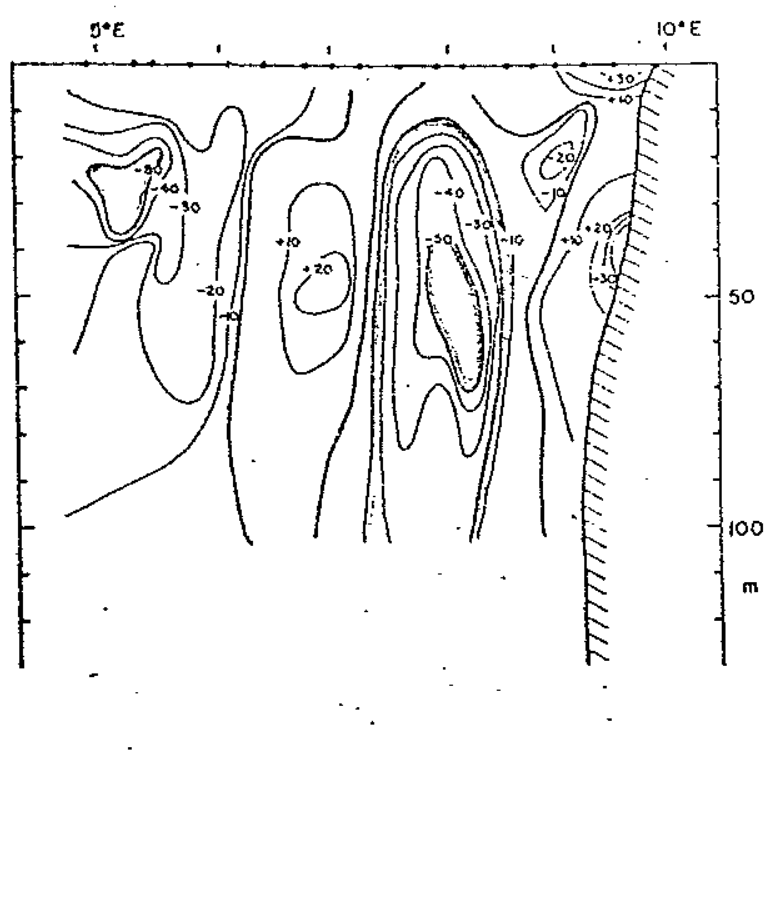

$\mathbf{b}$

Figure 31: Current measurements (referenced to $500 \mathrm{~m}$ ) in the Gulf of Guinea in May 1973.

a. $0-100 \mathrm{~m}$ transports through the sections indicated on the map. b. Vertical distribution of velocity across the southernmost section of (a).

(Morlière et aị., 1974). 


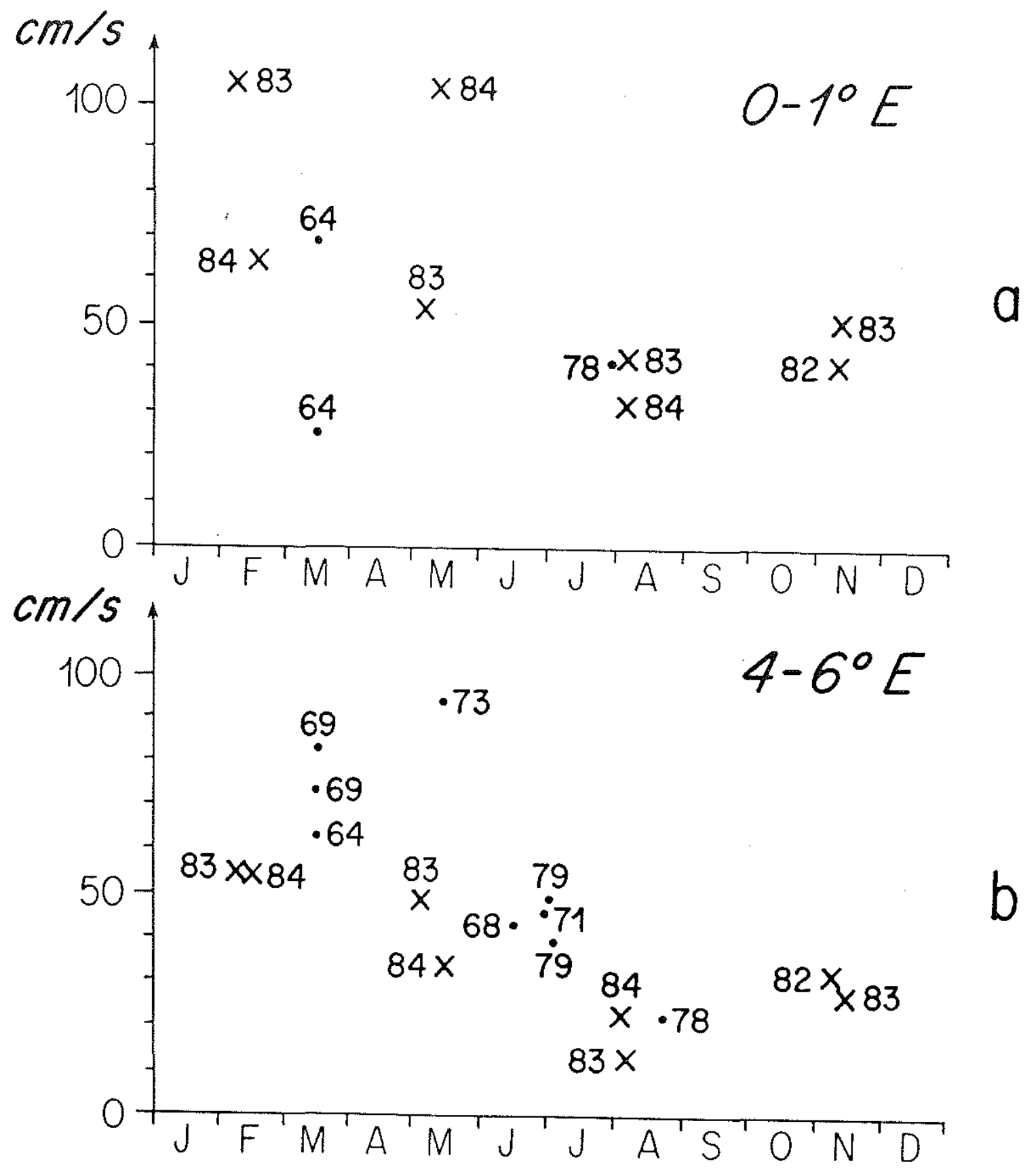

Figure 32: Estimates of the Atlantic EUC maximum velocity at (a) $0-1^{\circ} \mathrm{E}$ and (b) $4-6^{\circ} \mathrm{E}$. Abscissae give the month and labels give the year of the measurements.

(x) refer to the FOCAL program (Hénin et al., 1986),

(-) refer to earlier measurements (cf Table 1). 
TABLE 1

Measurements of the EUC Maximum Velocity in the Eastern Gulf of Guinea

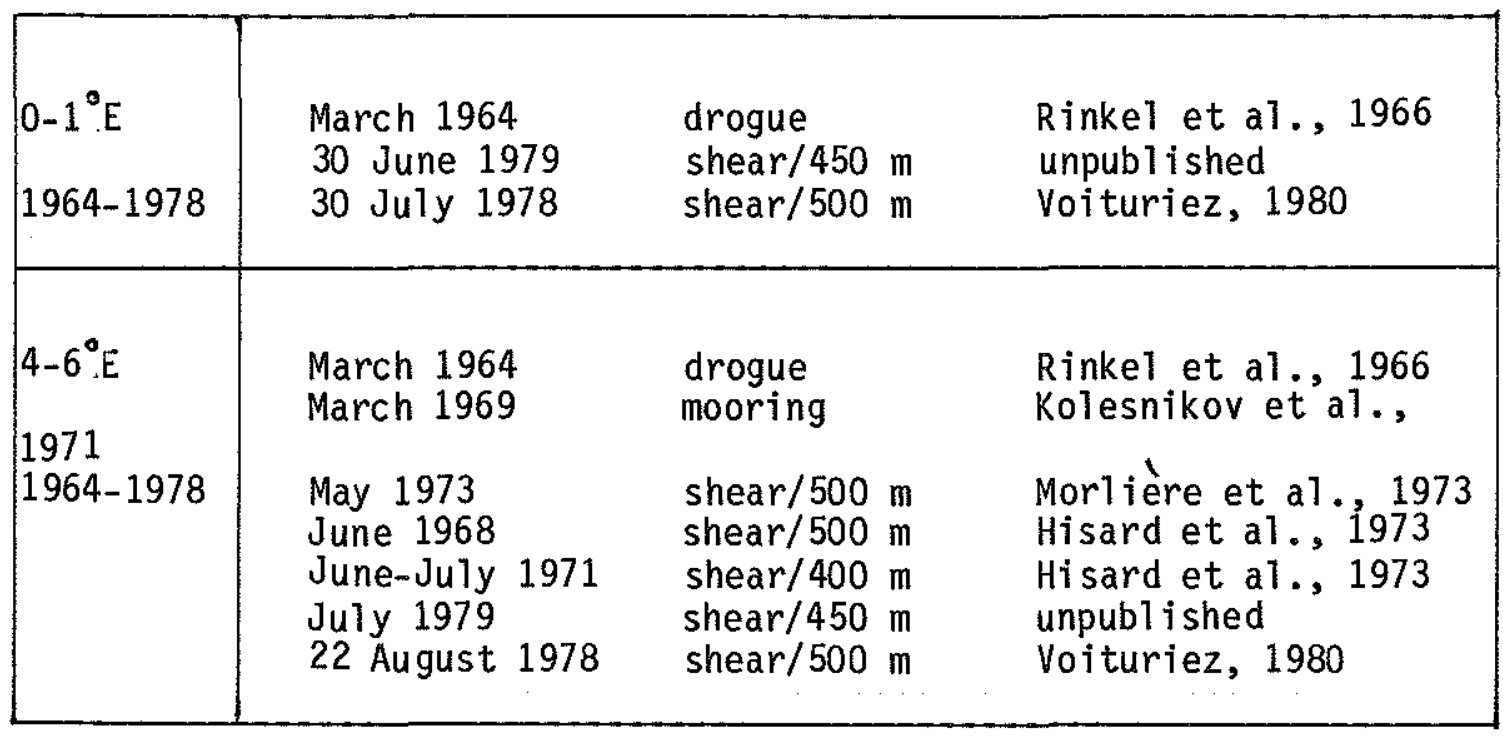

\begin{tabular}{|c|c|c|c|c|}
\hline \multirow[b]{2}{*}{$\begin{array}{l}1^{\circ} \mathrm{E} \\
\text { and } \\
6^{\circ} \mathrm{E} \\
1982-1984\end{array}$} & \multicolumn{3}{|c|}{$\begin{array}{ll}\text { Program FOCAL } & \text { shear } / 500 \mathrm{~m} \\
\text { R.V. NIZERY, } & \text { O.R.S.T.O.M: }\end{array}$} & Hénin et a1., 1986 \\
\hline & $\begin{array}{l}\text { 3-17 November } \\
1-17 \text { February } \\
27 \text { Apri 1-12 Ma } \\
28 \text { July-12 Aug } \\
4-20 \text { November } \\
10-25 \text { February } \\
4-20 \text { May } 1984 \\
27 \text { July-10 Aug }\end{array}$ & $\begin{array}{l}2 \\
3 \\
983 \\
1983 \\
3 \\
84 \\
1984\end{array}$ & $\begin{array}{l}\text { NICAL } \\
- \\
- \\
- \\
- \\
- \\
-\end{array}$ & $\begin{array}{l}1 \\
2 \\
3 \\
4 \\
5 \\
5 \\
6 \\
7 \\
8\end{array}$ \\
\hline
\end{tabular}



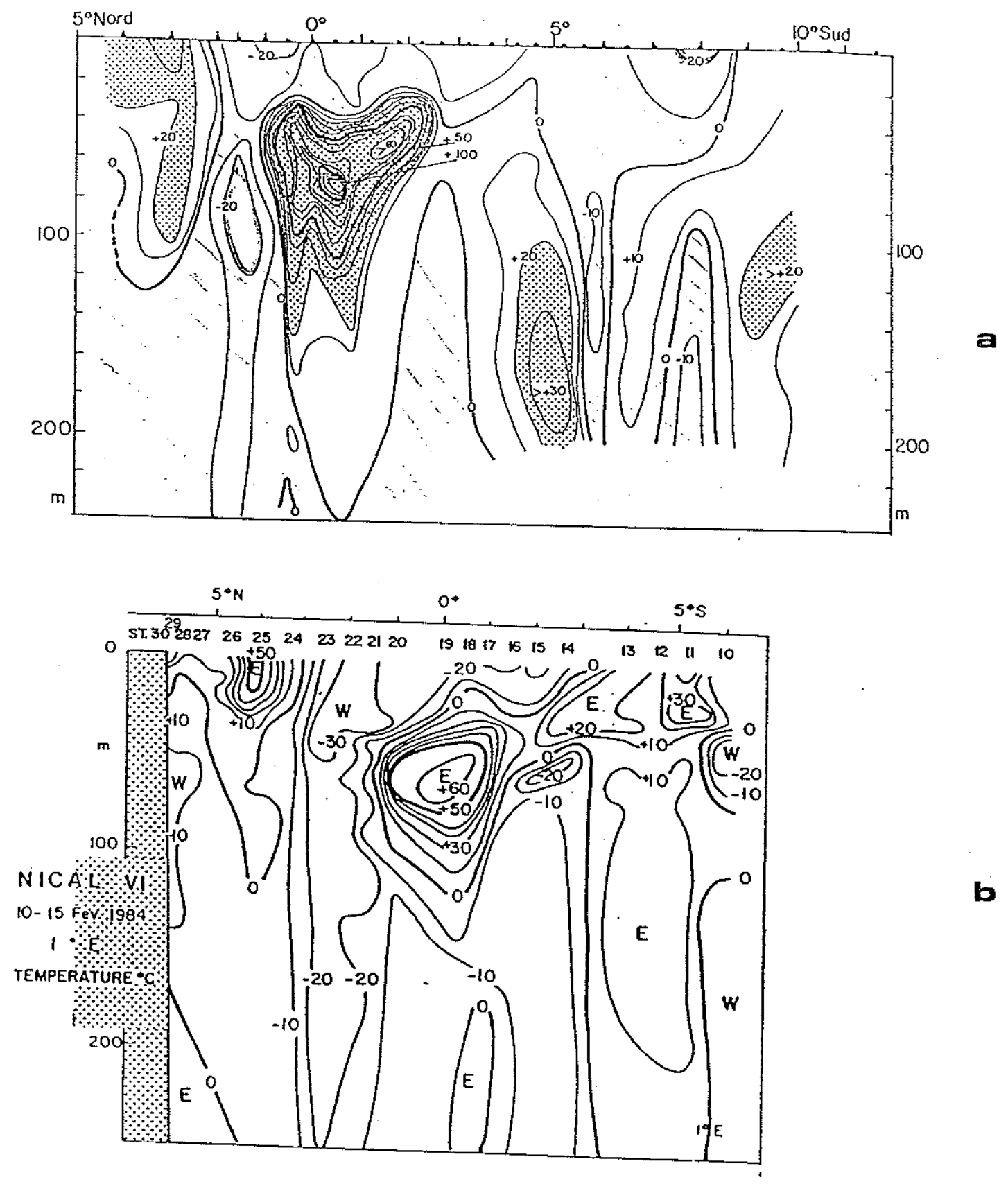

Figure 33: Meridional sections of zonal velocity across the equator at (a) $5^{\circ} \mathrm{W}$ in January 1975 (Hisard et a1., 1976); (b) $1^{\circ} \mathrm{E}$ in February 1984 (Hénin et al., 1986). Westward flows are seen on both f1anks of the EUC. 
148 
the interior, flows equatorwards into the EUC in agreement with vorticity conservation arguments (Figure 12b, section 1.6.1.1).

Let us finally discuss the accuracy of the current meter measurements and the type of errors associated with them. A11 of the velocity measurements at $1^{\circ} \mathrm{E}$ and $6^{\circ} \mathrm{E}$ from the FOCAL program (NICAL cruises 1982-1984, Figure 32) and many previous measurements in the Gulf of Guinea were made using an Aanderaa profiler current meter (Düing and Johnson, 1972). Typically, the instrument is lowered from a drifting ship down to $500 \mathrm{~m}$ and returned to the surface within $1 / 2$ hour to 1 hour. The exact drift is in general not known but the velocities at $500 \mathrm{~m}$ are expected to be negligible compared to the velocities above. At the analysis stage, the $500 \mathrm{~m}$-value is thus interpreted as a measure of the ship drift (assumed steady during the lowering of the instrument) and it is subtracted from all other levels. So the vertical profile of shear with respect to $500 \mathrm{~m}$ is thought to provide an estimate of the absolute velocity profile in the upper ocean. The vertical resolution is very good since the sampling interval is often less than $5 \mathrm{~m}$.

The advantage of the profiling technique is that, by generating enough highly resolved vertical profiles across a meridional section spanning the equator (typically every half degree of latitude), one gets a picture of both the vertical and the meridional structure of the upper equatorial currents (Figure 33). In the case of the EUC which has been shown to meander about the equator on time scales of the order of three weeks (Düing et a1., 1975) it is therefore a much more reliable method of locating and resolving the EUC core than if the measurements were made at a fixed point.

The disadvantage of the technique is that it is very difficult to quantify its accuracy. Some sources of errors, such as the inclination of the instrument due to cable angle in strong shear flow, are discussed in Düing and Johnson (1972). Overa11, these authors estimate that, when used from an anchored ship, the profiler technique yields estimates of instantaneous absolute velocities accurate to 
within 5 percent (e.g. $\pm 0.05 \mathrm{~m} / \mathrm{s}$ of $1.00 \mathrm{~m} / \mathrm{s}$, or $\pm 0.025 \mathrm{~m} / \mathrm{s}$ of $0.50 \mathrm{~m} / \mathrm{s}$ ). When used from a drifting ship, an extra uncertainty is introduced: the instantaneous velocity shear with respect to $500 \mathrm{~m}$ is a reasonable measure of the absolute velocity above $500 \mathrm{~m}$ only if the absolute flow velocity at $500 \mathrm{~m}$ is negligible. But long term subsurface moored measurements at $0^{\circ} \mathrm{N} 3^{\circ} \mathrm{W}$ taken between January 1977 and June 1978 show that the zonal velocity at $558 \mathrm{~m}$ often reaches values of $\pm 0.10 \mathrm{~m} / \mathrm{s}$ (Weisberg and Horigan, 1981).

It is also difficult to evaluate the effect of temporal variability. Each vertical profile obtained from a $1 / 2$ hour to 1 hourlong station can certainly be considered instantaneous, but there is no guarantee that the current system is not changing within, for example, the five days it took to sample the section of Figure 33b. The best indication that at least the signal is not dominated by large amplitude high frequency variability are the spatially coherent structures one finds when attempting to contour the vertical profiles taken at successive latitudes.

Finally, one wishes to know to what extent a quasiinstantaneous section is representative of the month at which it was taken. What variability to expect is however not obvious: isolated moored current measurements do provide long time series, but typically they are not dense enough in the vertical to adequately resolve a sharp feature like the EUC core, and they are not part of a dense meridional array with which to monitor the core's lateral excursions. So both vertical and horizontal displacements of the EUC core can be aliased into the temporal variability measured at the fixed levels of an isolated mooring. [Recal1 Figure 21 at $95^{\circ} \mathrm{W}$ in the eastern Pacific.] It might be possible to better quantify the alias problem by estimating r.m.s. velocities in given frequency ranges from moored data (Toole, personal communication). A more straightforward way to simultaneously resolve the spatial and temporal variability of the EUC would be to have at one's disposal long time series of velocity measured by some autonomous profiler current meter (PCM) devices lowered from a dense 
meridional array of moorings. Experimental costs however appear prohibitory for the realization of such an experiment soon.

In conclusion, accepting that the instantaneous shear with respect to $500 \mathrm{~m}$ obtained during a PCM station from a drifting ship is accurate to within 5 percent, the instantaneous absolute velocity profile is probably not known better than within 0.10 or $0.15 \mathrm{~m} / \mathrm{s}$. The further error made in implicitly interpreting quasi-instantaneous velocity sections as monthly mean ones is difficult to quantify, but it is bound to be larger than 0.10 or $0.15 \mathrm{~m} / \mathrm{s}$ at the depth of the EUC core. The high velocities measured at $1^{\circ}, E$ and $6^{\circ} . E$ in the spring (Figure 32) would have little statistical significance if the error were to reach $0.25 \mathrm{~m} / \mathrm{s}$ (the standard deviation of the scatters if one assumes no time dependence). Since however the scatter of maximum velocity values at both $0-1^{\circ} \mathrm{E}$ and $4-6^{\circ} \mathrm{E}$ appears systematically larger during the first half of the year (Figure 32), I believe that it is indicative indeed of the occurrence of higher EUC velocities in winter and spring than in summer and fall between $0^{\circ}, \mathrm{E}$ and $6^{\circ} \mathrm{E}$.

\subsection{Seasonal variations of the EUC at $4 \%$}

We saw above that the observations of the EUC maximum velocity made in the eastern equatorial Atlantic between $0^{\circ} \mathrm{E}$ and $6^{\circ}, \mathrm{E}$ suggest a stronger flow in winter and spring, a weaker flow in summer and fall. These observations are also compatible with the concept of a rapid intensification in the form of an eastward propagating pulse, reminiscent of the Kelvin wave that Lukas $(1981,1986)$ describes as responsible for the spring intensification of the eastern Pacific EUC (section 2.1). Through the years, more observations of the EUC maximum velocity were made at $4^{\circ} \mathrm{W}$ than farther east. It therefore appeared logical to undertake a critical review of the $4^{\circ}, \mathrm{W}$ data to see whether or not they confirm the seasonal behaviour suggested by the $0^{\circ} \mathrm{E}-6^{\circ} \mathrm{E}$ data.

The first attempt at determining the seasonal variations of the EUC at $4^{\circ}$ W was published by Hisard (1973), who reviewed the current measurements reported by various sources prior to 1973 . Hisard 
obtained the data points reproduced as black circles ( ) on Figure 34 a. Two more data points represented by crosses $\left({ }^{+}\right)$were added based on results published later by Hisard et a1. (1976). Table 2 recapitulates the nature of the various measurements. At least two types of current meters (Ekman and Aanderaa) were used. Figure $34 \mathrm{a}$ again suggests a stronger equatorial undercurrent in winter and spring, a weaker undercurrent in summer and fall. Again, the interannual scatter is large in the winter and could indicate various triggering dates for the intensification (earlier in 1975, later in 1968).

The second attempt was presented by Voituriez (1981, 1983). In order to limit experimental errors, Voituriez chose to ignore early measurements by disparate instruments and limited his analysis to a homogeneous set of Aanderaa PCM measurements taken between 1977 and 1980 on cruises of R.V. CAPRICORNE (0.R.S.T.O.M.) out of Abidjan (Table 2). All velocity profiles are taken from a drifting ship and the shear is referenced to $500 \mathrm{~m}$. Voituriez' estimates are reproduced as open circles $\left({ }^{\circ}\right)$ on Figure $34 b$. His interpretation of the results is that the EUC weakens during the summer as a consequence of the enhanced upwelling at that season. The same mechanism of transfer into the westward flowing surface layer and mixing with deeper fresh upwelled waters which erodes the high salinity core associated with the EUC (section 2.2) would act on the zonal momentum and erode the upper 1 ayers of the EUC. The deep upwelled fresh waters are slower but still eastwards, so even in a case where the maximum salinity core disappears entirely, the maximum velocity core may still be present, only weaker. To explain the weakening of the EUC by the intensification of the upwelling, the two phenomena must be simultaneous, and the EUC should regain strength once the summer upwelling is over in the fall. The high November 1979 value of Figure 34b is therefore as important for the argument as the high April 1979 one and the low summer values. Whether the same confidence should be put in each individual data point is however not discussed by Voituriez, and a detailed re-evaluation of his measurements is necessary. 

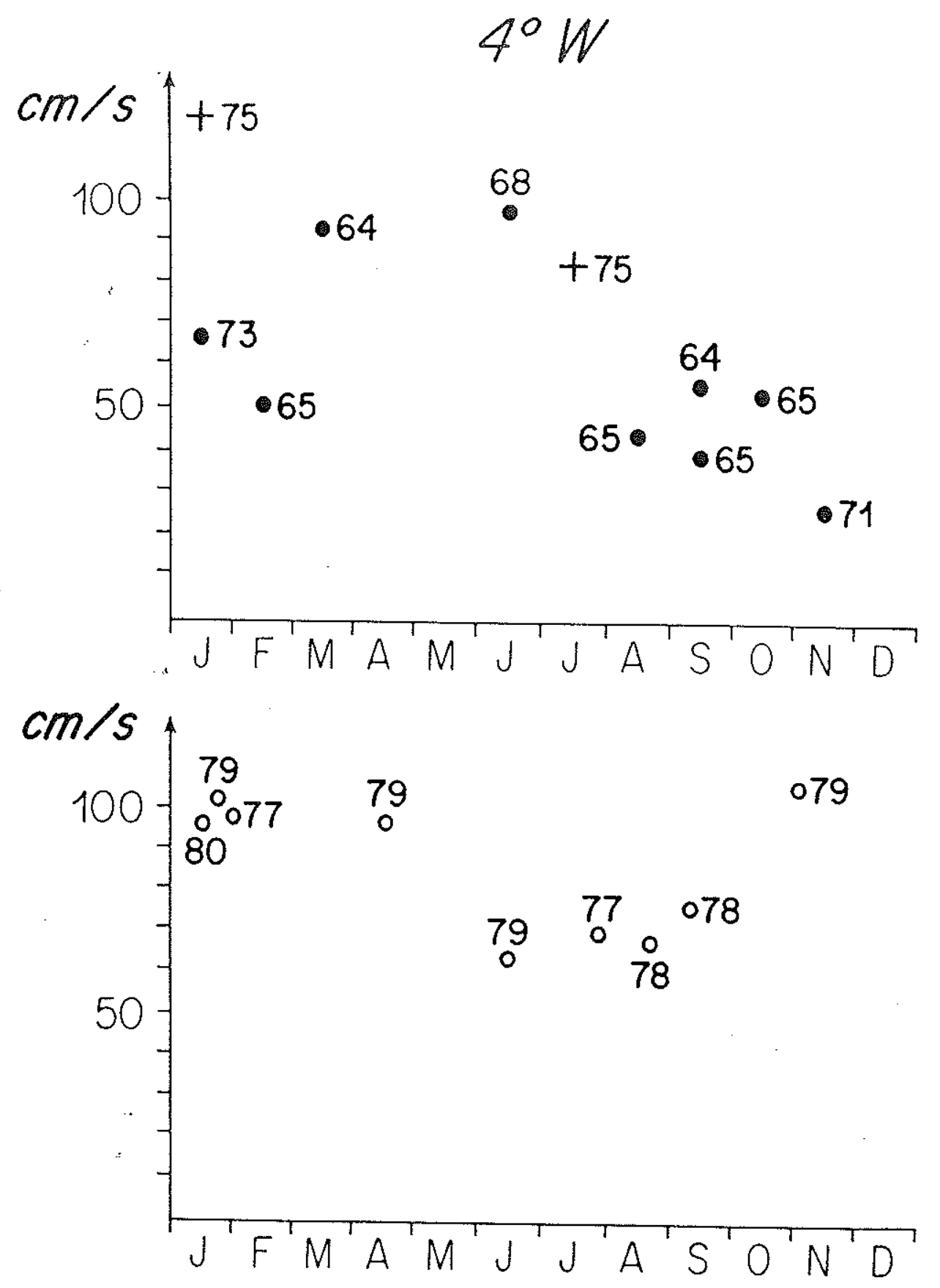

Figure 34: Estimates of the Atlantic EUC maximum velocity at $4^{\circ} \mathrm{W}$

a. according to Hisard (1973),

b. according to Voituriez $(1981,1983)$,

c. from the FOCAL program (Hénin et al., 1986),

d. all estimates from (a), (b) and (c) (cf Table 2). Abscissae give the month and labels give the year of the measurements. 

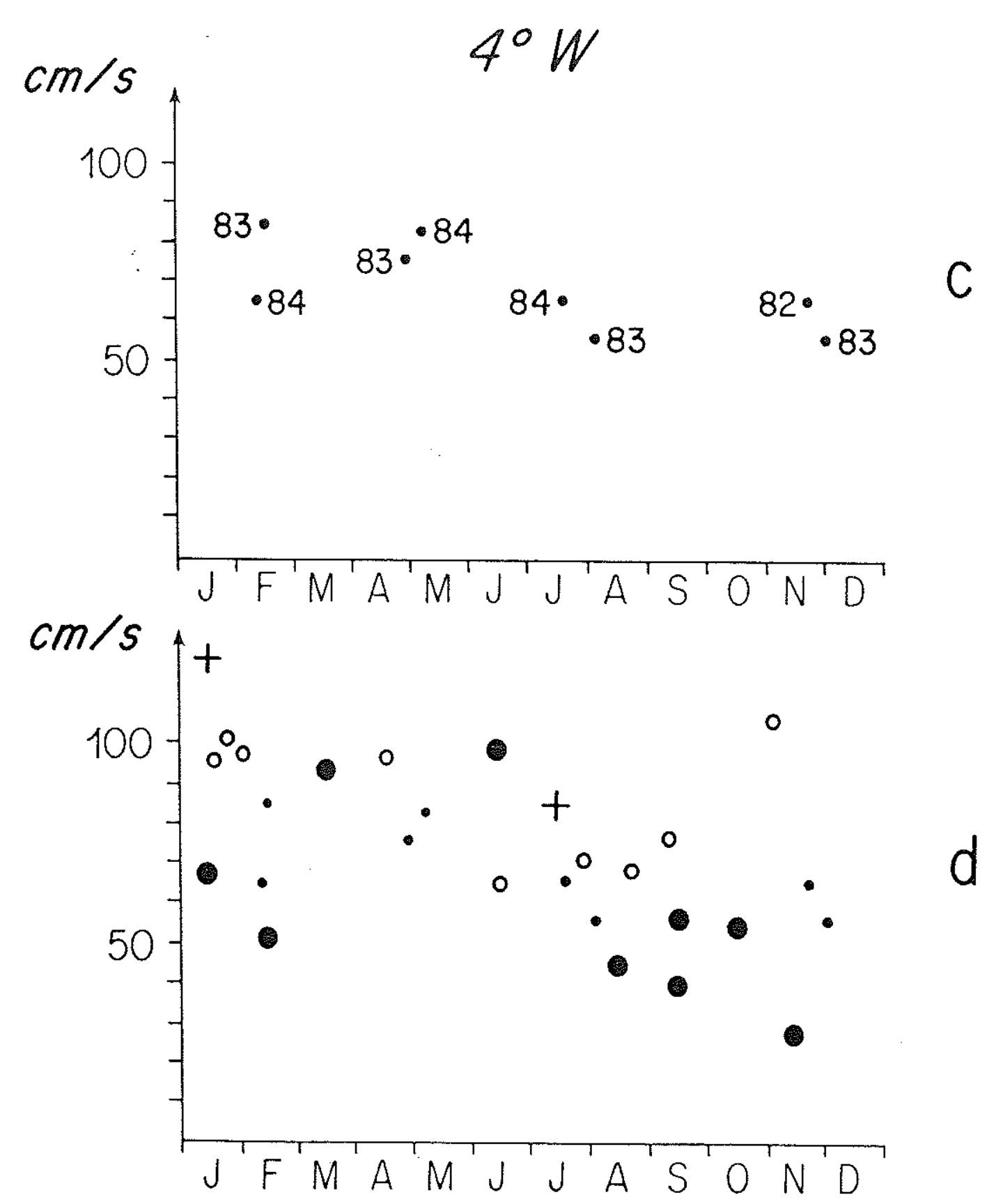

Figure 34 (Continued) 
TABLE 2

Measurements of the EUC Maximum Velocity Near $4^{\circ} \mathrm{W}$

\begin{tabular}{|c|c|c|c|}
\hline $\begin{array}{l}4-5^{\circ} \mathrm{W} \\
1964-1975\end{array}$ & $\begin{array}{l}\text { January } 1973 \\
\text { + January } 1975 \\
\text { - February } 1965 \\
\text { March } 1964 \\
\text { - June } 1968 \\
\text { + Ju1y } 1975 \\
\text { - August } 1965 \\
\text { - September } 1964 \\
\text { - September } 1965 \\
\text { October } 1965 \\
\text { - November } 1971\end{array}$ & $\begin{array}{l}\text { shear } / 500 \mathrm{~m} \\
\text { shear } / ? \\
\text { shear } / 1000 \mathrm{~m} \\
\text { drogue } \\
\text { shear } / 500 \mathrm{~m} \\
\text { shear } / ? \\
\text { shear } / 1000 \mathrm{~m} \\
\text { drogue } \\
\text { shear } / 1000 \mathrm{~m} \\
\text { shear } / 1000 \mathrm{~m} \\
\text { shear } / 500 \mathrm{~m}\end{array}$ & $\begin{array}{l}\text { Hi sard, } 1973 \\
\text { Hi sard et al., } 1976 \\
\text { Hi sard, } 1973 \\
\text { Hi sard, 1973 } \\
\text { Hi sard, } 1973 \\
\text { Hi sard et al., } 1976 \\
\text { Hi sard, } 1973 \\
\text { Hi sard, } 1973 \\
\text { Hi sard, } 1973 \\
\text { Hi sard, } 1973 \\
\text { Hi sard, } 1973\end{array}$ \\
\hline
\end{tabular}

\begin{tabular}{|c|c|c|c|}
\hline $4^{\circ} \mathrm{W}$ & & $\begin{array}{l}\text { shear } / 500 \mathrm{~m} \\
\text { R.V. CAPRICORNE, } \\
\text { O.R.S.T.O.M. }\end{array}$ & Voituriez, 1981,1983 \\
\hline $1977-1980$ & $\begin{array}{l}\text { January } 1977 \\
\text { July } 1977 \\
\text { August } 1978 \\
\text { Apri1 } 1979 \\
\text { June } 1979 \\
\text { November } 1979 \\
\text { January } 1980\end{array}$ & $\begin{array}{ll}\text { KA } & 7701 \\
\text { KA } & 7706 \\
\text { KA } & 7802 \\
\text { KA } & 7902 \\
\text { KA } & 7906 \\
\text { KA } & 7910 \\
\text { KA } & 8001\end{array}$ & \\
\hline
\end{tabular}

\begin{tabular}{|c|c|c|c|c|}
\hline $4^{\circ} . \mathrm{W}$ & Program FOCAL & \multicolumn{2}{|c|}{$\begin{array}{l}\text { shear } / 500 \mathrm{~m} \\
\text { R.V. CAPRICORNE, } \\
\text { O.R.S.T.O.M. }\end{array}$} & Hénin et a1., 1986 \\
\hline $1982-1984$ & $\begin{array}{l}\text { 3-17 November } 1 \\
1-17 \text { February } 1 \\
27 \text { April-12 May } \\
28 \text { Ju1y-12 Augu } \\
4-20 \text { November } 1 \\
10-25 \text { February } \\
4-20 \text { May } 1984 \\
27 \text { July-10 Augu }\end{array}$ & $\begin{array}{l}82 \\
83 \\
1983 \\
t \quad 1983 \\
83 \\
984 \\
t \quad 1984\end{array}$ & $\begin{array}{cc}\text { FOCAL } & 1 \\
- & 2 \\
- & 3 \\
- & 4 \\
- & 5 \\
- & 6 \\
- & 7 \\
- & 8\end{array}$ & \\
\hline
\end{tabular}


A further motivation for re-examining the measurements used to construct Figure 34b is provided by the results from the more recent FOCAL cruises (1982-1984; Hénin, Hisard and Piton, 1986). Figure 34c shows the estimates of the EUC maximum velocity at $4^{\circ} \mathrm{W}$ obtained during this program by R.V. CAPRICORNE. The instrument is again an Aanderaa profiler current meter, but it is lowered from a buoy in order to avoid contamination by the rolling and maneuvering of the ship. The measurements are thus expected to provide better estimates of absolute velocity profiles (Hisard and Hénin, 1984). Each point (.) on Figure $34 \mathrm{c}$ is obtained by locating the maximum zonal velocity in depth and latitude from the published meridional sections, sampled every half degree of latitude on average (Hénin et a1., 1986). The temporal resolution is rather poor since sections were made only four times a year. But the tendency shown on Figure $34 c$ is still alarming when compared with Figure $34 a, b$ : the difference between values obtained during the first and the second half of the year is small, and, if there is a sign of slight summer weakening, there is no sign of a fall reintensification. Figure $34 d$ reproduces al1 the data from (a), (b) and (c) in a single plot, illustrating that only Voituriez' November 1979 estimate indicates reintensification of the EUC in the fall.

Figure 35 shows a continuous time series of the equatorial currents at $0^{\circ} \mathrm{N} 4^{\circ} \mathrm{W}$ measured between February 1983 and September 1984 from Colin's FOCAL mooring (Weisberg and Colin, 1986). What is gained in temporal resolution is lost in lateral and vertical resolution of the core (see sampling levels on the right-hand side of Figure 35). Again there is no clear seasonal signal from one year to the other. It may of course be overwhelmed by interannual variability, since 1984 appeared particularly unusual (Philander, 1986).

In the following, we re-examine the Aanderaa profiler current meter data collected in the Gulf of Guinea prior to the FOCAL program. The goal of the analysis is to evaluate the robustness of Voituriez's conclusion that, on a normal seasonal cycle, the EUC at $4^{\circ} \mathrm{W}$ weakens in summer due to enhanced upwelling. The PCM data were kindly 
provided by B. Voituriez and B. Piton, 0.R.S.T.0.M., through the B.N.D.0. data bank in Brest, France. The set includes stations at $4^{\circ} \mathrm{W}, 1^{\circ} \mathrm{E}, 6^{\circ} \mathrm{E}$, and between $1^{\circ} \mathrm{S}$ and $6^{\circ} \mathrm{S}$ along sections perpendicular to the coast of Gabon and Congo. The coastal stations will be examined in section 2.5 below. Some stations at $1^{\circ} \mathrm{B}$. and $6^{\circ}, \mathrm{E}$ were used above as "unpublished" observations (Figure 32, Table 1). In the following, we limit our attention to the $4^{\circ}, \mathrm{W}$ data and further isolate a subset formed of the stations located between $2^{\circ} \mathrm{S}$ and $2^{\circ} \mathrm{N}$ within 20 minutes of longitude from $4^{\circ} \mathrm{W}$, and to the profiles which extend deeper than $450 \mathrm{~m}$. The source of the data is summarized on Table 3 . Underlined are the cruises used by Voituriez $(1981,1983)$ which correspond in general to meridional sections across the equator. In addition, many stations were made while the ship remained close to the equator. During cruise KA7912 for instance, seventy-one PCM stations were made at $0^{\circ} \mathrm{N} 4^{\circ} \mathrm{W}$ within three to six hours from each other between 20 0ctober and 1 September 1979. Cruise KA7701, in parentheses on Table 3, was used by Voituriez but was not part of the data set obtained for the purpose of this study.

Out of the $2^{\circ} \mathrm{N}-2^{\Delta} \mathrm{S} / 4^{\circ} \mathrm{W}$ subset of one hundred and eightyfive PCM stations deeper than $450 \mathrm{~m}$, let us first examine the stations made as part of meridional sections across the equator. Ten such sections totalling forty-nine PCM stations were made between 1977 and 1980 and are 1isted in Table 4. It is immediately apparent from this presentation that the meridional resolution is very different from one section to the other. Thus the more densely sampled sections, such as the ones made in January 1980 (KA8001) and September 6-10, 1978 (KA7802), will give a more accurate estimate of the EUC instantaneous core velocity than the poorly sampled ones, such as those made in June 1979 (KA7910) or August 1978 (KA7802).

Let us now consider the stations made repeatedly at the equator. They still have the advantage of good vertical resolution, but they may have missed the EUC core if it happened to be off the equator, and thus they may underestimate the instantaneous velocity of 


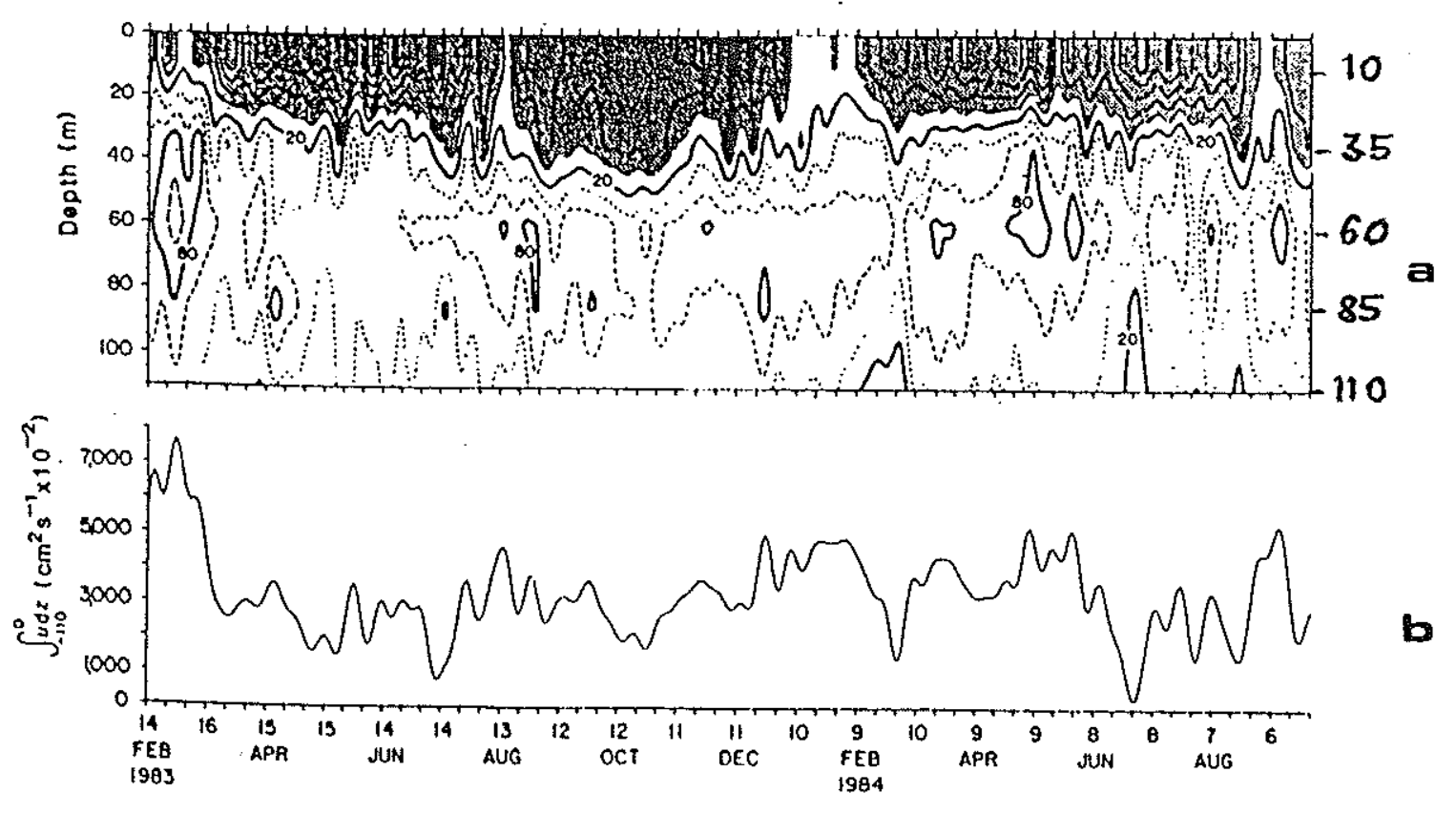

Figure 35: Zonal velocity in $\mathrm{cm}$ (a) and 0-110 $\mathrm{m}$ transport per unit width (b) from an equatorial mooring at $4^{\circ} \mathrm{W}$ between 1983 and 1985 (Wejsberg and Colin, 1986). The average depth of the current meters is indicated on the right of the upper panel. 
Table 3

PCM stations (deeper than $450 \mathrm{~m}$ ) at $2^{\circ} \mathrm{N}-2^{\circ} \mathrm{S} / 4^{\circ} \mathrm{W}, 1977-1980$

\begin{tabular}{|c|c|c|c|}
\hline Cruise & Date & $\begin{array}{l}\text { Number of } \\
\text { Stations }\end{array}$ & $\begin{array}{l}\text { Number of Stations } \\
\text { Repeated at } 0 . \mathrm{N} 4^{\$}, \mathrm{~W}\end{array}$ \\
\hline (KA7701) & January 1977 & $?$ & $?$ \\
\hline KA7901 & 7-9 January 1979 & 5 & 0 \\
\hline KA7902 & 15-28 January 1979 & 21 & 18 \\
\hline KA8001 & 16-23 January 1980 & 10 & 3 \\
\hline KA7903 & 5-18 February 1979 & 9 & 9 \\
\hline KA7904 & 25-26 February 1979 & 4 & 4 \\
\hline KA7906 & 2-26 April 1979 & 9 & 3 \\
\hline KA7907 & 5-12 June 1979 & 10 & 10 \\
\hline KA7910 & 23 June-15 Ju1y 1979 & 3 & 0 \\
\hline KA7706 & 11-22 July 1977 & 6 & 2 \\
\hline KE7802 & 3-22 August 1978 & 9 & 9 \\
\hline KA7802 & 8 August-12 September 1978 & 21 & 3 \\
\hline \multirow[t]{2}{*}{ KA7912 } & 20 0ctober-9 November 1979 & 77 & 71 \\
\hline & & 185 & 132 \\
\hline
\end{tabular}




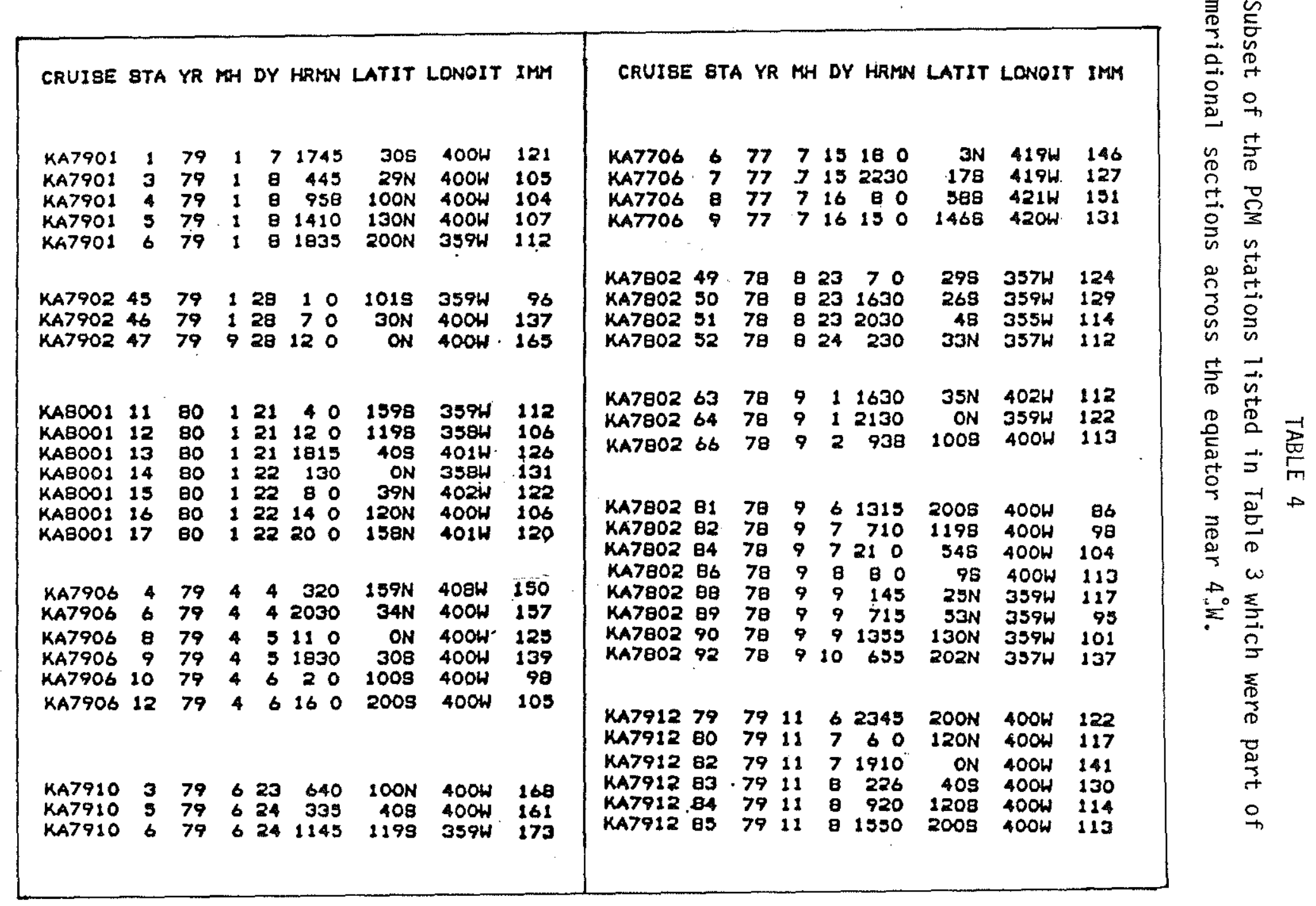


the EUC. Assuming that most of the variability observed from successive profiles is indeed due to lateral meandering of the core, the best estimate of the EUC maximum velocity obtained from a series of successive PCM stations at the equator is the highest estimate.

The procedure adopted to analyse the Aanderaa PCM data set can be summarized as follows. Raw values of temperature, salinity, speed and direction were printed for all stations. Levels at which the values of either speed or direction were obviously erroneous were deleted from the files. Speed and direction were transformed into zonal and meridional velocities. Velocities between 425 and $475 \mathrm{~m}$ were then averaged, and the mean $450 \mathrm{~m}$ value so obtained was subtracted from al1 levels. This method of obtaining the velocity with respect to $450 \mathrm{~m}$ is not standard, but provides more stable estimates of the profiles than subtracting the one level closest to 450 (or 500 $\mathrm{m}$ ), because velocities of $\pm 0.05 \mathrm{~m} / \mathrm{s}$ on average (referenced to $450 \mathrm{~m}$ ) are observed below $400 \mathrm{~m}$. All velocity profiles were then plotted and examined for aberrant points. The whole procedure was repeated if such aberrant values were spotted which might contaminate the estimate of either the deep reference velocity or the peak subsurface velocity. Finally all values of the maximum subsurface eastward velocity (relative to $450 \mathrm{~m})$ were tabulated along with the speed $\left(u^{2}+v^{2}\right)^{1 / 2}$ at the same level. (In case of a large meridional component at the EUC level, it was felt that the total speed was a better measure of the strength of the current than its zonal component.)

Results are shown on Figure 36. Diamonds $(\Delta)$ refer to the estimates of the EUC maximum velocity obtained from meridional sections. A11 profiles from a given quasi-instantaneous section were examined in turn and only the one exhibiting the strongest EUC retained. The maximum zonal component rather than the speed obtained in that fashion is plotted for a better comparison with Voituriez' estimates (Figure 34b). The only large and unexplained discrepancy between the circles on Figure $34 \mathrm{~b}$ and the diamonds on Figure 36 occurs in January 1979: our two estimates of the EUC maximum velocity from cruises KA7901 and KA7902 
are only $0.55 \mathrm{~m} / \mathrm{s}$, i.e. half of the estimate published by Voituriez from cruise KA7902.

Dots on Figure 36 indicate the maximum speeds measured by all the profiles repeated in the vicinity of $0^{\circ}, \mathrm{N} 4^{\circ}, \mathrm{W}$. As already mentioned above, if temporal variability within the core is, on short time scales, negligible compared to spatial variability due to meridional excursions of the core, these measurements should provide values less or equal to the EUC speed at a given time. Unless a strong meridional component is present, dots should therefore tend to be found below diamonds on Figure 36. However, this is only the case for the octoberNovember 1979 measurements (cruise KA7912). In August 1978 (cruises KA7802, KE7802), a persistent meridional velocity is present at the EUC core level and individual estimates of the maximum speed are considerably higher than estimates of the maximum zonal velocity from meridional sections. Individual EUC speeds from cruise KA7907 in early June 1979 are much larger than the estimate of zonal velocity from cruise KA7910 in late June, despite the absence of a systematic meridional component. They are also the largest estimates by far of the whole data set and may have to be flagged as suspicious. Finally, individual speed estimates in January 1979 are larger than our two zonal velocity estimates and more in support of Voituriez' larger estimate. [Meridional sections made at the beginning and the end of January 1979 do lack meridional resolution if one retains only the deep stations (Table 4).]

Finally, Figures 37 and 38 were prepared for a better look at the temporal variability of the system at short time scales. On Figure 37, instantaneous stations occupied between 0ctober 20 and November 1, 1979 during cruise KA7912 are averaged daily, and vertical profiles of the velocity components (a, b) and of the salinity (c) are contoured as a function of time. During the first week, the zonal velocity (b) at the EUC level decreases to a minimum (with the core appearing to split into two), the meridional velocity (a) at similar levels is on average negative, and the salinity decreases. Subsequent1y, the subsurface zonal velocity increases, the meridional 


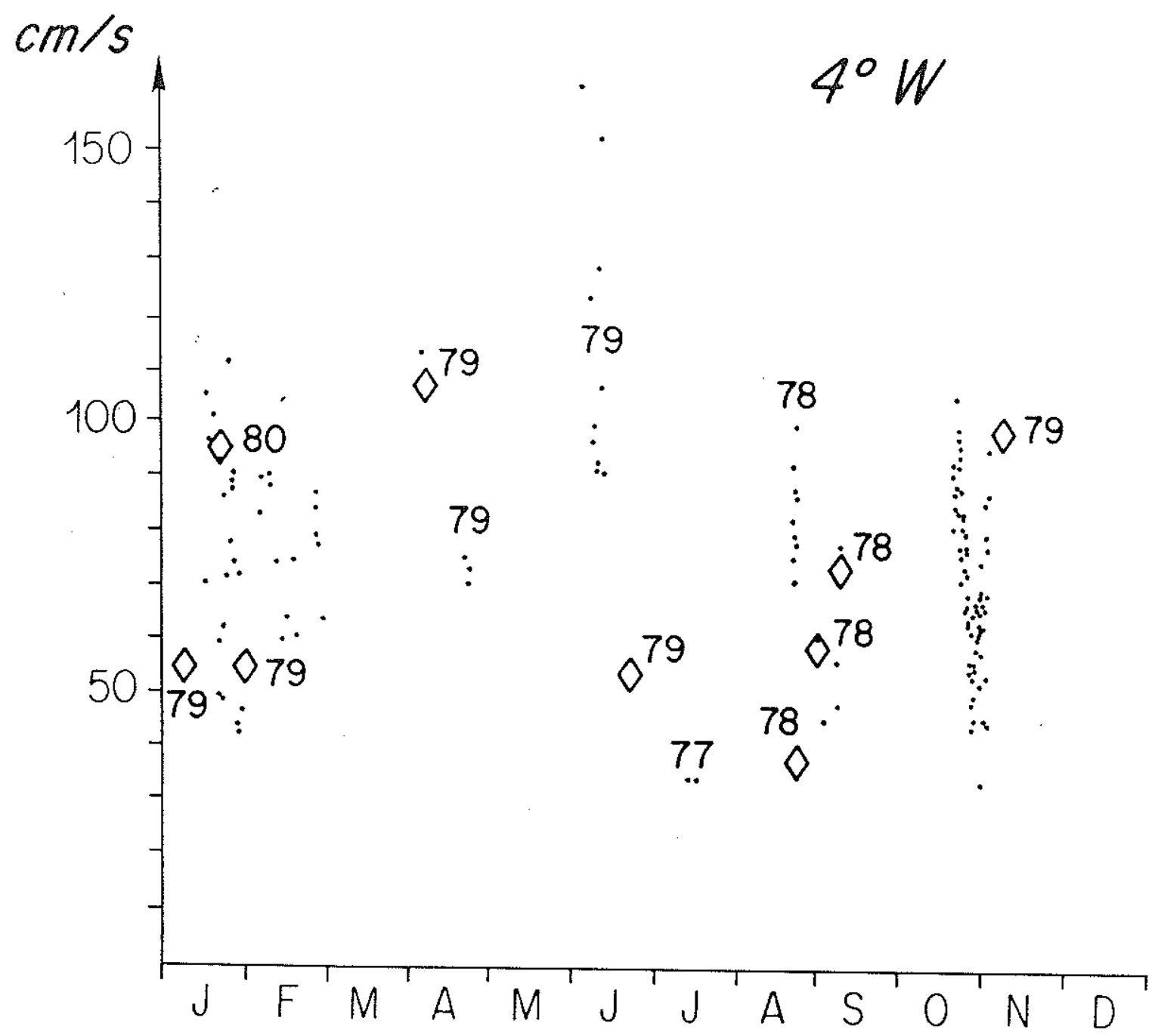

Figure 36: Estimates of the EUC maximum zonal velocity $(\diamond)$ and speed $(\cdot)$ at $4^{\circ} \mathrm{W}$, using profiler current meter measurements across meridional sections spanning the equator $(\diamond)$ or at a fixed point on the equator $(\cdot)$. Abscissae give the month and labels give
the year of the measurements. 
$0^{\circ} \mathrm{N} 4^{\circ} \mathrm{W} \quad \mathrm{KAT912}$

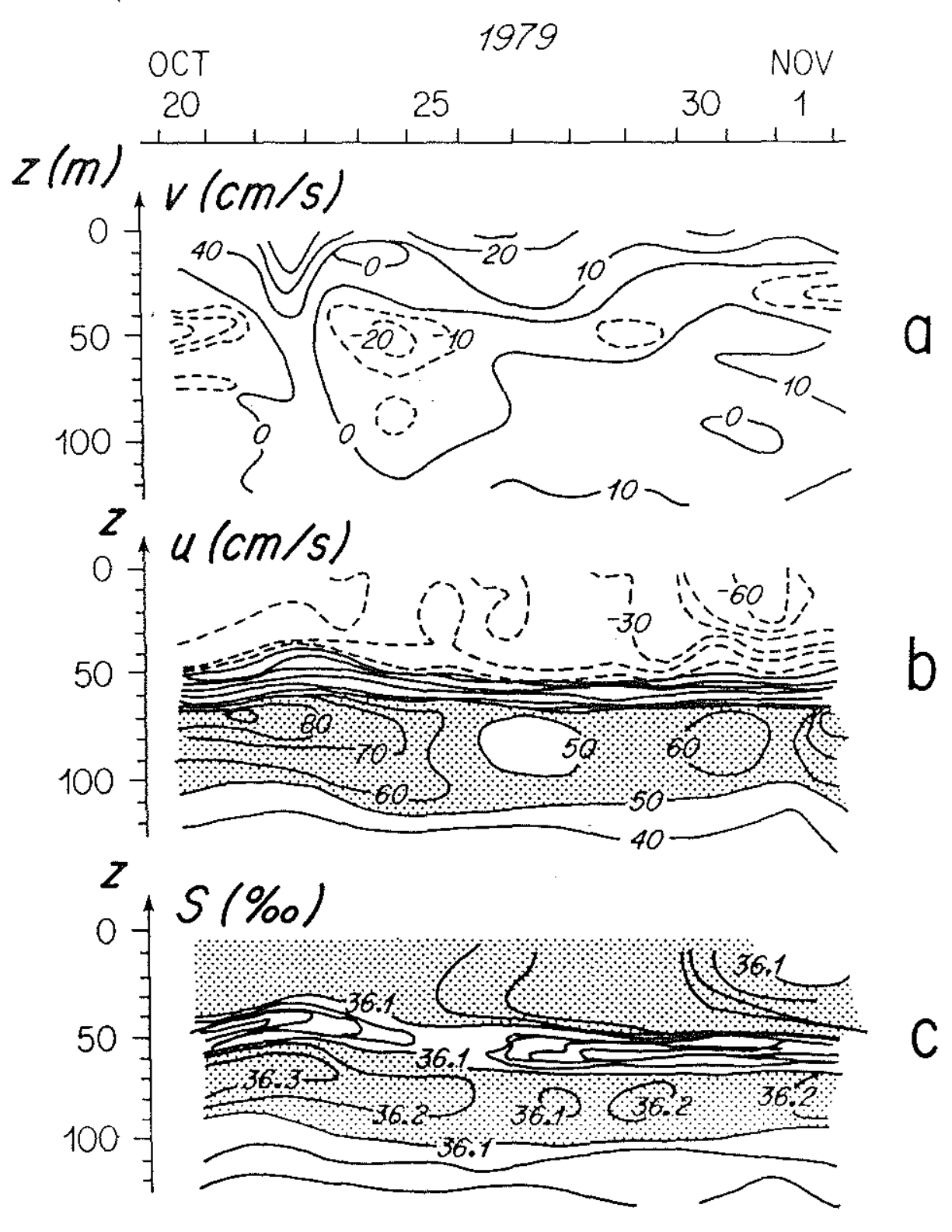

Figure 37: Time-depth contour plots of (a) meridional, (b) zonal velocities and (c) salinity from repeated profiling at $0{ }^{\circ} \mathrm{N} / 4^{\circ} \mathrm{W}$ between October 20 and November 1, 1979. 
velocity becomes positive and increases, and the salinity increases. It seems that the EUC velocity core and its associated salinity maximum were displaced south of the measuring point between 0ctober 20 and 27 , then northwards again. If one now plots as a function of time the maximum subsurface eastward velocity given by each individual profile, Figure 38 obtains. Onto the mean trend described above, a $0.20 \mathrm{~m} \mathrm{~s}^{-1}$ scatter (roughly estimated by eye) is superimposed. This scatter constitutes our best estimate of the error bar associated with the method.

In conclusion, a closer look at the available measurements of the EUC velocity at $4^{\circ} \mathrm{W}$ reveals that its seasonal variation is not well resolved. There is no unambiguous evidence for either the sharp spring intensification/weaker fall and winter values suggested farther east, or for the weak summer regime that Voituriez associates with the upwelling season. We suspect that interannual variability is the principal cause for the observed seasonal scatter. There is a chance that, by increasing the number of observations at $1^{\circ} \mathrm{E}$ and $6^{\circ} \mathrm{E}$ from what it is presently to what it is at $4^{\circ} \mathrm{W}$, one would only increase the seasonal scatter at $1^{\circ} \mathrm{E}$ and $6^{\circ} \mathrm{E}$, and that much longer time series are needed to separate seasonal from interannual variations. It is also possible that the pulse-like spring increase in EUC strength at $1^{\circ} \mathrm{E}$ and $6^{\circ} \mathrm{E}$ is a reality but that either of the following happens: (1) the variation exists also at $4^{\circ} \mathrm{W}$ but remains undetected because the background flow is stronger there than at $1^{\circ} \mathrm{E}$ and $6^{\circ} \mathrm{E} ;(2)$ the variation does not exist at $4^{\circ} \mathrm{W}$ because a transition occurs at an intermediate longitude between a mostly time-independent regime at and west of $4 \mathrm{~W}$ and a seasonally varying regime at and east of $1^{\circ} \mathrm{E}$.

The exact uncertainty associated with the measurement techniques and the role of that uncertainty in the observed scatter is still subject to debate. From the analysis of repeated profiling stations at the equator in fall 1978, we feel however that an error bar of $0.20 \mathrm{~m} / \mathrm{s}$ may be appropriate for estimates of the EUC velocity obtained from PCM measurements. By contrast, the overall range of EUC velocity estimates at $4^{\circ} \mathrm{W}$ is closer to $0.50 \mathrm{~m} / \mathrm{s}$ on average (Figures $34 \mathrm{~d}$ and 36 ). 


\subsection{Coastal undercurrent off the coast of Gabon}

The location of the coastal Aanderaa profiler current meter (PCM) stations obtained for this study is shown on Figure 39 . They were made from R.V. NIZERY during fourteen cruises out of Pointe Noire in 1977 and 1978. Most of these cruises were part of the program ETERLOM devoted to the observation of a southeastward-flowing coastal branch of the EUC (B. Piton, O.R.S.T.O.M., France). For the following study, we only considered the one hundred and eighty-nine stations made from the moored ship above the continental shelf and slope (Table 5). Some additional stations made from drifting ships were also available further offshore, but it was felt that absolute velocities were too sma11 to be subjected to the extra uncertainty of reference level choice. Most of the data lie along four sections starting at the coast of Gabon and Congo close to $2^{\circ} \mathrm{S}, 3^{\circ} \mathrm{S}, 4^{\circ} \mathrm{S}$ and $5^{\circ} \mathrm{S}$, and running offshore perpendicular to the (approximately straight) coastline. For these four sections, the coordinate system was rotated $42^{\circ}$ counterclockwise into directions perpendicular $(x, u)$ and parallel $(y, v)$ to the coast. Distances were then counted from the coast along $(-x)$ and from the equator along $(-y)$ (Figure 39$)$. The $1^{\circ}, 25^{\prime} S$ section was treated separately using zonal and meridional coordinates.

The procedure adopted to edit the data was as described in section 2.4 for the $4^{\circ} \mathrm{W}$-subset. Edited data were binned into $5 \mathrm{~m}$ levels, printed out by cruise and by section and contoured in order to identify features of the flow. When subsurface southeastward flow was observed, it tended to be at the offshore extremity of the sections (above the shelf break) and was highly variable. Stations between $2 \%$ S

and $6^{\circ} \mathrm{S}$ were therefore further grouped into boxes parallel to the coast: a western box between 90 and $60 \mathrm{~km}$ offshore above the shelf break, a central box between 60 and $25 \mathrm{~km}$ offshore, and an eastern box between $25 \mathrm{~km}$ offshore and the coast. To include all four sections the boxes extended from about $300 \mathrm{~km}$ to about $730 \mathrm{~km}$ south of the equator in the alongshore direction (Figure 39).

Several averages were then calculated in order to obtain statistically significant estimates of the mean circulation. Grouping 


\section{$0^{\circ} \mathrm{N} 4^{\circ} \mathrm{W}$ KA7912}

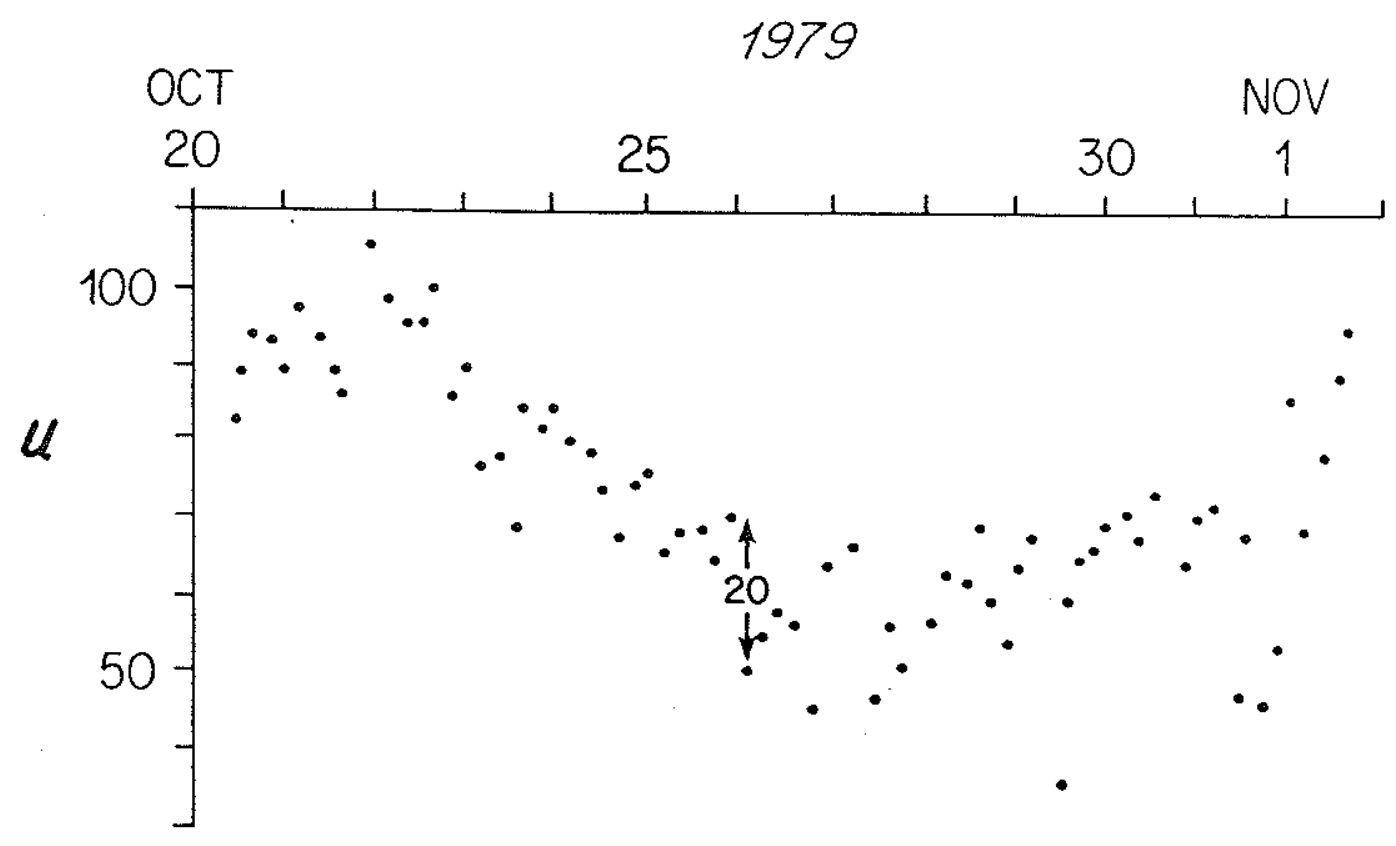

Figure 38: EUC maximum velocity at $0^{\circ} \mathrm{N} / 4^{\circ} \mathrm{W}$ from repeated profiling between 0ctober 20 and November 1, 1979 (cf Figure 37). 


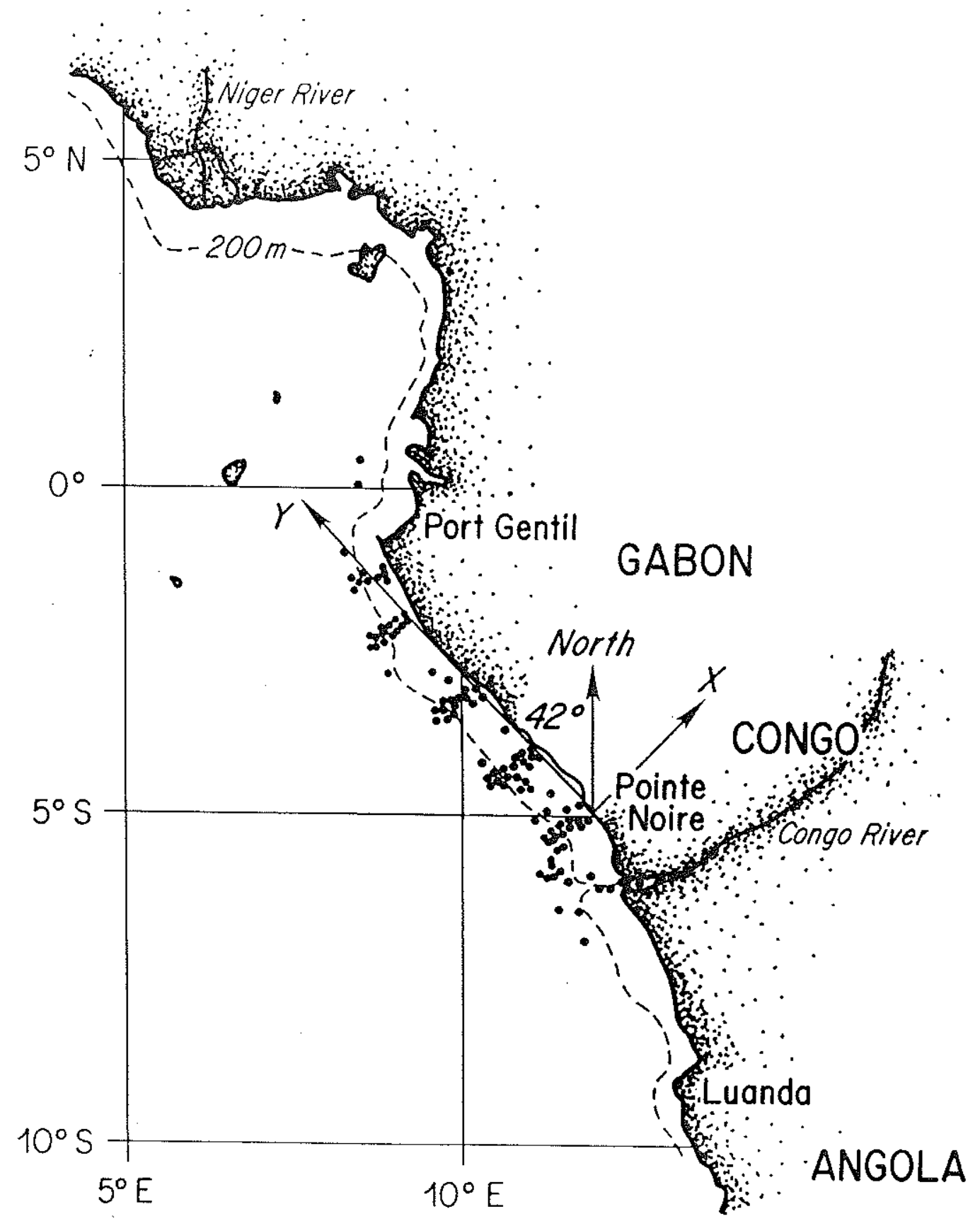

Figure 39: Location of the moored profiler current meter stations off the coasts of Gabon and Congo (cf Table 5). The cross-shore and alongshore axes used in the analys is are shown. 
Table 5

Moored PCM stations along the west-African coast, 1977-78

R.V. NIZERY, O.R.S.T.O.M.

\begin{tabular}{|llc|}
\hline Cruise & \multicolumn{1}{c|}{ Date } & Number of Stations \\
\hline KG7703 & March 9,1977 & 2 \\
KG7704 & May 13-21,1977 & 20 \\
KG7705 & June 13-19,1977 & 18 \\
KG7706 & Ju1y 11-16,1977 & 23 \\
KG7707 & August 22-24,1977 & 21 \\
KG7708 & December 16-17,1977 & 4 \\
\hline KG7802 & March 14-19,1978 \\
KG7803 & Apri1 10-14,1978 \\
KG7804 & May 16-21, 1978 & 17 \\
KG7806 & July 2-12, 1978 & 13 \\
KG7897 & August 24-28, 1978 & 20 \\
KG7808 & October 17-22,1978 & 7 \\
KG7809 & November 14-19,1978 & 5 \\
KG7810 & December 11-15, 1978 & 9 \\
& & 17 \\
\hline
\end{tabular}


all stations from all seasons and all boxes blurred all signal below a very thin westward surface flow. Grouping stations from all seasons within the western box over the shelf break yielded a weak alongshore poleward flow below the surface flow. Grouping stations within the western box by seasons produced the result shown on Figure 40 . The upper panel (a), loosely labelled as "summer 77-78" corresponds to the upwelling season (cold and saline surface waters: $23^{\circ} \mathrm{C}, 34.9^{\circ} / .00$ ) and includes the months of April to August. The lower panel (b) labelled "averaged winter 78" corresponds to the nonupwelling season (warm and fresh surface waters: $27^{\circ} \mathrm{C}, 32.4^{\circ} \% 0$ ) and includes the months of September to March (all the stations to be found within the western box in nonupwelling months were taken in 1978). The continuous profiles are the cross and alongshore velocities, and the dotted profiles are corresponding standard deviations $\sigma$, a measure of the variability of individual profiles about the mean.

Despite the change of scale between the upper and the lower panel of Figure 40 , it is clear that there is a better developed subsurface poleward flow (negative v) above the shelf break during the summer (a) than during the winter (b). On average, forty values enter the determination of each level of the mean summer profiles of Figure $40 a$. The error on the mean, $\sigma / \sqrt{40}$, is therefore of the order of $0.02 \mathrm{~m} / \mathrm{s}$. This gives statistical significance to the poleward summer flow of $0.08 \mathrm{~m} / \mathrm{s}$ paralle1 to the coast, but not to the cross-shore pattern of thin offshore surface flow and thick onshore subsurface flow (consistent with coastal upwelling). By contrast, only 10 values on average enter the determination of each level of the mean winter profiles of Figure 40b. Below the thin westward flow, the winter currents are therefore statistically indistinguishable from zero.

So a statistically significant $250 \mathrm{~m}$ thick mean subsurface poleward flow of about $0.08 \mathrm{~m} / \mathrm{s}$ emerges from our analysis of the boreal summer PCM stations moored above the shelf break between $2^{\circ} \mathrm{S}$ and $6^{\circ} \mathrm{S}$. That flow is not observed with the winter stations at the same location. 
A $15 \mathrm{~m}$-thick steady westward surface flow of about $0.20 \mathrm{~m} / \mathrm{s}$ and a subsurface salinity maximum of about $35.8^{\circ} . / \%$, located in the shear region below the surface flow are present year round. For an indication of alongshore evolution, the western box was subdivided into a northern and a southern box (Figure 41). The westward surface flow appears to be swifter in the south while the subsurface flow remains about the same in both boxes. Going south, surface temperatures increase from $22.8^{\circ} \mathrm{C}$ to $23.0^{\circ} \mathrm{C}$, surface salinities drop from $35.6^{\circ} \%$ to $34.6^{\circ} \% 0$ and subsurface salinities decrease from $35.9^{\circ} /$.0 to $35.8^{\circ} / 0$.

The same averaging exercise within various boxes was attempted with the stations above the shelf but failed to reveal any coherent feature of the circulation except a westward surface flow. This suggests at least that the absence of poleward undercurrent over the shelf break during the winter season is not due to the shifting of a vein of current onshore. It could still be due to its shifting offshore. If the poleward undercurrent stops rather than shifts offshore during the winter season, then it is tempting to attribute the existence of the summer flow to some geostrophic adjustment to the upwelled field of density. An attempt to relate the flow to cross-shore isotherm slopes however failed due to lack of adequate resolution in this direction.

The characteristics of the coastal undercurrent evidenced from this data set between $2^{\circ}, S$ and $6^{\circ}, S$ along west Africa are strongly reminiscent of those of the Peru-Chile undercurrent observed along the western coast of South America (section 2.1). The fact that our estimate of the mean poleward flow is only $0.08 \mathrm{~m} / \mathrm{s}$ while Gallardo (1981) and Guillerm (1981) report observations of a $0.30 \mathrm{~m} / \mathrm{s}$ southeastward flow off $5^{\circ} \mathrm{S}$ (section 2.2) is not alarming for three reasons. First, ours is an estimate of the mean rather than an instantaneous observation which can be noisy. Second, we may not have observed the same flow, or the PCM measurements presented in this section may have sampled only the periphery of a stronger offshore current, since some of the long sections off Pointe-Noire extended about four times further offshore than the ones examined here. [The geographical extent of the 

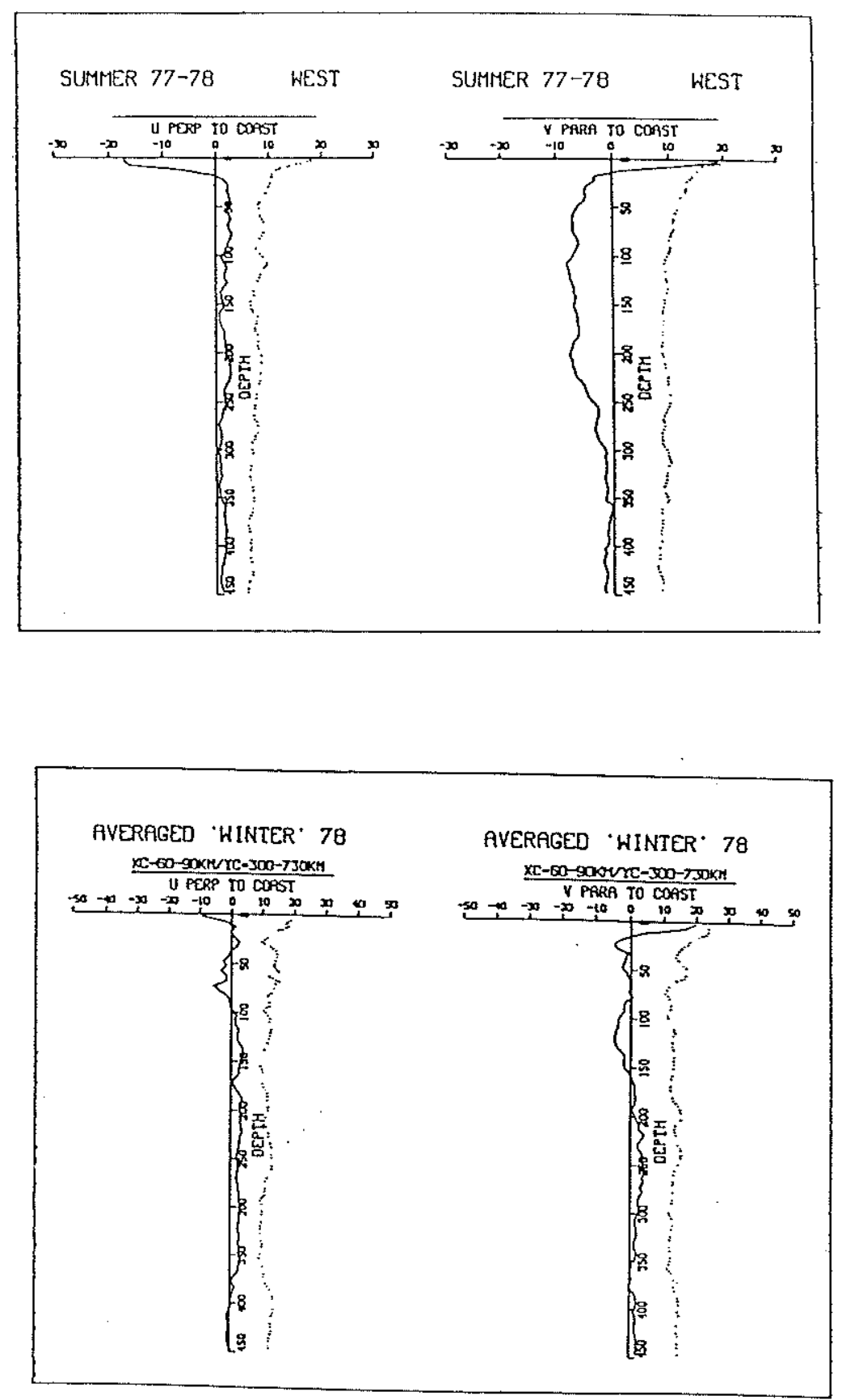

b

Figure 40: Vertical profiles of (1eft) cross-shore and (right) alongshore mean (solid) and r.m.s. (dotted) velocity components for a. the boreal "summer" months of 1977 and 1978 (upwelling

b. the boreal "winter" months of 1978 (warm season, September to March).

Averages were computed by season of all the velocity profiles made above the shelf break, between 60 and $90 \mathrm{~km}$ from the coast and between 300 and $730 \mathrm{~km}$ from the equator (cf Figure 41). 


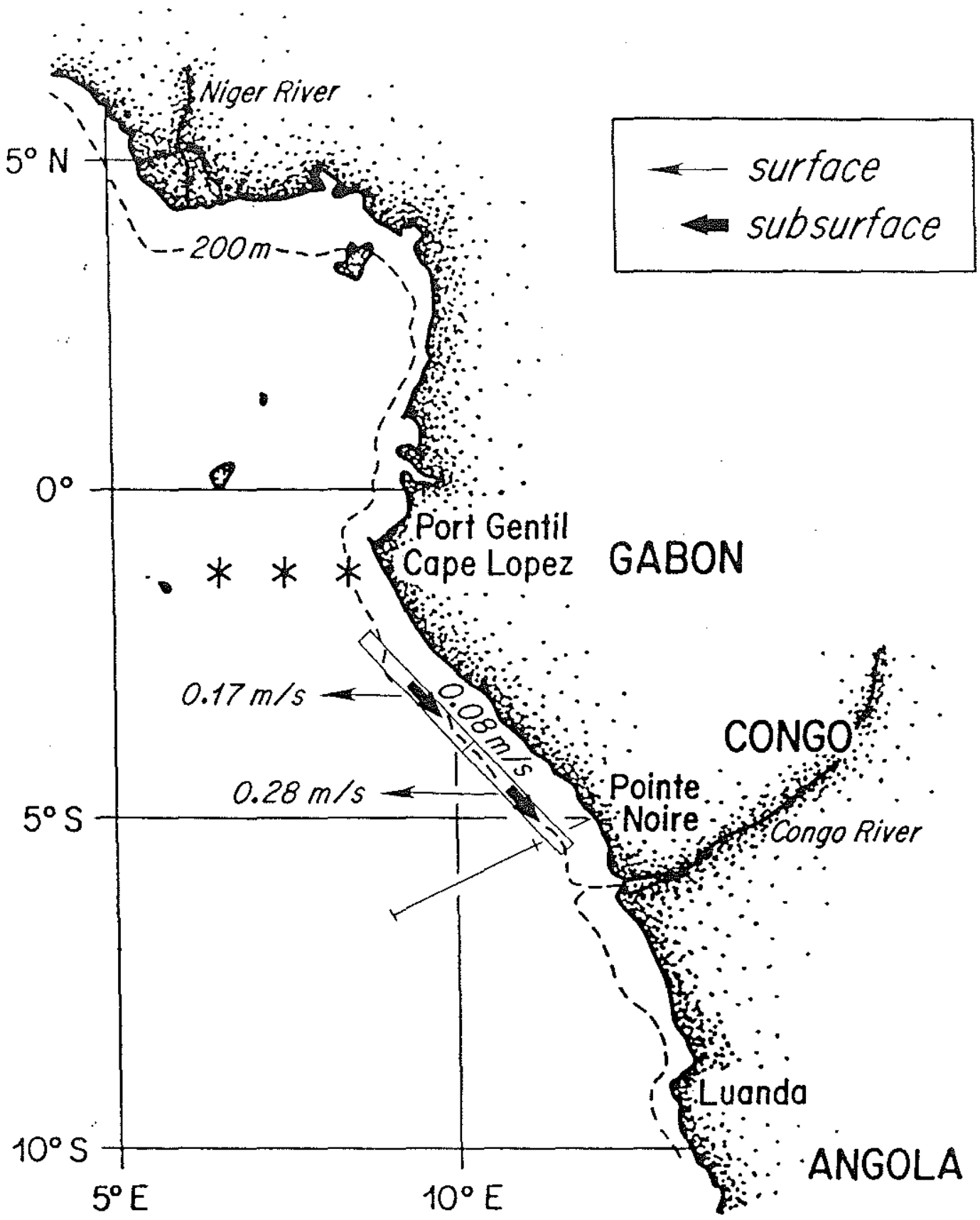

Figure 41: Limits of the sheif break profiler current meter (PCM) stations at which a statistically significant mean poleward coastal undercurrent $(0.08 \mathrm{~m} / \mathrm{s}$ thick arrows) was evidenced in boreal summer (upwelling season), below a mean westward surface flow $(0.17 \mathrm{~m} / \mathrm{s}$ and $0.28 \mathrm{~m} / \mathrm{s}$ thin arrows). Instantaneous subsurface poleward velocities of the order of $0.30 \mathrm{~m} / \mathrm{s}$ were also occasionally reported across the section drawn off Pointe Noire (Guillerm, 1981; Gallardo, 1981), and at the stations represented by asterisks $(*)$ on the $1^{\alpha} 25^{\prime} S$ section. 
long $(350 \mathrm{~km})$ and the short $(100 \mathrm{~km})$ sections made off Pointe-Noire is indicated on Figure 41]. Third, the offshore circulation south of $5^{\circ} \mathrm{S}$ is likely to be complicated by the inflow of SEUC waters (Figure 22). One should also remember that the observations analysed in this section concern only the 1977-78 period.

Across the $1^{\circ}, 25^{\prime} \mathrm{S} / 6^{\circ} \mathrm{E}-8^{\circ}, 30^{\prime} \mathrm{E}$ section, only seven out of the twenty -three profiles retained for the $1977-78$ period exhibit a sizeable poleward undercurrent centered around $50 \mathrm{~m}$ depth. Since there are not enough stations to compute any statisticaliy significant mean, we only present on Table 6 these seven instantaneous observations, made close to $6^{\circ}, 30^{\prime} \mathrm{E}, 7^{\circ}, 30^{\prime} \mathrm{E}$ and $8^{\circ} 30^{\prime} \mathrm{E}$ [asterisks $\left({ }^{*}\right)$ on Figure 41$]$. The $8^{\circ} 30^{\prime} \mathrm{E}$ profiles are located at the shelf break and were measured from a moored ship; the other values are shears relative to $450 \mathrm{~m}$ as at $4^{\circ} \mathrm{i} . \mathrm{W}$. Instantaneous values are of the order of $0.30 \mathrm{~m} / \mathrm{s}$ southwards, as is a drogue measurement reported for March 1964 by Rinkel et al. (1966), and the shear relative to $500 \mathrm{~m}$ reported for May 1973 by Morlière et al. (1974) (Figure 31).

\subsection{Conclusion}

We have seen in this chapter that presently available observations in the eastern equatorial Atlantic and Pacific do not provide a complete description of the fate of the EUC waters as the current approaches the eastern boundary. In particular, the dynamics of the undercurrent's termination and its seasonal variability are not well resolved.

What is clear from velocity measurements is that there still is considerable subsurface eastward momentum in the eastern part of both equatorial basins [e.g. o $(0.30 \mathrm{~m} / \mathrm{s})$ at $0^{\circ} \mathrm{N} 6^{\circ} \mathrm{E}$ in the Atlantic], even though some large scale weakening has taken place from the center of the basins eastwards. In the Pacific, this weakened EUC impinges on the Galapagos Islands at about the longitude of the wind reversal, $10^{\circ}$. of longitude west of the coast. In the Atlantic, it impinges on Sao Tome Island, $8^{\circ}$, of longitude east of the line of wind reversal and $3^{\circ}$. of longitude west of the coast. In both cases, a mostly southward 
(upwind) deflection seems to result. There are also signs of westward flows on the flanks and below the EUC which could return extra momentum westwards. Finally it is clear that a southeastward undercurrent exists at least part of the time along the eastern boundaries of both equatorial oceans south of the equator. In the Pacific, it is the Peru-Chile undercurrent, observed south of $5^{\circ} \mathrm{S}$ above the shelf break $(100 \mathrm{~m}$ depth, $0.10 \mathrm{~m} / \mathrm{s})$ and reported to be highly variable. In the Atlantic, it could be called the Gabon-Congo undercurrent. The new analysis presented here documents the existence of the Atlantic coastal undercurrent between $1^{\circ} \mathrm{S}$ and $6^{\circ} \mathrm{S}$ above the shelf break $(100 \mathrm{~m}$, $0.08 \mathrm{~m} / \mathrm{s}$ ) during boreal summer, the season of coastal upwelling. Owing to the large variability of the coastal circulation (consecutive sections may exhibit a poleward undercurrent, an equatorward one, or none at a11), severe box-averaging was required to obtain, for the first time in that region, statistical significance.

It is clear from hydrographic measurements that the EUC is the source of the high subsurface salinity and high oxygen content found in both eastern equatorial basins and along their eastern coast at least between $0^{\circ} \mathrm{N}$ and $5^{\circ} \mathrm{S}$ (sections 2.1 and 2.2). In the case of the eastern Atlantic, subsurface tongues of high salinity have been traced from the equator southeastwards; their axis is 25 to $50 \mathrm{~m}$ deep and is located about $150 \mathrm{~km}$ from the coast (or about $75 \mathrm{~m}$ from the shelf break) (Figure 42; Wauthy, 1977).

What is still unclear is the actual dynamical connection between the EUC and both the westward return flows and the coastal undercurrents, in particular the respective parts played by internal dynamics and external forcing. Recall the results from Cane (1979b): as his mostly inertial EUC forced in a rectangular basin by idealized constant symmetrical easterlies impinges on the eastern wall, it does create, within a thin boundary 1 ayer, the opposing pressure gradients necessary for poleward deflections of the flow. Within less than a couple of degrees of latitude from the equator however, these poleward flows leave the coast to return symmetrically westwards, in agreement with vorticity conservation (section 1.6.1.1). If one considers 
Table 6

Instantaneous observations of a southward undercurrent across section $1^{\circ} 25^{\prime} \mathrm{S} / 6^{\circ} \mathrm{E}-8^{\circ} 30^{\prime} \mathrm{E}$ (core around $50 \mathrm{~m}$ )

\begin{tabular}{|c|c|c|c|c|}
\hline \multirow[b]{2}{*}{ Cruise } & \multirow[b]{2}{*}{ Date } & \multicolumn{2}{|c|}{ Shear $/ 450 \mathrm{~m}$} & \multirow{2}{*}{$\begin{array}{l}\text { Moored Ship } \\
8^{\circ} 30^{\prime} \mathrm{S}\end{array}$} \\
\hline & & $6^{\circ} 30^{\prime} \mathrm{S}$ & $7^{\circ} 30^{\prime} \mathrm{S}$ & \\
\hline KG7803 & Apri1 19, 1978 & & $-0.50 \mathrm{~m} / \mathrm{s}$ & \\
\hline KG7704 & May 24, 1977 & $-0.20 \mathrm{~m} / \mathrm{s}$ & & \\
\hline KG7804 & May 21, 1978 & & & $-0.30 \mathrm{~m} / \mathrm{s}$ \\
\hline KG7805 & June 18,1978 & & & $-0.20 \mathrm{~m} / \mathrm{s}$ \\
\hline KG7897 & August 24, 1978 & & & $-0.15 \mathrm{~m} / \mathrm{s}$ \\
\hline KG7809 & November 23, 1978 & $-0.30 \mathrm{~m} / \mathrm{s}$ & & \\
\hline KG7810 & December 15, 1978 & & & $-0.25 \mathrm{~m} / \mathrm{s}$ \\
\hline
\end{tabular}

No entry corresponds either to no measurement at that longitude, depth and time, or to northward flow with no characteristic subsurface feature. 


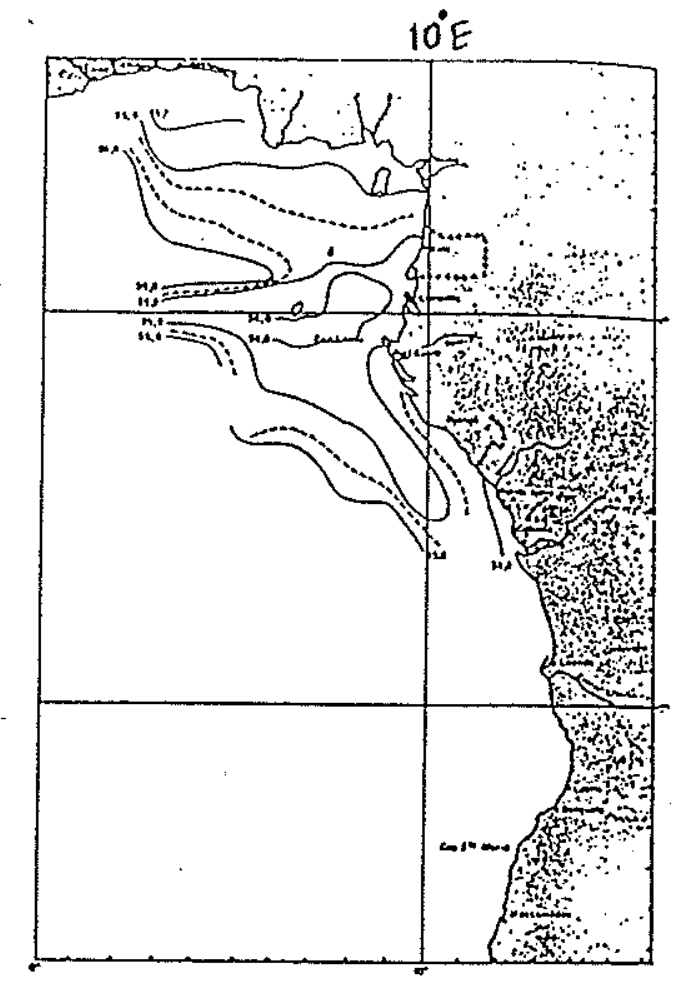

a

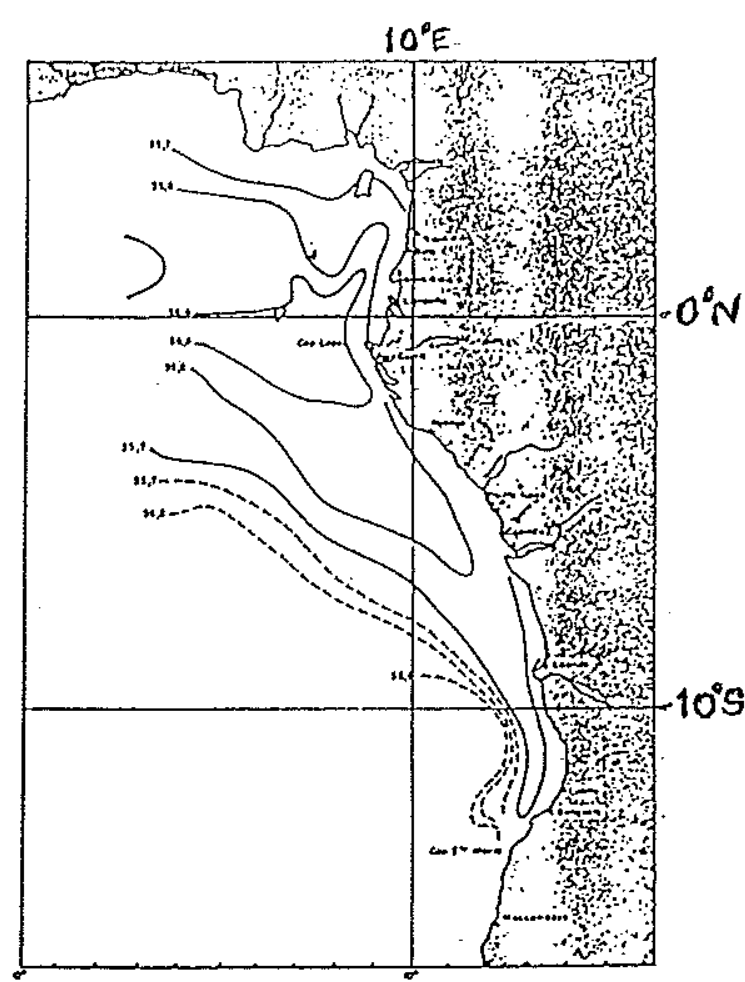

b

Figure 42: Tongues of subsurface salinity maximum off the coasts of Gabon and Congo (program OMBANGO, (a) February-March 1960 and (b) October-November 1959; Wauthy, 1977). 
192 
instead conservation of potential vorticity in a stratified ocean, asymmetry with respect to the equator can exist if the background stratified layers have different thicknesses south and north of the equator. This in turn can be the result of the coastal upwelling and downwelling created south and north of the equator respectively by a southerly component of the wind stress. The asymmetry in the termination might thus be traced to the asymmetrical effect of the meridional wind forcing.

In the case of the eastern Pacific, Lukas (1981, 1986; section 2.1) argues that the effect of the wind stress does not penetrate to the EUC level. Why then do we not observe a more symmetrical termination? In the case of the Atlantic, the observations do not rule out the possibility that, as the EUC impinges on Sao Tome Island, some of its water recirculate westwards symmetrically with respect to the equator while some is caught in an "independently existing" asymmetric coastal current system. Among the problems associated with the hypothesis of a direct dynamical connection between equatorial and coastal undercurrents, recall that the upwelling season in the Atlantic may correspond to a weakening of the EUC and a strengthening of the CUC. The seasonality and interannual variability of either current is what remains observationally most ambiguous at the present time. 
Chapter 3. DYNAMICS OF A SIMULATED EQUATORIAL UNDERCURRENT

Chapters 1 and 2 described observations relative to the zonal weakening and eastern termination of the EUC and reviewed the physical mechanisms likely to play an important role in these phenomena. The quality of the observations being insufficient for a quantitative test of the various possible models, it was decided to investigate the dynamics of the zonal weakening and eastern termination of a realistic numerical simulation of the EUC.

Chapter 3 is thus devoted to a dynamical analysis of Philander and Pacanowski's (1984) general circulation model of the seasonal cycle of the tropical Atlantic. This model is driven by realistic spatial and temporal patterns of wind stress and surface heat flux, it is governed by primitive equations, has 27 levels in the vertical and is elaborate enough to support most of the large scale physical processes that one expects to find in the real ocean. It is therefore of great value to find out which mechanisms such a system selects to govern a given phenomenon, such as the undercurrent's longitudinal variation.

First the model and $i$ ts simulation of the climatological circulation of the equatorial Atlantic are described. Then a diagnostic of the zonal momentum balance is presented and discussed as a function of longitude, latitude, depth and time, and regions characterized by distinct dynamical regimes are identified. Implications of the general circulaton model analysis for the interpretation of existing data and simpler model predictions are discussed in chapters 4 and 5 respectively. 


\subsection{Basic features of the model}

The model studied in the following is the general circulation model (GCM) developed by Philander and Pacanowski as an adaptation to the tropical ocean of the Bryan and Cox' model (Bryan, 1969;

Semtner, 1974; Cox, 1984). A general description of the model and several aspects of its behaviour when applied to the seasonal cycle of the tropical Atlantic are presented in three recent papers by Philander and Pacanowski (1986a,b; 1987).

The total model grid covers the domain between $30^{\circ} \mathrm{S}$ and $50^{\circ} \mathrm{N}$. The analysis presented below focuses on the dynamics of the equatorial undercurrent (EUC) simulated by the model in the Atlantic, and consequently uses only a subset of the total grid: an equatorial strip from $3^{\circ} \mathrm{S}$ to $2^{\circ} \mathrm{N}$ across the basin (Figure 43a). Only the model parameters relative to that equatorial region will therefore be summarized.

The model uses primitive equations on a staggered B-grid (Figure 43b) and makes the rigid-1id approximation. It has 27 levels in the vertical with a 10 m-resolution above $100 \mathrm{~m}$ (Figure $43 \mathrm{c}$ ), bottom topography, a realistic coastline, a meridional grid spacing of $1 / 3^{\circ}$ latitude, a zonal grid spacing of $1^{\circ}$ longitude, and a time-step of 1 hour.

The coefficient of horizontal eddy viscosity is constant:

$$
A_{H}=2 \times 10^{7} \mathrm{~cm}^{2} / \mathrm{s} \text {, }
$$

and the associated term of horizontal Newtonian friction is linear. The coefficient of vertical eddy viscosity is a function of the Richardson number (Pacanowski and Philander, 1981). Its value in $\mathrm{cm}^{2} / \mathrm{s}$ can be written:

$$
\begin{gathered}
v=1.34 \times 10^{-2}+50 /(1+5 R i)^{2} \\
R i=g \rho_{z} / \rho_{0}\left(u_{z}^{2}+v_{z}^{2}\right)
\end{gathered}
$$

so the term of vertical friction $\left(v(z) u_{z}\right)_{z}$ is highly nonlinear.

Density is computed from temperature and salinity using polynomial fits to the nonlinear equation of state (Bryan and Cox, 

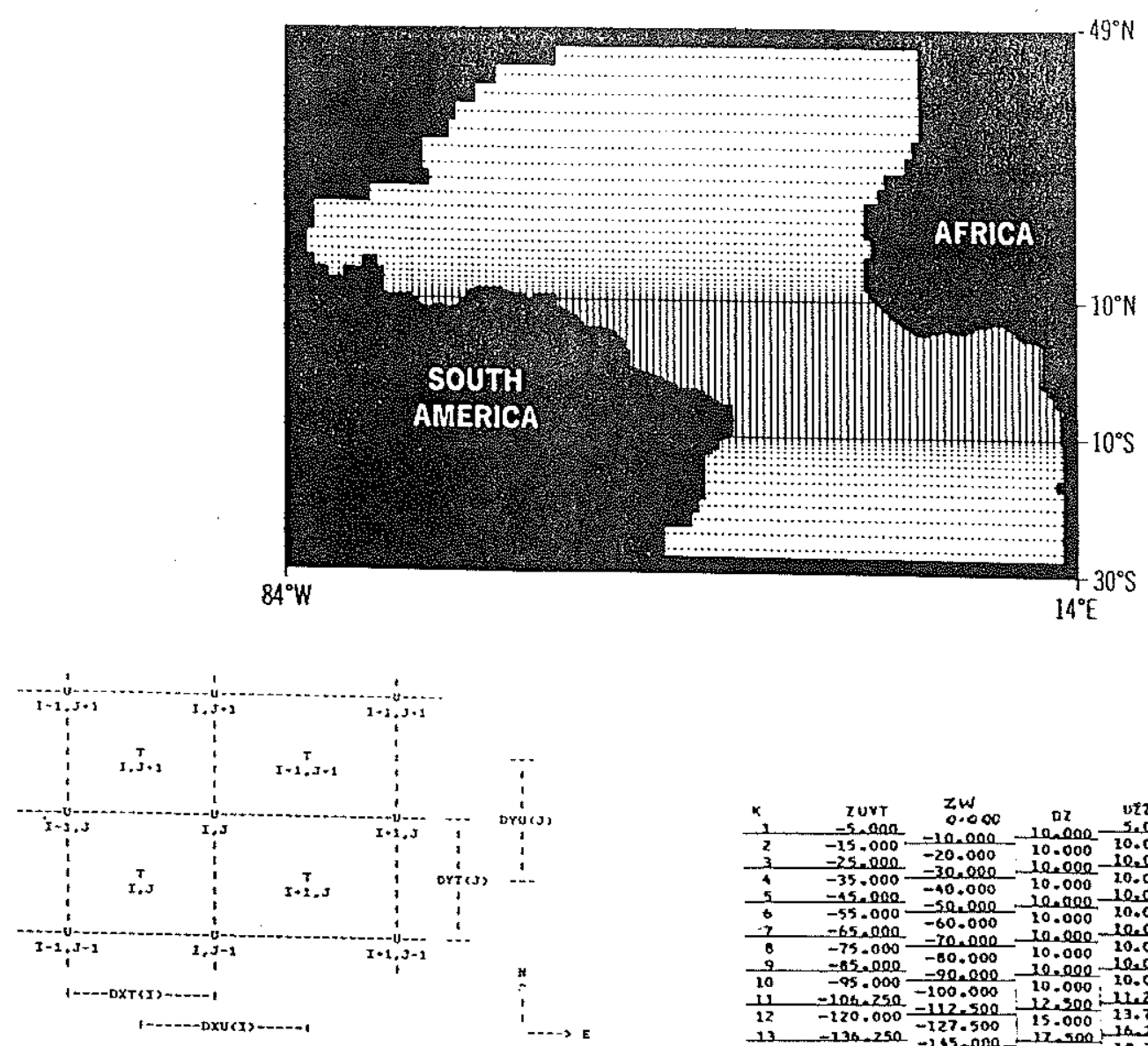

BORIZONTAL GRIO SPACIMG ANO IMDEXING
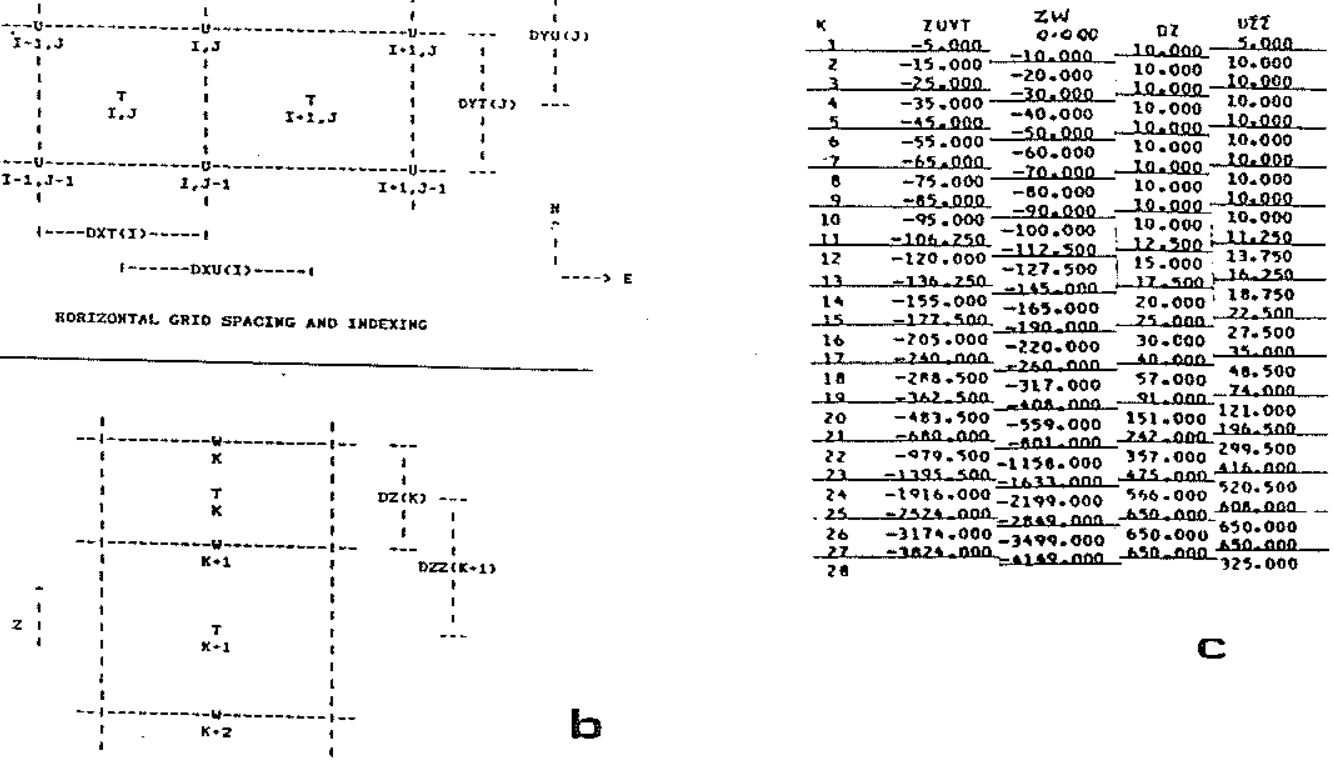

VERTICAL GRID SPACYNG AND IXDEXING

Figure 43: General circulation model grid.

a. Horizontal domain. The sub-region used for the dynamical analysis is a zonal band betweeen $3^{\circ} \mathrm{S}$ and $2^{\circ} \mathrm{N}$.

b. Horizontal and vertical grid spacing and indexing. c. Vertical levels for $u, v, T$ and $S$ (ZUVT) and for $w(Z W)$, and layer thicknesses. 
1972), and convective adjustment occurs when the stratification becomes unstable. The finite differencing is for the most part forward in space and centered in time, with a forward time-step performed every 17 time-steps for the purpose of numerical stability.

The model is forced from the top by climatological wind stress (Hellerman and Rosenstein, 1983), and seasonally varying air temperature at sea level is used to specify the surface heat flux. Both forcing fields are linearly interpolated in time and space in order to be applied as surface boundary conditions at each time-step and at each grid point of the model. Being interpolated from monthly values in $5^{\circ} \times 5^{\circ}$ boxes into hourly values in $1^{\circ} \times 1 / 3^{\circ}$ boxes, the wind stress field used to force the model is much smoother in time and space than the one which would be observed at any given instant. In particular, it is lacking the 10 to 50 days fluctuations which were shown to be able to cause a nonlinear intensification of the EUC of the order of 15 percent (section 1.6.2; Philander and Pacanowski, 1981). When comparing the simulation to observations, it should therefore be kept in mind that the model ocean's response to such a forcing can be closer to equilibrium than the response of the real ocean to the real forcing.

The initial condition imposed on the field of velocity is a state of rest, with the field of density defined by the climatological stratification for January (Levitus, 1982). It takes only two years of simulation to spin up the model so that a reproducible seasonal cycle is established in the upper layers. The fact that the stratification, being distorted for a year by linear and nonlinear processes, can still replicate the state it started from (rather than become totally unrealistic) is taken as a sign that the simulated dynamical and thermodynamical processes act in a realistic fashion.

Several outputs of the climatologically forced equatorial Atlantic were generated and are 1 isted below. The output most frequently used in the analysis presented in this chapter is the first on the 7 ist. 
- 3-day averaged values of T, S, u, v, w at all depths, all 1ongitudes and all latitudes between $3^{\circ} \mathrm{S}$ and $2^{\circ} \mathrm{N}$ (ten values per month)

- instantaneous values of $T, S, u, v, w$ at all depths, and surface values of $\nabla \mathrm{p} / \rho_{0}$ at all longitudes and all latitudes between $3^{\circ} \mathrm{S}$ and $2^{\circ} \mathrm{N}$ on three consecutive time-steps (one hour apart) three times a month (every ten days)

- instantaneous values of T, S, U, v, w at all depths, all longitudes and all latitudes once a month (on the $15^{\text {th }}$ )

- 3-day averaged values of T, S, u, v, w at all depths, selected longitudes and al1 latitudes ten times a month (every three days).

Only the second output 1 isted saved the value of the surface pressure gradient (the rigid-1id equivalent to a sea surface slope), thereby allowing the computation of absolute pressure gradients. In the other cases, pressure is referenced to a deep level such as $500 \mathrm{~m}$ or $1000 \mathrm{~m}$ as would dynamic height from real observations, under the hypothesis that motion at such depths, if not zero, is at least much weaker than in the upper layers. Analysis of the second output confirms the validity of this hypothesis. Exceptional cases of a bad choice of reference level show up as a depth-independent imbalance in the equation of conservation of zonal momentum. They can therefore be corrected a posteriori by subtracting the imbalance from the bad estimate of the zonal pressure gradient (errors in the computation of any other term of the zonal momentum balance would be depth-dependent).

\subsection{Description of the simulated circulation}

As discussed by Philander and Pacanowski (1986a), the tropical Atlantic simulation agrees fairly well with the somewhat scattered and imperfect available observations. The main global features reported in that paper are reviewed first. More detailed descriptions 
of the annual mean and time-varying EUC made as part of the present work are presented next.

Monthly horizontal maps of the model upper ocean heat content $\left(\int_{317 \mathrm{~m}}^{0} \mathrm{Tdz}\right)$ compare well with the month1y maps of dynamic topography of the surface relative to $500 \mathrm{~m}$ constructed by Merle and Arnault (1985). Note however that simpler linear models like Busalacchi and Picaut's (1983) reduced gravity model, or Tréguier and du Penhoat's (1983) continuously stratified model, when forced by climatological winds, are also successful at reproducing seasonal changes in quantities comparable to surface dynamic topography. The success of these 1 ast models has in fact sustained the belief that vertically integrated equatorial dynamics are mostly linear: the role of nonlinearities effecting redistributions of mass and momentum internally. We will see below that this is not really the case in the GCM.

Along the equator, the thermocline, which on average slopes up from about $120 \mathrm{~m}$ in the west to about $50 \mathrm{~m}$ near $10^{\circ} \mathrm{W}$, then down onto the eastern coast, is steeper in periods of strong winds, flatter in periods of weak winds. The seasonal occurrence of cold sea surface temperature (SST) along the equator and some of the coasts of the Gulf of Guinea is reproduced. The seasonality is related to the changes in thermocline depth and mixed-layer thickness, the vertical motion above the thermocline being upwards year-round. The amplitude of SST is in general good compared with monthly climatologies (e.g. Picaut et al., 1985), despite a tendency for warmer temperatures than observed in the northern Guif of Guinea.

Direction and phase of the main surface currents generally agree with observations such as historical ship drifts (Richardson and McKee, 1984). Amplitudes are less well reproduced: surface velocities simulated in the western part of the basin appear to be higher than the ship drifts on average (Richardson and Philander, 1986). The same study suggests that the downward penetration of the wind-stress may not be correctly reproduced by the model, and incriminates the parameterization of the vertical friction. A recent numerical experiment (Philander and Pacanowski, unpublished) however shows that 
uncertainties in the amplitude of the wind-stress itself may be large enough to explain the discrepancies between simulated and observed oceanic responses, so whether or not further adjustment of the model's parameters is necessary is still a matter of discussion.

In the western and central parts of the basin, the model's EUC is located slightly above and within the thermocline respectively, a bit south of the equator in general, and is associated with a vertical spreading of the isotherms consistent with geostrophy. The velocity core is accordingly deeper in the west and shallower in the east, but below rather than within the thermocline in the Gulf of Guinea. Latitudinal and vertical scales are in very good agreement with observations, but the strength of the EUC and its eastward penetration tend to be less than observed: while measurements consistently give velocities of the order of $0.9-1.0 \mathrm{~m} / \mathrm{s}$ around $25^{\circ} \mathrm{W}$ and $0.5 \mathrm{~m} / \mathrm{s}$ between $4^{\circ} \mathrm{W}$ and $6^{\circ} \mathrm{E}$ (chapter 2), the model's EUC does not have velocities above $0.8 \mathrm{~m} / \mathrm{s}$ at $25^{\circ} \mathrm{W}, 0.2 \mathrm{~m} / \mathrm{s}$ at $4^{\circ} \mathrm{W}$ and is often absent at $6^{\circ} \mathrm{E}$. How much of the discrepancy should be ascribed to the forcing itself (smooth climatology, choice of drag coefficients) will be addressed later.

On seasonal time scales, the core migrates vertically: it is closer to the surface when the easterlies and the westward surface flow are weak, deeper when they are strong. The maximum speed of the EUC also describes a seasonal cycle, relatively small in the west and the center, larger in the east. In the termination region of the model's EUC, Philander and Pacanowski (1986a) report in 0ctober a southward coasta1 undercurrent at a depth of about $25 \mathrm{~m}$ above the shelf break, which they associate with the eastern reversal of the thermocline slope, most pronounced during that month.

Finally, large amplitude waves contaminate the fields of meridional and vertical velocity during the second half of the year in the west and the center of the basin. Their 30-day period is similar to that of the instability waves observed in late summer and fall in these regions which are attributed to increased latitudinal shear between SEC and NECC following the intensification of the easterlies (e.g. Weisberg, 1984). 
As mentioned above, these general properties of the simulation are presented and discussed in Philander and Pacanowski (1986a). As a first step towards answering the specific questions addressed in this thesis, a more thorough description of the simulated EUC was needed. Various plots of the model EUC as a function of depth, longitude and time were therefore produced and are described in the following sections.

\subsubsection{Annual mean}

Figure 44 shows the horizontal pattern of the annually averaged wind stress and its components between $10^{\circ} \mathrm{S}$ and $10^{\circ} \mathrm{N}, 50^{\circ} \mathrm{W}$ and $10^{\circ} \mathrm{E}$. Both components have similar orders of magnitude, but the southerly component is mostly uniform with longitude while the easterly component monotonously decreases east of $25^{\circ} \mathrm{W}$ and switches to westerly at about $2^{\circ}$ W along the equator.

Circulation in the $x-\underline{z}$ plane: Figure 45 reproduces the longitudinal variation of the wind stress components along the equator (a) and shows equatorial sections of the annually-averaged zonal and vertical components of velocity $(b, c)$. It also shows a vector plot of the $x-z$ circulation drawn on an equatorial section of the annuallyaveraged temperature (d) and an equatorial section of the annuallyaveraged salinity (e). As briefly mentioned above, the model thermocline slopes upwards from the western coast to about $10^{\circ} \mathrm{W}$, then downwards to the eastern coast where it also gets much tighter (d). The EUC core also shoals eastwards from about $70 \mathrm{~m}$ at $40^{\circ} \mathrm{W}$ to about $55 \mathrm{~m}$ at $10^{\circ} \mathrm{W}$, and it subsequently deepens to about $65 \mathrm{~m}$ at $5^{\circ} \mathrm{E}$ (b). But the upward slope of the core is less than that of the thermocline, and all the subsurface eastward flow east of $10^{\circ} \mathrm{W}$ is actually found below the sharp thermocline of the Gulf of Guinea (d), and below the subsurface salinity maximum associated with the thermocline. Over most of the basin, the vertical velocity is upwards from the middle of the eastward-flowing layers below the EUC core (the zero line for $w$ roughly coincides with the 1 ower $0.2 \mathrm{~m} / \mathrm{s}$ isol ine for $u$ ) to the uppermost level. Before falling back to zero at the ocean surface, it reaches its maximum at about 
$35 \mathrm{~m}$, where the vertical shear between surface westward flow and subsurface eastward current is largest. In the lower layers of the EUC below the $0.2 \mathrm{~m} / \mathrm{s}$ isotach, there is weak downwelling into a region of deep slow westward current mostly visible east of $15^{\circ} \mathrm{W}$ for the range of depths presented in Figure 45.

Figure 45 thus illustrates an eastward and upward motion of most of the subsurface flow. The upward motion appears as an upward sloping of the isotachs below the EUC core, but not above owing to the presence of the opposing westward surface flow (b). One can illustrate the importance of vertical exchanges between surface and subsurface levels by approximating the $x-z$ trajectory of a given water parcel initially slightly above the EUC core in the western basin (say at $60 \mathrm{~m}$ at $\left.30^{\circ} \mathrm{W}\right)$. Figure $45 \mathrm{~b}, \mathrm{c}$ provide the orders of magnitude $0.5 \mathrm{~m} / \mathrm{s}$ and $20 \times 10^{-6} \mathrm{~m} / \mathrm{s}$ for the zonal and vertical velocities respectively. In order to exit the 50 m-thick eastward flow above the EUC core and pass into the westward surface flow, it will take the parcel:

$$
\Delta z / w=50 /\left(20 \times 10^{-6}\right)=2.5 \times 10^{6} \mathrm{~s}
$$

i.e. about 1 month. In that amount of time, the parcel will have gone a zonal distance:

$$
\Delta x=u \times \Delta z / w=0.5 \times 2.5 \times 10^{6}=1.25 \times 10^{6} \mathrm{~m}=1250 \mathrm{~km}
$$

i.e about $10^{\circ}$ longitude, or only $1 / 5$ of the basin length. So none of the water parcels originating in the upper thermocline in the western and central parts of the basin is likely to reach the eastern coast intact.

Let us now consider a water parcel originating considerably below the EUC core in the western basin (say at $135 \mathrm{~m}$ at $30^{\circ} \mathrm{W}$, with initial zonal and vertical velocities of 0.2 and $5 \times 10^{-6} \mathrm{~m} / \mathrm{s}$ respectively). Approximating the $x-z$ trajectory of such a parcel as above, one finds that it is now able to go about $40^{\circ}$ longitude (beyond the eastern limit of the basin from $30^{\circ} \mathrm{W}$ ) in about eight months before it goes $100 \mathrm{~m}$ upwards. So water parcels originating in the western 10 wer thermocline are likely to stay within the EUC throughout the basin. 

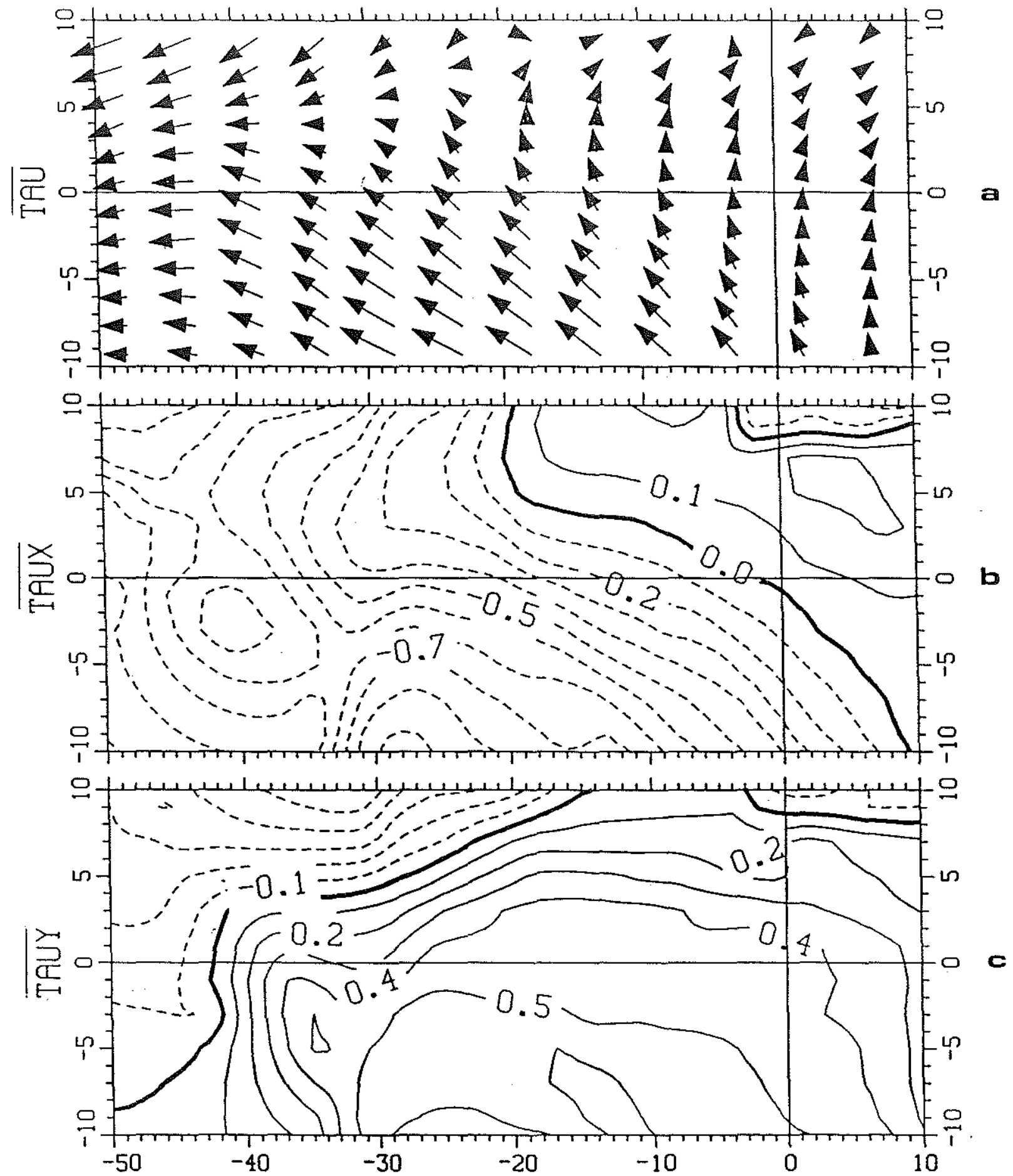

Figure 44: Annual average of the wind stress field $\left(10^{-1} \mathrm{Nm}^{-2}\right)$ used to force the Atlantic general circulation model (cf Figure 1). Arrow plot of the wind stress vector (a) and contour plots of ifs zonal component $\vec{\tau}(x)$ (b) and its meridional component $\left.\nabla^{\mathrm{y}}\right)^{(\mathrm{c})}$ between $50^{\circ} \mathrm{W}$ and $10^{6} \mathrm{E}, 10^{\circ} \mathrm{S}$ and $10^{\circ} \mathrm{N}$. 
206 


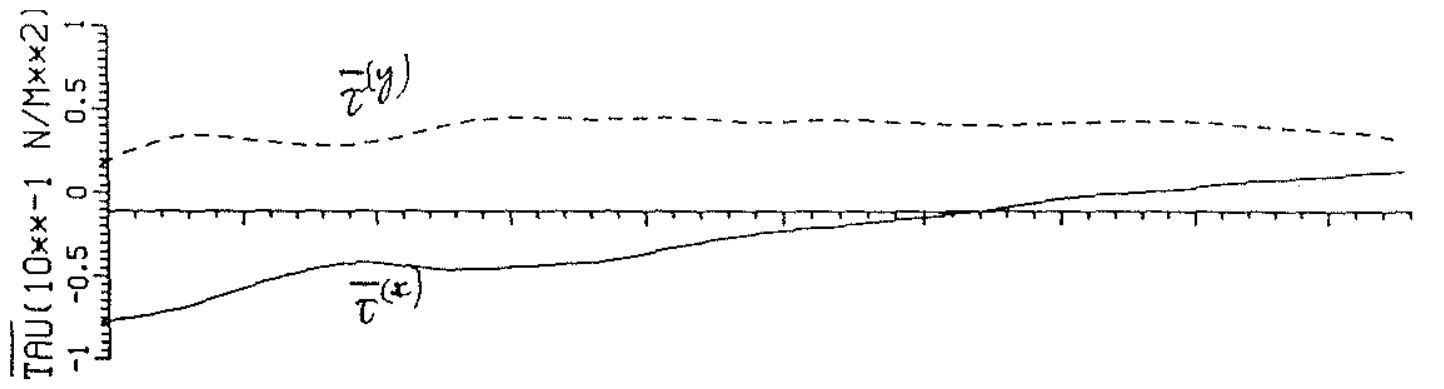

a

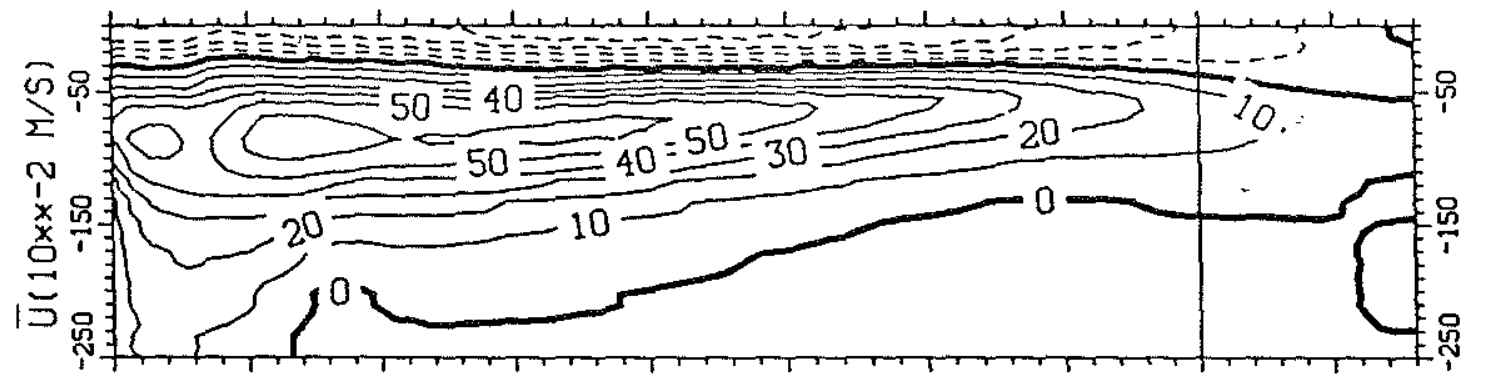

$\mathbf{b}$

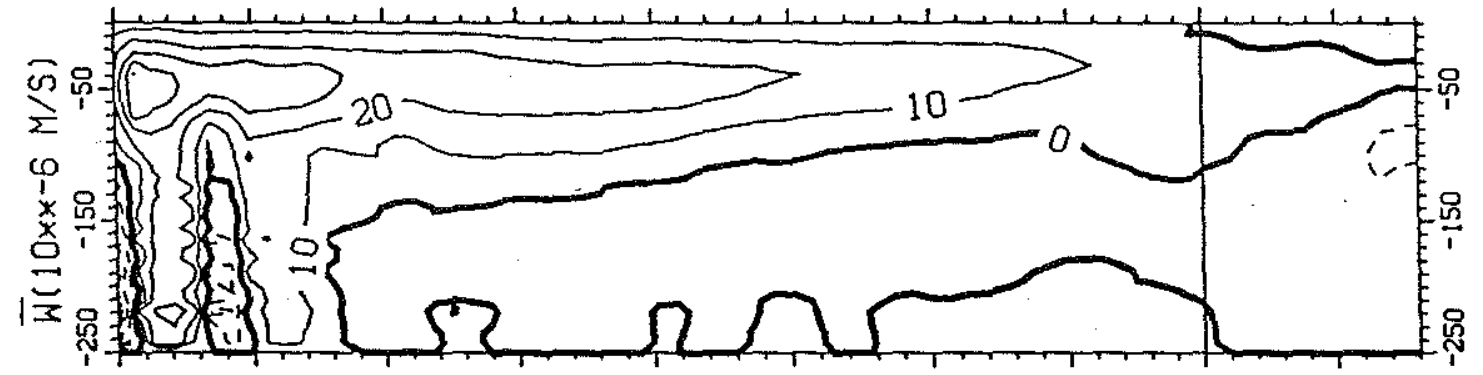

c
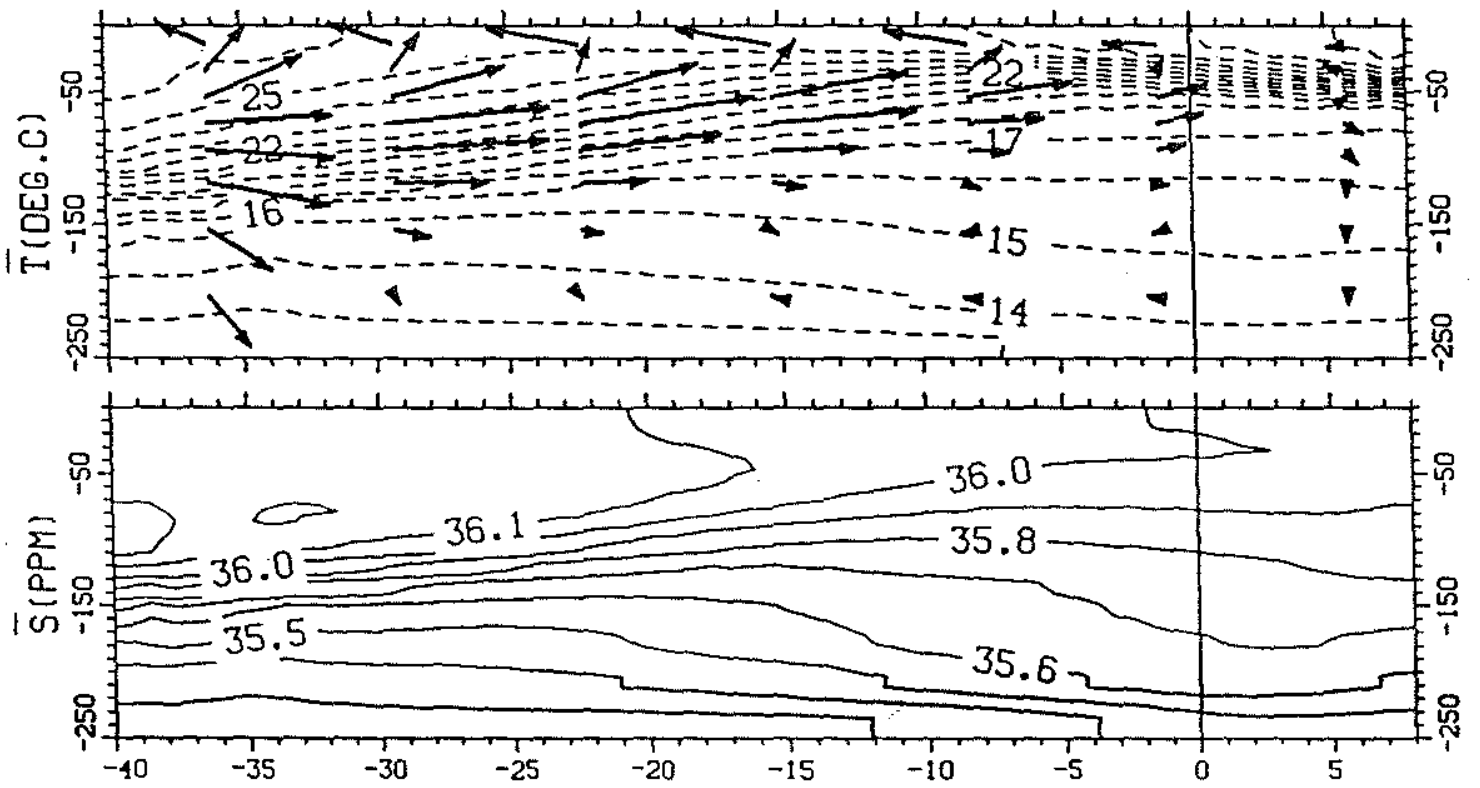

Figure 45: Equatorial sections of the annually averaged zonal velocity $\bar{u}$ (b), vertical velocity $\bar{w}(c)$, temperature $T(d)$ and salinity $\bar{S}$ (e) from the GCM simulation between $40^{\circ} \mathrm{W}$ and $8^{\circ} \mathrm{E}$ above $250 \mathrm{~m}$. The zonal (solid) and meridional (dashed) components of the annual mean wind stress at the equator are plotted in (a) as a function of longitude. A vector plot of the $(\bar{u}-\bar{w})$ circulation is superimposed on the isotherms $(d)$. 
The large difference in typical residence times so obtained for the EUC water above and below the thermocline also suggests that, in order to account for the existence of a still swift eastward flow at relatively shallow subsurface levels east of $20^{\circ} \mathrm{W}$, water needs to be fed into the EUC laterally along the equator to compensate for the rapid vertical 10ss: as will be developed in the following section, the source for the upper EUC waters is indeed longitudinally distributed rather than concentrated in the west.

The zonal pattern of vertical velocity most closely reflects that of the zonal wind stress: maximum west of $30^{\circ} \mathrm{W}$, monotonic decrease eastwards, surface reversal east of $2^{\circ} \mathrm{W}$. The westward surface flow is maximum between $25^{\circ} \mathrm{W}$ and $15^{\circ} \mathrm{W}$ rather than above the maximum of W. It weakens east of $15^{\circ} \mathrm{W}$ but on the annual mean it is still westwards over most of the eastern Gulf of Guinea where zonal wind and surface vertical velocity have changed sign. For the EUC, one can roughiy distinguish three regions in longitude: a narrow region of zonal acceleration $\left(u_{x}>0\right)$ west of about $30^{\circ} \mathrm{W}$, a region more uniform with 1 ongitude, and a region of zonal deceleration $\left(u_{x}<0\right)$ in the east. Above the EUC core, say at the $45 \mathrm{~m}$-level on Figure $45 \mathrm{~b}$, the zonally decelerating region is concentrated east of $10^{\circ} \mathrm{W}$ in the Gulf of Guinea. Below the EUC core, say at the $95 \mathrm{~m}-1$ evel on Figure 45b, the region of zonal deceleration starts around $30^{\circ} \mathrm{W}$ with the sloping up of the isotachs. As we will see better later, there is however a tendency for part of the lower flow to conserve its zonal momentum along $(u, w)$ 1ines. What we are describing so far is horizontal deceleration with longi tude.

In their diagnostic of the mean circulation in the central Pacific, Bryden and Brady (1985) describe an along-isotherm eastward upwelling of the EUC core (section 1.4.2.1). To see whether that result holds in the numerical simulation of the central Atlantic, zonal slopes of $w / u$ at various levels were compared to those of the closest isotherms at $0^{\circ} \mathrm{N} 25^{\circ} \mathrm{W}$. Above $85 \mathrm{~m}$ where the EUC core 1 ies, $w / \mathrm{u}$ was found larger than the isotherms' slope. Around $25 \mathrm{~m}$ where $w$ is maximum this corresponds to a positive cross-isotherm component as large 
as $16 \times 10^{-6} \mathrm{~m} / \mathrm{s}$, or 80 percent of the $10 \mathrm{cal} w$. Below the core, w/u was found to be less than the isotherms' slope, implying a negative cross-isotherm component. Right around the core, the slopes were simi$1 \mathrm{ar}$, and the core water at $0^{\circ} \mathrm{N} 25^{\circ} \mathrm{W}$ can indeed be described as flowing along an isotherm. Orders of magnitude for $w$ and for the crossisotherm flow also agree with Bryden and Brady's estimates for the central Pacific. Note that this description of the EUC core flowing along isotherms does not hold at all longitudes in the model results since, as already mentioned, the core of the simulated EUC is found above the thermocline in the west, and below in the east.

Circulation in the $x-\underline{y}$ plane: According to Figure 45b, the core of the EUC at the equator typically 1 ies between 55 and $75 \mathrm{~m}$. Horizontal maps of the $x-y$ circulation averaged between those two levels are presented on Figure 46. In a, the horizontal pattern of the zonal wind stress is reproduced between $3^{\circ} \mathrm{S}$ and $2^{\circ} \mathrm{N}, 38^{\circ} \mathrm{W}$ and $9^{\circ} \mathrm{E}$. All quantities in $b, c$, and $d$ are drawn over the same horizontal domain and they are averaged over the three model levels 55,65 and $75 \mathrm{~m}$. In $\mathrm{b}$, a vector plot of the $x-y$ circulation is superimposed onto the horizontal pattern of salinity. In $c$, and $d$, contour plots of the zonal and meridional velocities are shown.

West of $15^{\circ} \mathrm{W}$ on Figure $46 \mathrm{~b}$, one can see a clear pattern of water converging towards the EUC from higher latitudes and veering eastwards as it does so. The existence of an equatorial salinity maximum is also clearly illustrated. In that region, the core of the EUC is located at about $1 / 2^{\circ}$ latitude south of the equator $(c)$. The western meridional asymmetry is probably an upwind shift of the core due to the southerly component of the wind: surface water pushed frictionally northwards, subsurface water returned southwards by the opposing meridional pressure gradient force (section 1.2 ). Why then not observe a similar shift of the core in the east, where $\tau^{(y)}$ has values similar to those in the west? Probably because the effect of the meridional stress does not penetrate deep enough in the east where a tight shallow 

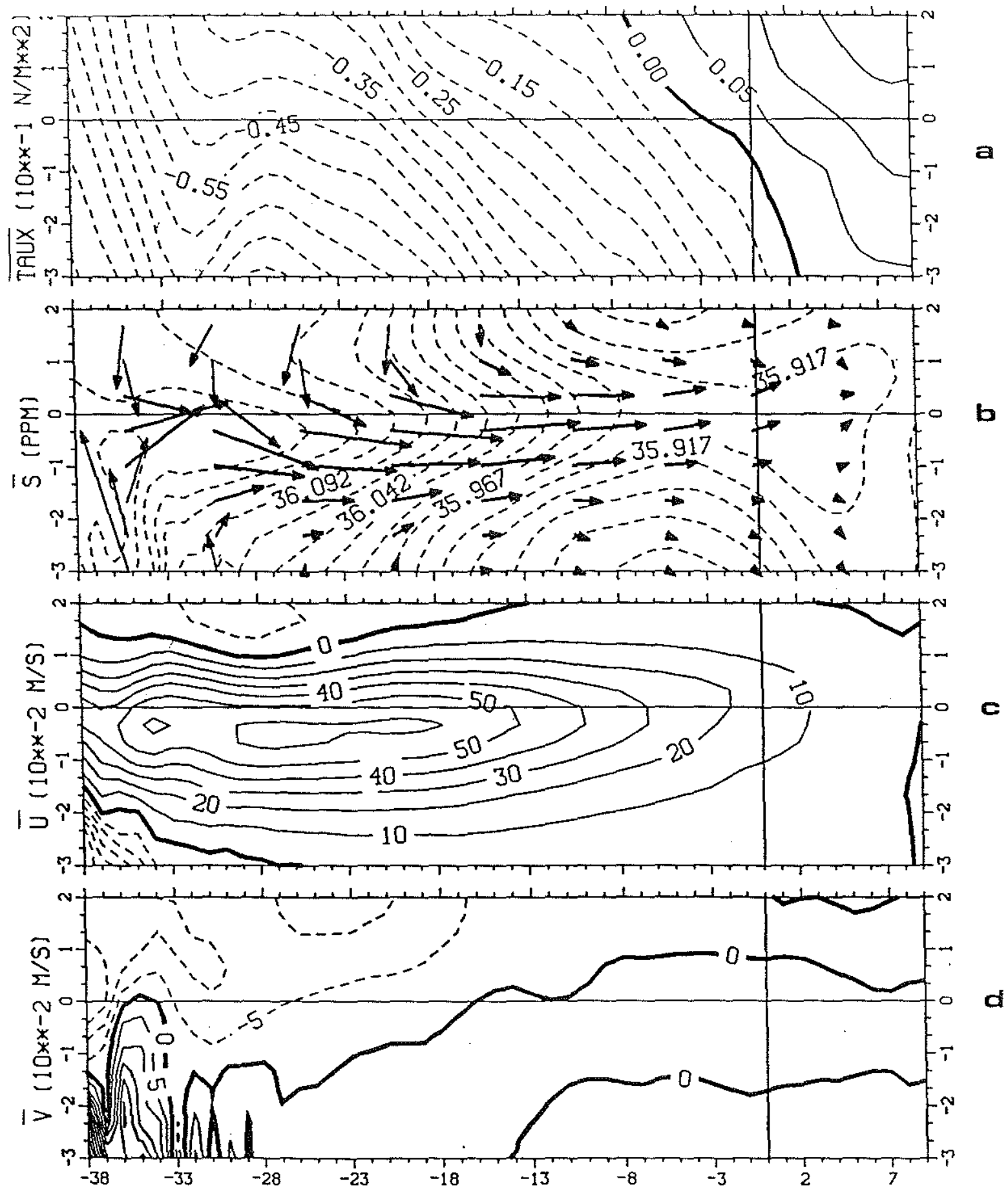

Figure 46: Horizontal section of the annual mean fields of $\bar{\tau}(x)$ (a), $S(b), \bar{u}(c)$ and $v(d)$ from the GCM simulation averaged about the EUC core between 55 and $75 \mathrm{~m}$. 
thermocline shelters what is left of the core. The pressure gradient profiles show this vertical difference (section 3.3).

East of $15^{*} \mathrm{~W}$, the eastward flow south of the equator seems to adopt a southeast course in basic agreement with the salinity pattern (Figure 46b). But the flow north of the equator continues to be equatorwards in disagreement with the salinity pattern which is roughly symmetrical with respect to the equator, suggesting symmetrical southward and northward paths. In fact, velocity vectors converge towards $1^{\circ} \mathrm{N} 5^{\circ} \mathrm{E}$, which is a zone of downwelling.

Figure $46 \mathrm{~b}$ thus shows water coming into the EUC laterally from the north at all longitudes, and from the south west of $15^{\circ} \mathrm{W}$. We have seen on Figure 45 how some of that water upwells out of the EUC into the westward surface current, and how some downwells into a deeper westward flow. Figure 46b now also shows that some water south of the equator and east of $15^{\circ} \mathrm{W}$ leaves the equatorial region southeastwards in agreement with the observational estimates of chapter 2.

Circulation in the $y-\underline{z}$ plane: Figure 47 shows meridional sections of $\mathrm{T}, \mathrm{S}, \mathrm{u}, \mathrm{v}$ and $\mathrm{w}$ at the three longitudes $30^{\circ} \mathrm{W}, 15^{\circ} \mathrm{W}$ and $0^{\circ} \mathrm{E}$. The equatorial bowing of the isotherms characteristic of the presence of a geostrophic eastward flow is clearly seen at $30^{\circ} \mathrm{W}$ and $15^{\circ} \mathrm{W}(\mathrm{a})$. This is not the case at $0^{\circ} \mathrm{E}$ where, as mentioned previously, the thermocline is very tight and lies above the weak core of subsurface eastward flow.

Figure $47 \mathrm{c}$ illustrates again the upwind shift of the EUC core at $30^{\circ} \mathrm{W}$ and $15^{\circ} \mathrm{W}$, its zonal weakening, its apparent upward translation between $30^{\circ} \mathrm{W}$ and $15^{\circ} \mathrm{W}$, and its apparent downward translation between $15^{\circ}, \mathrm{W}$ and $0^{\circ} \mathrm{E}$. Zonal transports (within the $0.10 \mathrm{~m} \mathrm{~s}^{-1}$ isotach) can be roughly estimated as $45 \times 10^{6}, 25 \times 10^{6}$ and $3 \times 10^{6} \mathrm{~m}^{3} \mathrm{~s}^{-1}$ through $30^{\circ} \mathrm{W}, 15^{\circ} \mathrm{W}$ and $0^{\circ} \mathrm{E}$ respectively. These figures illustrate that about 45 percent of the zonal transport present at $30^{\circ}, \mathrm{W}$ has disappeared by $15^{\circ} \mathrm{W}$, and that only about 5 percent of the $30^{\circ} \mathrm{W}$-transport is still present at $0^{a} \mathrm{E}$. 
As one goes east, the pattern of subsurface meridional velocity (d) becomes more symmetrical with respect to the equator while that of vertical velocity (e) becomes less so. This reflects the increasing role of $\tau^{(y)}$ relative to $\tau^{(x)}$. The vertical velocity in the upper layers appears mostly determined by the meridional divergence. In the west, that divergence is mostly due to the poleward Ekman transport driven by the easterlies, in the east it is mostly due to the cross equatorial flows driven by the southerly component of the wind. The $0^{\circ} \mathrm{E}$-section of $w(e)$ also shows the region of subsurface convergence/ downwelling between $0^{\circ}$ and $1^{\circ} \mathrm{N}$ mentioned in the previous paragraph.

\subsubsection{Time dependence}

Three figures were prepared to illustrate the behaviour of the velocity field and of the stratification with time using the threeday averaged model output (120 data points in the year). Figures 48 and 49 present time series of zonal and meridional stress, $u, v, w$ and $\rho_{s}$ [the density $\left(\rho-\rho_{0}\right)$ relative to the surface] as a function of depth at $0^{\circ} \mathrm{N} 25^{\circ} \mathrm{W}$ with and without the fall thirty-day instability waves respectively. Thick dots indicate the location of the largest vertical gradient of density. Figure 50 presents similar plots at $0^{\circ} \mathrm{N}$ $0^{\circ} \mathrm{E}$. The amplitude of the zonal wind stress is much less at $0^{\circ} \mathrm{E}$ than at $25^{\circ} \mathrm{W}$, and so is the amplitude of its time variations. But instead of being easterly year-round as at $25^{\circ} \mathrm{W}$, the wind at $0^{\circ} \mathrm{E}$ changes direction in the course of the year, and this results in more spectacular seasonal changes in the circulation and in the stratification at $0^{\circ} \mathrm{E}$ than at $25^{\circ} \mathrm{W}$.

At $25^{\circ} \mathrm{W}$ (Figure 48 ), the core of the EUC is found closest to the surface $\lfloor 65 \mathrm{~m})$ in the spring, after a period of weak southeasterlies which leave the westward surface flow considerably weakened. On the contrary, the core is found at its deepest level $(95 \mathrm{~m})$ in the fall, after a period of strong southeasterlies which leave the surface flow considerably intensified (b). This apparent up and down motion of the core cannot be described as a simple vertical translation of an isolated vein of subsurface eastward flow (decrease of amplitude at a 

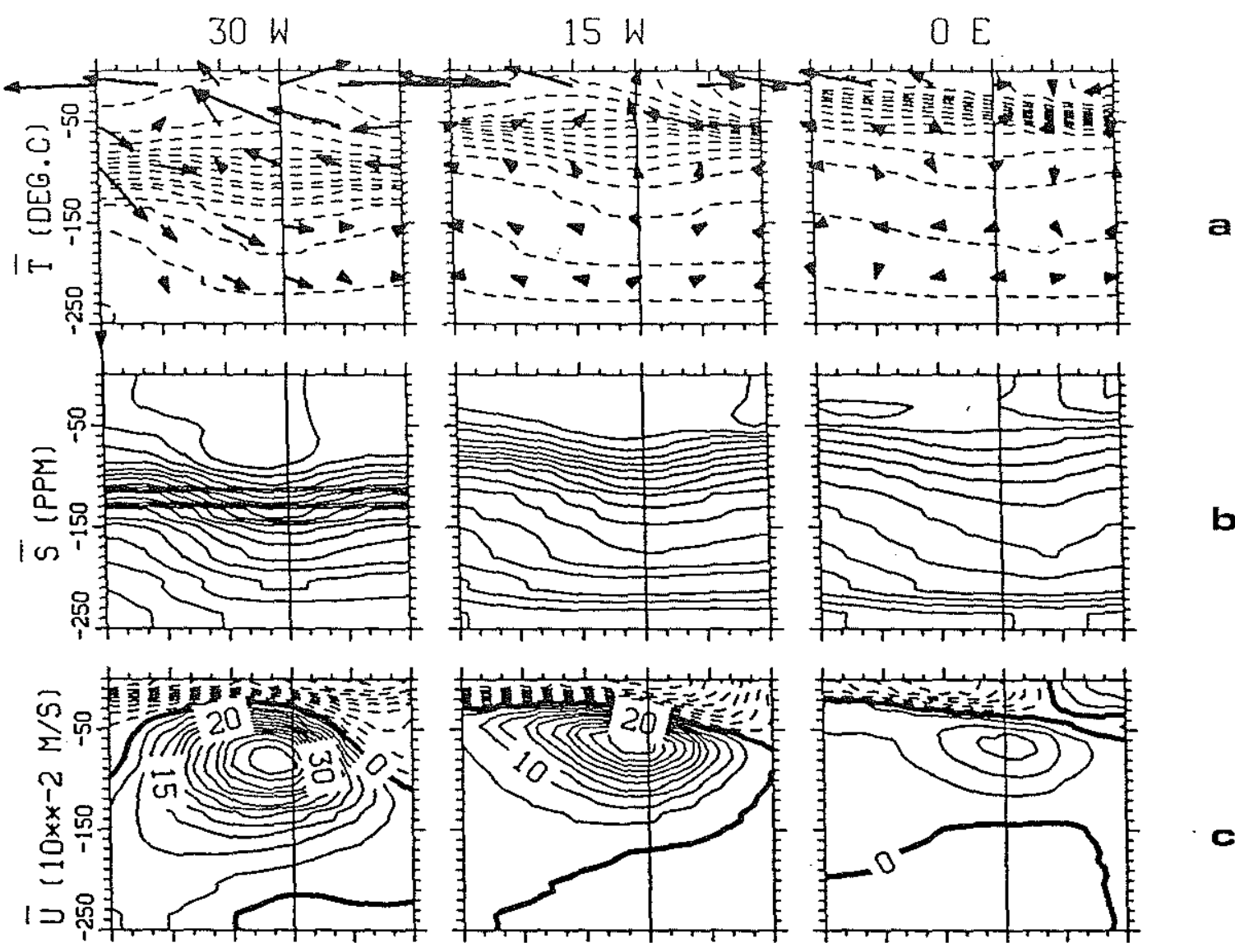

$\mathbf{b}$
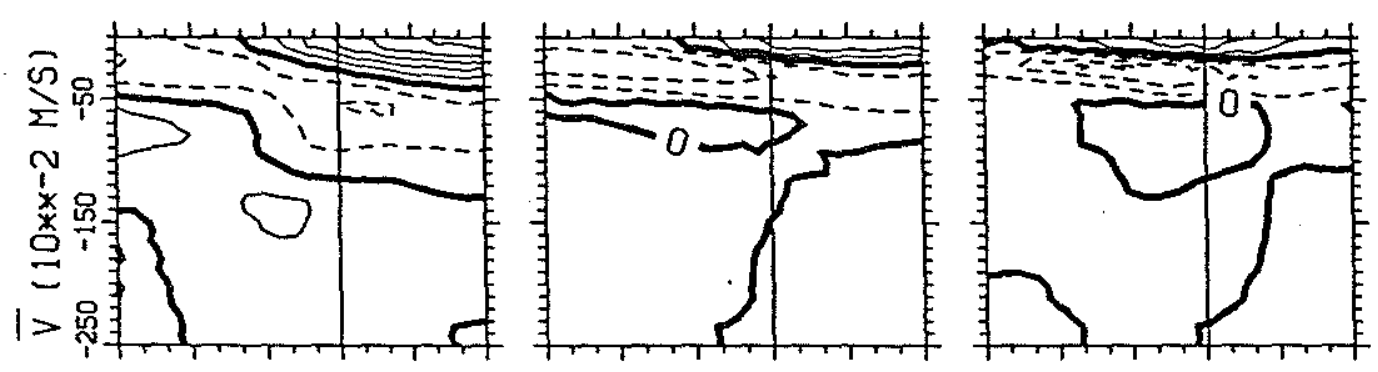

c
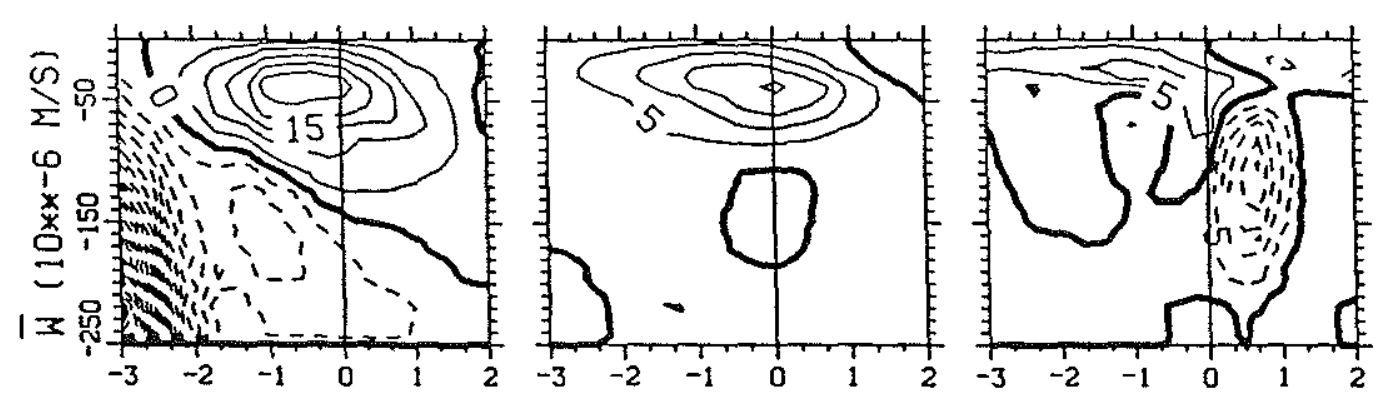

d

e

Figure 47: Meridional sections of annually averaged temperature $\vec{T}(a)$, sal inity $\bar{S}(b)$, and velocity components $\bar{u}(c), \bar{v}(d)$ and $\bar{w}(e)$ at $30^{\circ} \mathrm{W}$ (left), $15^{\circ} \mathrm{W}$ (center), $0^{\circ} \mathrm{E}$ (right) from the GCM simulation between $3^{\circ} \mathrm{S}$ and $2^{\circ} \mathrm{N}$ aboye $250 \mathrm{~m}$. Contour $\mathrm{l}$ ines are $1^{\circ} \mathrm{C}$ for $\mathrm{T}_{\text {, }}$ $0.05^{\circ} / 0$ for $\overline{\mathrm{S}}, 5 \times 10^{-2} \mathrm{~m} \mathrm{~s}-1$ for $\overline{\mathrm{u}}$ and $\overline{\mathrm{v}}, 5 \times 10^{-6} \mathrm{~m} \mathrm{~s}^{-1}$ for $\overline{\mathrm{w}}$. 


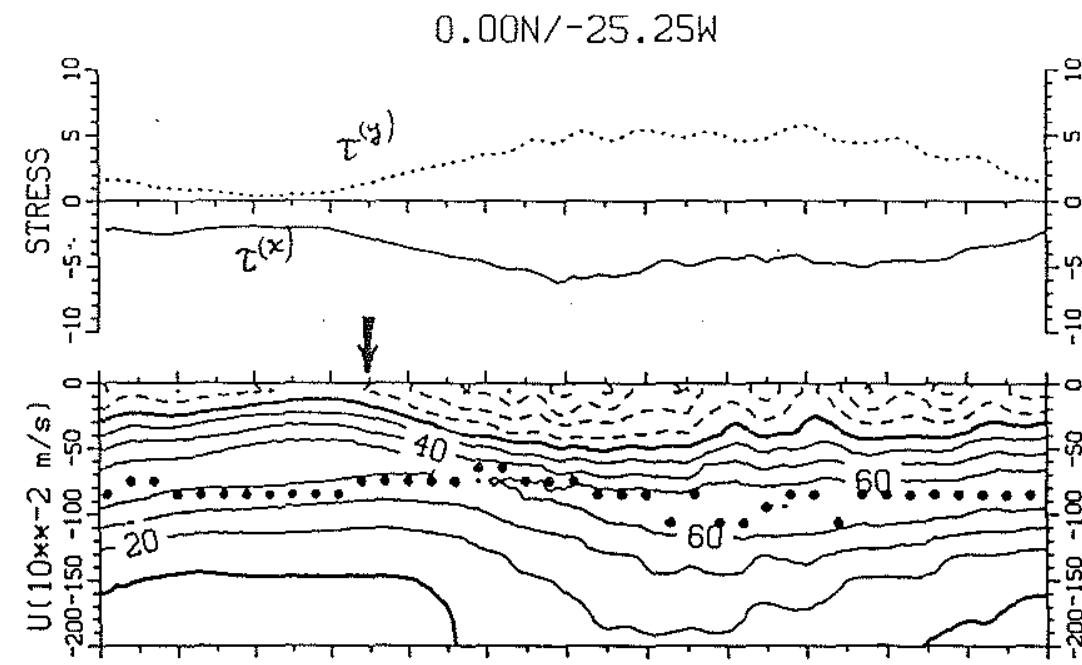

a

$\mathbf{b}$

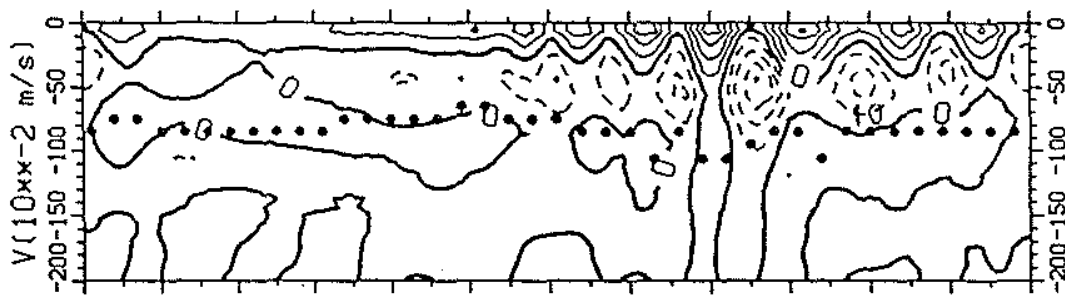

C
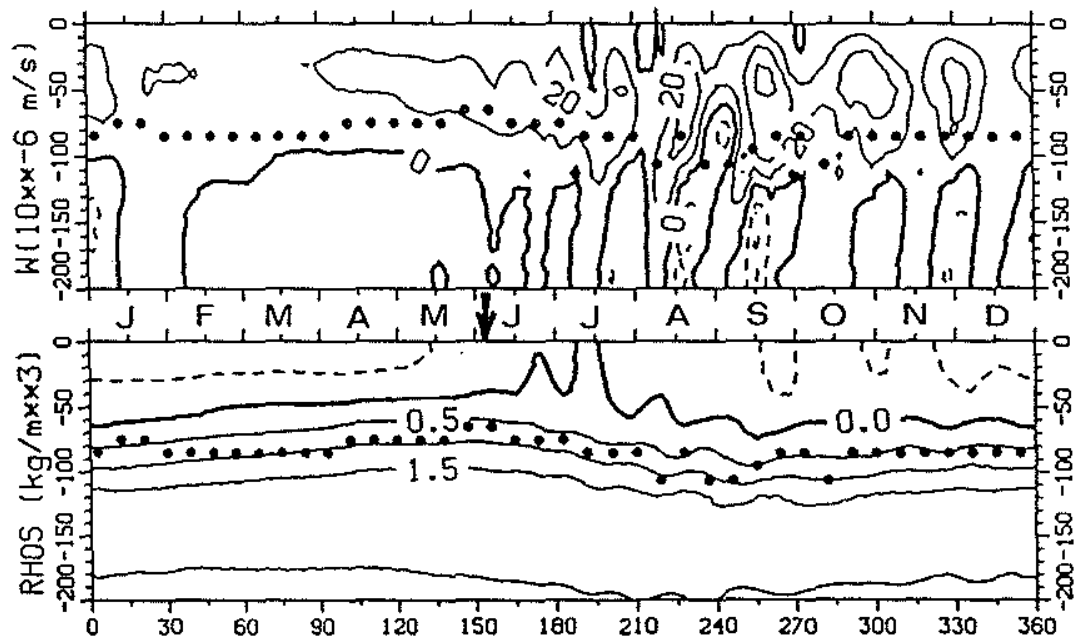

d

e

Figure 48: Time-depth contour plots of the simulated fields of zonal

(b), meridional (c), and vertical (d) velocities, and density referenced to the surface (e) at the equator at $25^{\circ} \mathrm{W}$. The time evolution of the zonal (solid) and meridional (dashed) stress at $15 \mathrm{~m}$ ( in $10^{-1} \mathrm{Nm}^{-2}$ ) is plotted in (a).

Arrows at mid-April in (b) and at the beginning of June in (e) indicate the start of the deepening of the isotachs and isopycnals respectively in response to the wind stress increase which starts at the beginning of April (a).

Note the presence of 30 -day waves during the fall, especially on the fields of $v(c)$ and $w(d)$. 
given upper level, increase of amplitude at some lower level, leaving the maximum unchanged): the zonal velocity maximum does experience some (sma11) variations during transitional periods ( \pm 15 percent of $0.65 \mathrm{~m} / \mathrm{s}$ ), and the deep flow below $150 \mathrm{~m}$ reverses sign seasonally, resulting in important changes in the vertical structure of the eastward flow.

By comparing (b) and (e) on Figure 48 , one can see that the spring deepening of the EUC precedes that of the thermocline: the deepening of the core starts in April with the increase of the wind stress, while the deepening of the thermocline starts only around the end of May (see arrows). This observation suggests that, in the model, the adjustment time of the density field to variations in the dynamical forcing is of the order of one and a half months, while frictional stresses adjust instantaneousiy. Comparisons with data are presented in chapter 4.

During the second half of the year, the variations with time of the meridional and vertical components of velocity are dominated by the presence of waves with a period of the order of a month (Figure $48 \mathrm{c}, \mathrm{d}$ ). These waves also have a signature in the surface westward flow (b), but they are not evident on the stratification (e), nor on the zonal velocity below the surface flow (b). According to Philander and Pacanowski (1986a) and to Philander, Hurlin and Pacanowski (1986), these waves are partly the result of an instability associated with the latitudinal shear of the zonal equatorial currents. It is not the purpose of this thesis to study them, and whenever possible, they will be smoothed out. Figure 49 thus shows the same fields as Figure 48 after a one-month running average has been applied. The oscillations are no longer visible and the fall (when both components of the wind forcing are stronger) appears to be on average a period of stronger meridional circulation.

At $0^{\circ} \mathrm{E}$ (Figure 50 ), the whole vertical structure of the zonal circulation appears to respond to the zonal wind stress reversals. Paradoxically, the EUC is strongest in January and September when $\tau(x)$ 
and the surface current are both reversed towards the east. Despite the fact that the resulting eastward flow still has a subsurface core rather than being surface-intensified, this is reminiscent of the fast "frictional" response described by Cane (1980) in relation with the Indian 0cean EUC. In that paper, the existence of subsurface eastward flow in the presence of westerlies is explained by the fact that the surface current itsel $f$ is eastward and the off equatorial Ekman flow convergent, resulting in downwelling at the equator and downward advection of the surface eastward momentum. After the June weakening of the EUC (b) corresponding to strong upwelling $(d, e)$, the abrupt September intensification of the EUC (b) [as the zonal wind stress becomes westerly (a)] indeed coincides with a brief period of strong downwelling $(d, e)$. Notice though how the shallow and tight thermocline separates the 45 m-thick surface flow from the subsurface eastward core.

0ther noticeable features of Figure 50 are the strong vertical shear which develops in the meridional flow in July-August (c), the June-July reversal of the mean westward flow below the EUC (b) (which occurs at about the same time as at $25^{\circ} \mathrm{W}$, but is more spectacu$\mathrm{lar}$ at $0^{\circ} \mathrm{E}$ because it produces a pattern of seasonal variations out of phase with that of the EUC), and the absence of 30-day waves.

\subsection{Dynamical analysis of the general circulation model}

In order to gain some insight into the mechanisms causing the spatial and temporal variations of the EUC, it was decided to analyze the spatial and temporal variations of the various terms of the zonal momentum balance (ZMB). It is understood that the value of the EUC velocity at any point and time does not derive directly from the knowledge of the balance of forces at that same point and time: what one obtains are acceleration terms. But by knowing the distances and time intervals over which these accelerations act, one obtains velocity changes which in turn should provide information on the formation, termination and seasonal variations of the EUC. The approach also allows one to address directly such questions as: what forces an EUC in the 


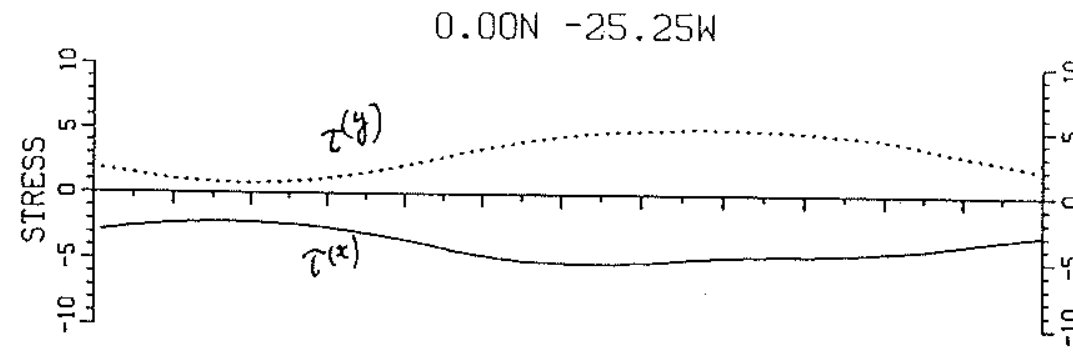

a

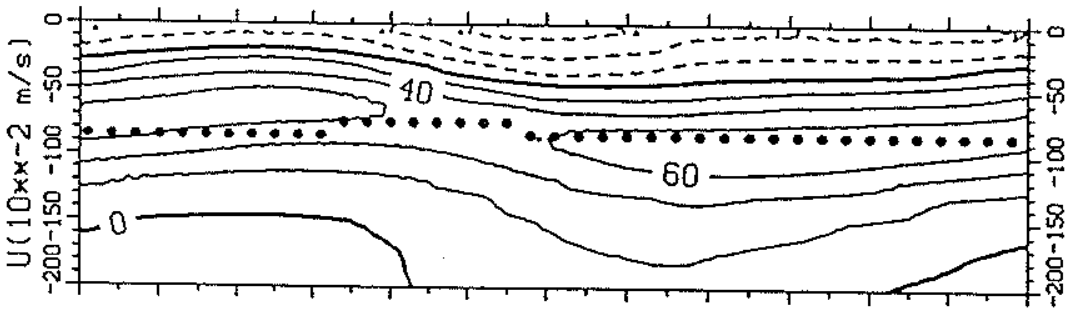

b

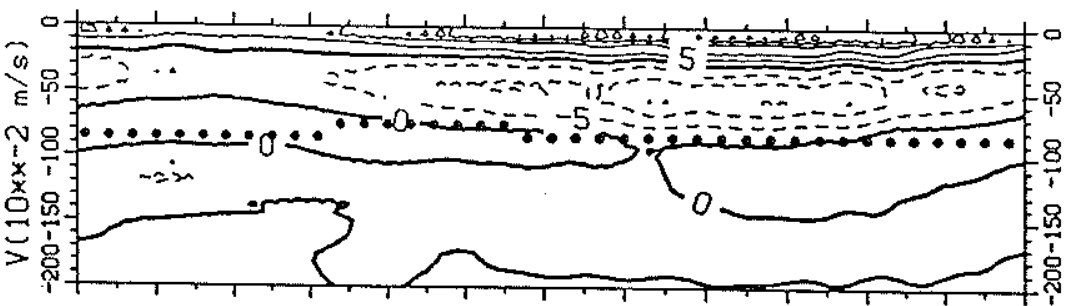

$c$

d
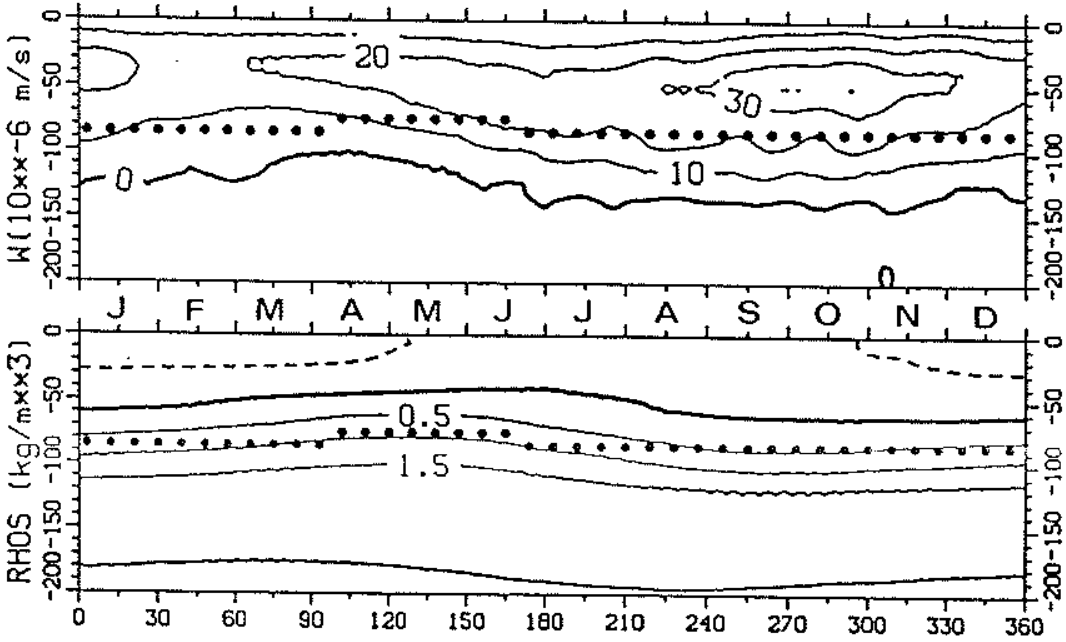

Figure 49: Same as Figure 48 after a one-month running average has been applied to all fields. 
$O^{\circ} N O^{\circ} E$

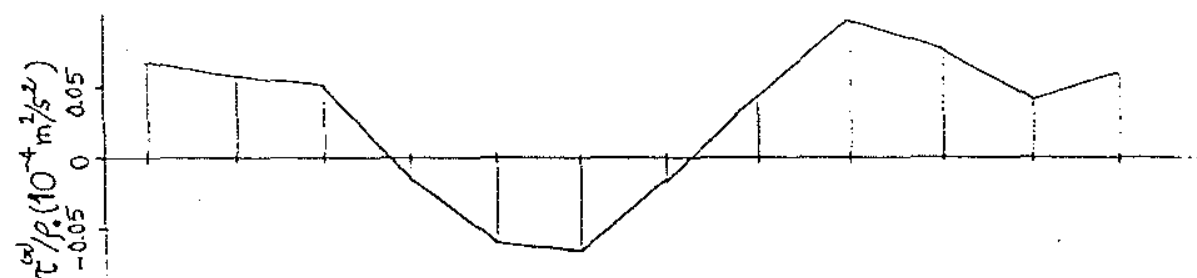

a
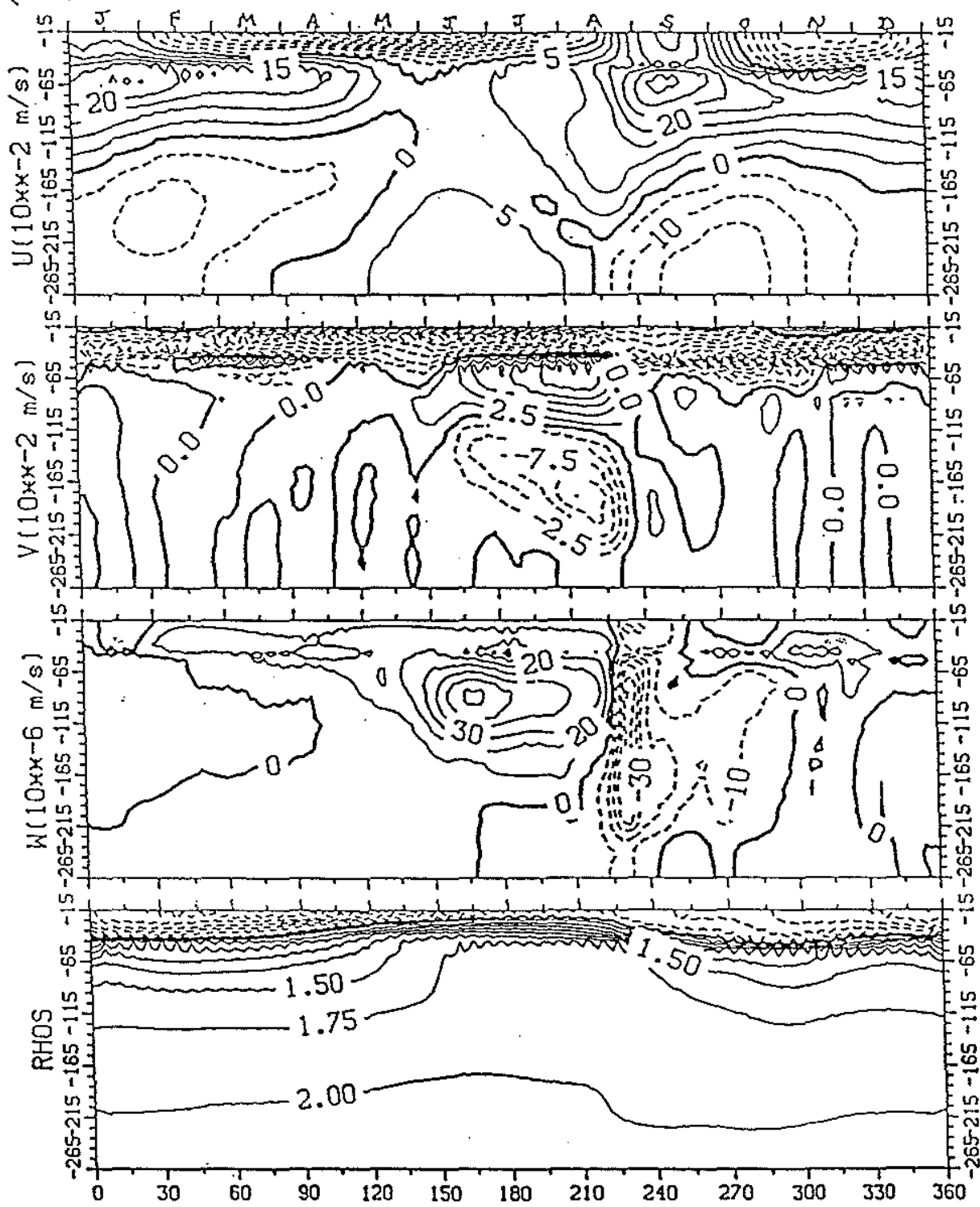

d

e

Figure 50: Same as Figure 48 but at $0^{\circ} \mathrm{E} . \quad$ Only $\tau^{(x)}$ is represented in (a). 
eastern Gulf of Guinea where the wind becomes westerly and the ZPG seems to reverse?

The ZMB can be written:

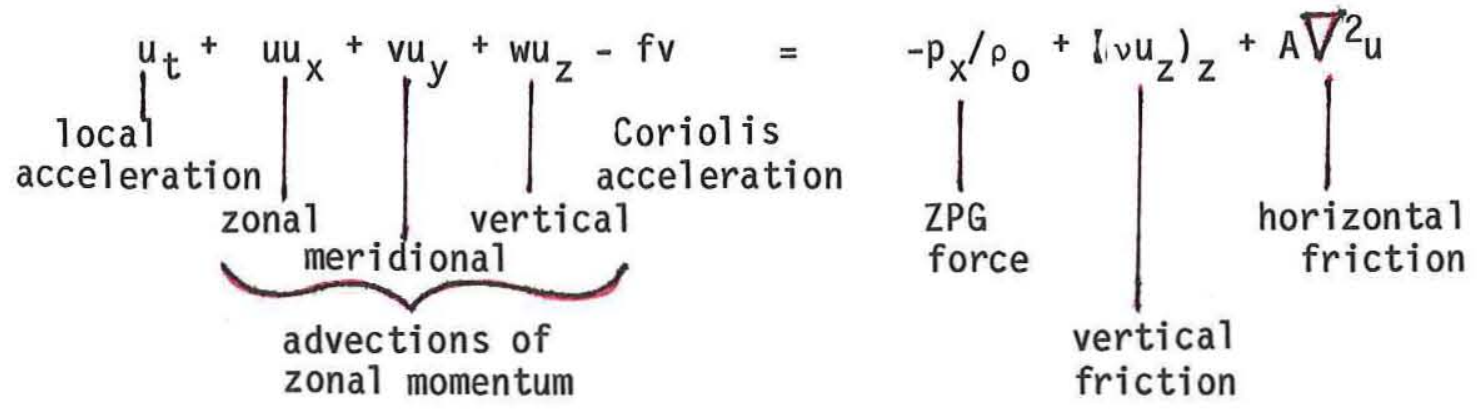

This is the equation that the model uses (in its discretized form) to integrate the zonal velocity in time from an initial value. Each dynamical term was recomputed using the model output of three-day averaged $T, S, u, v, w$ and the same finite difference schemes as in the model's code.

We will first investigate the time-averaged zonal and vertical structure of the ZMB (sections 3.3 .1 and 3.3.2), before attempting to look at its local time variations (section (3.3.3). And we will first describe the mean annual ZMB along the equator (section 3.3.1) before looking at its meridional structure at various longitudes (section 3.3.2). Because the core of the EUC is generally displaced slightly south of the equator (Figure 46c) meridional fluxes are present at $0^{\circ} \mathrm{N}$.

\subsubsection{Zonal evolution of the annually averaged_ZMB_along_the} equator

The mean annual ZMB was obtained by accumulating and averaging each of its terms over a full seasonal cycle. By definition, one thus gets $\overline{u_{t}}=0$, and the balance, expressed at the equator, reduces to the six terms:

$$
\overline{u u_{x}}+\overline{v u_{y}}+\overline{w u_{z}}=\overline{-p_{x} / \rho_{0}}+\overline{\left.i v u_{z}\right)_{z}}+\overline{A \nabla^{2} u} .
$$

In the following, we will be discussing the longitudinal and vertical structure of these six terms along $0^{\circ} \mathrm{N}$, 10oking for 
regions where some of them become negligible compared to the others. Given the confusing number of variables and parameters involved, let us begin with the cartoon-like summary drawn on Figure 51 . Five different dynamical regimes and their geographical 1 imits are indicated:

- The middle of the thermocline (i.e. the location of largest vertical gradient of density) roughly separates the upper regimes (1) and (3) where vertical friction is important from the lower regimes (2) and (4) which are shel tered from direct wind influence.

- The $30^{\circ} \mathrm{W}$ longi tude approximately separates western regions (1) and (2) where the EUC accelerates eastwards, from the central. and eastern regions (3) and (4) where the EUC loses eastward momentum with longitude. The loss of eastward momentum is due to vertical exchanges with the overlying westward flow in the upper thermocline (3) and to lateral friction in the lower thermocl ine (4).

$-2^{\circ} \mathrm{W}$ is the longitude at which the zonal wind stress reverses from easterly over (3) to westerly over (5), forces a reversal of the ZPG force from eastwards to westwards, and thus brings the remaining upper thermocl ine eastward flow to a total halt (even though the surface layer starts being exposed to an eastward stress). Those reversals do not affect the eastern lower thermocl ine regime.

Admittedly, Figure 51 is a very crude interpretation of the results of this section. A closer look quickly reveals that defining geographical boundaries to dynamical regimes is not straightforward, especially in deep and eastern regions where all terms become small and difficult to differentiate. However, it is helfpul to keep this cartoon in mind while examining the details of the analysis.

Figure 52 shows series of vertical profiles of the six terms of the mean annual ZMB between 0 and $150 \mathrm{~m}$ at nine equidistant longitudes across the basin, from $35^{\circ} \mathrm{W}$ to $5^{\circ} \mathrm{E}$. Al1 the profiles are drawn to the same scale in order to appreciate their zonal evolution 


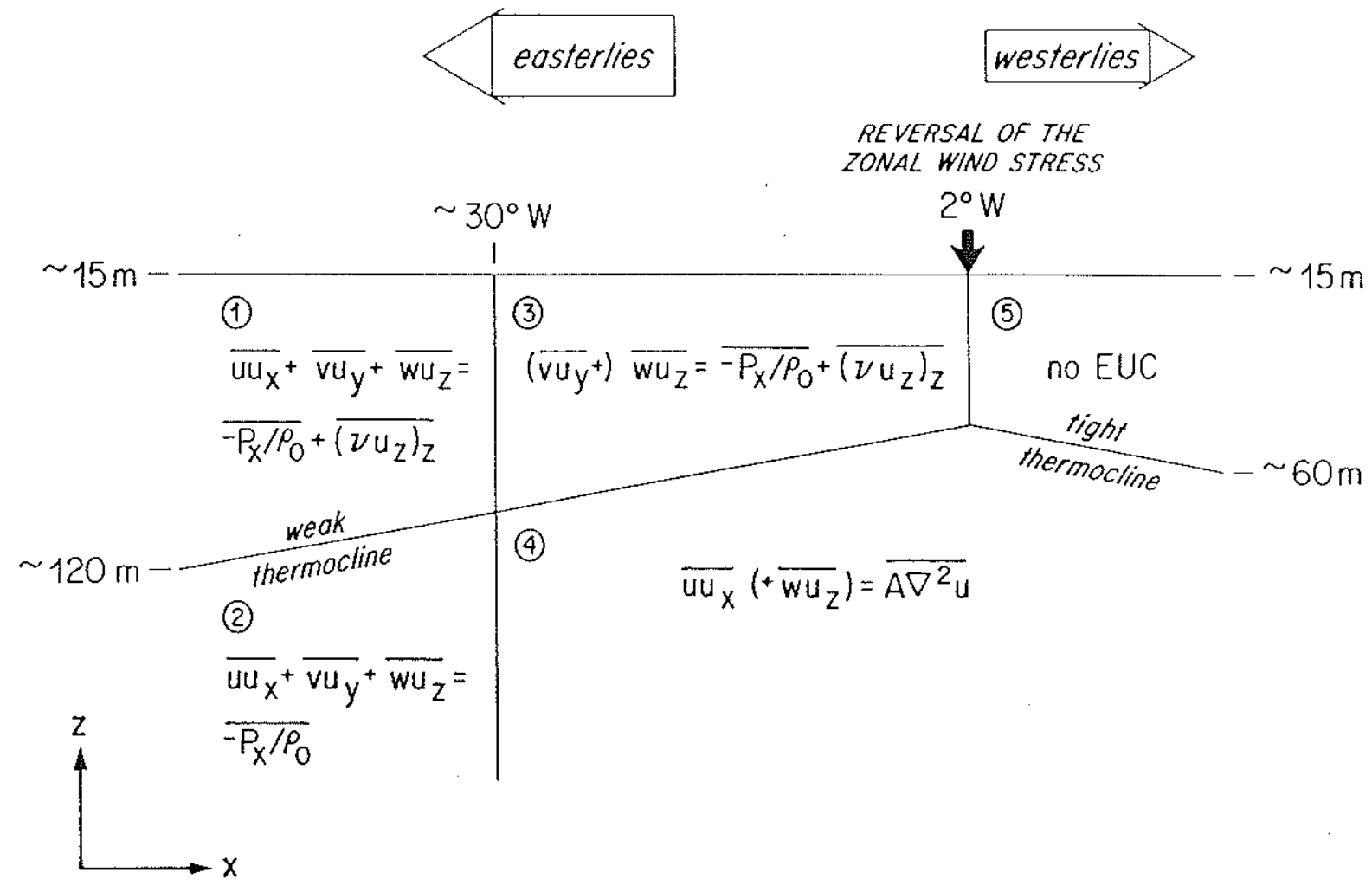

Figure 51: Schematic summary of the various dynamical regimes found in the simulated undercurrent and characterized by different approximations of the zonal momentum balance.

1. inertio-frictional; zonal acceleration

2. inertial; zonal acceleration

3. inertio-frictiona 1 ; strong zonal deceleration by vertical friction

4. inertio-frictional; weaker zonal deceleration by lateral friction

5. reversed pressure gradient; no undercurrent. 


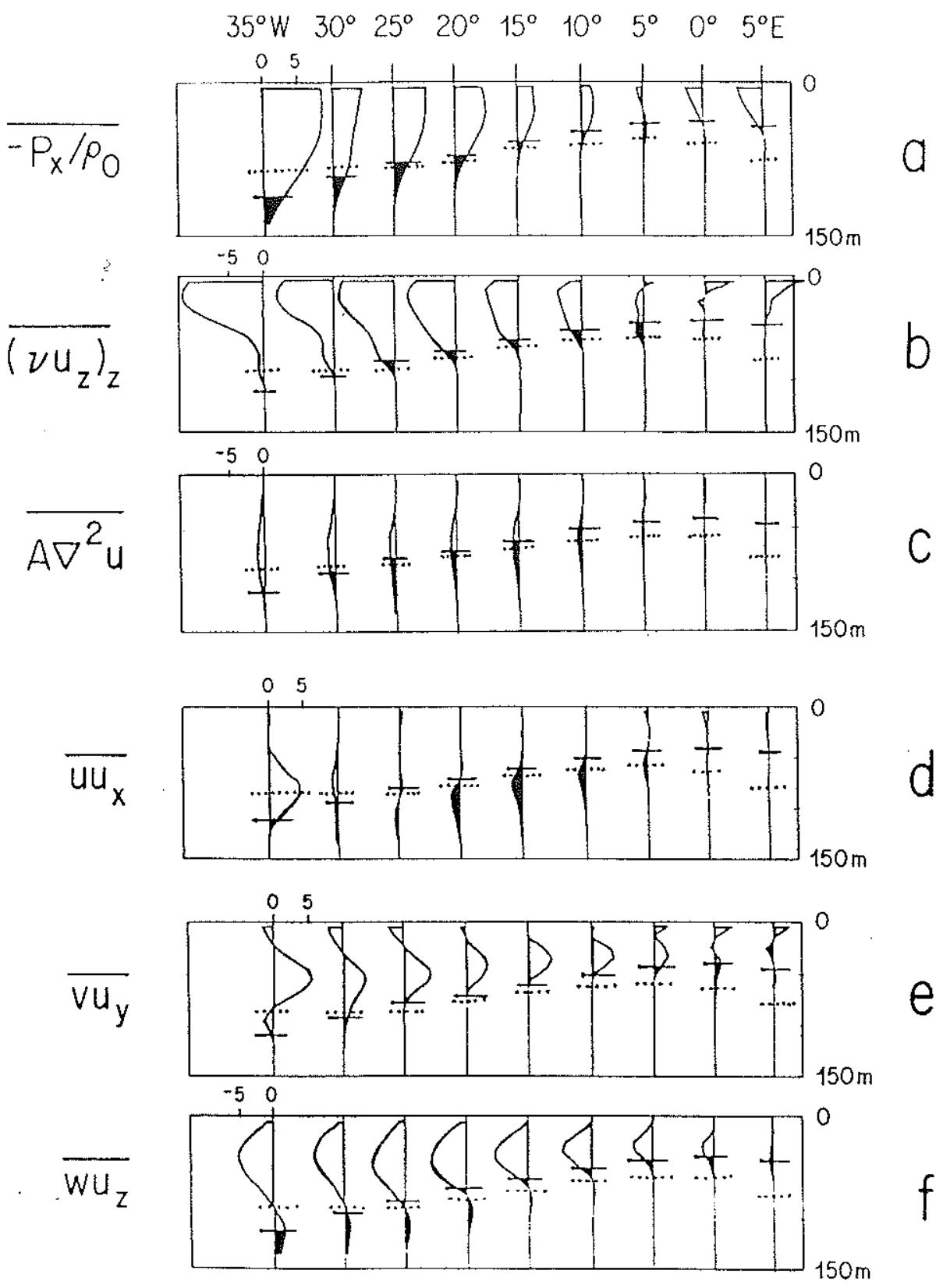

Figure 52: Vertical profiles of the terms of the annually averaged zonal momentum balance at $0^{\circ} \mathrm{N}$ at nine equally spaced longitudes between $35^{\circ} \mathrm{W}$ and $5^{\circ} \mathrm{E}$. The dotted line indicates the location of the EUC core, the solid line that of the center of the thermocl ine. 
and to intercompare their magnitudes. On each profile, the vertical location of the EUC core is indicated by a dotted line and that of the middle of the thermocline by a solid line, below which the profiles are shaded. Note again how the thermocline slopes up to about $0^{\circ} \mathrm{E}$ and down farther east, and how the core of the EUC is found above the thermocline west of $25^{\circ} \mathrm{W}$ and below it from $25^{\circ} \mathrm{W}$ eastwards. Note also the way in which the profiles are confined to shallower and shallower levels as $x$ increases, reflecting the zonal changes in the thermocline depth. At first glance, the largest terms over most of the basin are $\left.\overline{\left(-p_{x} / \rho_{0}\right.}\right), \overline{\left(v u_{z}\right)}, \overline{\left(v u_{y}\right)}$ and $\overline{\left(w u_{z}\right)}$ (Figure $\left.52 a, b, e, f\right)$. The 1 arge values of these terms are, however, mostly confined to the upper thermocline levels below a $15 \mathrm{~m}$-thick surface layer [where $\left(-\mathrm{p}_{\mathrm{x}} / \mathrm{\rho}_{0}\right)$ and $\overline{\left(v u_{z}\right)_{z}}$ usually dominate]. In the lower thermocline, $\overline{\left(v u_{z}\right)_{z}}$ and $\left(v u_{y}\right)$ become mostly negligible, while $\left(A \nabla^{2} u\right)$ and $\overline{\left(u u_{x}\right)}$ (c and $d$ ) become relatively more important. Another striking feature of Figure 52 is the tendency for $\overline{\left(-p_{x} / \rho_{0}\right)}$ and $\overline{\left(v u_{z}\right)_{z}}$ on the one hand, and for $\left(\overline{\left.v u_{y}\right)}\right.$ and $\overline{\left(w u_{z}\right)}$ on the other, to somewhat balance in the upper thermociine. There is also a tendency for $\overline{\left(u u_{x}\right)}$ and $\overline{\left(w u_{z}\right)}$ to balance in the lower thermocline. This is better illustrated in Figure 53, which reproduces these terms by pairs followed by their sum. Again, the location of the EUC core is indicated on each profile by a dotted line, and that of the middle of the thermocline by a continuous 1 ine.

Let us now use Figure $53 a, b$ to discuss the zonal evolution of the forcing terms in the upper thermocline east of $25^{\circ} \mathrm{W}$ [regions (3) and (5) on Figure 51]. In these regions, the sum of the ZPG force and of the vertical friction terms corresponds to a net deceleration (b). As $x$ increases and $\left|\tau^{(x)}\right|$ decreases, both $\left|\left(\overline{-p_{x} / \rho_{0}}\right)\right|$ and $\mid\left(v u_{z} z_{z} \mid\right.$ decrease until they change sign with the zonal wind between $5^{\circ} \mathrm{W}$ and $0^{\circ} \mathrm{E}$. East of $5^{\circ} \mathrm{W}$, both terms still tend to balance above the thermocline, but they have switched roles: $\left(-p_{x} / \rho_{0}\right)$ has become a westward force and $\overline{\left(v u_{z}\right)_{z}}$ an eastward one. Below a thin surface layer, their sum is dominated by the reversed ZPG force and therefore continues to be negative, more so, in fact, than slightly upstream. Note however that no reversal occurs in the lower thermocline where $\overline{\left(-p_{x} / \rho_{0}\right)}$ and $\overline{\left(\nu u_{z}\right)_{z}}$ 
tend to add up to a zero net acceleration at most longitudes east of $25^{\circ} \mathrm{W}$. Looking now west of $25^{\circ} \mathrm{W}$, one can see that the vertical profiles of $\overline{\left(-p_{x} / \rho_{0}\right)}$ and $\overline{\left(\nu u_{z}\right)_{z}}$ are not at all symmetrical at depth $(a)$ : the accelerating effect of the eastward ZPG force penetrates considerably deeper than the retarding frictional effect of the westward surface current. At $35^{\circ} \mathrm{W}$ (b) and further west (shown later on Figure 55), a large net eastward acceleration results at depth below a region of westward acceleration, very much in agreement with Arthur's (1960) description of the balance of forces in a continuously stratified equatorial ocean (section 1.2).

So in this mode1, only in the westernmost basin [region (1)] can one talk about the ZPG directly forcing an undercurrent in the upper thermocline. Further east [regions (3) and (5)], the ZPG force is either overcompensated by the westward vertical friction term, or it is reversed and dominating the eastward vertical friction; in either case, the net effect is not to favour but to oppose eastward flow, and indeed one observes a rapid erosion with longitude of the eastward flow above the thermocline, and its actual disappearance between $5^{\circ} \mathrm{W}$ and $0^{\circ} \mathrm{E}$ (Figure 54c). At these longitudes [region (5)], the ZPG reversal effectively "gives the last blow" to the already much weakened "upper EUC". Its zonal velocity at a given depth (say $55 \mathrm{~m}$ ) has a longitudinal pattern very well correlated to that of the easterly wind stress (Figure 54a). East of $25^{\circ} \mathrm{W}$ below the EUC core [region (4)], the flow is mostly unforced, as the ZPG is either negligible itself or quickly compensated by the remaining vertical friction (Figure 53b). In particular, the deep flow does not appear to feel at all the eastern reversal of the wind stress. As developed in the following paragraph, the flow in region (4) above the zero line for $w$ (Figure 54e) appears instead to be advecting eastwards and upwards across the basin the value of zonal velocity created west of $25^{\circ} \mathrm{W}$, while being gradually dissipated by lateral friction. In the Gulf of Guinea this deep eastward flow becomes the bulk of the EUC as the layers above have become westwards (Figure 54c). This description ignores on purpose the thin region between the thermocline and the EUC core, which appears to be a 


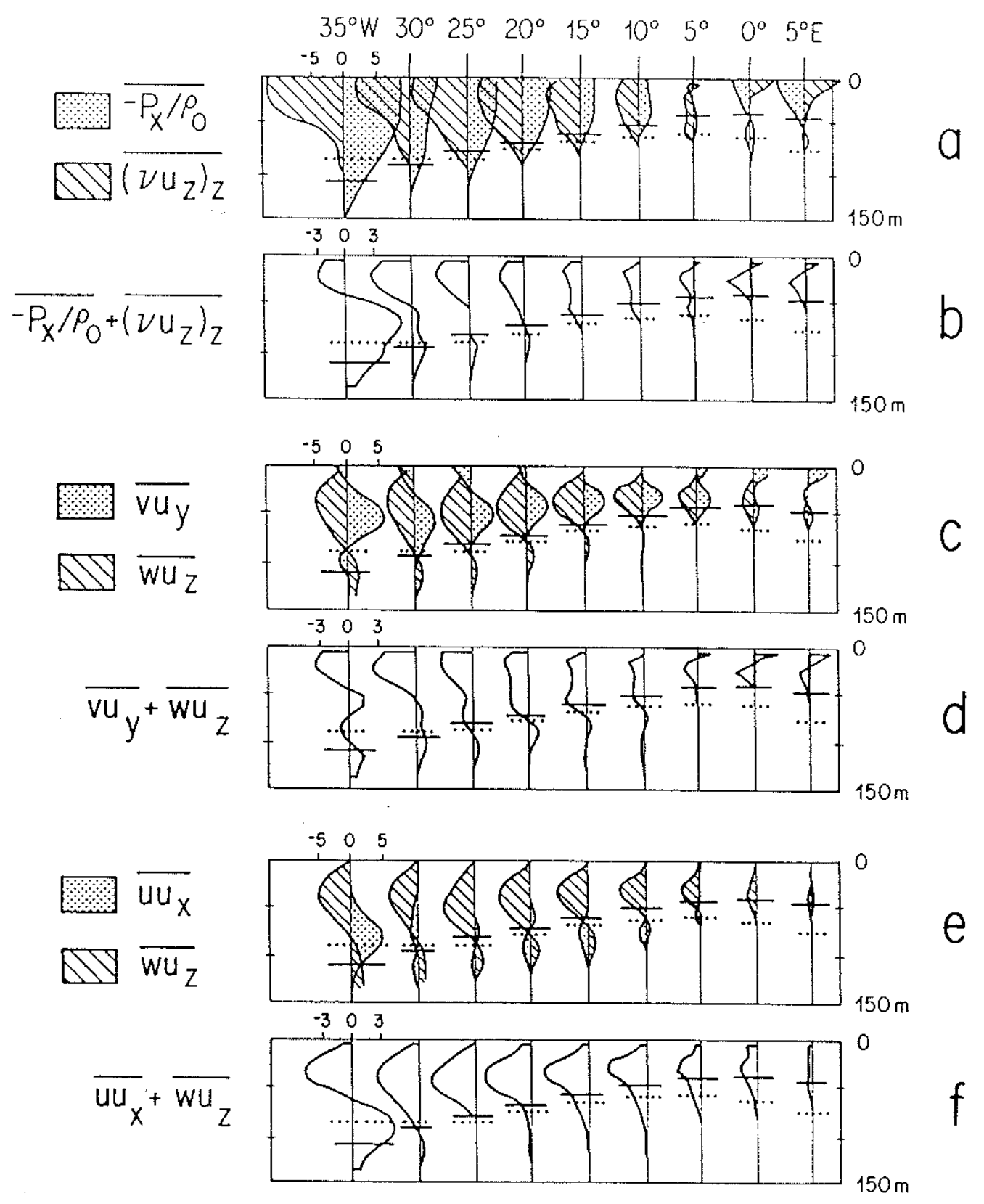

Figure 53: Same as Figure 52, but with the terms grouped by pairs and followed by their sum. 


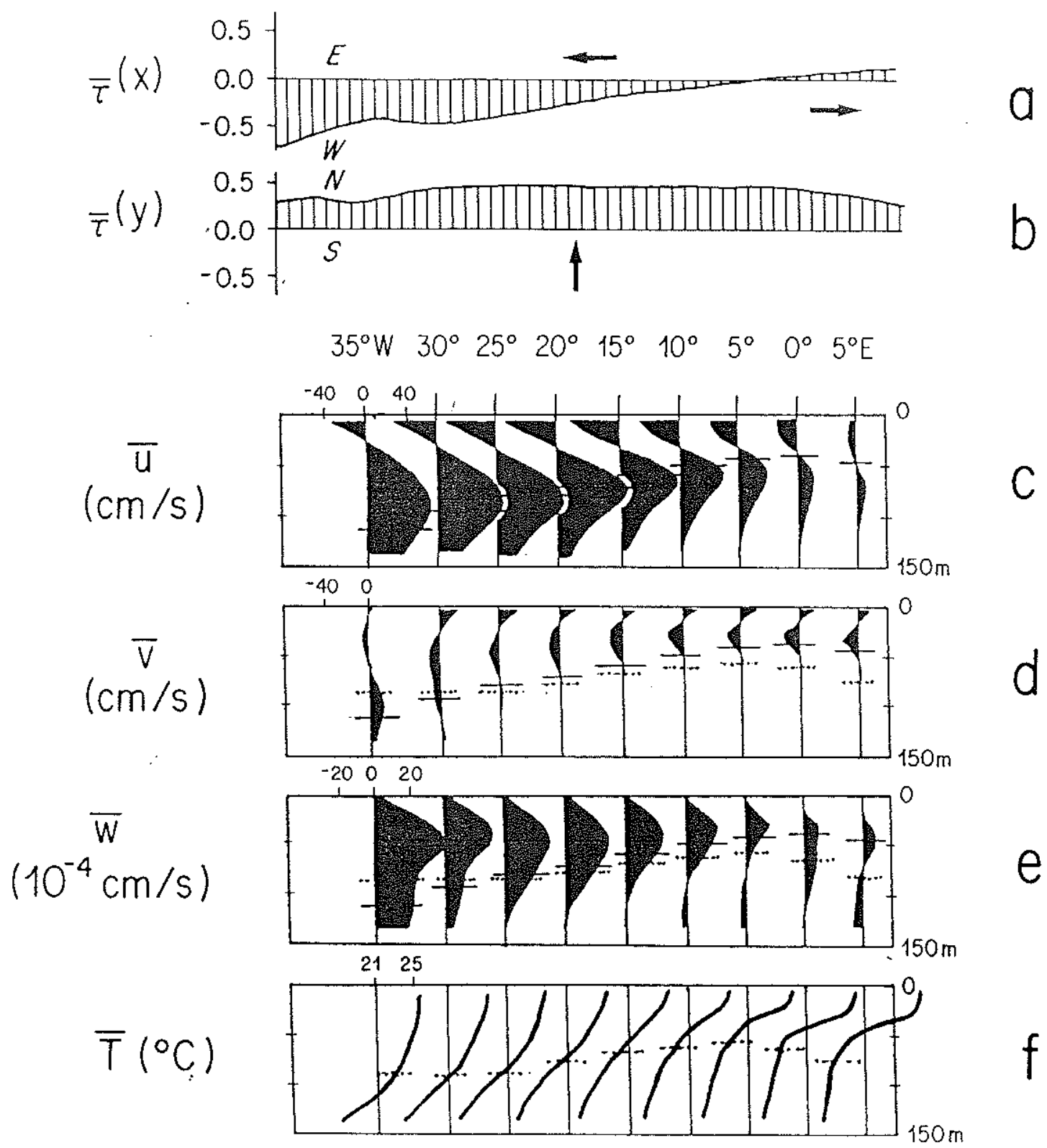

Figure 54: Vertical profiles of the annually averaged simulated fields of $\bar{u}(c), \bar{v}(d), \bar{w}(e)$ and $\bar{T}(f)$ at $0 \mathrm{~N}$ at the same longitudes as Figures 52 and 53 . (a) and (b) show the longitudinal variation of $\vec{\tau}(x)$ and $\bar{\tau}(\dot{y})$ (the imposed wind stress components). The dotted line indicates the location of the EUC core [see $(c)]$, the solid line that of the center of the thermocline $[$ see $(f)]$. 
zone of transition between upper and lower regimes where most terms enter the ZMB with equal magnitude. Below the zero line for $w$, the balance in region (4) west of $5^{\circ} \mathrm{W}$ is further reduced to:

$$
\overline{u u_{x}}=\overline{A \nabla^{2} u} \quad \text { (Figure 52c,d). }
$$

The resolution of Figures 52 and 53 does not allow much elaboration on the deep eastern region. It will be discussed 1ater (Figure 57).

\section{Let us now examine in more detail the nature of the} accelerations and decelerations. East of $30^{\circ} \mathrm{W}$ in the upper thermocline [region (3)], the dominant inertial terms are, as already mentioned, $\overline{v u_{y}}$ and $\overline{w u}$ (Figure 52e,f). The ZMB, just below a 15 m-thick surface layer, simplifies to:

$$
\overline{v u_{y}}+\overline{w u_{z}}=\overline{\left(-p_{x} / \rho_{0}\right.}+\overline{\left(v u_{z}\right)_{z}} .
$$

The left-hand side of this equation represents the meridional circulation advecting zonal momentum southwards across the equator towards the displaced core of the EUC and upwards. (See section 3.3.2 for the meridional structure of these advection terms.) Note how $\overline{v u_{y}}$ at $0{ }^{\circ} \mathrm{N}$ is strictly confined above the middle of the thermocline, except in transitional regions such as around $0^{\circ} \mathrm{E}$ (Figure 52e). The net frictional dissipation in the right-hand side corresponds in the left-hand side to a net loss of zonal momentum upwards, the vertical flux of zonal momentum being in excess of the lateral influx. This description is consistent with that of the $x-z$ circulation of section 3.2.1 which showed water parcels leaving the upper EUC quickly by upwelling into the overlying westward flow.

East of $30^{\circ} \mathrm{W}$ and below the core of the EUC [region (4)], $\overline{v u_{y}}$ is negligible, the acceleration is solely composed of $\overline{u u_{x}}$ and $\overline{w u_{z}}$ (Figure 53e) and the ZMB west of $5^{\circ} \mathrm{W}$ simplifies to:

$$
\overline{u u_{x}}+\overline{w u_{z}}=\overline{A \nabla^{2} u}
$$


above the isotach $w=0$, and:

$$
\overline{u u_{x}}=\overline{A \nabla^{2} u}
$$

below. (Compare Figures $52 \mathrm{c}$ and $53 \mathrm{f}$ in the lower thermocline). This equation can be further simplified to:

$$
\overline{\overline{D u}}=\overline{\overline{\mathrm{A}}} \mathrm{u}_{\mathrm{yy}} \text {, as } u_{x x} \ll u_{y y} \text {, }
$$

where $s$ is such that $\partial x / \partial s=u$ and $\partial z / \partial s=w$. Without the lateral friction term, this would be the equation of a free zonal inertial jet going eastwards and upwards along $w / u$ slopes (or almost horizontally eastwards below the isotach $w=0$ ). In the presence of lateral friction, the jet gradually weakens along its course $\left(\overline{u u_{x}}\right.$ exceeds $\overline{w u_{z}}$ ). Note that there is no suggestion of lateral influx along the course of this lower flow, only the suggestion of a western source. This is again in agreement with section 3.2.1 which showed the ability of water parcels from the lower EUC to remain within it throughout the basin. This point will be developed in section 3.3.2.

Finally west of $30^{\circ} \mathrm{W}$ [regions (1) and (2)], the excess of $\left(\overleftarrow{-p_{x} / \rho_{0}}\right)$ over $\overline{\left(v u_{z}\right)_{z}}$ at depth mostly corresponds to a positive $\overline{u u_{x}}$, as seen from comparing the leftmost profiles of Figures 52d and 53b. Indeed in the neighbourhood of the EUC core at $35^{\circ} \mathrm{W}$, the ZMB roughly reduces to:

$$
\overline{u u_{x}}=-\overline{p_{x} / \rho_{0}} \text {, or equivalently: }\left(\overline{u^{2} / 2}+\overline{p / \rho_{0}}\right)_{x}=0
$$

The value reached by the maximum velocity of the EUC thus depends on the value of the pressure below the layer of frictional influence in the western basin and on the range of longitudes over which the Bernoulli function $\left(u^{2} / 2+\overline{p / \rho_{0}}\right)$ can be considered constant. The difference in stratification of the western Atlantic and Pacific may therefore explain that the velocities reached by the Pacific EUC exceed those reached by the Atlantic EUC, as already suspected from the observational review (section 1.4.1). 
Similarly, if the Atlantic simulation underestimates the zonal and vertical extent of the region of net acceleration, by misrepresenting the stratification or overestimating the vertical dissipation, the maximum speed of the EUC is likely to be underestimated. Thus too weak an eastward penetration of the lower EUC into the easternmost basin [region (4)] can be traced back to too weak a lower EUC emerging from the western accelerating region (2), or it can be due to an overestimate of the lateral dissipation along the eastward course of the lower EUC.

Western formation region: Figure 55 shows details of the region between $43^{\circ} \mathrm{W}$ (off the continental rise at the Brazilian coast) and $35^{\circ} \mathrm{W}$. Because of a meandering pattern of the horizontal flow at these longitudes, representing the components of the velocity and the ZMB terms along the equator is not ideal. Such a representation however still illustrates the net eastward force below about $55 \mathrm{~m}$ caused by the contrast between the slow baroclinic adjustment of the ZPG with depth and the fast vertical decay of the vertical friction term ( $f, g)$. This force corresponds to a positive acceleration centered in the upper thermocline and expressed either as a large positive $\overline{u u_{x}}\left(i: 35^{\circ} \mathrm{W}\right.$, $\left.39^{\circ} \mathrm{W}, 41^{\circ} \mathrm{W}\right)$ or as a large positive $\overrightarrow{\mathrm{vu}_{\mathrm{y}}}\left(\mathrm{j}: 37^{\circ} \mathrm{W}\right)$. And that positive acceleration at depth is apparent at a11 longitudes of Figure 55 in the vertical profiles of the zonal velocity, starting to give rise east of $43^{\circ} \mathrm{W}$ to an eastward subsurface current which keeps strengthening eastwards over the domain (b).

Termination region: Figure 56 presents vertical profiles of the annually averaged velocity components, temperature, and dynamical terms between $0^{\circ} \mathrm{E}$ and $8^{\circ} \mathrm{E}$ along the equator. The location of the EUC core is indicated by a dotted line, that of the middle of the thermocline by a continuous line. On (b), one can see the effect of the wind reversal on the velocity shear penetrate deeper as the westerly wind increases to the east. By $8^{\circ} \mathrm{E}$, the change of sign of the surface shear reaches $40 \mathrm{~m}$. The zonal weakening of the subsurface eastward 
flow is also clearly seen: its thickness goes from $100 \mathrm{~m}$ at $0^{\circ} \mathrm{E}$ to $50 \mathrm{~m}$ at $8^{\circ} \mathrm{E}$, and its peak velocity from $0.16 \mathrm{~m} / \mathrm{s}$ at $0^{\circ} \mathrm{E}$ to $0.04 \mathrm{~m} / \mathrm{s}$ at $8^{\circ} \mathrm{E}$ (remember that those characteristics were $200 \mathrm{~m}$ and $0.65 \mathrm{~m} / \mathrm{s}$ at $\left.0^{\circ} \mathrm{N} 25^{\circ} \mathrm{W}\right)$. Above the shallow tight thermocline (e), the flow is westward and the balance between a westward ZPG force (f) and an eastward vertical friction term $(g)$, with some contribution from $\overline{v u_{y}}(j)$ and $\overline{w u_{z}}(k)$. This corresponds to region \5) on Figure 51 .

Below the thermocline within the eastward flow, all the terms are very small and were therefore redrawn at a different scale between 50 and $150 \mathrm{~m}$ on Figure 57. Note that the new scale -0.6 to $0.6 \times 10^{-7} \mathrm{~m} / \mathrm{s}^{2}$ is one order of magnitude smaller than the scale suitable for the $0^{\circ} \mathrm{E}-8^{\circ} \mathrm{E}$ upper regime (Figure 56 ), which is itself about one third the scale suitable for the $43^{\circ} \mathrm{W}-35^{\circ} \mathrm{W}$ upper regime (Figure 55). Below the EUC core (dotted 1ine), the ZMB can generally be written:

$$
\overline{u u_{x}}+\overline{w u_{z}}=\overline{-p_{x} / \rho_{0}}+\overline{A \nabla^{2} u} \quad \text { (Figure } 57 a, c, d, f \text { ). }
$$

The ZPG force, which at comparable levels in the central basin was either negligible compared to the other terms or reversed (as better shown in the following section), acts on average as a positive forcing for the remaining inertial EUC in the termination region. The effect of the ZPG force is however counteracted by lateral friction, resulting in a net zonal deceleration of the flow. At the two or three model levels bracketed by the thermocline and the core, the mean balance includes:

$$
\left.\left.\overline{u u_{x}}+\overline{v u_{y}}+\overline{w u_{z}}=-\overline{p_{x} / \rho_{0}}+1 \overline{v u_{z}}\right) \quad \text { (Figure } 57 a, b, d, e, f\right) .
$$

So the ZMB within the easternmost EUC can be paradoxically written in a way very similar to that within the westernmost EUC [regions (1) and 【2) of Figure 51 and Figure 55], al though over a much reduced depth range. The difference of course is that the net $\overline{u u_{x}}$ is positive in the west and negative in the east. This similarity is better emphasized in the next section devoted to the meridional structure of the ZMB where again different scales are used within different regimes. 

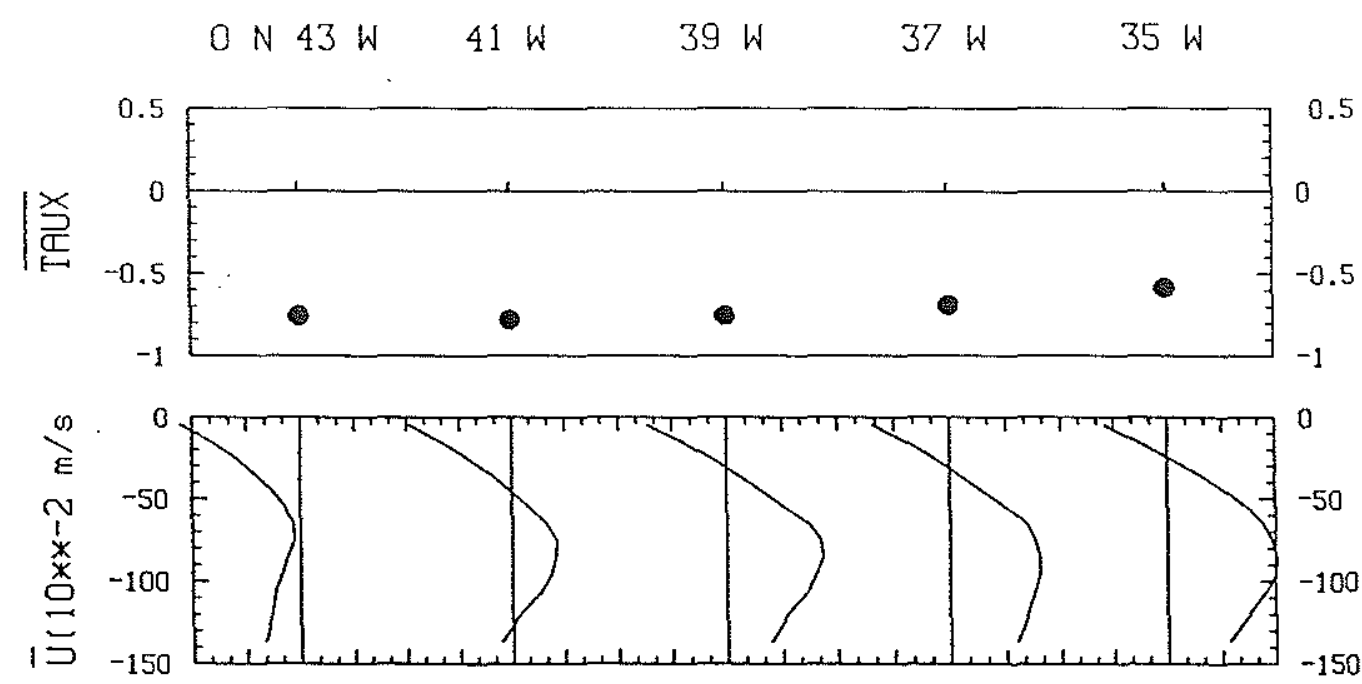

b
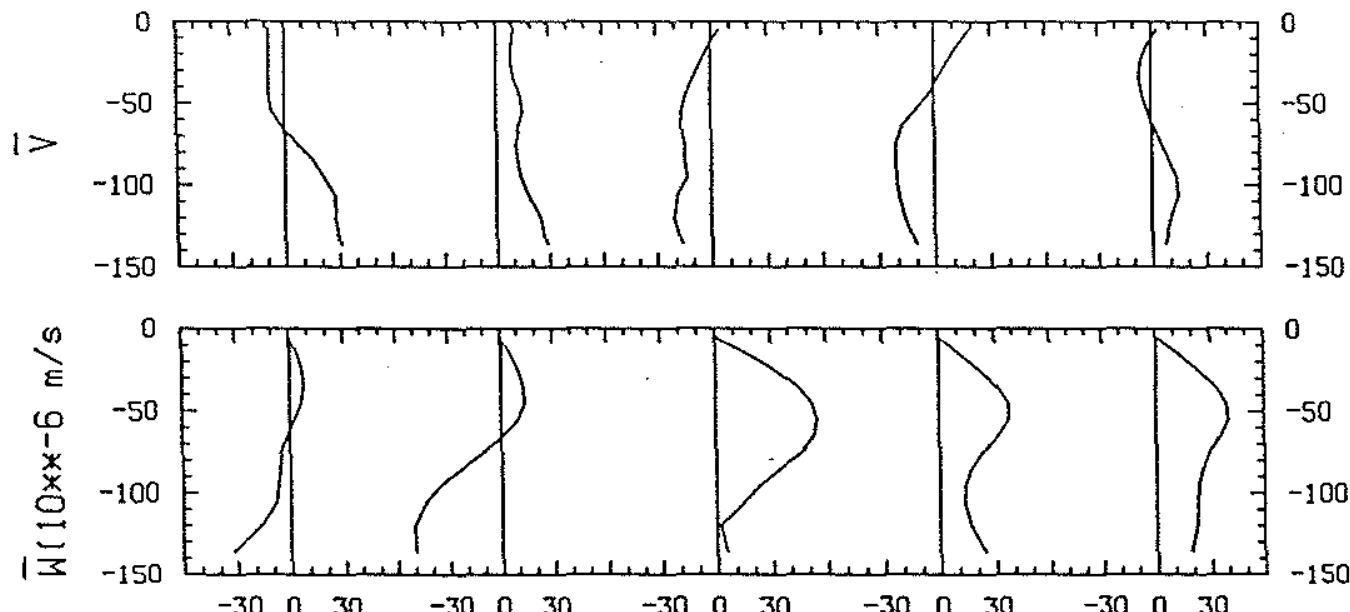

c

d

e

Figure 55: Vertical profiles of the annually averaged simulated veloc$i$ ty components and temperature ( $b$ to $e$ ) and ZMB terms ( $f$ to $k$ ) at $0^{\circ} \mathrm{N}$ at five longitudes with the EUC formation region, between $43^{\circ} \mathrm{W}$ and $35^{\circ} \mathrm{W}$. The values of the imposed zonal wind stress at these longitudes is plotted in (a). 
$0 N 43 W 41 W \quad 39 \omega \omega$

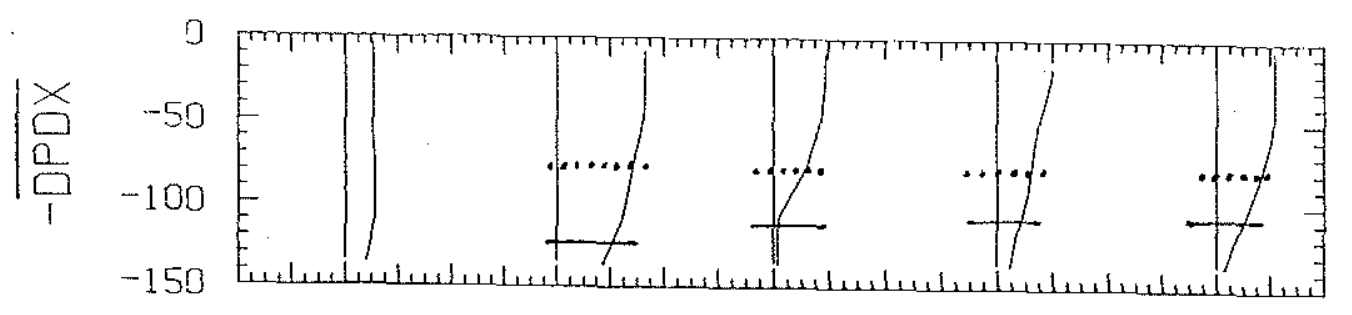

0

$-50$

$-100$

$-150$

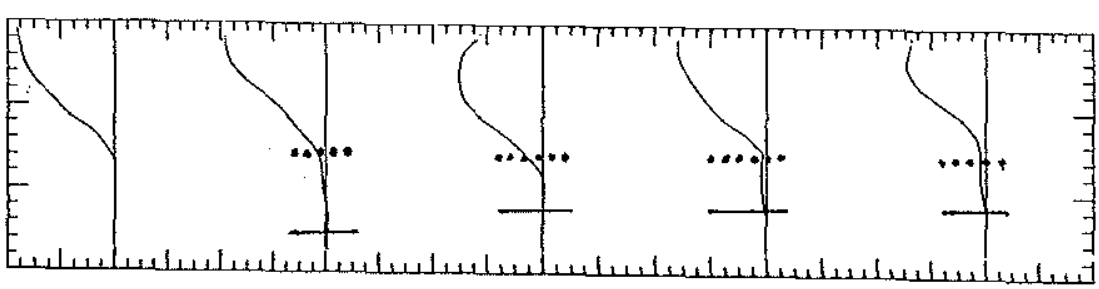

0

$\mid \begin{aligned} & 0 \\ & \vdots \\ & \square \\ & \vdots \\ & \vdots\end{aligned}$

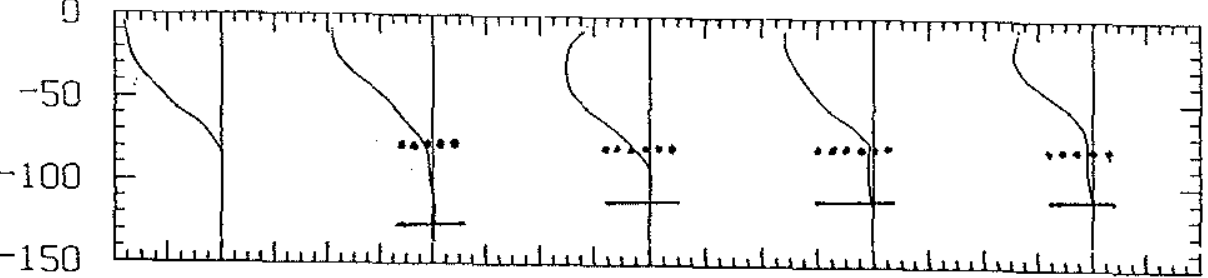

$-50$

$-100$

9

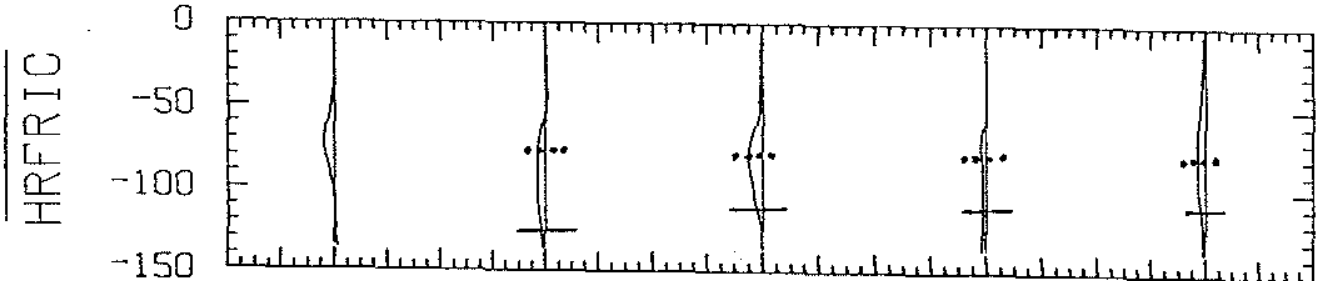

$-150$

0

$-50$

h

$-100$

$-150$

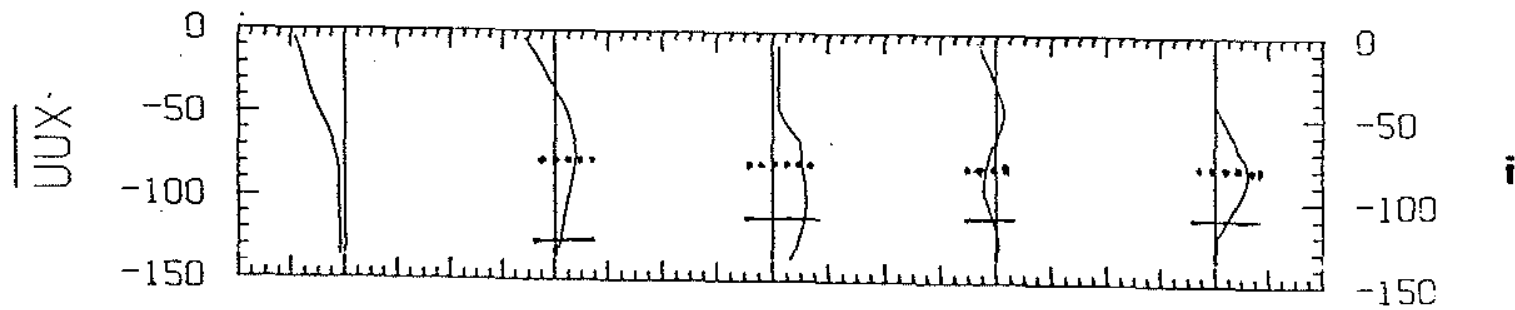

1390

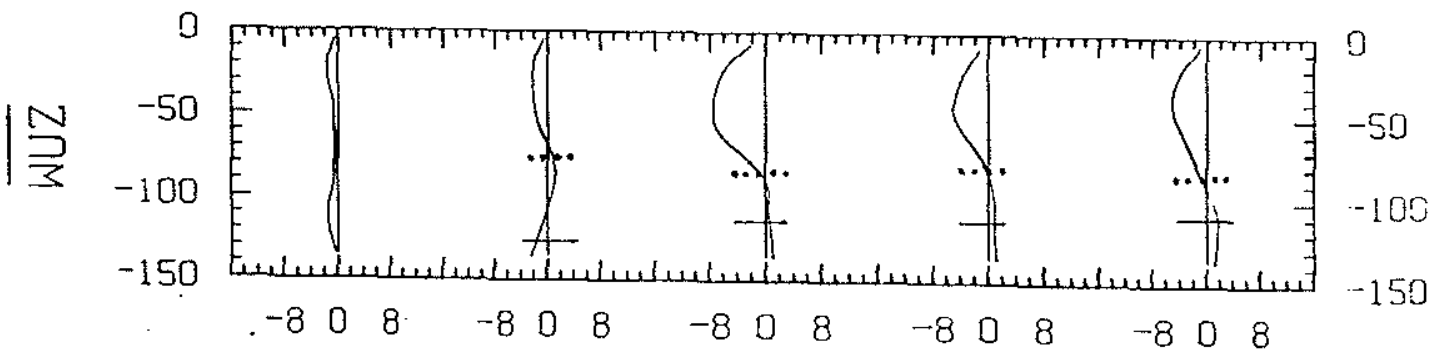

Figure 55 (Continued): The dotted 1ine indicates the location of the EUC core, the solid line that of the center of the thermocline. 


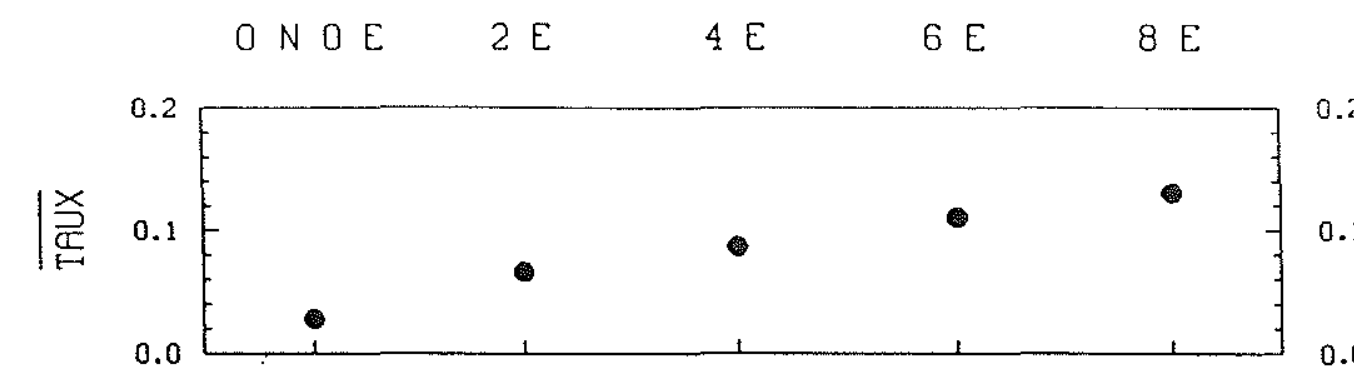

0.2

$0.1 \quad a$

0.0

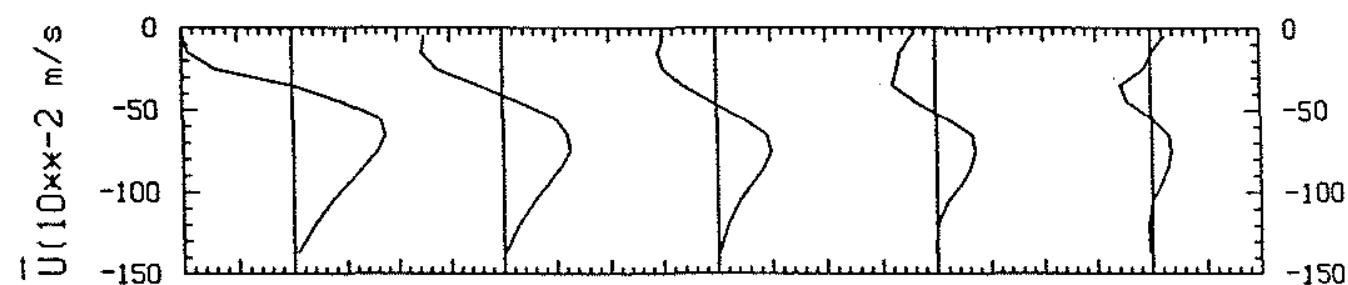

b
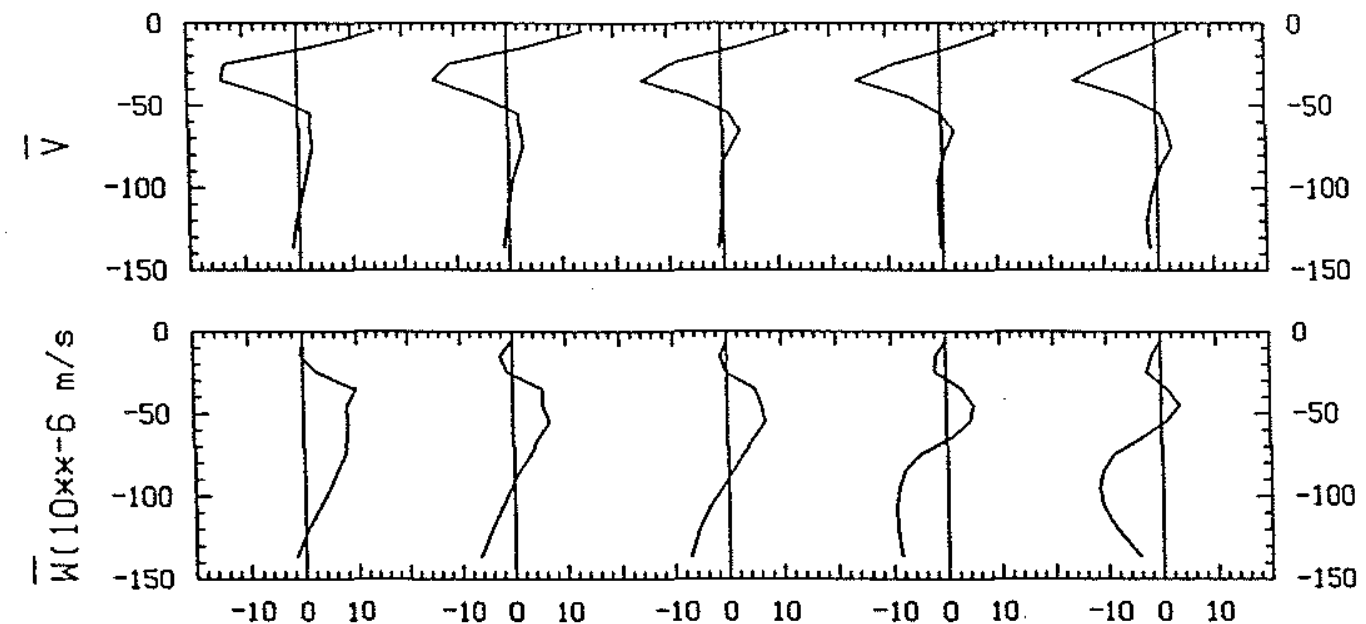

d

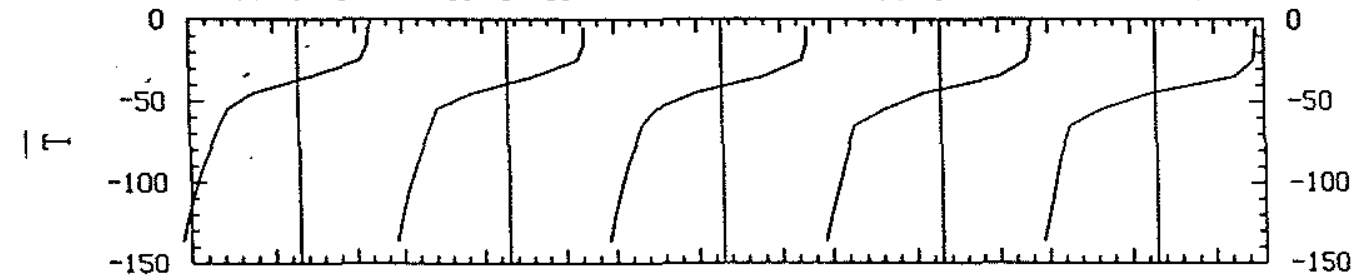

Figure 56: Same as Figure 55 but for the EUC termination region, between $0^{\circ} \mathrm{E}$ and $8^{\circ} \mathrm{E}$. 


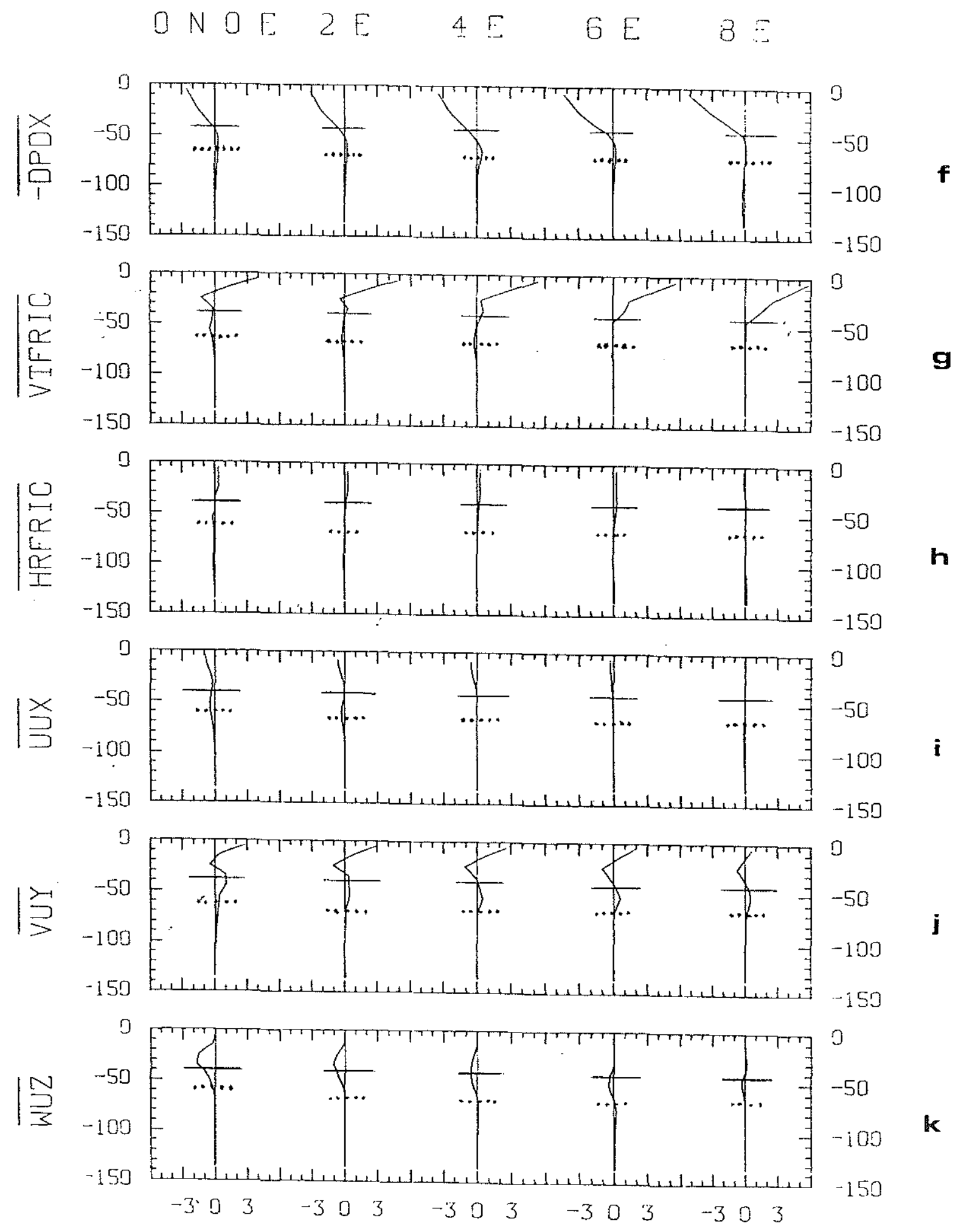

Figure 56 (Continued) 
ONOE $2 \mathrm{E} \quad 4 \mathrm{E} \quad 6 \mathrm{E} \quad 8 \mathrm{E}$

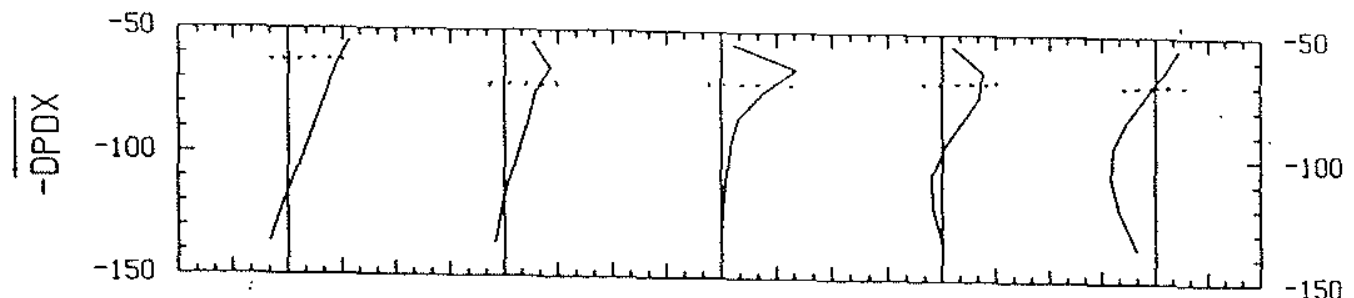

a

b

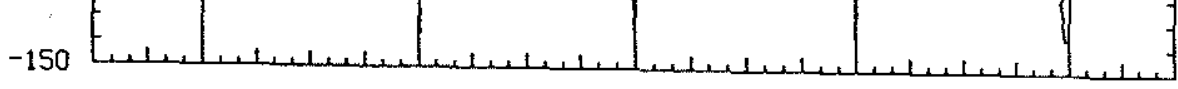

$-150$

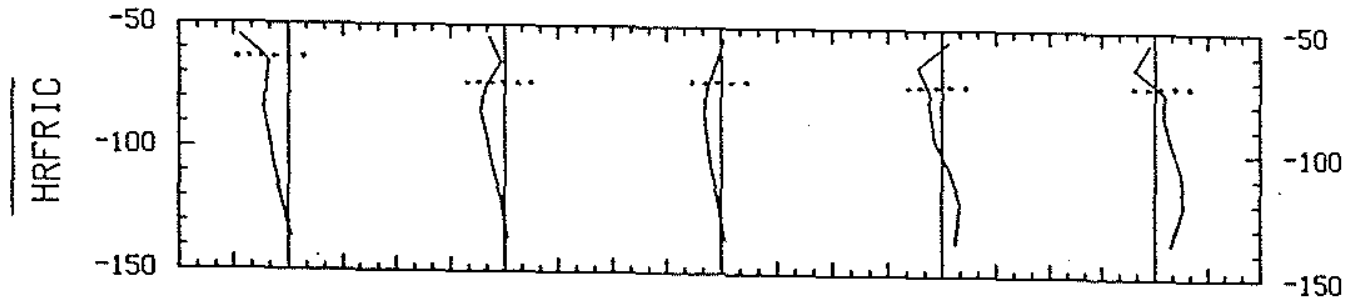

50
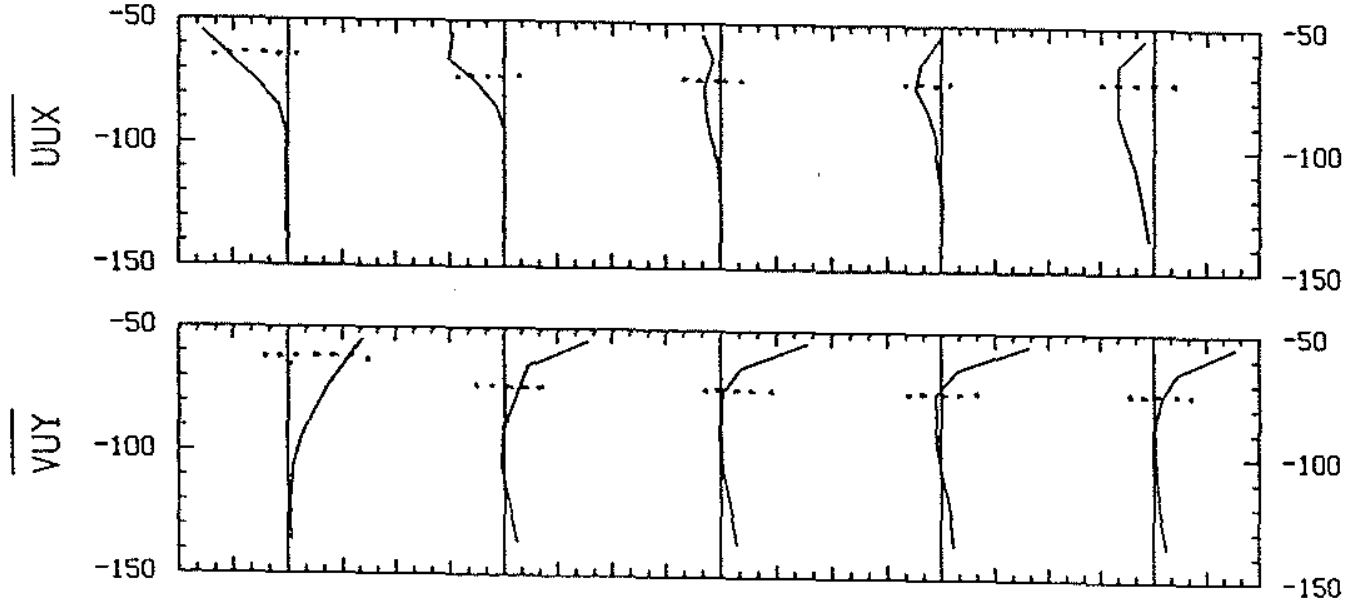

$-150$

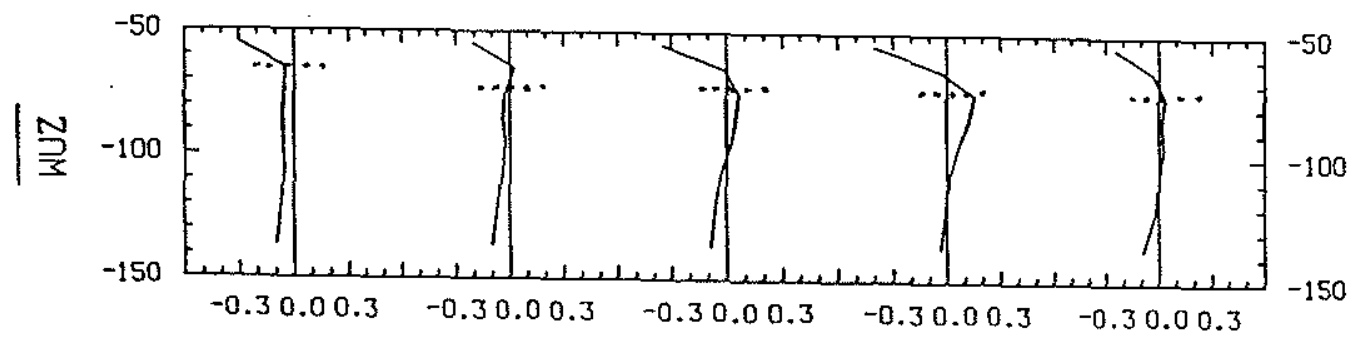

d

e

Figure 57: Same as Figure 56 (cont.)but for the vertical range $50 \mathrm{~m}$ to $150 \mathrm{~m}$. The scale of the abscissa is one tenth that of Figure 56 (cont.). 


\subsubsection{Meridional_structure_of the annually_averaged ZMB various longitudes}

The previous section dealt with the longitudinal and vertical structure of the annually averaged ZMB right along the equator. The term of mean meridional advection of zonal momentum $\overline{v u_{y}}$ was shown to be positive and to play a non-negligible role in the balance for the upper layers of the EUC [Figure 51: (1), (3) and (5)], along with the term of mean vertical advection of zonal momentum $\overline{w u_{z}}$. These terms express the role of the meridional circulation $(v, w)$ in transporting eastward momentum southwards towards the core of the EUC and upwards away from it. Their sum $\left(\overline{v u_{y}}+\overline{w u_{z}}\right)$, dominated by $\overline{w u_{z}}$ and thus negative, balanced the excess of vertical friction over pressure forcing (Figure 53b,d). Another important result of the previous section was that $\overline{v u}_{y}$ appears negligible in the lower layers of the EUC outside the western accelerating regime. That suggested that at least the lower part of region (4) (Figure 51), which on the mean does not experience vertical exchanges of momentum with the upper layers, is not fed laterally either and has for its sole source of eastward momentum that emerging from the western accelerating region (2). The following questions therefore arise. How does the upper balance change as the core of the EUC is approached, i.e. as $u_{y}$ and $v$ tend towards zero and $\overline{v u_{y}}$ presumably becomes negligible? Does the study of $\overline{v_{y}(z)}$ at slightly higher latitudes confirm the lack of lateral source of eastward momentum for the lower EUC? And how does the nonl inear equatorial regime evolve into linear off-equatorial dynamics? $25^{\circ}$.W will be the meridional section mostly used to illustrate the answers to these questions.

From Figures 46 and 47 , it became apparent that, in the central basin, the core of the EUC lies on average at about half a degree of latitude south of the equator. Al so apparent from Figure 47 was the mid-basin symmetry of $\bar{W}$ with respect to the equator, in contrast with the asymmetry of $\bar{u}$ and $\vec{v}$. Figure 58 now shows the meridional structure of $\overline{v u_{y}}(a), \overline{w u_{z}}(b), \overline{-p_{x} / \rho_{0}}(c)$, and $\overline{\left(v u_{z}\right)_{z}}(d)$ at $25^{\circ} \mathrm{W}$. Shaded in on each plot is the core of the EUC defined by the limits of the $0.5 \mathrm{~m} / \mathrm{s}$ isotach. Following, for instance, the $65 \mathrm{~m}-1 \mathrm{evel}$ 
from the equator southwards into the EUC core, one observes a decrease in the intensity of both $\overline{v u_{y}}$ and $\overline{w u_{z}}(a, b)$, but not much change in $\left.\overline{\left(-p_{x} / p_{0}\right.}\right)$ and $\overline{\left.\sqrt\left[v u_{z}\right)\right]{z}}(c, d)$.

That $\overline{v u_{y}}$ does not drop exactly to zero at the latitude where the mean EUC is maximum (i.e. where $\overline{u_{y}}$ is zero) is not alarming: it is due to the nonlinear nature of $\overline{v u}$ and reflects the fact that the latitude of maximum EUC speed has shifted somewhat during the year, so that:

$$
\overline{v u}_{y} \neq \bar{v} \bar{u}_{y} .
$$

(For the same reason, the depth at which $\overline{w u_{z}}$ goes to zero may slightly differ from that at which $\overline{u_{z}}$ is zero.)

The main point of Figure 58 then is that, in the upper EUC at the latitude of its core, $\overline{v u_{y}}$ indeed gets negligible compared to

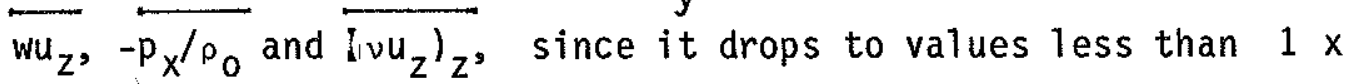
$10^{-7} \mathrm{~m} / \mathrm{s}^{2}$, compared to values of the order of $4 \times 10^{-7} \mathrm{~m} / \mathrm{s}^{2}$. In the same region, $\overline{u u_{x}}$ and $\overline{A \nabla^{2} u}$ (not shown) remain negligible as at $0^{\circ} \mathrm{N}$, and the now nonzero mean Coriolis acceleration $\overline{(-f v)}$ is not yet large enough to enter the balance (not shown either). So, above the maximum speed of the EUC, i.e. $1 / 3$ or $2 / 3$ of a degree of latitude south of the equator, the mean ZMB in region 13 ) of Figure 51 reduces to:

$$
\overline{w u}_{z}=\overline{-p_{x} / \rho_{0}}+\left(\overline{v u_{z}}\right)_{z} \text {. }
$$

The net westward force in the right-hand side of this equation has about the same amplitude as at $0^{\circ} \mathrm{N}$. It thus causes the same deceleration of the subsurface eastward flow via upwelling of zonal momentum away from the core into the westward surface flow. But that upwelling of momentum is weaker than at the equator since it does not need to balance any more acceleration due to the cross equatorial flow.

The meridional and vertical structure of the annually averaged ZMB at $25^{\circ} \mathrm{W}$ is discussed in detail in Appendix $\mathrm{I}$. It is here summarized schematically on Figure 59, which can be described as follows. 

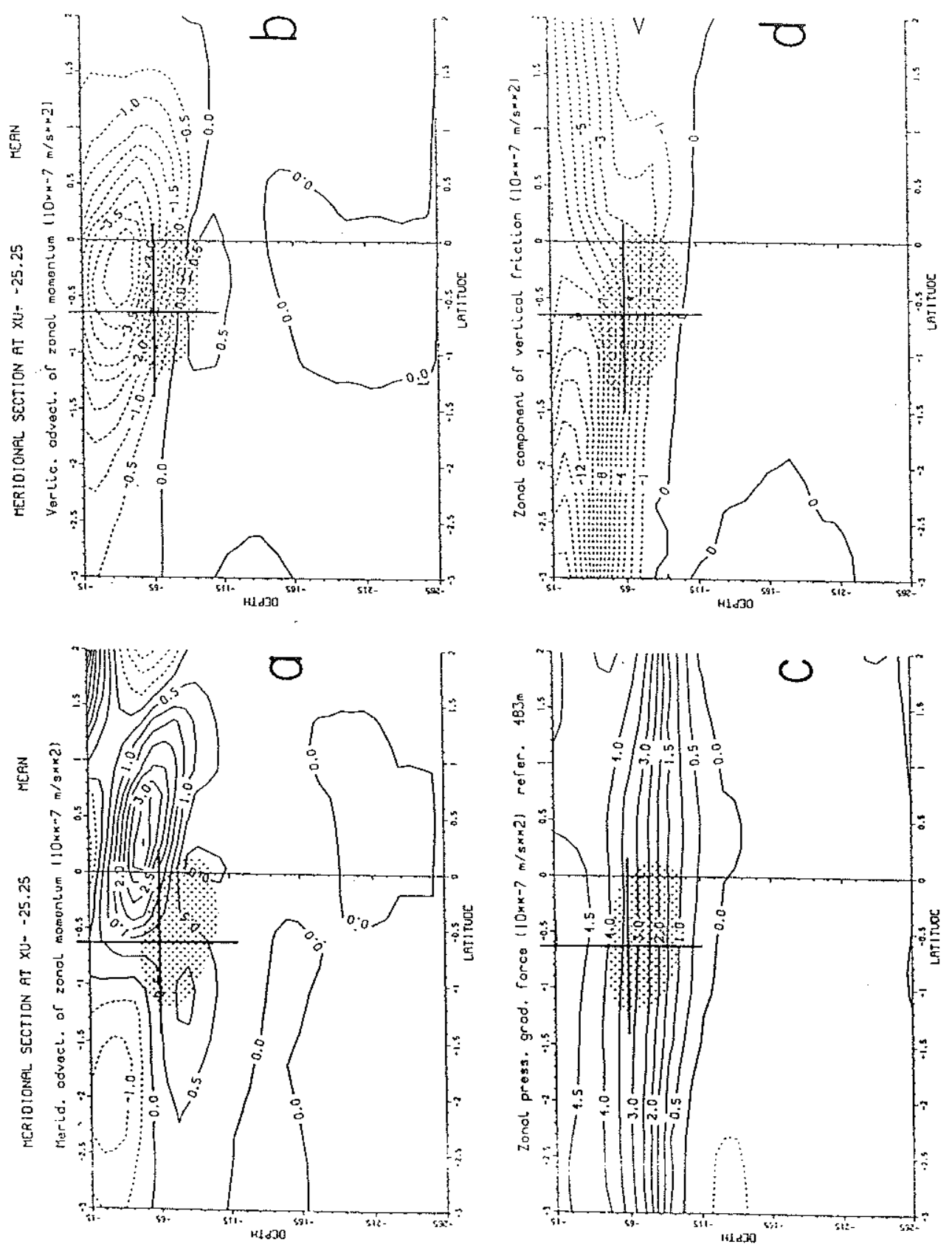

Figure 58: Meridional sections of the annually averaged simulated fields of $\overline{v u_{y}}(a), \overline{w u_{z}}(\mathrm{~b}),-\overline{p_{x} / p_{0}}(\mathrm{c})$ and $\overline{\left(\nu u_{z}\right)_{z}}(\mathrm{~d})$ at $25^{\circ} \mathrm{W}$ between $3^{\circ} \mathrm{S}$ and $2 \mathrm{~N}$ above $265 \mathrm{~m}$. The location of the EUC core (zonal velocities larger than $0.20 \mathrm{~m} \mathrm{~s}^{-1}$ ) is shaded. The cross indicates the position of the absolute maximum of zonal velocity. 


\section{Annual mean

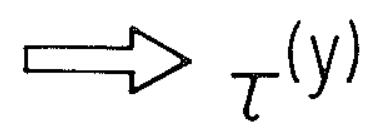 \\ $25^{\circ} \mathrm{W}$}

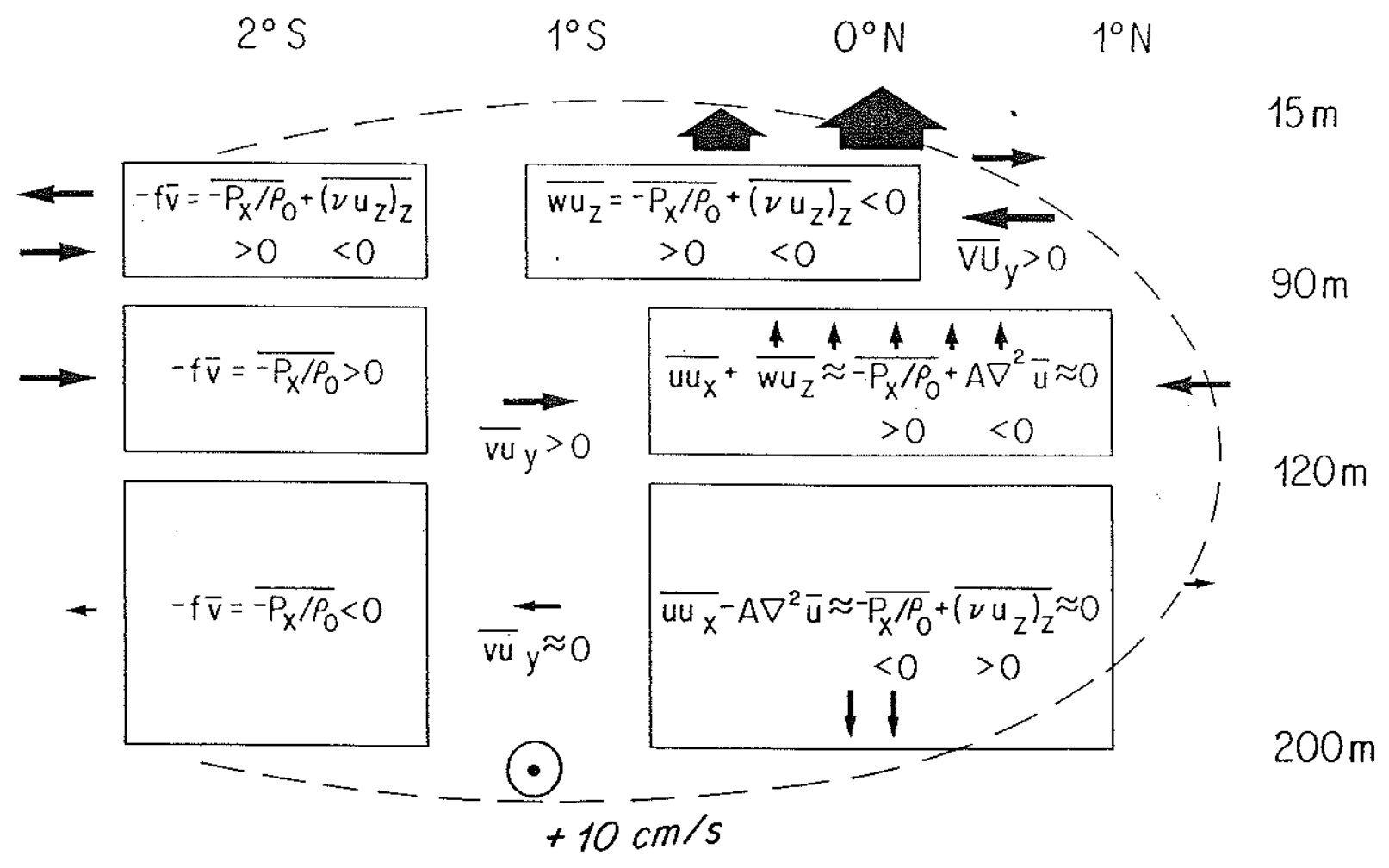

Figure 59: Schematic summary of the structure of the annually averaged simulated zonal momentum balance in a $y-z$ plane at $25^{\circ} \mathrm{W}$. The $0.10 \mathrm{~m} \mathrm{~s}^{-1}$-isotach is indicated by the dashed line surrounding the plot. 
Above $90 \mathrm{~m}$, the dynamics are dominated by vertical friction even off the equator and are asymmetric about the equator. The lateral flux of eastward momentum into the displaced core of the EUC which is present at $0^{\circ} \mathrm{N}$ becomes negligible at the latitude of the core. Net loss of eastward momentum by the upper EUC occurs through vertical exchange with the overlying westward flow.

Below $90 \mathrm{~m}$, the dynamics are no longer markedly influenced by the northwestward surface stress and become more symmetric about the equator. Between 90 and $120 \mathrm{~m}$, a thin layer of meridional geostrophic convergence supports an inertial equatorial jet exposed to no net forcing or dissipation, which thus tends to conserve its, zonal momentum as it flows eastwards and upwards. Slightly off the equator, the flow is accelerated by equatorward advection of zonal momentum.

Below $120 \mathrm{~m}$ is a region of equatorial downwelling and meridional geostrophic divergence, too weak to decelerate the offequatorial EUC through poleward advection of zonal momentum. The ZMB at the equator is the equation of an inertial jet dissipated eastwards by 1 ateral friction. Its main source of zonal momentum 1 ies further west.

The inertial terms, important at the equator, become negligible compared to the Coriol is acceleration between $1^{\circ}$ and $2^{\circ}$ off the equator. At all the levels described above, there is a tendency for the vertical stress (and the term of vertical friction) to penetrate deeper at the equator (where the stratification is weaker) than at neighbouring latitudes (see Figures in Appendix I).

Finally, let us comment on how the meridional structure of the ZMB changes east and west of $25^{\circ} \mathrm{W}$. The contrast between an asymmetric upper frictional regime and more symmetric lower regimes is found at all longitudes, reflecting the fact that $\tau^{(y)}$ itself is nearly constant zonally (Figure 54b). The thin intermediate pressureforced regime described at $25^{\circ} \mathrm{W}$ thickens westwards, where it merges with region (2) of Figure 51, as can be seen on Figure 53a. But it thins eastwards as the zero crossings of the vertical profiles of $\widetilde{\left(-p_{x} / \rho_{0}\right)}$ and $\overline{\left(\nu u_{z}\right)_{z}}$ move closer together. By $15^{\circ} \mathrm{W}$, it has disappeared, 
but a similar regime is again found in the lower EUC east of $5^{\circ}$.W where the stratification at depth forces a positive ZPG force below the level at which $\overline{\left(\nu u_{z}\right)_{z}}$ vanishes. The zonal structure of this deep stratification can be seen from the shape of the mean isotherms and isohalines of Figure 45 below about $75 \mathrm{~m}$.

Let us summarize the zonal and meridional structure of the annually averaged ZMB simulated by the GCM with the help of Figure 60 . In Figure 51, for the sake of simplicity, dynamical regimes were crudely separated by the middle of the thermocline and by the longitudes $30^{\circ} \mathrm{W}$ and $2^{\circ} \mathrm{W}$. In Figure 60 , a more precise representation is attempted on the basis of the depths at which various dynamical quantities go to zero as a function of longitude. For reference, the limits of mean eastward flow, the core of the EUC and the thermocline are also represented.

Consider the western region (west of $30^{\circ} \mathrm{W}$ ). The thick continuous line delimits the accelerating domain below about $50 \mathrm{~m}$ $(D u / D t>0)$. Above that line, westward vertical friction dominates the eastward pressure forcing $\left(\overline{-p_{x} / \rho_{0}}+\overline{\left(v u_{z}\right)_{z}}<0\right)$. Below, the eastward ZPG force dominates both the term of vertical friction and that of horizontal friction (at least above $250 \mathrm{~m}$ ). The thin dashed 1 ine along which $\overline{\left(v u_{z}{ }_{z}\right.}$ vanishes separates the mostly frictional upper regime from the mostly nonfrictional lower regime.

$\frac{\text { Over most of the rest of the basin, the sum }\left[\overline{-p_{X} / \rho_{0}}+\right.}{\left(v u_{z}\right)_{z}}+\overline{\left.A \nabla^{2} u\right] \text { is negative and the flow is inertially decelerating. }}$ Exceptions are found near the surface in the east where eastward vertical friction dominates the westward ZPG force and in the small subsurface domain centered around $4^{\circ} \mathrm{E}$ and $75 \mathrm{~m}$ where a deep eastward ZPG force locally overcomes the retarding effects of both vertical and horizontal friction terms.

What is not immediately apparent from Figure 60 is the strength of the inertial accelerations and decelerations within the various regions, or equivalently the magnitude of the imbalance between forcing and dissipation. That imbalance is very large and positive in 


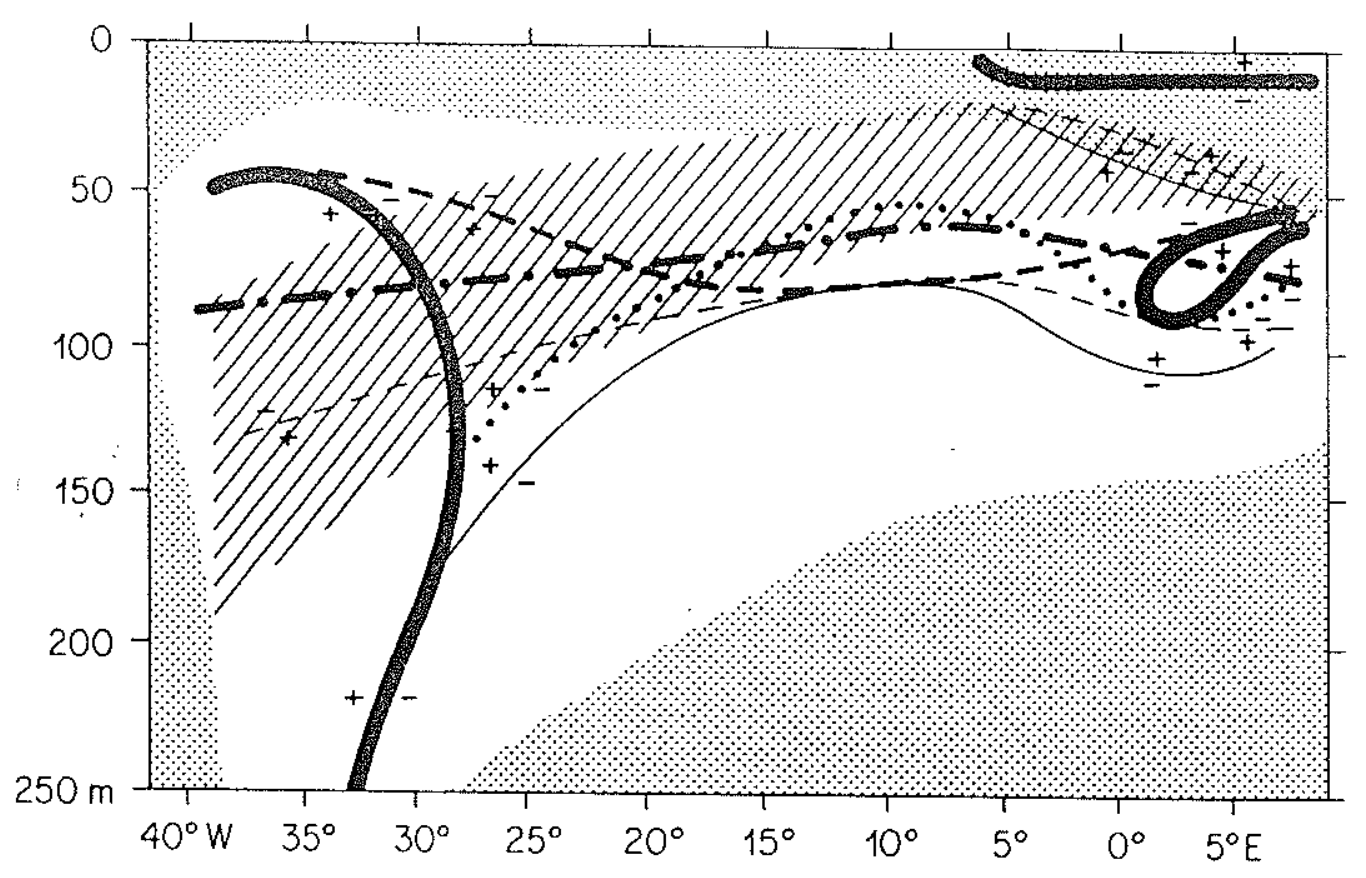

? westward flow

$\square$ eastward flow

ZIA thermocline

-.- EUC core

zero net acceleration

$-\overline{-P_{X} / \rho_{0}}+\overline{\left(\nu u_{z}\right)_{z}}=0$

.... $\overline{-P_{X} / P_{0}}+A \nabla^{2} \bar{u}=0$

$-\overline{-P_{X} / P_{0}}=0$

$--\overline{\left(\nu u_{z}\right)_{z}}=0$

Figure 60: Location of an equatorial section of the zero-crossings of various simulated mean fields and of the various dynamical regimes sketched on Figure 51 . 
the western accelerating domain [regions $/ 1$ ) and $\mid 2)]$; it is relatively 1 arge and negative in the region of positive ZPG forcing dominated by vertical friction ["upper EUC" (3)] and in the shallow region of positive stress dominated by a reversed ZPG force at the longitudes where the zonal wind has changed sign $[5$ ). The imbalance between forcing and dissipation is negative and relatively small elsewhere (4).

The analysis of the meridional structure of the annually averaged $Z M B$ has further shown that, in the region of positive ZPG (which, off the equator, corresponds to an equatorward geostrophic flow component), $\overline{v u_{y}}$ enters the ZMB as a positive acceleration slightly away from the exact latitude of the EUC core. The upper EUC thus has a lateral source of zonal momentum along its eastward course. In the region of negative ZPG force which, off the equator, corresponds to a weak poleward geostrophic flow component, $\overline{v u_{y}}$ is too small to enter the zonal balance of forces. The eastward vertical friction somewhat accelerates the lower levels of region (4), but its upper levels (dissipated mostly laterally) have for sole source of eastward momentum the western accelerating region which has the effect of a Bernoulli head.

The ZMB within the various parts of the upper $[1,1),(3)]$ and lower $[12),(4)]$ EUC can be written:

$$
\begin{aligned}
& \overline{\text { Du/Dt }}=-\overline{p_{x} / \rho_{0}}+\left(\overline{v u_{z}}\right)_{z}>0 \\
& \text { with } \overline{u u_{x}}>0
\end{aligned}
$$

$$
\begin{aligned}
& \overline{\text { Du/Dt }}=-\overline{p_{x} / \rho_{0}}>0 \\
& \text { with } \overline{u u_{x}}>0
\end{aligned}
$$

$$
\left.\overline{\left(v u_{y}\right.}+\right) \overline{w u_{z}}=\overline{-p_{x} / \rho_{0}}+\overline{\left(v u_{z}\right)_{z}}<0
$$

a negative $u u_{x}$ also enters the balance in the east

$$
\overline{u u_{x}}+\overline{w u_{z}}-\overline{A \nabla^{2} u}=\overline{-p_{x} / \rho_{0}}+\left(\overline{v u_{z}}\right)_{z} \sim 0
$$

$$
<0 \quad<0 \quad>0
$$


where $\overline{-p_{x} / \rho_{0}}$ and $\overline{\left(\nu u_{z}\right)_{z}}$ tend to enter the balance only in the lower levels of region (4) where $\bar{w}$ has become downwards.

\subsubsection{Time evolution of the ZMB at $0^{\circ} \mathrm{N}-25^{\circ} \mathrm{W}$}

In the previous section, we have investigated how the balance of forces within the EUC changes with longitude, how part of these changes can be traced back to longitudinal variations in the dynamical forcing itself, and how they can explain the longitudinal variations of the simulated circulation described in section 3.2.1. The goals of the present section are to investigate how the balance of forces changes with time at given longitudes, how these changes relate to temporal variations of the local forcing, and how they can explain the temporal variations of the simulated circulation described in section 3.2.2. The main focus of this dissertation being the mean circulation, the study of the time evolution of the ZMB is 1 imited to $25^{\circ} \mathrm{W}$ (a typical mid-basin 1ongi tude).

Figure 61 presents all the terms of the ZMB, calculated from the three-day averaged model output, as a function of depth and time at $0^{\circ} \mathrm{N} 25^{\circ} \mathrm{W}$. The thick dotted line represents the position of the center of the thermocline, defined as the depth at which the vertical gradient of $\rho_{s}$ (the local density relative to the surface one) reaches its largest absolute value. All the fields are drawn using the same contour interval of $2 \times 10^{-7} \mathrm{~m} / \mathrm{s}^{2}$ (or $2 \times 10^{-5} \mathrm{dyne} / \mathrm{g}$ ), making it clear that, in time, the dynamics above the thermocline are dominated by the meridional and vertical advection of zonal momentum $(c, d)$, the $Z P G$ force $(f)$, and the term of vertical friction $(g)$, just as in the annually averaged case. The Coriol is force (e) is uniformly zero at the equator.

In the fall, the thirty-day waves which were seen to greatly distort the circulation in the meridional plane (Figure 48) have, not unexpectedly, a clear signature in the fields of $v u_{y}$ (Figure $61 c$ ) and $w u_{z}(d)$. To a lesser extent, they also appear at the 


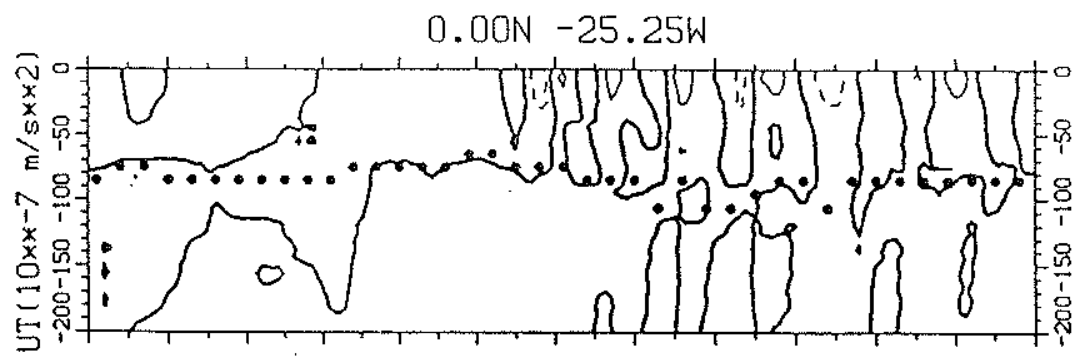

$\mathbf{b}$
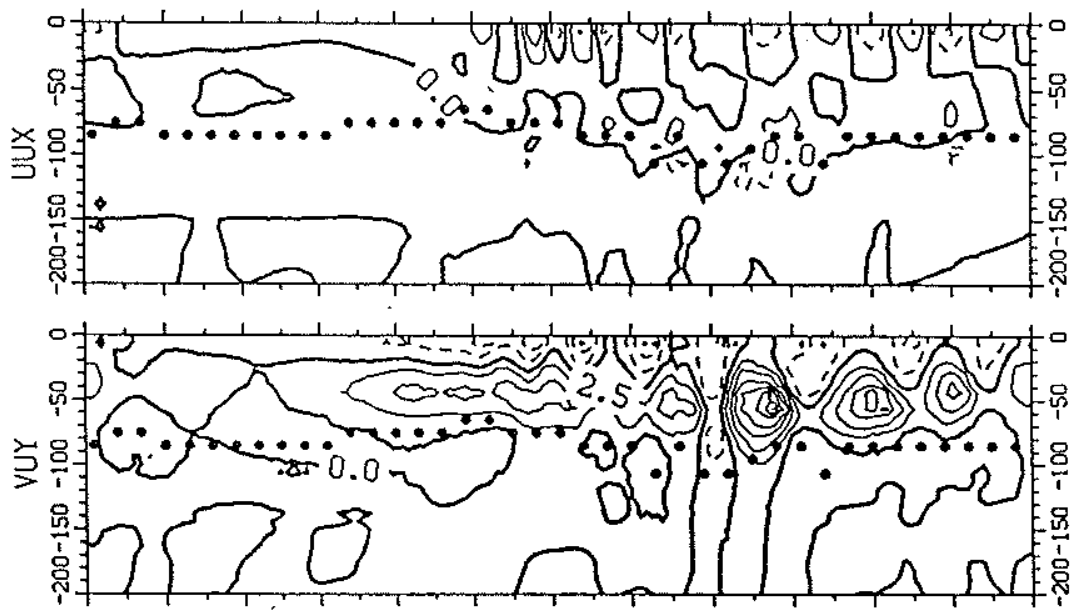

c

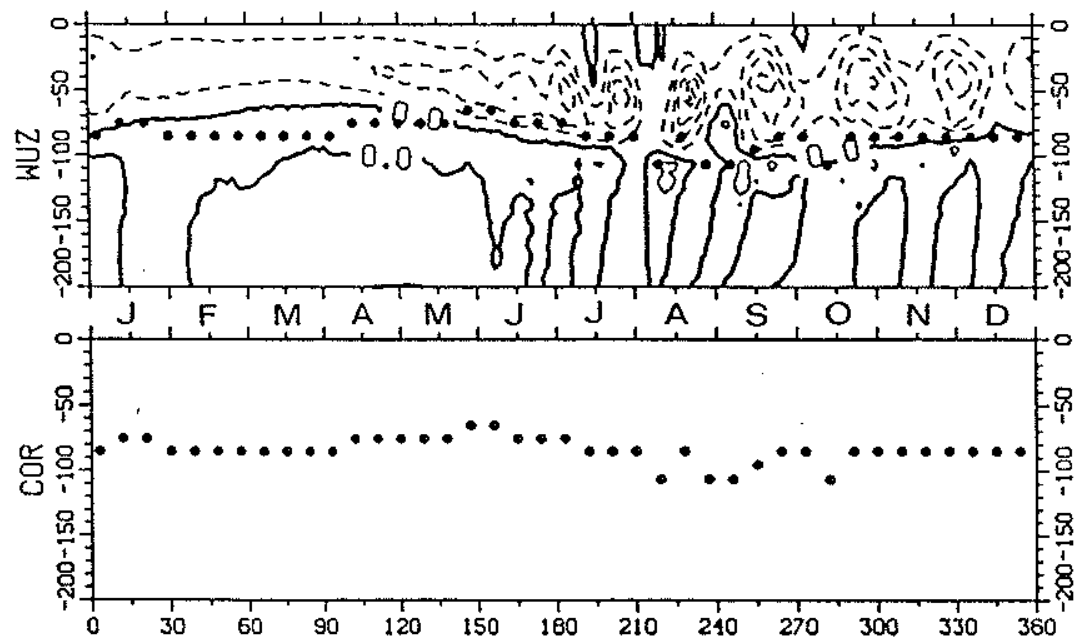

d

e

Figure 61: Time-depth contour plots of the terms of the simulated zonal momentum balance at $0^{\circ} \mathrm{N} 25^{\circ} \mathrm{W}$ above $200 \mathrm{~m}$. The dotted line indicates the location of the middle of the thermocline (see Figure 48). All fields are scaled identically (contour interva1 $2.5 \times 10^{-7} \mathrm{~m} \mathrm{~s}^{-2}$ ). 
264 


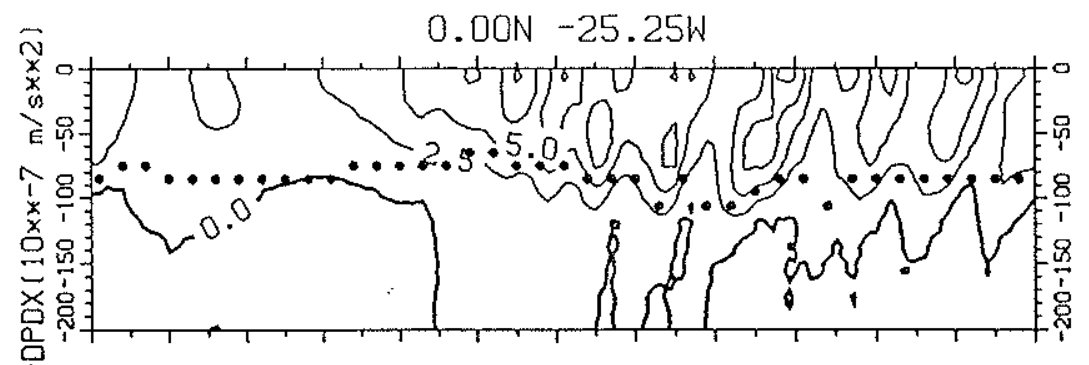

9
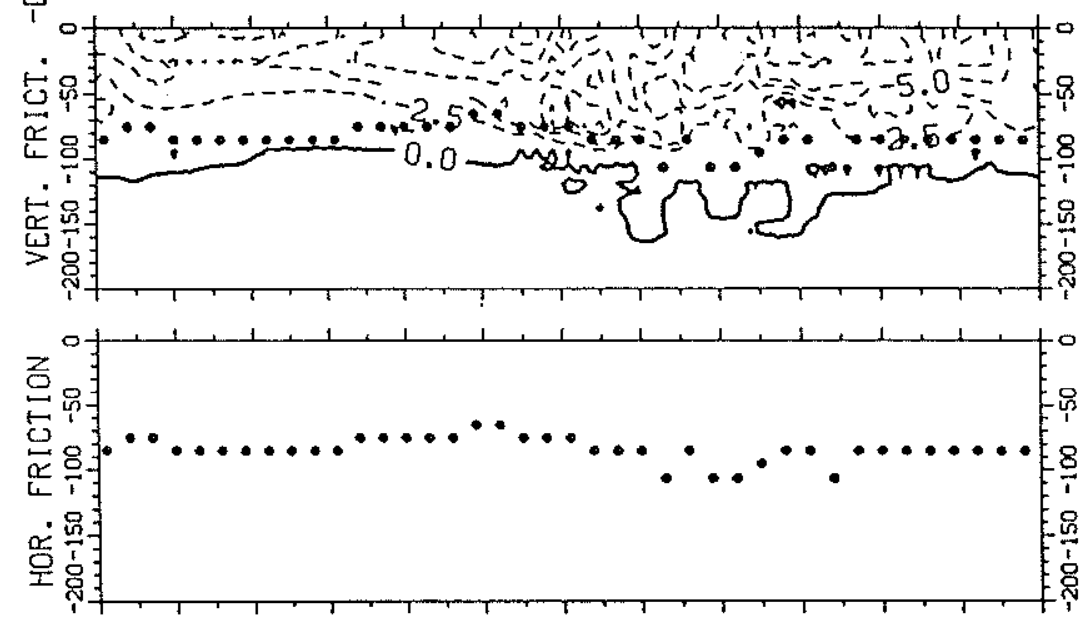

h
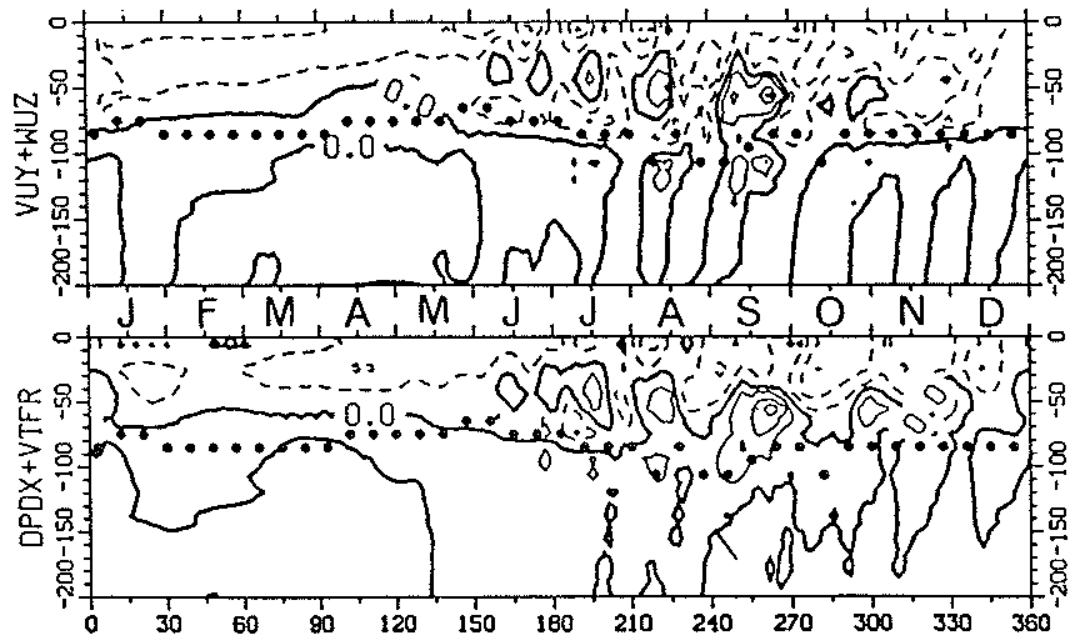

Figure 61 (Continued) 
surface in the fields of $u_{t}(a)$ and $u_{x}(b)$, and they noticeably distort the fields of $\left(-p_{x} / \rho_{0}\right)(f)$ and $\left.l_{\nu} u_{z}\right)_{z}(g)$. For our purpose, their presence in the western basin in the fall is of concern only because of the possibility that they may interact with the mean flow and be, on the mean, a source or a sink of zonal momentum for the EUC. In order to appreciate their effect on the annually averaged EUC, associated Reynolds stresses were estimated using the following procedure. First the sum of the advective fluxes of the mean ZMB was computed as in section 3.3.1, using the three-day averaged simulated velocity field at each of the 120 time-steps of the model output, and accumulating and averaging them over the year. Second the sum of the same terms was computed from the annually averaged simulated velocity field. The difference between the two, as written explicitly below, is the divergence of the Reynolds stresses, which acts as an extra force on the righthand side of the equation for the mean zonal flow $u$ :

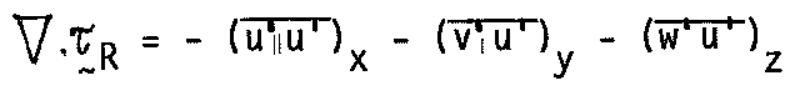

$$
\begin{aligned}
& =\left[(\bar{u} \bar{u})_{x}+(\bar{v} \bar{u})_{y}(\bar{w} \bar{u})_{z}\right]-\left[(\overline{u u})_{x}+(\overline{v u})_{y}+(\overline{w u})_{z}\right]
\end{aligned}
$$

with $\underset{\sim}{\bar{u}}$ the annually averaged velocity and with: $\underline{\sim}_{\sim}^{\prime} \equiv \underset{\sim}{u}-\bar{u}$. The computation was performed along meridional sections at $40^{\circ} \mathrm{W}$ and $25^{\circ} \mathrm{W}$ between $3^{\circ} \mathrm{S}$ and $2^{\circ} \mathrm{N}$. $\nabla \cdot \tau_{\sim}$ appears 1 arger (in absolute value) at $40^{\circ} \mathrm{W}$, where the waves are stronger than at $25^{\circ} \mathrm{W}$, and largest between $0^{\circ} \mathrm{N}$ and $1^{\circ} \mathrm{N}$. But at either longitude, this term is essentially negligible compared to the other forcing terms of the balance.

Thus the thirty-day waves in the model appear to perturb the mean state without having an appreciable net effect on the zonal circulation. In the following, at longitudes where instability waves develop during the fall, a thirty-one day running average is applied to the fields of computed dynamical terms as it was on the fields of simulated velocity in section 3.2.2. 
We saw on Figure 49 that, on average, to the stronger wind stress of the summer-fall period (a) correspond at $0^{\circ} \mathrm{N} 25^{\circ} \mathrm{W}$ (1) a more intense surface circulation in both the zonal and the meridional direction (b, c), (2) a more intense subsurface circulation in the meridional plane $(c, d), \downarrow 3)$ some spreading of the upper thermocline $(e)$, and (4) an eastward reversal of the deep flow below the EUC (b). The core of the EUC itself appears only slightly faster and deeper in the fall than in the spring, with the two states separated by a brief intermediate state of weakened flow (b).

Figure 62 now shows the terms of the smoothed $Z M B$ at $0^{\circ} \mathrm{N}$ $25^{\circ} \mathrm{W}$ (compare with Figure 61 ). The contour interval was reduced to $1 \times 10^{-7} \mathrm{~m} / \mathrm{s}^{2}$ for the dominant terms and to $0.5 \times 10^{-7} \mathrm{~m} / \mathrm{s}^{2}$ for $u_{t}$ (a), $u u_{x}(b)$ and $A \nabla^{2} u(h)$. The thick dotted 1 ine still indicates the position of the center of the thermocline. Above and in the upper thermocline, $u_{t}$ is consistently negligible, and the zonal momentum equation can be said to go through a succession of steady states:

$$
\left.v u_{y}+w u_{z}=-p_{x} / \rho_{0}+I_{v} u_{z}\right)_{z}
$$

In the spring when the wind forcing is weaker, all four terms are weaker, while in the fall following its intensification all four terms are stronger. The upper parts of frames $j$ and $i$ labove the dotted 1 ine on Figure 62) show the time and depth evolution of $\left[-p_{x} / \rho_{0}+\right.$ $\left.\left(v u_{z}\right)_{z}\right]$ and $\left[v u_{y}+w u_{z}\right]$ respectively. They thus show the evolution of the net force acting on the zonal flow at $0^{\circ} \mathrm{N} 25^{\circ} \mathrm{W}$, and of the net resulting acceleration. Throughout most of the year, the net force tends to be dominated by friction as for the annual mean, and therefore to correspond for the upper EUC to a deceleration caused by a net loss of zonal momentum upwards. An exception to this regime can be observed in the fall around $65 \mathrm{~m}$ where the net force reverses to eastwards for a while due to the temporary predominance of $\left(-p_{x} / \rho_{0}\right)$ over $\left(v u_{z}\right)_{z}$, while vu $u_{y}$ and $w u_{z}$ still add up to a negative acceleration: a small positive $u u_{x}$ needs enter the ZMB as a consequence (b).

Let us summarize the time evolution of the upper EUC dynamics at $0^{\circ} \mathrm{N} 25^{\circ} \mathrm{W}$ using Figure 63 which, for clarity, isolates 


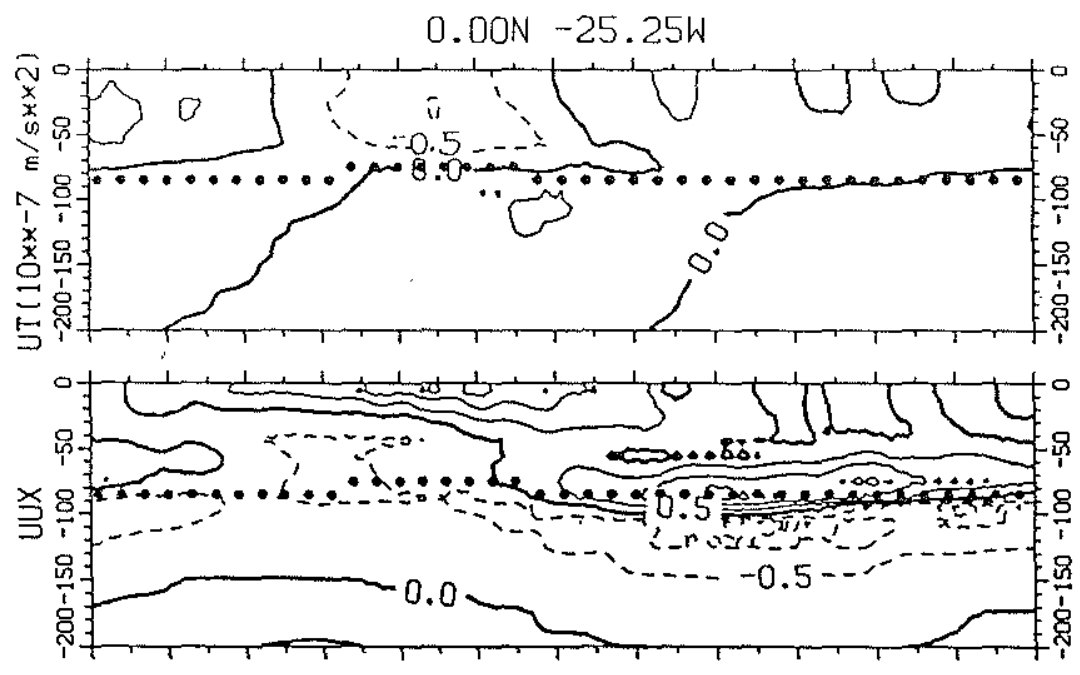

a

b

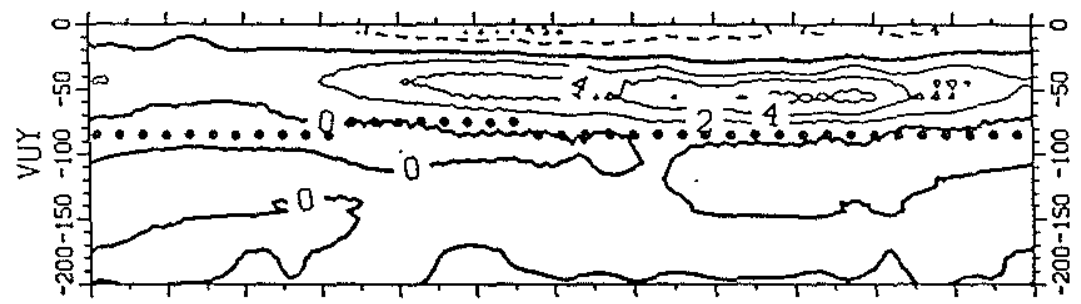

$\mathbf{c}$

d

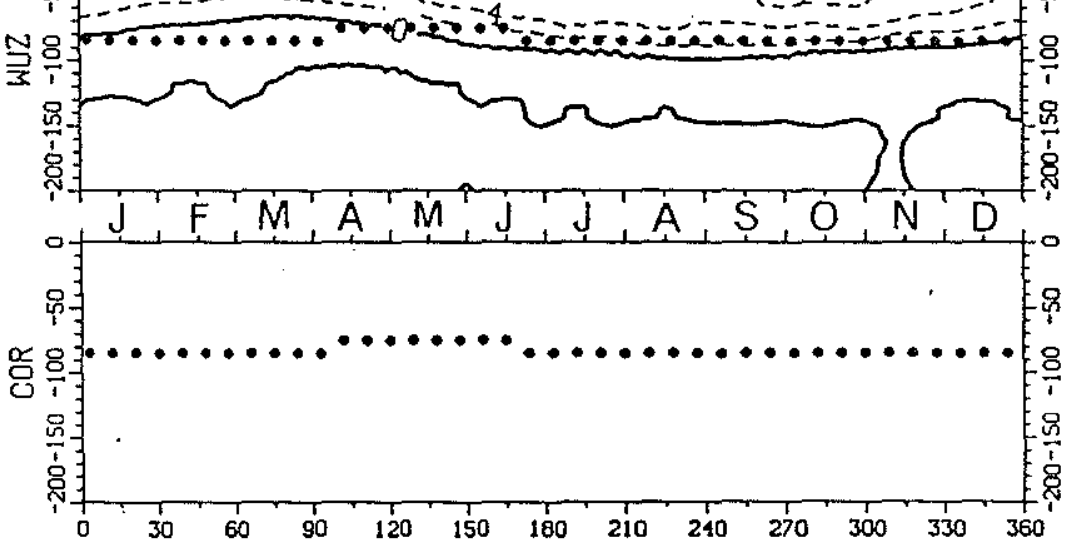

e

Figure 62: Same as Figure 61 after a one-month running average has been applied to all fields. The contour interval is $2 x$ $10^{-7} \mathrm{~m} \mathrm{~s}^{-2}$ except for $u_{t}(a), u u_{x}$ (b) and $A \nabla^{2} u(h)$ where it is $0.5 \times 10^{-7} \mathrm{~m} \mathrm{~s}^{-2}$. 

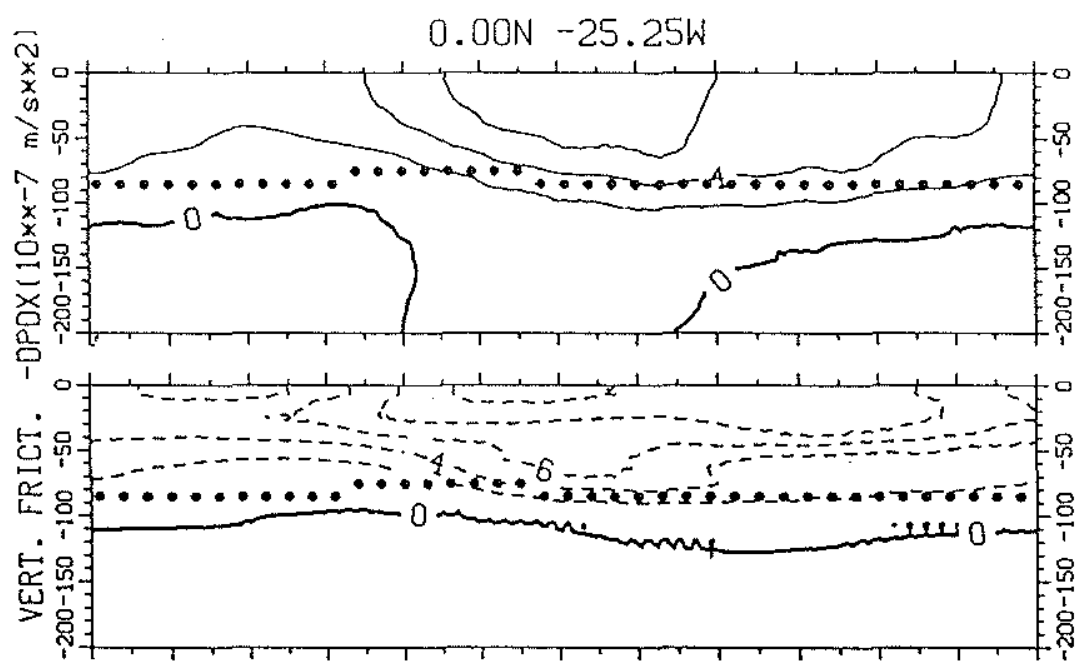

$\mathbf{g}$

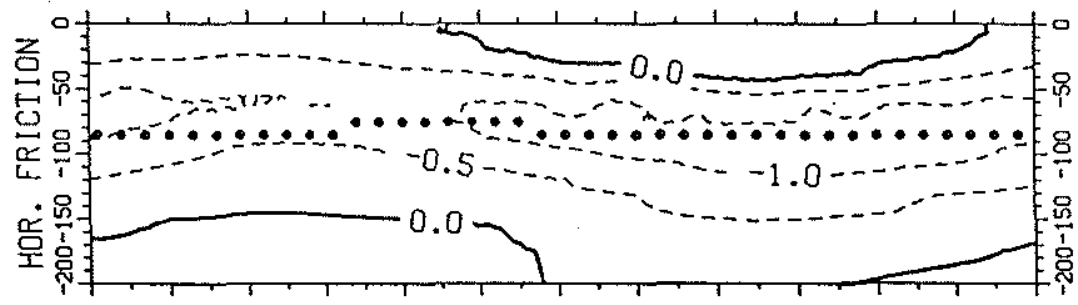

h
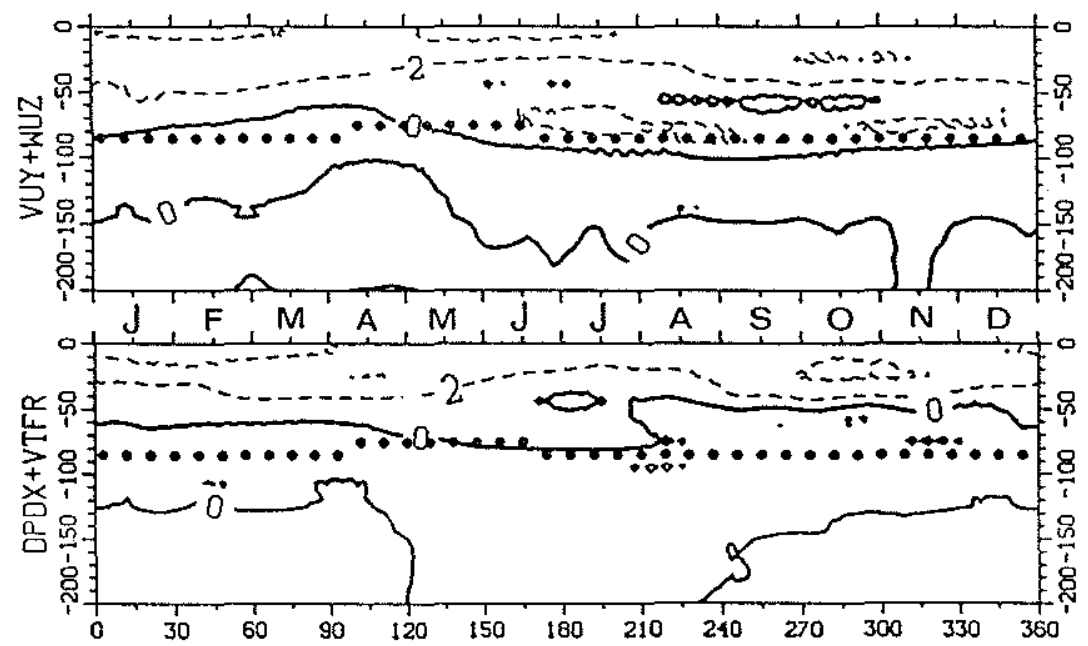

Figure 62 (Continued) 


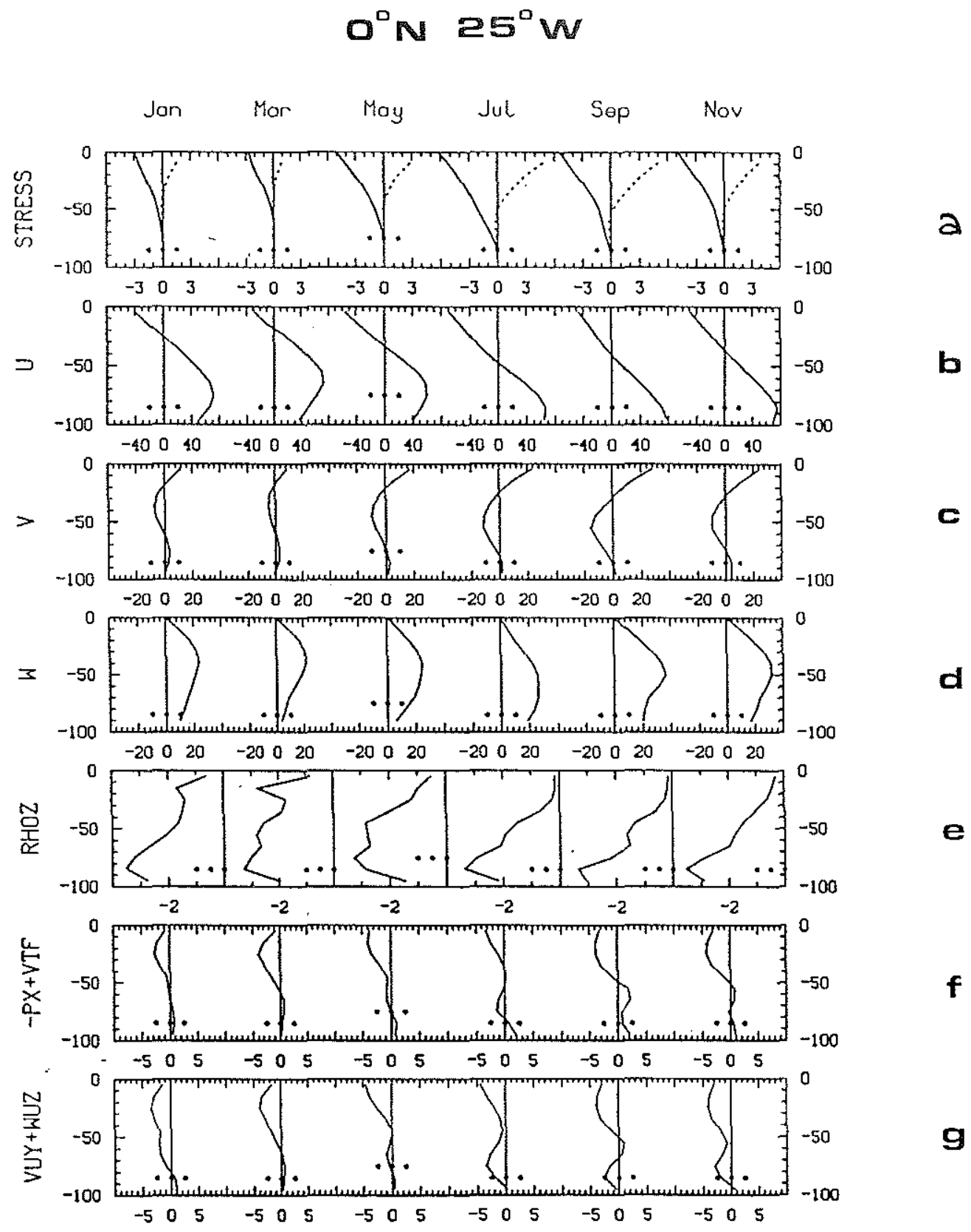

Figure 63: Vertical profiles of the simulated stress (a), velocity components ( $b$ to $d$ ), density (e) and ZMB terms ( $h$ to $n$ ) at $0 \mathrm{~N}$, $25^{\circ} \mathrm{W}$ at the end of every other month above $100 \mathrm{~m}$. Panels $(\mathrm{f})$ and (g) show the sums $\left[-p_{x} / \rho_{0}+\left(v u_{z}\right)_{z}\right]$ and $\left(v u_{y}+w u_{z}\right)$ respectively. The dotted line indicates the location of the middle of the thermocline. 


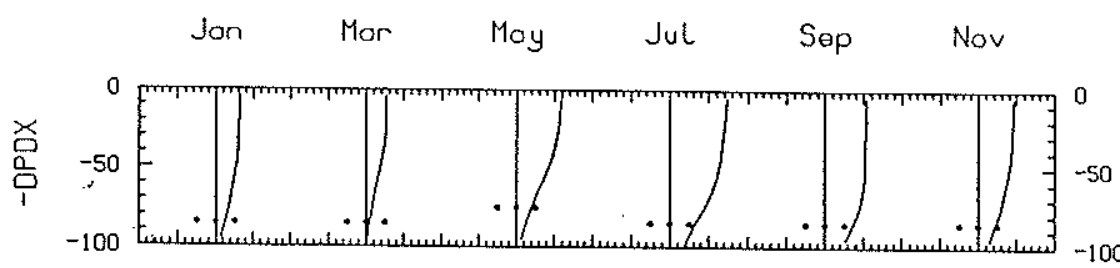

h
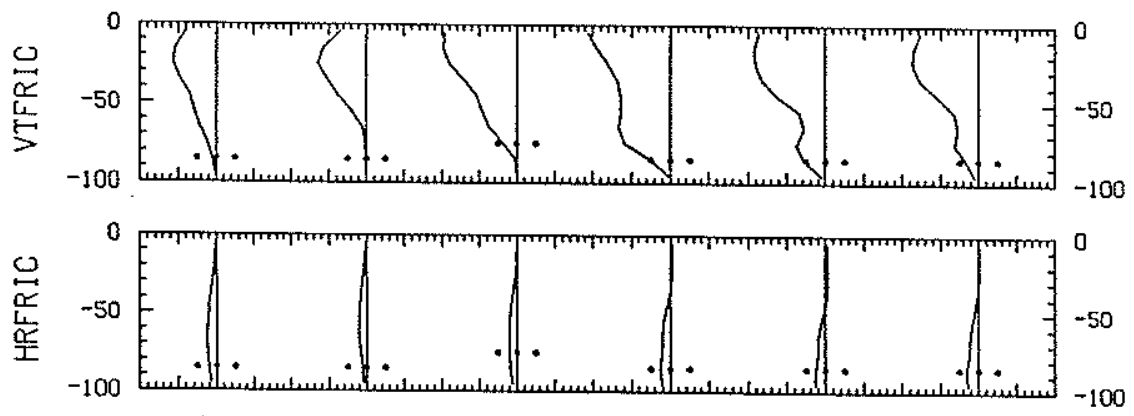

$\underbrace{-50}$

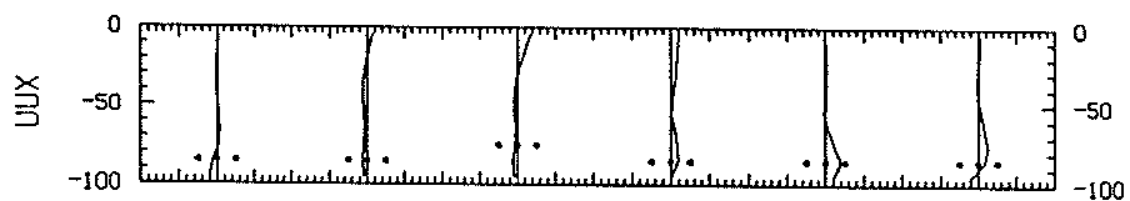

k

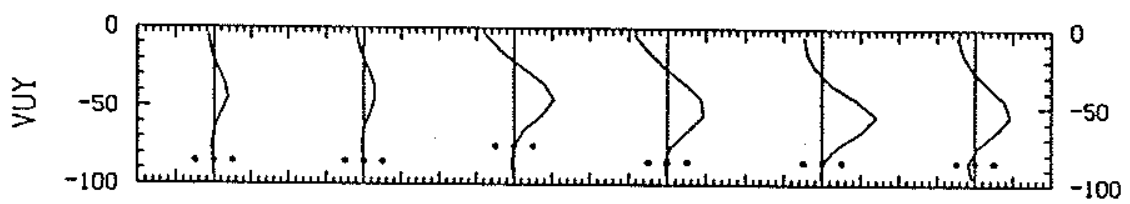

$m$

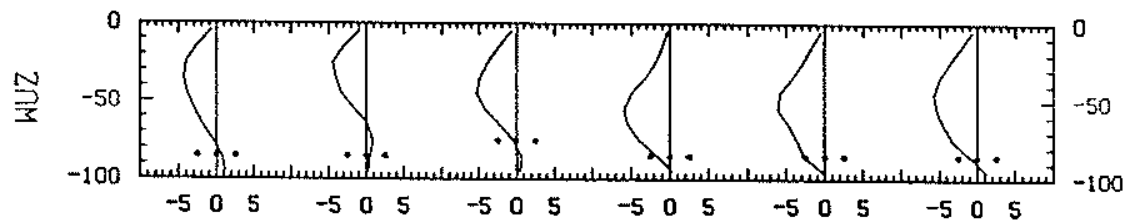

n

Figure 63 (Continued) 
276 
bimonthly vertical sections from the continuous time series presented previously. Between March and July, the strength of the easterlies doubles (a), and so do the depth of penetration of the zonal stress into the ocean, and the strength and thickness of the westward surface current (b). The strength of the northward surface flow and of the southward subsurface flow increases by a factor closer to 3 (c), as do the strengths of the surface ZPG force ( $h$ ) and vertical friction (i), and the surface and subsurface lobes of meridional advection of zonal momentum $(m)$. Changes in the vertical velocity (d) and in the vertical advection of zonal momentum $(m)$ as more subtle. The increase of westward momentum in the surface layer between March and July appears in the clear change of slope of the profiles of forcing ( $f$ ) and deceleration $(g)$ at the surface. The decrease of eastward momentum between the $55 \mathrm{~m}$ and $85 \mathrm{~m}$ levels during the same period appears similarly as a change of sign of both profiles in that depth range ( $f$ and $g$ ). The deeper penetration of the forcing in the summer and fall coincides with a weaker stratification $\partial \rho_{s} / \partial z$ (e) near the surface. During this time, the downward tapering of the ZPG force by baroclinic adjustment effectively starts deeper. However, the net effect of the local wind increase at $0^{\circ} \mathrm{N} 25^{\circ} \mathrm{W}$ appears to be a net weakening of the upper EUC because an excess of westward momentum is introduced frictionally in the surface layer and vertical exchanges with the underlying EUC are amplified.

Let us now describe the time evolution of the flow in and below the lower thermocline at $0^{\circ} \mathrm{N} 25^{\circ} \mathrm{W}$. Figure 62 is not very useful for that purpose since $i$ ts scales were appropriate for the upper regime. Let us therefore use Figure 64 which presents the rescaled lower part of the bimonthly vertical sections of Figure 63 . From Figure $64 \mathrm{~h}$ to $n$, it is clear that, at $0^{\circ} \mathrm{N} 25^{\circ} \mathrm{W}$, only the terms of vertical friction (i) and meridional advection of zonal momentum (m) have become negligible compared to the other terms of the ZMB below $100 \mathrm{~m}$. The zonal balance of forces therefore reduces to: 


$$
u_{t}+u u_{x}+w u_{z}=-p_{x} / \rho_{0}+A \nabla^{2} u
$$

Recall that, on the annual mean, it could be further simplified to:

$$
\overline{u u_{x}}+\overline{w u_{z}}=\overline{A \nabla^{2} u}
$$

Since $\overline{u_{t}}=0$ by definition of the averaging operator, that means that: $\frac{p_{x} / p_{0}}{1}=0$. Indeed, below about $100 \mathrm{~m}$, the vertical profiles of $\left(-p_{x} / \rho_{0}\right)(h)$ and of $u_{t}(k)$ both change sign throughout the year while the profiles of $u u_{x}(1)$ and $w u_{z}(n)$ only change amplitude. As the zonal flow weakens with depth, nonl inear terms become negligible and the balance ultimately simplifies to the 1 inear equation:

$$
u_{t}+p_{x} / p_{0}=0
$$

So the lower thermocline regime, described in the annual mean as a dissipative inertial jet traceable to a western source, appears to be seasonally modulated by local accelerations and decelerations balancing positive and negative values of the deep ZPG force. Positive values of the ZPG force at depth in turn seem to be a local response to the intensification of the overlying easterlies, since these values are seen at the same time as an increase in the surface ZPG force when the stratification of the upper layers weakens. The increase in the local easterlies, which has a net decelerating effect on the upper EUC at $0^{\circ} \mathrm{N} 25^{\circ} \mathrm{W}$, on the contrary has a net accelerating effect on the lower EUC. That explains the apparent downward displacement of the core at a time of increased upwelling (Figure 49b,d). 
$0^{\circ} \mathrm{N} e 5^{\circ} \mathrm{N}$

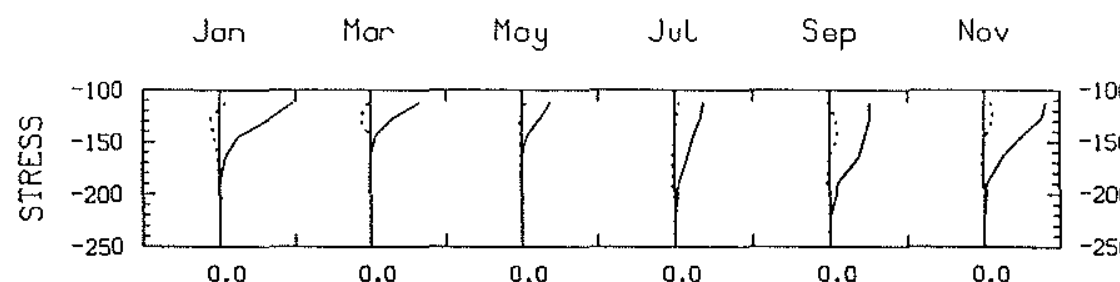

a

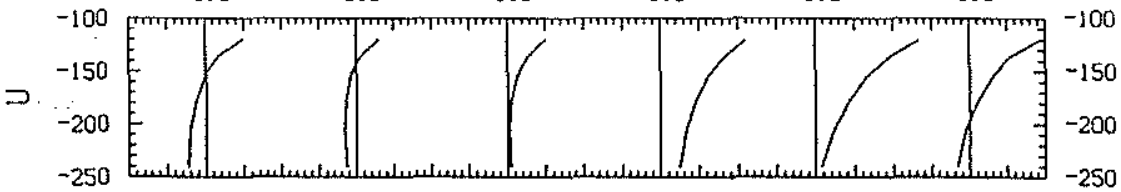

$-150$

b

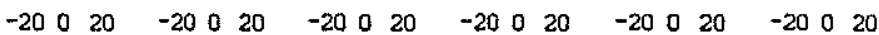

$>-150$ - 200 -

$\mathbf{c}$

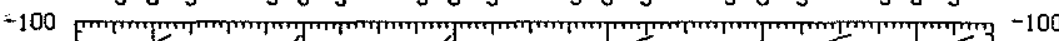

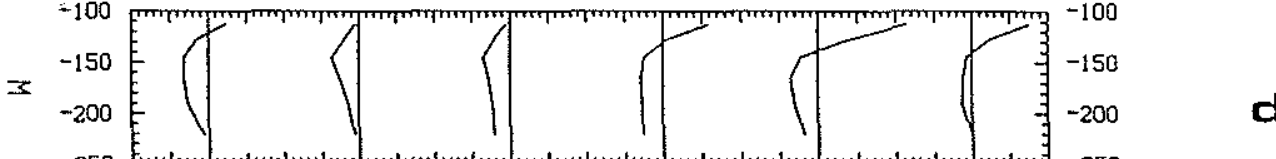

d

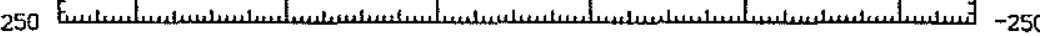

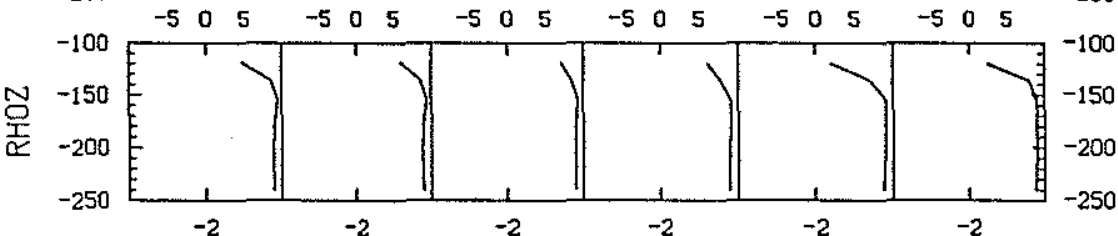

150

200

e

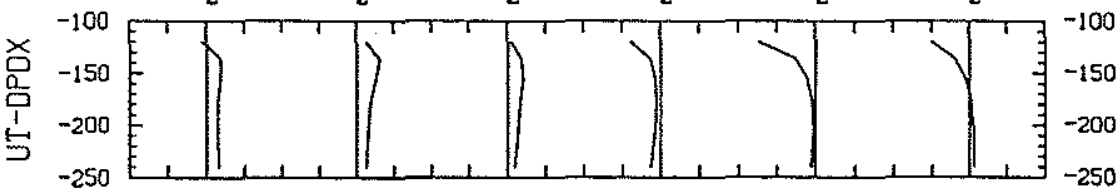

$-150$

200

$\mathbf{f}$

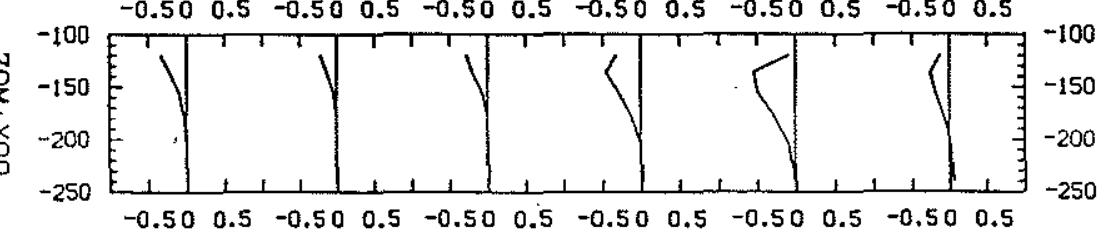

9

Figure 64: Same as Figure 63 but for the range $100 \mathrm{~m}$ to $250 \mathrm{~m}$. The scales for the ZMB terms ( $f$ to $n$ ) is one tenth of that of Figure 63. Note also the scale changes for $u, v$ and $w$ (b to $d$ ). 


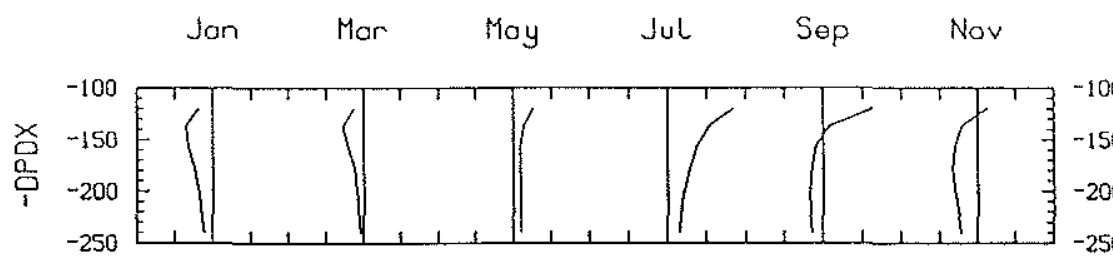

h
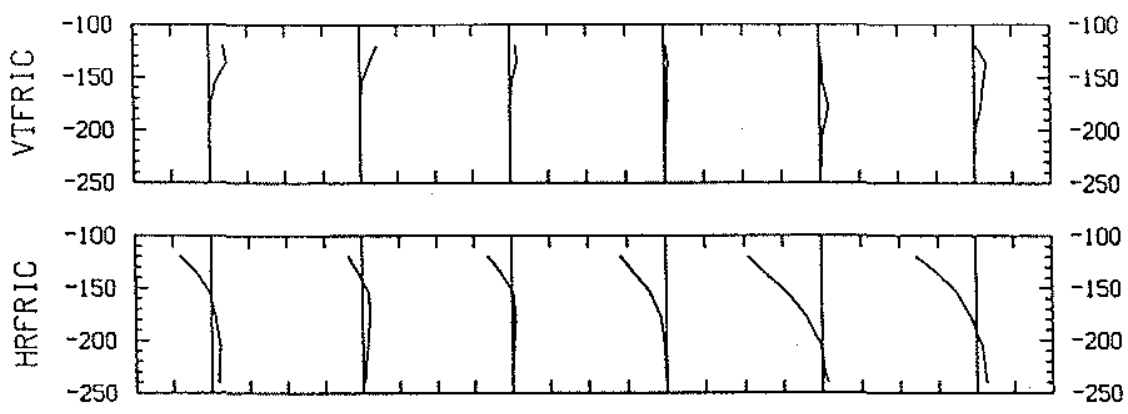
$-150$ 200
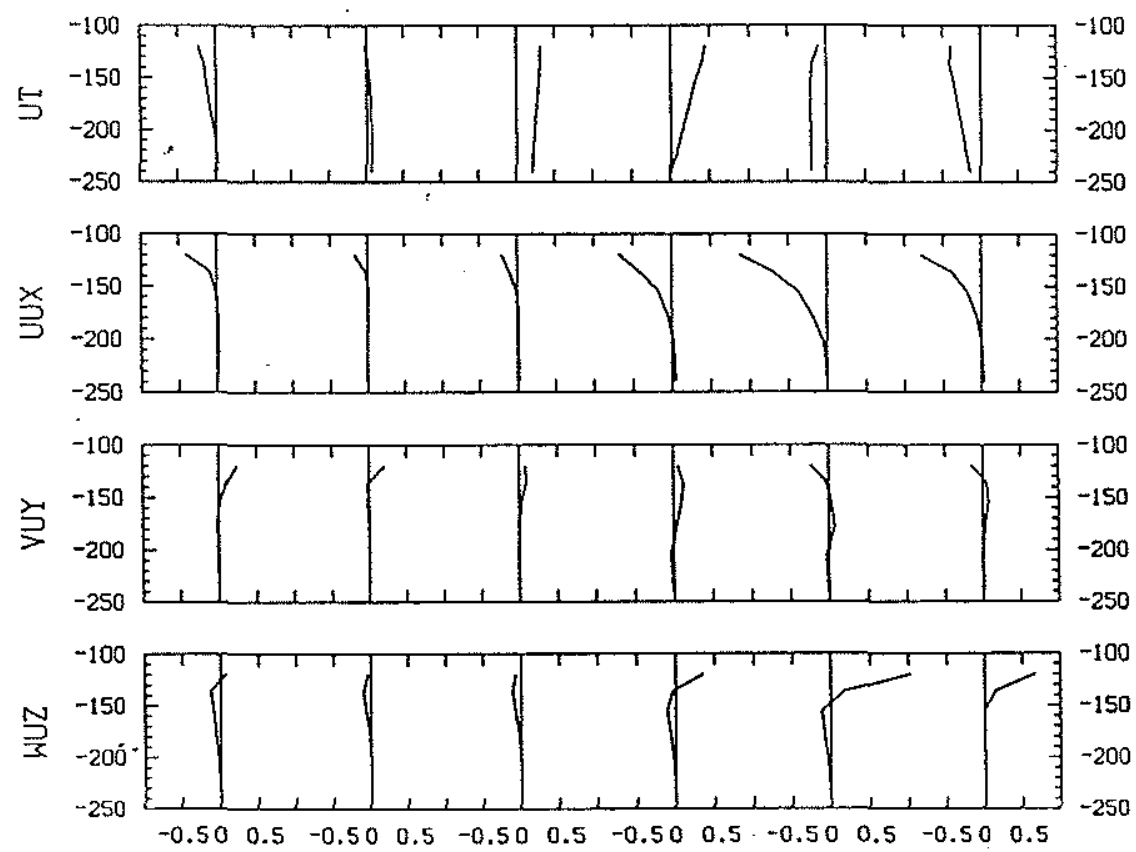

m

n

\section{Figure 64 (Continued)}


Chapter 4. PERFORMANCE OF THE GENERAL CIRCULATION MODEL IN SIMULATING ATLANTIC OBSERVATIONS

We have seen in chapter 3 that the GCM simulates an EUC which accelerates zonally over a relatively narrow western region then slowly decelerates over most of the remaining basin. The simulated undercurrent tended to be found above the middle of the thermocline in the west and mostly below the thermocline in the east. Frictional processes were shown to be responsible for these behaviours. This contrasts with the concept of an inertial current which would conserve its momentum or keep accelerating eastwards while closely following isopycnals, and which would decelerate abruptly only as it impinges on an eastern wall.

Direct and indirect observations yield estimates of frictional terms of the same order of magnitude as the inertial terms at the equator. In the Pacific, Lukas $(1981,1986)$ describes the EUC as impinging on the Galapagos Islands at about $92^{\circ} \mathrm{W}$ (section 2.1 ), but a large scale weakening of the flow of about $0.75 \times 10^{-2} \mathrm{~m} \mathrm{~s}^{-1}$ per degree of longitude has already taken place between $150^{\circ} \mathrm{W}$ and $110^{\circ} \mathrm{W}$, eighteen degrees of longitude west of the Galapagos (Bryden and Brady, 1985). In the Atlantic, the recent SEQUAL/FOCAL observational program similarly shows a large scale zonal weakening of about $0.80 \times 10^{-2} \mathrm{~m} \mathrm{~s}^{-1}$ per degree of longitude between $28^{\circ} \mathrm{W}$ and $4^{\circ} \mathrm{W}$, ten degrees of longitude west of Sao Tome Island (Weisberg and Colin, 1986). The FOCAL data set also seems to agree with the model's prediction of an EUC above the thermocline in the west, below in the east (Figure 65; Hénin et a1., 1986). This feature is worth emphasizing since it has received little attention in the past.

On an equatorial section of the simulated temperature, only the isotherms of the western upper thermocline slope upwards to the east. The isotherms of the western lower thermocline on the contrary tend to "peel off" eastwards and become horizontal or bend downwards forming a 1 ayer of weak stratification of increasing thickness to the east. This 
again is a realistic feature of the observations (Figure 66; Lemasson and Piton, 1968). As mentioned in chapter 2, the resulting thermostad has even been treated as an indicator of the EUC in the eastern Pacific by Lukas (1981, 1986). We will see below why we agree that the model's thermostad constitutes one of its dynamical responses rather than a reflection of the imposed initial stratification.

In section 3.2, we saw that, when forced by climatological wind stresses (Hellerman and Rosenstein, 1983), the GCM simulates many other known features of the equatorial circulation, such as the western instability waves and the eastern surface cooling during summer and fal1. Less satisfactory was the absence of instability waves in the east, the tendency for the simulated western surface flow to be too fast, and the tendency for the simulated EUC to have a lesser overal1 amplitude and eastward penetration than observed. The uncertainty of the wind stress and the suspicion that it might be overestimated by Hellerman and Rosenstein's choice of drag coefficient was noted.

Before incriminating any aspect of the model (in particular its parameterizations of frictional processes), it is interesting to examine the model response to a field of weaker wind stress. Philander and Pacanowski (personal communication) reran the Atlantic model using a monthly smoothed version of the wind stress field collected during the SEQUAL program (Harrison and Cardone, 1984; Cardone, Greenwood, Tourre and Chavy, 1988) and reported to be about 75 percent of the Hellerman and Rosenstein's climatology overal1. That run is particularly valuable since its results can be directly compared to "simultaneous" ocean measurements.

This chapter compares observations from the SEQUAL/FOCAL program with the GCM run forced by the "SEQUAL winds". Then this run is compared to another run forced by the climatological wind stress field divided by two. A discussion follows and ways to improve the simulation are proposed to conclude the chapter. 


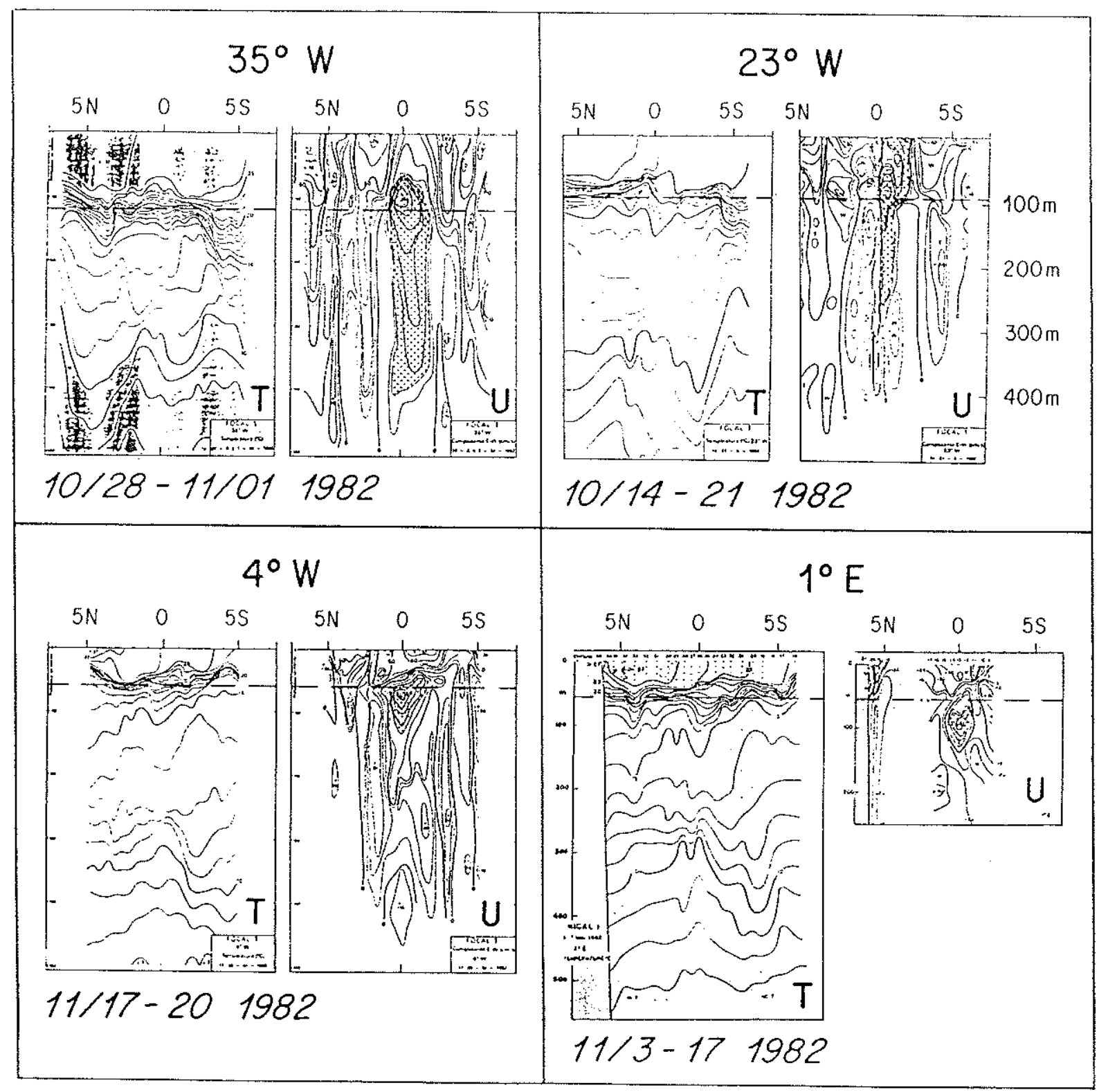

Figure 65: Meridional sections of observed temperature and zonal velocity $\left(5^{\circ} \mathrm{S}-5^{\circ} \mathrm{N}, 0-500 \mathrm{~m}\right)$ at $35^{\circ} \mathrm{W}, 23^{\circ} \mathrm{W}, 4^{\circ} \mathrm{W}, 1^{\circ} \mathrm{E}$ (FOCAL-NICAL program; Hénin et al., 1986). 


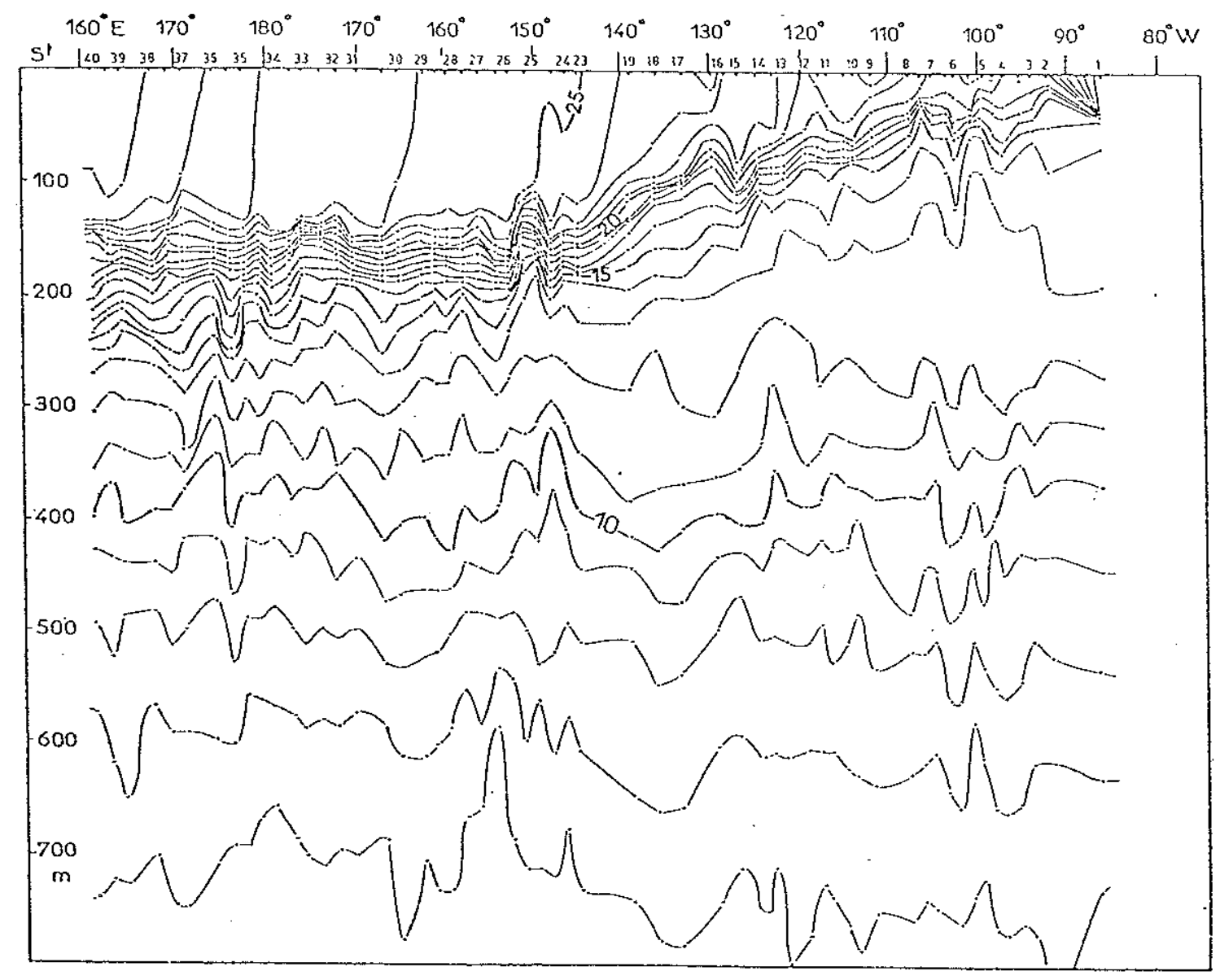

Figure 66: Equatorial section of temperature across the Pacific Ocean (cruise ALIZE, 1965; Lemasson and Piton, 1968). 


\subsection{The SEQUAL run}

In Figures 67 and 68, time series of temperature and zonal velocity respectively are represented as a function of depth. Upper panels correspond to moored observations at $0^{\circ} \mathrm{N} 28^{\circ} \mathrm{W}$ and lower panels to the simulation at $0^{\circ} \mathrm{N} 30^{\circ} \mathrm{W}$. Due to the smoothing of the forcing field by months, the simulation lacks the higher frequencies apparent in the observations of both $T$ and $u$. On average, the model thermocline has similar depths and temperatures as the observed thermocline, but tends to be centered $20 \mathrm{~m}$ shallower on average (Figure 67). Periods of warmer and cooler surface temperature roughly coincide, but shallowings and deepenings of the thermocline appear steeper in the observations. There is a tendency for the model ocean to be warmer by about $1^{\circ} \mathrm{C}$ below the thermocline (see the range 150-200 $\mathrm{m}$ on Figure 67 ).

The model EUC core is also found within the right range of depths, al though again slightly shallower $(70 \mathrm{~m}$ versus $85 \mathrm{~m}$ on average, Figure 68 ). The amplitude of its zonal velocity at $30^{\circ} \mathrm{W}$ compares we 11 with the current meter measurements at $28^{\circ} \mathrm{W}$, except in the fall of 1984 when it is weaker. The apparent vertical motion of the EUC core in response to changes in the easterly wind stress forcing and in the depth of the westward surface flow is clearly a common feature to both the observations and the simulation. No clear pattern of seasonal variation in EUC core velocity however emerge from either the observations or the simulation. Finally the simulated EUC appears to penetrate less deep than the observed EUC or equivalently to have stronger vertical shear below the core: by $200 \mathrm{~m}$, the model subsurface flow has reached $0.0 \mathrm{~m} / \mathrm{s}$ on average while the observed flow is still eastwards at about $0.2 \mathrm{~m} / \mathrm{s}$.

Figures 69 and 70 present a similar comparison between observed and simulated time series of $T$ and $u$ near $0^{\circ} \mathrm{N} 4^{\circ} \mathrm{W}$. At this longitude, the simulated thermocline tends to be shallower than the observed one ( $25 \mathrm{~m}$ versus $40 \mathrm{~m}$ on average, Figure 69). It also tends to be sharper (e.g. $2^{\circ} \mathrm{C}$ per $5 \mathrm{~m}$ versus $1^{\circ} \mathrm{C}$ per $5 \mathrm{~m}$ in November 1983). The clear seasonal sequence of upwellings and downwellings of the observed thermocline does coincide with that of the model's thermocline. 
The displacements of the deep isotherms in the model however tend to $1 \mathrm{ag}$ those in the observations by about one month and to have a larger amplitude, sharpening the eastern thermocline even further. Warmings and coolings of the sea surface roughly coincide in timing and amplitude. Again, however, the temperatures below the thermocline tend to be warmer in the model than in the ocean $117^{\circ} \mathrm{C}$ versus $15^{\circ} \mathrm{C}$ at $100 \mathrm{~m}$ on average). Comparing Figures 67 and 69 then, one can see that the observed mean temperature at $100 \mathrm{~m}$ changes from about $18^{\circ} \mathrm{C}$ at $28^{\circ} \mathrm{W}$ to about $15^{\circ} \mathrm{C}$ at $4^{\circ} \mathrm{W}$. By contrast, the simulated mean temperature at $100 \mathrm{~m}$ only changes from about $18^{\circ} \mathrm{C}$ at $30^{\circ} \mathrm{W}$ to about $17^{\circ} \mathrm{C}$ at $4^{\circ} \mathrm{W}$. It is therefore possible that the model underestimates the value of the zonal pressure gradient below the thermocline and underestimates the vertical penetration of its accelerating effect. As a possible illustration, the rate of weakening of the observed EUC core velocity between $28^{\circ} \mathrm{W}$ and $4^{\circ} \mathrm{W}$ is about $-0.8 \times 10^{-2} \mathrm{~m} / \mathrm{s}$ per degree of longitude; but the same rate in the SEQUAL simulation between $30^{\circ} \mathrm{W}$ and $4^{\circ} \mathrm{W}$ is $-1.9 \times 10^{-2} \mathrm{~m} / \mathrm{s}$ per degree of longitude, about two times as large.

Like the thermocline, the simulated EUC core at $4^{\circ} \mathrm{W}$ appears shallower than the observed core $145 \mathrm{~m}$ versus $60 \mathrm{~m}$ on average, Figure 70). The westward surface flow tends to be weaker $10.30 \mathrm{~m} / \mathrm{s}$ versus $0.50 \mathrm{~m} / \mathrm{s}$ ), and so does the eastward subsurface flow (peak velocity of $0.40 \mathrm{~m} / \mathrm{s}$ versus $0.80 \mathrm{~m} / \mathrm{s}$, velocity at $100 \mathrm{~m}$ of $0.05 \mathrm{~m} / \mathrm{s}$ versus $0.40 \mathrm{~m} / \mathrm{s}$ ). However, the seasonal evolution of the flows (eastward reversals of the surface current, intensifications of the EUC) is rather well reproduced by the GCM.

So, when forced by the SEQUAL winds, Philander and Pacanowski's GCM produces a thermocline which is shallower than observed, and considerably sharper in the east. Below the thermocline the model produces slightly warmer temperatures and a slower eastward flow. The simulated EUC has a core velocity comparable to the observations in the west but about half as fast in the east. In general the SEQUAL run appears paradoxically less in agreement with the SEQUAL/ FOCAL observations than the climatologically forced run. 

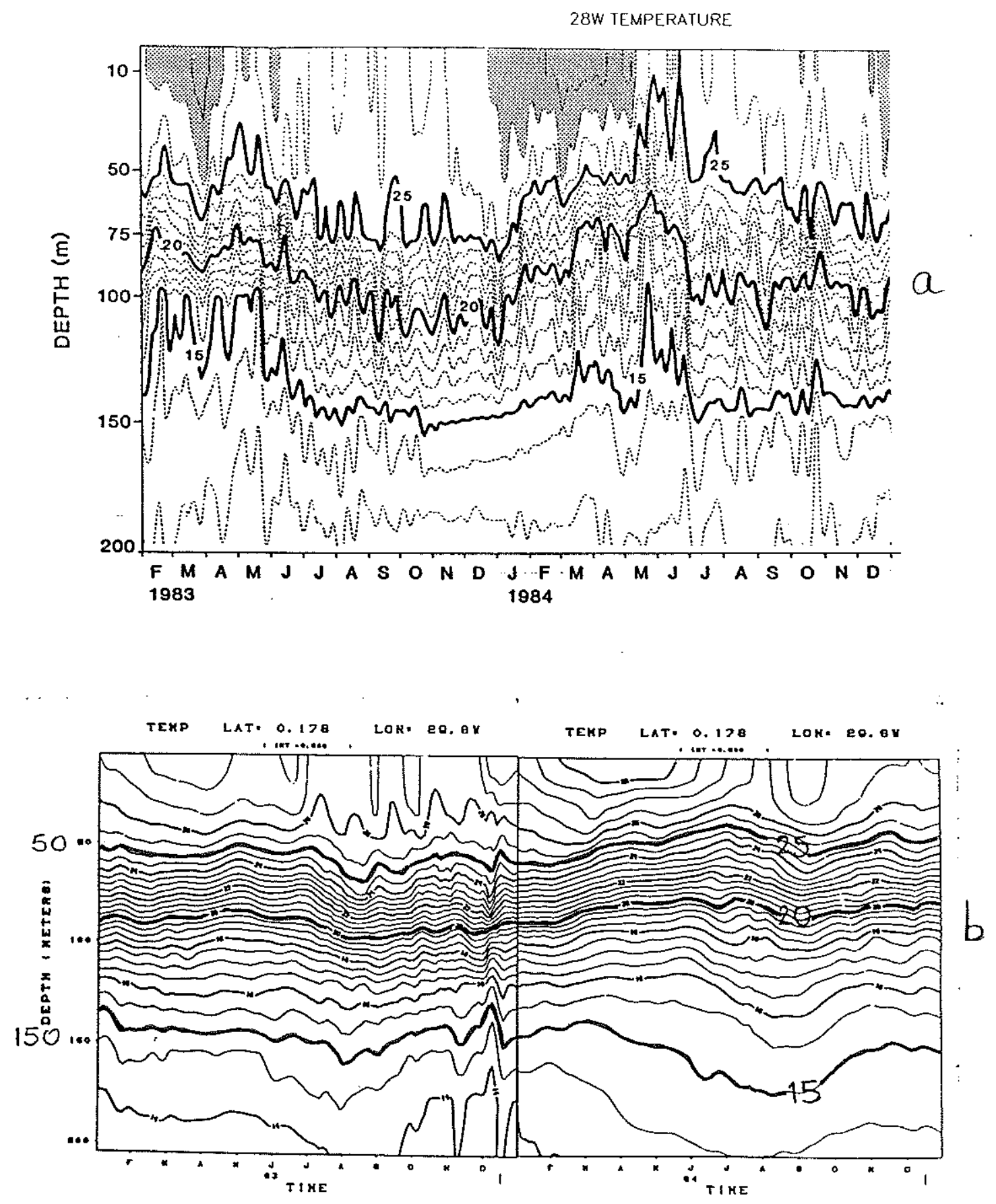

Figure 67: Time series of vertical profiles of temperature observed at $0^{\circ} \mathrm{N} 28^{\circ} \mathrm{W}[(\mathrm{a})$; program SEQUAL/FOCAL; Weisberg and Colin, 1986] and simulated at $0^{\circ} \mathrm{N} 30^{\circ} \mathrm{W}$ [b; run SEQUAL; Philander and Pacanowski, personal communication]. 


$$
292
$$



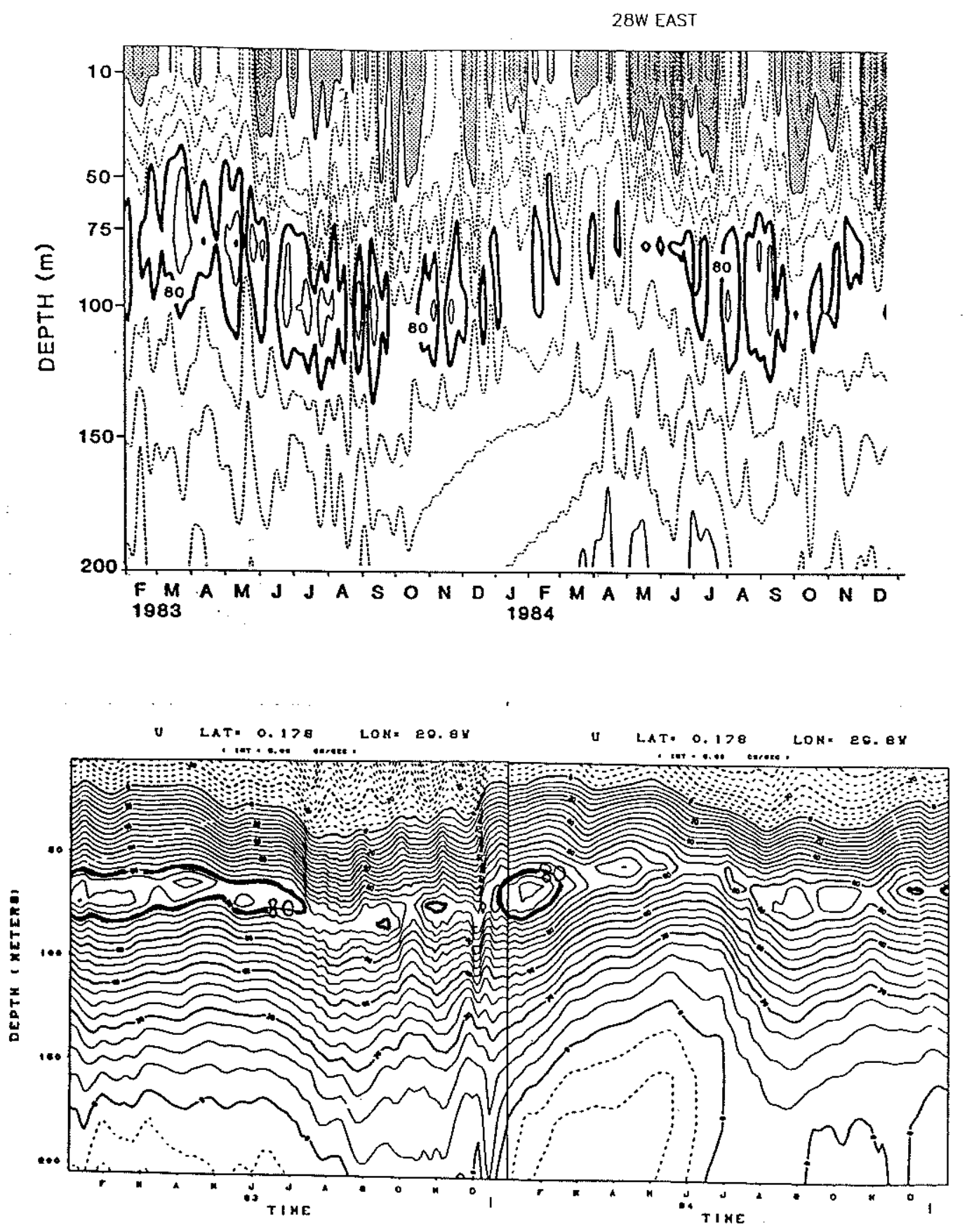

Figure 68: Sarie as Figure 67 but for zonal velocity. 
294 

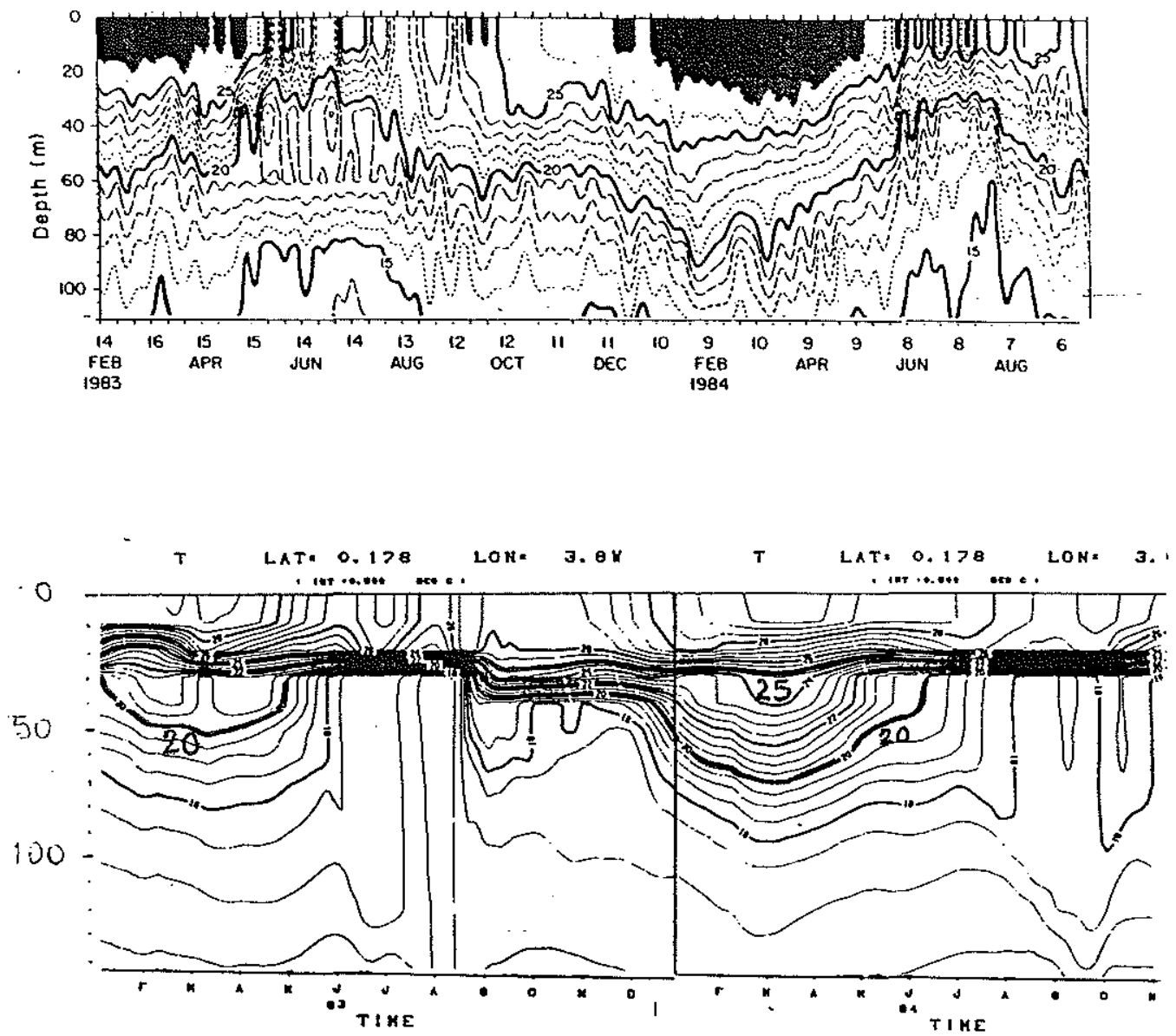

Figure 69: Same as Figure 67 but near $0^{\circ} \mathrm{N} 4^{\circ} \mathrm{W}$. 
296 

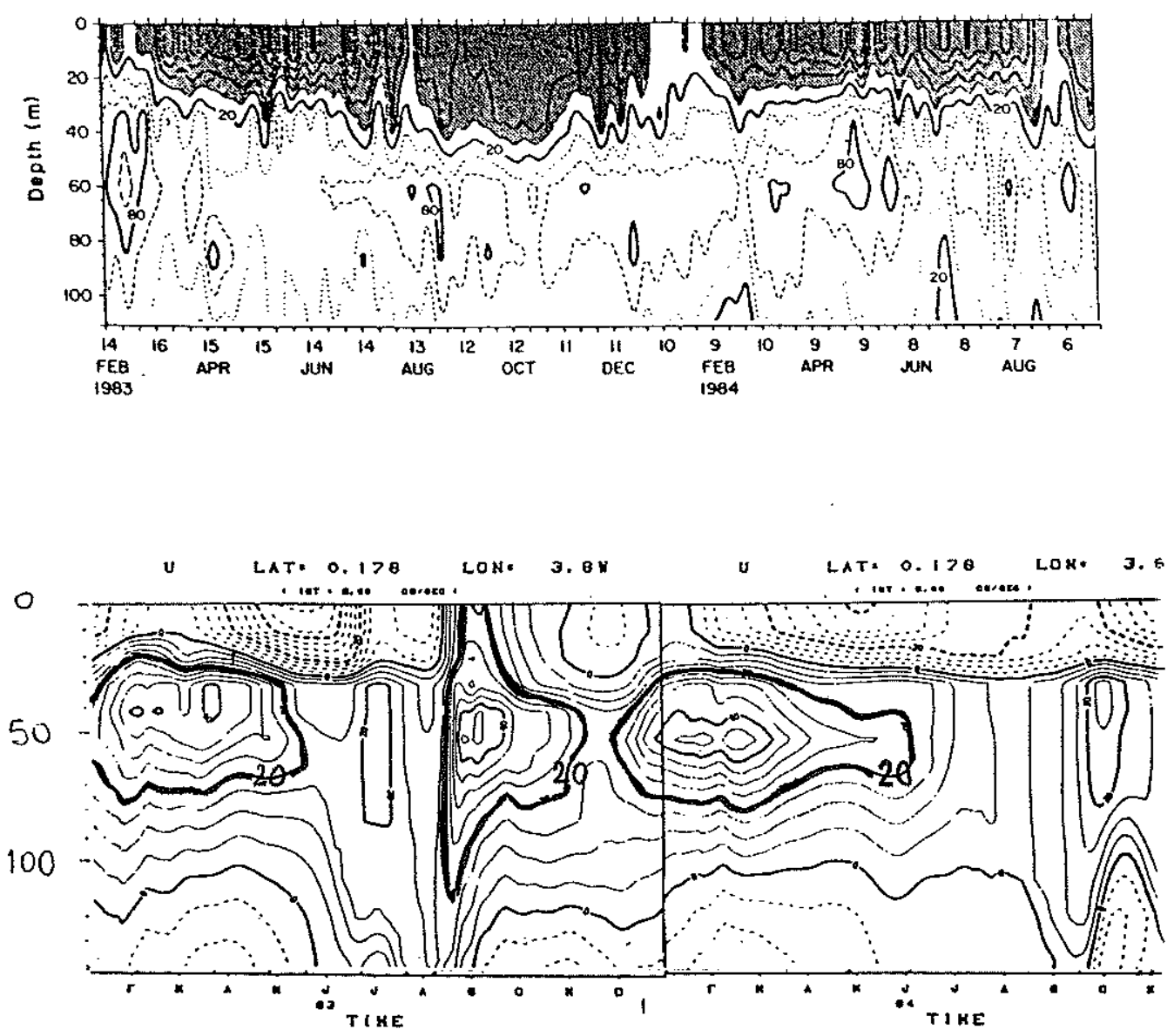

Figure 70: Same as Figure 68 but near $0^{\circ} \mathrm{N} 4^{\circ} \mathrm{W}$. 


\subsection{The half climatology run}

For a cleaner picture of the effect of an overall decrease of wind intensity on the EUC speed, a new run was generated: the Atlantic GCM was forced by the climatological wind stresses divided by two. The new output was treated as described in Chapter 3 for the previous output, and annual mean fields were generated. Figure 71 shows the fields of $\bar{u}$ and $\bar{T}$ from the half forced run $(b, d)$ underneath the same fields from the fully forced run $(a, c)$. In the half forced run, the zonal tilt of the thermocline is less, the sea surface temperature warmer by about $1^{\circ} \mathrm{C}$, the western thermocline slightly less deep and the eastern thermocline less sharp than in the fully forced run. The westward surface current is about half as swift and less deep than in the fully forced run. The EUC does not reach as deep in the west but it penetrates farther east zonally. The velocity of the EUC core is reduced by only $0.05 \mathrm{~m} / \mathrm{s}$ (less than 10 percent) in the west but its rate of weakening with longitude is also reduced (roughiy $-0.9 \times 10^{-2} \mathrm{~m} / \mathrm{s}$ versus $-1.5 \times 10^{-2} \mathrm{~m} / \mathrm{s}$ per degree of longitude between $30^{\circ} \mathrm{W}$ and $4^{\circ} \mathrm{W}$ ). As a result, the core velocity in the east is actually higher by about $0.07 \mathrm{~m} / \mathrm{s}$ ( 30 percent) in the half forced than in the fully forced run. Note that, compared to observations, the EUC velocity of the half forced run is uniformly low by about $0.25 \mathrm{~m} / \mathrm{s}$ (approximately like the fully forced case), but the zonal weakening of the half forced EUC is more realistic.

\subsection{Discussion}

Table 7 summarizes the comparison presented so far between the various GCM runs and the SEQUAL/FOCAL observations near $30^{\circ} \mathrm{W}$ and

$4^{\circ} \mathrm{W}$ at the equator. Values were simply read off Figures 67 to 71 . (In the case of Figures 67 to 70 , values are estimated averages through the measurement period.) When forced by the SEQUAL wind stresses, the GCM simulates thermocline and EUC core depths shallower than those simu1 ated with either the full or the halved Hellerman and Rosenstein's wind stresses. The SEQUAL run produces the best estimate of the EUC core velocity in the west, but the worst estimate of its rate of zonal 
weakening. The best estimate of that rate is simulated by the half forced run. This suggests that the differences between the climatological and the SEQUAL runs may be due less to differences in the overal 1 forcing intensity than to possible differences in the spatial structure of the forcing fields. Since the SEQUAL simulation is somewhat worse than the climatological one when compared to the SEQUAL/FOCAL observations (except for the value of the core velocity in the west), it will be worthwhile to identify these differences between the two wind stress fields and check how real they may be. To our knowledge, such a study is not available at the time.

Note that the above argument, like the rest of this thesis, relies on the assumption that the role of the thermal forcing is neg1 igible compared to that of the dynamical forcing. In fact, Pacanowski and Philander (1981) have shown that an appropriate surface condition on the heat flux is indispensable for the simulation of a realistic $x$-variation of the surface mixed layer thickness and thus of a zonally tilted thermocline. However, their analysis does not suggest that the introduction of a nonzero surface heat flux condition modifies the average depth of the thermocline.

In the GCM examined in this thesis (Philander and Pacanowski, 1986a) the parameterization of the surface heat flux is more elaborate than described by Pacanowski and Philander (1981). The variations of the surface heat flux are mostly due to variations in the evaporation, itself proportional to the wind speed and a complicated function of the atmospheric and oceanic temperatures at the ocean surface. There is no detailed study of the influence of changes in that surface heat flux field on the density structure and the dynamics of the GCM response, but we expect that the effects would be similar to those described by Pacanowski and Philander (1981). If that is the case, then an increase of the heat flux decreases mixing and, as in the previous paragraph, may increase the thermocline tilt without affecting the average depth of the thermocline.

Like the original wind stress used to force the GCM, the imposed air temperature is a monthly climatological function of $x$ and 

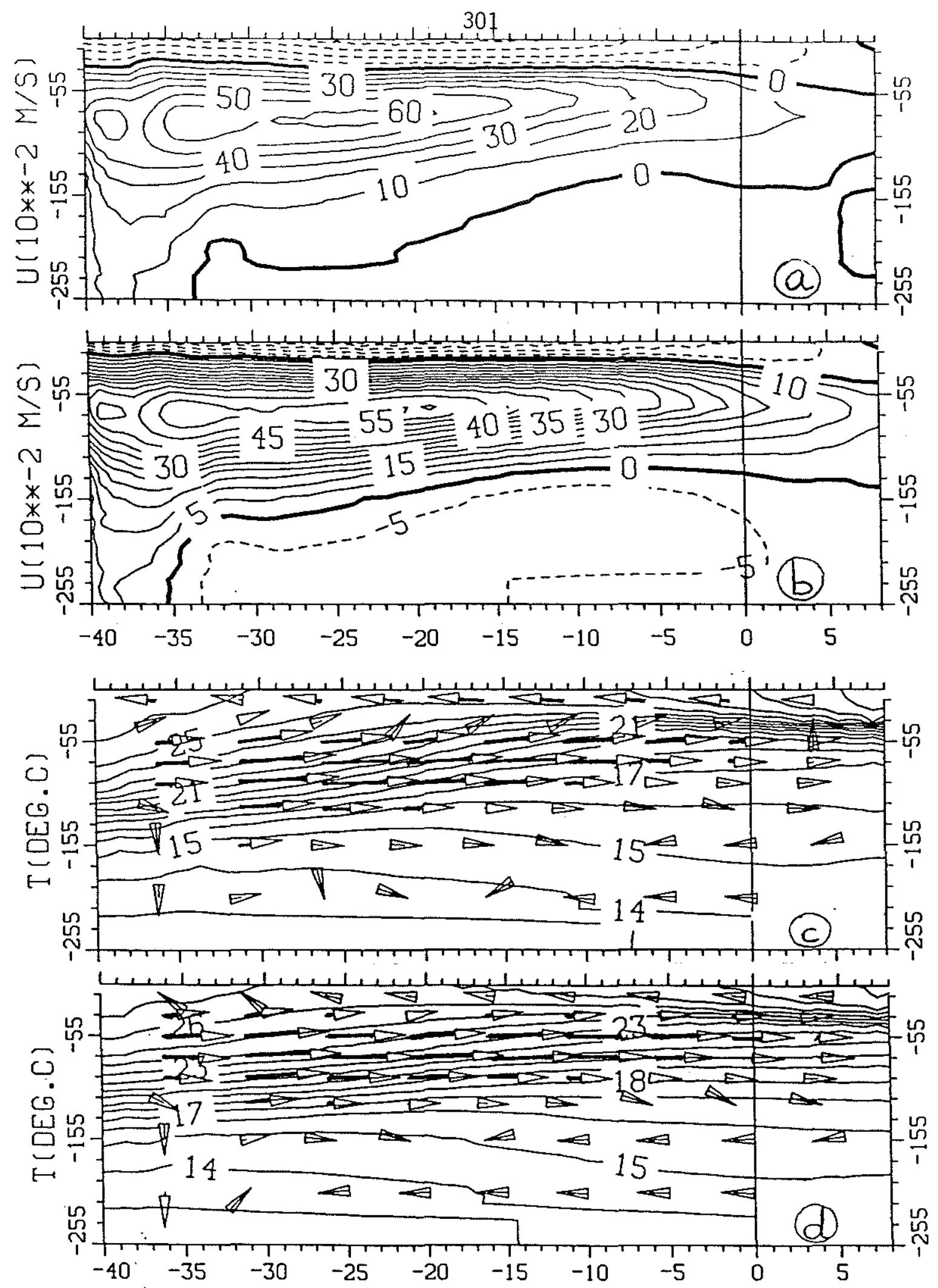

Figure 71: Comparison between equatorial sections of zonal velocity $(a, b)$ and temperature $(c, d)$ simulated by the climatological run $(a, c)$ and by the half forced run $(b, d)$. Note the change in contour interval between (a) and (b). 
302 
TABLE 7

Comparison between the various GCM runs and the SEQUAL/FOCAL observations near $30^{\circ} \mathrm{W}$ and $4^{\circ} \mathrm{W}$ at the equator.

\begin{tabular}{|c|c|c|c|c|}
\hline & $\underset{\text { Run }}{C 1 \text { imatological }}$ & $\begin{array}{l}\text { SEQUAL } \\
\text { Run }\end{array}$ & $\begin{array}{l}\text { 1/2 Forced } \\
\text { Run }\end{array}$ & $\begin{array}{l}\text { SEQUAL/FOCAL } \\
\text { Observations }\end{array}$ \\
\hline $\begin{array}{l}\text { Thermocl ine } \\
\text { Depth (m) }\end{array} 4^{\circ} \mathrm{W}$ & $\begin{array}{r}105 \\
35\end{array}$ & $\begin{array}{l}75 \\
25\end{array}$ & $\begin{array}{r}105 \\
30\end{array}$ & $\begin{array}{l}95 \\
40\end{array}$ \\
\hline $\begin{array}{ll}\text { EUC Core } & 30^{\circ} \mathrm{W} \\
\text { Depth }(\mathrm{m}) & 4 \% \mathrm{~W}\end{array}$ & $\begin{array}{l}90 \\
70\end{array}$ & $\begin{array}{l}70 \\
45\end{array}$ & $\begin{array}{l}80 \\
65\end{array}$ & $\begin{array}{l}85 \\
60\end{array}$ \\
\hline $\begin{array}{ll}\text { EUC Core } & 30^{\circ} \mathrm{W} \\
\text { Velocity } & \\
(\mathrm{m} / \mathrm{s}) & 4^{\circ} \mathrm{W}\end{array}$ & $\begin{array}{l}0.65 \\
0.25\end{array}$ & $\begin{array}{l}0.75 \\
0.25\end{array}$ & $\begin{array}{l}0.55 \\
0.32\end{array}$ & $\begin{array}{l}0.80 \\
0.60\end{array}$ \\
\hline $\begin{array}{l}\text { Rate of zonal } \\
\text { weakening } \\
\left(10^{-2} \mathrm{~m} / \mathrm{s} \text { per }\right. \\
\text { degree of } \\
1 \text { ongitude })\end{array}$ & -1.5 & -1.9 & -0.9 & -0.8 \\
\hline
\end{tabular}


$y$. When the model is forced by different fields of wind stress, the external field of air temperature is kept equal to the climatological field (no analysed field was derived from the measurements taken during the SEQUAL/FOCAL program). It is likely that, for consistency, the field of air temperature should also have been changed. An error in the simulation of the surface heat flux may therefore result, which in turn may affect the model response. However, plausible changes in air temperature and SST modify evaporation less than the changes in wind speed, so the error should be sma11. Moreover the error would affect both the runs forced by the SEQUAL wind stresses and by the halved Hellerman and Rosenstein climatological wind stresses. The difference in the thermocline depth between the two runs is thus likely to be caused by differences in the wind forcings.

Finally, there are indications that the initial stratification from which the integration of the model starts influences the final equilibrium state, in particular the mean depth of the thermocline and the EUC strength. Delecluse and Andrich (personal communication) developed a GCM of the tropical Atlantic very similar to Philander and Pacanowski's: the parameterization of vertical friction is the same and the numerical scheme comparable. That model was also forced by the SEQUAL wind stress field, and plots of the evolution of the response through 1983 and 1984 were produced. The main difference between the runs by Delecluse and Andrich (henceforth DA) and Philander and Pacanowski (henceforth PP) is in the choice of the initial condition for stratification. In the PP run Levitus' January climatology of $T$ and $S$ is used, so that the initial thermocline is a fairly realistic function of $x, y$ and $z$. In the DA run an average of the vertical profile of observed temperature over the whole basin is used, so that the initial thermocline at the equator is considerably deeper and more diffuse than in reality due to the weight of higher latitudes. (Also the effect of salinity on density is not taken into account by DA.) Once spun up to an equilibrium seasonal cycle (which involves large vertical motions of the thermocline) the models were expected to have forgotten their initial stratification. In reality, the final equatorial 
thermocline of the DA model is on average considerably deeper and more diffuse (like the initial one) than the final equatorial thermocline of the PP model. Note, however, that even though the initial thermocline of the DA model is flat, the final one is tilted upwards to the east. A thermostad (thickening to the east) is developed, which suggests that the presence of a realistic thermostad in the PP model is not just a consequence of the initial stratification but a sign that the simulated equatorial circulation is adequate to cause and maintain such details of the final stratification. Also, the EUC of the DA model is deeper and weaker overall than in the PP model but the core of the EUC shallows to the east as in the PP model (again being found above the western thermocline and below the eastern one). Compared to the SEQUAL observations at $30^{\circ} \mathrm{W}$ then, the DA model simulates too deep and too diffuse a thermocline and too weak an EUC. At $4^{\circ} \mathrm{W}$ it simulates a more realistic thermocline than the PP model but an even weaker EUC. The rate of weakening of the EUC velocity with longitude is comparable in the two models, and too large compared to the SEQUAL/FOCAL observations.

\section{4 Possible ways to improve the simulation}

We have studied in chapter 3 the numerical simulation of the tropical Atlantic by Philander and Pacanowski's GCM in order to gain new insight into the dynamics of the EUC, and have indeed come up with a richer picture than in the past of coexisting regimes of distinct dynamics. For this purpose, we only needed (and estimated we had) qualitative agreement between broad features of the simulation and the observations. We were not concerned by local discrepancies and did not attempt any parameter study of the model. Such a study would be very valuable and we therefore now wish to discuss the guidance provided by results of our dynamical analysis. One parameter study should consider the thermodynamics of the model, which undoubtediy play a role in determining the stratification. Of particular concern is the question of the amount by which the initial condition on density and the surface condition on heat flux constrain the final structure of the thermocline (its mean depth, its thickness, the magnitude of vertical 
gradients).

Looking at the circulation, we have seen through this work that the GCM simulation would be more satisfying if the western surface flow were slower and if the EUC were everywhere faster, weakening eastwards at a slower rate and reaching deeper in the water column. An undercurrent which slows too fast with longitude immediately suggests too frictional a regime. Too strong a surface current on another hand suggests not enough mixing. After comparing surface currents from historical ship drift data and GCM results, Richardson and Philander (1987) indeed incriminated the parameterization of vertical friction. They argued that the lower bound set on eddy viscosity just below the surface (to represent the effect of high frequency wind fluctuations absent from a monthly climatology) might have to be set higher in general and made to affect deeper levels towards the west. They also suggested that the parameterization of vertical friction in terms of the Richardson number be revised so as to let vertical friction be a function of wind intensity even when the upper layer becomes homogeneous. Such changes in parameterization primarily affect the levels closest to the surface, but what effect they have on deeper levels is likely to further weaken the EUC: the extra westward surface momentum must be redistributed vertically.

Our dynamical analysis has suggested, however, that vertical mixing substantially retards only the upper layers of the model EUC. The lower layers are retarded by lateral friction, and reducing the coefficient for horizontal mixing of momentum would thus reduce the rate at which they are retarded. [Pacanowski and Philander (1981) mention that, for an earlier version of the GCM forced by steady easterlies, a decrease of the coefficient from 2 to $1 \times 10^{3} \mathrm{~m}^{2} \mathrm{~s}^{-1}$ results in an increase of the maximum speed of the EUC from 0.80 to $1.05 \mathrm{~m} \mathrm{~s}^{-1}$.] This is appealing since, in the observations as in the simulation, the lower layers of the mid-basin undercurrent become the bulk of the eastern undercurrent. Therefore a reduction of the rate of zonal weakening of the lower western flow implies an improvement of the eastern penetration of the EUC as a whole. 
It is worth re-emphasizing that the apparent eastern diving of the EUC under the thermocline (i.e. the fact that the EUC core is found above the thermocline in the west, below the thermocline in the east) is a feature common to the simulation and the observations. In the model this apparent diving means that the upper layers are retarded by vertical friction more efficiently than the lower layers by lateral friction. In the simulation as in the observations, the upper thermocline flow becomes increasingly westwards as one looks from west to east. This may be taken as a clue that the parameterization of the effect of vertical friction is mostly correct, and that a parameter study should assign highest priority to reducing the value of the coefficient for horizontal mixing. In any case, fine tuning of the parameters for both vertical and horizontal friction will require a more precise experimental determination of the vertical profile of Reynolds stresses at various locations of the equatorial region.

Finally, our dynamical analysis of the GCM illustrated the existence in the western basin of an intermediate layer inertially accelerated by the ZPG force and not substantially retarded by either vertical or horizontal mixing effects. Such a regime is likely to exist in the ocean given the observed westward increase of the vertical scale for baroclinic adjustment. In the model, that inertially acce1erated layer shrank eastwards and acted as a Bernoul1i head for the lower thermocline flow. The depth of the layer, related to the depth at which substantial values of $\left(-p_{x} / \rho_{0}\right)$ are found in the west, and its zonal extent are therefore important for determining the western zonal acceleration of the EUC prior to its zonal deceleration over the rest of the basin. If the maximum velocity reached by the EUC is underestimated, the current will appear too weak at all longitudes. It is thus important that the vertical profile of the ZPG force be well simulated, which brings us back to the necessity for the model to have a realistic stratification, and thus for a parameter study to investigate the roles of the imposed initial condition on density and of the boundary condition on surface heat flux. 
Chapter 5. DISCUSSION OF THE EQUATORIAL UNDERCURRENT DYNAMICS SIMULATED BY THE GENERAL CIRCULATION MODEL

The goal of this final chapter is to propose a more conceptual interpretation of the model dynamics described in section 3.3. First the various dynamical regimes simulated by the GCM are compared with the available simpler steady models of the EUC reviewed in section 1.6.1. The comparison is made from the point of view of scale analysis which is the starting point of the analysis that follows. 
5.1 Comparison between the dynamical regimes simulated by the GCM and by simpler models

We will first consider the models in which the EUC is represented as a homogeneous layer in motion above an abyssal layer at rest, and will be comparing our region (3) to Charney's (1960) and Charney and Spiegel's (1971) models and our region (2) to Pedlosky's (1987) model (see Figures 51 and 60 for the definition of the various regions). Next we will consider Veronis' (1960) analytical model of a stratified EUC, in comparison with region (3).

Unless otherwise specified, the notations used to scale the equations of motion will be:

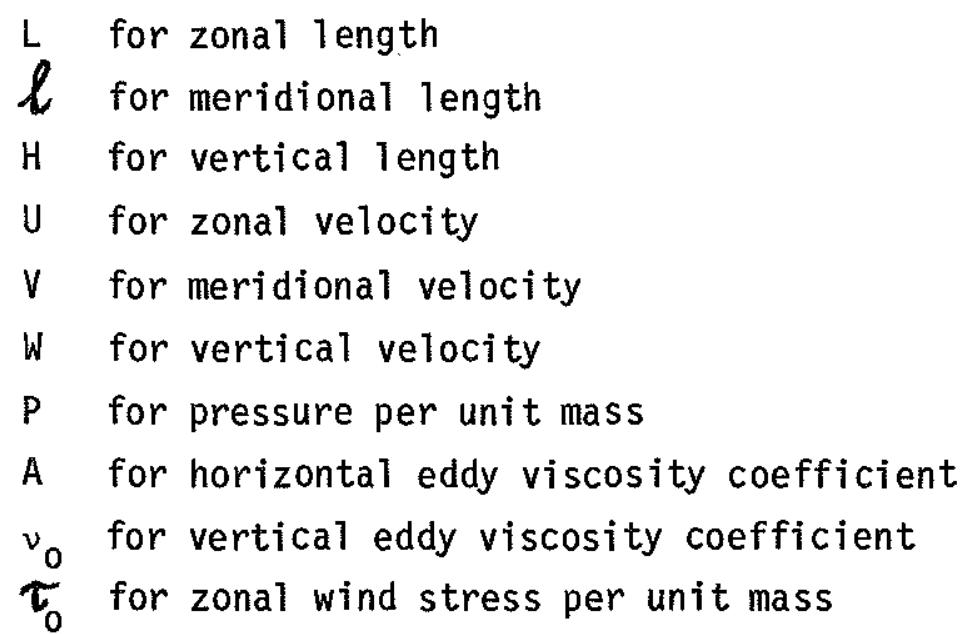

The full zonal momentum balance will thus be written in scaled form:

$\frac{U^{2}}{L} u u_{x}+\frac{v U}{\ell} v u_{y}+\frac{W U}{H} w u_{z}-\beta v y v=-\frac{P}{L} p_{x}+\frac{v_{0} U}{H^{2}}\left(v u_{z}\right)_{z}+\frac{A U}{\ell^{2}}\left(\frac{\ell^{2}}{L^{2}} u_{x x}+u_{y y}\right)$

\subsubsection{Charney's (1960) nonlinear frictional EUC}

Charney (1960) and Charney and Spiegel (1971), view the thermocline as a surface of density discontinuity which inhibits any vertical exchange of momentum between upper and abyssal layers. $X$-variations are ignored (except in $p_{x}$ ), $v$ is taken constant, lateral friction is assumed negligible, and a bottom boundary condition of zero velocity is imposed to satisfy the requirement of no motion in the underlying layer. The computed nonlinear frictional undercurrent 
is thus entirely confined to the homogeneous layer above the thermocline. In reality, the EUC is observed to have its maximum velocity in or close to the thermocline. A more realistic vertical profile of zonal velocity might thus obtain if the model used, instead of a no slip bottom boundary condition, a no stress bottom boundary condition as did Stomme1 (1960). [A different representation of the lower layers would have to be developed.]

The zonal momentum equation is written:

$$
v u_{y}+w u_{z}-\beta y v=-p_{x} / p+v u_{z z}
$$

So it would be identical to our regime (3) at the equator for $v$ constant if all terms had the same magnitude.

Taking a constant layer thickness $H$, the same velocity scale $U$ in both the zonal and the meridional direction (a choice somewhat difficult to understand) but different length scales $L$ and $l$ in the zonal and meridional directions, and relating $Z P G$ and wind stress by $P / L=\tau_{0} / H$ (based on the expectation that the vertically integrated pressure gradient should approximately balance the surface stress), Charney derives an inertial scaling for the EUC as follows:

$$
\frac{U^{2}}{l}=\frac{W U}{H}={ }_{B} l U=\frac{-P}{L}=\frac{-\tau_{0}}{H} ;
$$

so that

$$
U={ }_{B} l^{2}=\left(\frac{\tau_{0}^{2}}{H^{2}}\right)^{1 / 3} ; W=\left({ }_{B} \tau_{0} H^{2}\right)^{1 / 3} ; \quad l=\left(\frac{\tau_{0}}{{ }_{B}{ }}\right)^{1 / 3} ;
$$

and

$$
c=\frac{\left[v u_{z z}\right]}{\left[v u_{y}\right]}=\frac{v}{{ }_{\beta} l H^{2}}=\left(\frac{v^{3}}{B H^{5} \tau_{0}}\right)^{1 / 3} .
$$

For:

$$
\begin{aligned}
& 10 \times 10^{-4} \leq v \leq 100 \times 10^{-4} \mathrm{~m}^{2} \mathrm{~s}^{-1} \\
& \beta=2.3 \times 10^{-11} \mathrm{~m}^{-1} \mathrm{~s}^{-1}
\end{aligned}
$$




$$
\begin{aligned}
& H=150 \mathrm{~m} \\
& \tau_{0}=0.45 \times 10^{-4} \mathrm{~m}^{2} \mathrm{~s}^{-2}
\end{aligned}
$$

the following orders of magnitude result:

$$
\begin{aligned}
& \frac{P}{L} \sim 3 \times 10^{-7} \mathrm{~m} \mathrm{~s}^{-2} \\
& U \sim 0.15 \mathrm{~m} / \mathrm{s} \\
& \ell \sim 85 \mathrm{~km} \\
& \frac{1}{40} \leq c \leq \frac{1}{4} .
\end{aligned}
$$

These scales correspond to a somewhat weak and narrow flow compared to the undercurrent, but this is not surprising since $U$ is more a scale for (uv) $)^{1 / 2}$ than for $u$. The point though is that, for $v$ between $10 \mathrm{x}$ $10^{-4}$ and $100 \times 10^{-4} \mathrm{~m}^{2} \mathrm{~s}^{-1}$, the number $c$ which measures the relative importance of vertical friction, is small. Therefore the effects of vertical friction are 1 imited to boundary layers at the top and bottom of the layer under study. An estimate of the boundary layer thickness D can be found by setting:

$$
c=\left(\frac{\nu^{3}}{{ }_{B} D^{5} \tau_{0}}\right)^{1 / 3} \sim 1 \Rightarrow D \sim\left(\frac{\nu^{3}}{\beta \tau_{0}}\right)^{1 / 5}
$$

With the above values, $D$ is of order $30 \mathrm{~m}$ (between 25 and $40 \mathrm{~m}$ for $v$ between $10 \times 10^{-4}$ and $\left.100 \times 10^{-4} \mathrm{~m}^{2} \mathrm{~s}^{-1}\right)$, i.e. thinner than region (3) from the GCM simulation (Figure 51 ), which is about $75 \mathrm{~m}$ thick.

The numerical simulations performed by Charney (1960) and Charney and Spiegel (1971) confirm that, in order for the vertical profiles of zonal velocity to exhibit a subsurface eastward flow of realistic magnitude, $c$ needs to be of order 1/25. For larger values of c such as $1 / 4$ (more viscous case), the whole profile is westward and no subsurface eastward flow develops. For values of $c$ less than 
about $1 / 30$ ( $\nu$ less than about $15 \times 10^{-4} \mathrm{~m}^{2} \mathrm{~s}^{-1}$ ) the computation blows up. This of course is in contrast with the GCM results which suggests that, in region (3) of the simulated EUC, vertical friction is as important as inertial terms.

\subsubsection{Pedlosky's_(1987) purely_inertial EUC}

In Pedlosky's (1987) model, the EUC lies in the lower layer (density $\rho_{2}$ ) of a two-layer system above a motionless abyss (density $\rho_{3}$ ). Motion in that lower layer (of thickness $H$ ) is assumed to be frictionless and strictly parallel to isopycnal surfaces. It is determined using conservation of potential vorticity and Bernoulli function. Pressure gradients vanish underneath. So the model may be relevant for the region of the GCM where pressure gradients are sti11 present but direct wind forcing has become negligible, i.e. for region (2) where:

$$
\begin{aligned}
& \frac{D u}{D t}=-\frac{p_{x}}{\rho_{0}}, \text { with here: } \frac{p_{x}}{\rho_{0}}=r_{2} H_{x}, r_{2}=\frac{g\left(\rho_{3}-\rho_{2}\right)}{\rho_{3}}, \\
& \text { and }: \frac{D u}{D t}=u u_{x}+v u_{y}
\end{aligned}
$$

Compared to a realistic stratification, it probably best represents the thermocline itself, the interface between surface layer (density $\rho_{1}$ ) and intermediate layer (density $\rho_{2}$ ) being the top of the thermocl ine.

A scale $H$ for the layer thickness is obtained using the depth of the Sverdrup regime to which the equatorial region connects at higher latitude. That depth can be expressed as a function of a zonal integral of the Ekman pumping (Luyten et al., 1983) and can be scaled as:

$$
H=\left(\frac{-\tau_{0} L}{\gamma_{2}}\right)^{1 / 2}
$$

calling $L$ an east-west scale of order the basin dimension. Remember that $H$ scales the EUC layer thickness, below a surface layer of unknown thickness. The ZPG force thus scales as: 


$$
\frac{P}{L}=\frac{\gamma_{2} H}{L}=\left(\frac{-\gamma_{2} \tau_{0}}{L}\right)^{1 / 2}
$$

and scales for zonal velocity and meridional dimension follow:

$$
\begin{aligned}
& \frac{U^{2}}{L}=\frac{P}{L}=\left(\frac{-\gamma_{2} \tau_{0}}{L}\right)^{1 / 2} \Rightarrow U=\left(-\gamma_{2} L \tau_{0}\right)^{1 / 4} \\
& l=\left(\frac{U}{\beta}\right)^{1 / 2}=\frac{\left(-\gamma_{2} L \tau_{0}\right)^{1 / 8}}{\beta^{1 / 2}}
\end{aligned}
$$

For the values:

$$
\begin{aligned}
& \tau_{0}=-10^{-4} \mathrm{~m}^{2} \mathrm{~s}^{-2} \\
& \gamma_{2}=10^{-2} \mathrm{~m} \mathrm{~s}^{-2} \\
& L=3000 \mathrm{~km}
\end{aligned}
$$

chosen by Pediosky, $H,-P / L, U$ and $l$ are respectively equal to about $175 \mathrm{~m}, 6 \times 10^{-7} \mathrm{~m} \mathrm{~s}^{-2}, 1.30 \mathrm{~m} \mathrm{~s}^{-1}$ and $240 \mathrm{~km}$. For a weaker wind over a longer zonal scale (more representative of the Atlantic ocean):

$$
\begin{aligned}
& \tau_{0}=-0.50 \times 10^{-4} \mathrm{~m}^{2} \mathrm{~s}^{-2} \\
& \gamma_{2}=10^{-2} \mathrm{~m} \mathrm{~s}^{-2} \\
& L^{2}=6000 \mathrm{~km}
\end{aligned}
$$

$\mathrm{H},-\mathrm{P} / \mathrm{L}, U$ and $\ell$ have the values $175 \mathrm{~m}, 3 \times 10^{-7} \mathrm{~m} \mathrm{~s}^{-2}, 1.30 \mathrm{~m} \mathrm{~s}^{-1}$ and $240 \mathrm{~km}$. The net effect of weakening the wind but increasing the length scale over which it acts by the same factor 2 is null for $H, U$ and $l$, but the ZPG scale is divided by 2 . Conversely, this illustrates that, for comparable wind stresses and comparable ZPG, the EUC velocity still can be different if the fetch is different.

Note that the main difference between this inertial scaling and Charney's is that the vertical scale itself is related to the forcing rather than taken as an independent constant parameter. By writing as in Charney's analysis $\frac{P}{L}=\frac{\tau_{0}}{H}$ and substituting Pedlosky's $H=$ $\left(\frac{\tau_{0} L}{\gamma_{2}}\right)^{1 / 2}$, one recovers $\frac{P}{L}=\left(\frac{\gamma_{2} L \tau_{0}}{L}\right)^{1 / 2}$ as in Pedlosky's scaling. 
[One cannot go from one scaling of $u$ to the other in the same fashion since Charney's $U$ is really a scale for (uv) ${ }^{1 / 2}$, while Pedlosky's $U$ is indeed a scale for $u$ ]. Note that the vertical scales of Charney's and Pedlosky's analyses refer to somewhat different entities, namely, the distance from the ocean surface to the EUC bottom in Charney's case, the thickness of the EUC layer in Pedlosky's case.

By further taking into account the fact that the vertical scale should also vary with longitude [since it is a function of $\left.\int_{x}^{x_{E}} \tau d x\right]$, we will show in section 5.2.1 that, for parameters representative of the equatorial Atlantic, a purely inertial frictionless regime like Pedlosky's cannot exist past a critical longitude (of the order of a third to half the basin dimension) at which inertial and frictional depth scales become comparable and the term of zonal inertial acceleration negligible. This will justify the limited size of the western inertial regime in the GCM simulation.

\subsubsection{Veronis' (1960) nonl inear frictional stratified EUC}

This model is mostly concerned with the vertical structure of the current system which develops in a stratified ocean when a surface zonal pressure gradient is imposed. The frictional effect of the easterly wind stress is thought to be the cause for the surface ZPG (in practice the zonal gradient of sea surface temperature), and the baroclinic adjustment of the stratified layers which reduces pressure gradients (in practice isotherms slope) with depth is thought to be the cause for the 1 imited vertical extension of the current system. Lateral friction and zonal variation of the velocity are ignored, forcing and ocean response are assumed symmetrical about the equator, and the zonal momentum balance under consideration at the equator is thus:

$$
w u_{z}=-p_{x} / \rho+v u_{z z},
$$

similar to regime (3) simulated by the GOM for $u_{y}=0$ and $\nu=$ constant.

By choosing the same eddy coefficient for diffusion and

viscosity, the heat equation at the equator can be written: 


$$
u T_{x}+w T_{z}=v T_{z z}
$$

Taking $v$ constant, imposing a linear variation of temperature with longitude at the surface $\left(T_{x}=\right.$ constant; $\left.T_{x x}=0\right)$, and replacing $w(x, z)$ by a constant average value $w$, Veronis further derives:

$$
W T_{X z}=v T_{x z z}
$$

According to this last relation, the zonal temperature gradient decays exponentially with depth from its imposed surface value, with the depth scale $H=\frac{\nu}{W}$. The vertical profiles of $Z P G$ and zonal velocity are also proportional to $\exp (W z / v)$ and the $Z P G$ can be derived from the hydrostatic equation by:

$$
\mathrm{p}_{Z} / \rho=\mathrm{g}_{\alpha} \mathrm{T} \Rightarrow \mathrm{p}_{\mathrm{X}} / \rho=(\nu / W)\left(\mathrm{p}_{z X} / \rho\right)=(\nu / W) \mathrm{g}_{\alpha} \mathrm{T}_{\mathrm{X}}
$$

(where $\alpha$ is the thermal expansion coefficient). Veronis then vertically integrates the ZMB to obtain an analytical expression for $u(z)$, using the boundary conditions:

$$
T_{X}=\Delta T / L \text { and } v u_{z}=\tau_{0} @ z=0
$$

(where $\Delta T$ is the difference in surface temperature and $L$ the zonal distance between western and eastern ends of the domain), and

$$
T_{x}=u=0 @ z \rightarrow-\infty \text {. }
$$

The determination of $W$ also requires the continuity equation $\left(v_{y}+w_{z}=0\right)$ and the geostropic meridional momentum equation $($ Byu $=-p y / \rho)$. Veronis finally obtains an analytical expression for $H=\frac{\nu}{W}$ which depends on the depth over which $W$ is averaged and which is proportional to $\left(\frac{\tau_{0} L}{g_{\alpha} \Delta T}\right) 1 / 2$.

In terms of scales, this result is equivalent to setting directly:

$$
\int_{-\infty}^{0} p_{x} / \rho d z=\int_{-\infty}^{0} v u_{z z} d z,
$$

since this can be rewritten:

$$
\left(\frac{\nu}{W}\right)^{2} g_{\alpha} \frac{\Delta T}{L}=\tau_{0} \Rightarrow H=\frac{\nu}{W}=\left(\frac{\tau_{0} L}{g \alpha \Delta T}\right)^{1 / 2}
$$


Al though equal to $\frac{v}{W}$, the depth scale can thus be expressed entirely in terms of the external parameters $\tau_{0}$ and $\Delta T / L$. It is independent of the exact value of $v$. For the values chosen by Veronis for the Pacific ocean:

$$
\begin{aligned}
& \tau_{0}=-0.2 \times 10^{-4} \mathrm{~m}^{2} \mathrm{~s}^{-1} \\
& \mathrm{~L}=10^{7} \mathrm{~m} \\
& \mathrm{~g}=10 \mathrm{~m} \mathrm{~s}^{-2} \\
& \alpha=2.5 \times 10^{-4}\left({ }^{\circ} \mathrm{C}\right)^{-1} \\
& \Delta T=5^{\circ} \mathrm{C}
\end{aligned}
$$

one obtains: $H=125 \mathrm{~m}$. Note that, in contrast with Charney's and Pedlosky's models, the above depth scale corresponds in Veronis' final solution to the depth of the EUC core rather than to the bottom of the EUC or to its thickness. For the central Pacific Ocean, $H=125 \mathrm{~m}$ is a realistic core depth. Note also that the dependence of this depth scale on wind intensity and zonal length scale $\left(-\tau_{0} L\right)^{1 / 2}$ is the same as that from Pedlosky's model.

\subsection{Vertical scales relevant for the dynamical regimes simulated by the GCM}

The eastward shallowing of the various isolines of Figure 72 illustrates a westward increase in the vertical extent of the various fields simulated by the GaM (section 3.3). The isotachs $0.00,0.25$ and $0.50 \mathrm{~m} \mathrm{~s}^{-1}$ of zonal velocity are superimposed on the other fields for a visual comparison of their respective extents. Disregarding the complications introduced in the east by the wind reversal, we see that, over most of the basin, there is some correlation between the deep isolines of $-p_{x} / \rho_{0}, u, w$, and $\left(v u_{z}\right)^{*}$. The deeper $0.25 \mathrm{~m} \mathrm{~s}^{-1} u$-isotach for example lies near the zero-crossing of ZPG (e) and $w(d)$, and the $0.50 \mathrm{~m} \mathrm{~s}^{-1}$ u-isotach 1 ies near the zero-crossing of vertical friction (h). The zero-line of ZPG (along with the deeper $0.25 \mathrm{~m} \mathrm{~s}^{-1}$ isotach of 
$u$ and the $0.00 \mathrm{~m} \mathrm{~s}^{-1}$ isotach of $\left.w\right)$ roughly coincides with the bottom of the thermocline (b), which however cannot be identified with a single isotherm since the deep isotherms "peel off" downwards to the east, forming the thermostad. At shallower levels, the similarity between the zonal patterns of ZPG and vertical friction isolines persists (directly reflecting the zonal weakening of the surface easterly stress). The isotachs of zonal velocity on the contrary become horizontal and tend to cross most other isolines.

At about $10^{\circ}$ of longitude ( $1 / 6$ of the basin size) from the western boundary, the rate of westward increase in the vertical extent of the fields of ZPG (Figure 72e), vertical (d) and zonal (a) velocity [and horizontal friction $(f)$ ] becomes abruptly larger. For example, the isotach $0.10 \mathrm{~m} \mathrm{~s}^{-1}$ which had deepened by $70 \mathrm{~m}$ in 30 degrees between $4^{\circ} \mathrm{W}$ and $34^{\circ} \mathrm{W}$ abruptly deepens by $100 \mathrm{~m}$ in 3 degrees between $34^{\circ} \mathrm{W}$ and $37^{\circ} \mathrm{W}$, a rate of deepening about 14 times 1 arger. The increase in the penetration of the ZPG effect can be seen on the western deep isotherms of the mode1, e.g. 13,14 of $15^{\circ} \mathrm{C}(\mathrm{b})$ : their zonal slope from east to west changes from flat or upwards east of $33^{\circ} \mathrm{W}$ to downwards (1ike the shallower isotherms) west of $33^{\circ} \mathrm{W}$. Western sloping of otherwise flat deep isobars can also be seen on the Atlantic mean dynamic topography west of about $30^{\circ} \mathrm{W}$ (Figure 2). Note however that the rate of westward increase in the vertical extent of the simulated vertical friction ( $h$ ) does not appear to exhibit a similar western anomaly.

The above description (based on results described in more detail in section 3.3) suggests that a good estimate for a depth scale $D^{*}$ relevant to the equatorial circulation over most of the basin (central region of Figure 51) would be the zero-line of $Z P G$, which is close to the zero-line of vertical friction and $w$, close to the deeper $0.25 \mathrm{~m} \mathrm{~s}^{-1} u$-isotach, and representative of the bottom of the thermocline. This scale should decrease with increasing distance eastwards and, given the similarity between the zonal and vertical structures of the fields of $\left(-p_{x} / \rho_{0}\right)$ and $\left(v u_{z}\right)_{z}$ in the region, it can be based on the bal ance: 

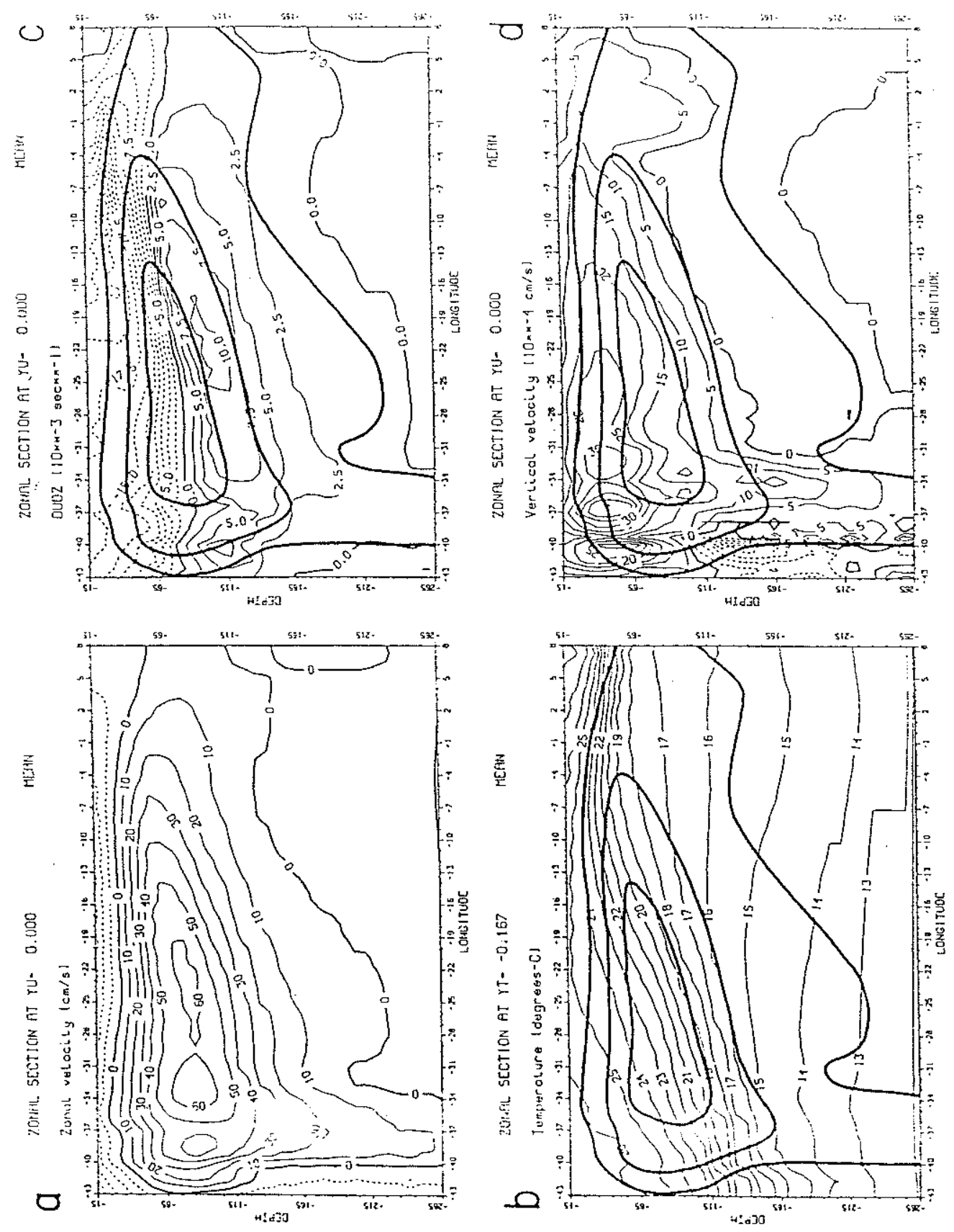

Figure 72: Equatorial sections of basic fields and ZMB terms simulated by the GCM. The isotachs $0.00,0.25$ and $0.50 \mathrm{~m} \mathrm{~s}^{-1}$ of zonal velocity have been superimposed on the other contour plots for a visual comparison of the various depth scales and their zonal variation. 

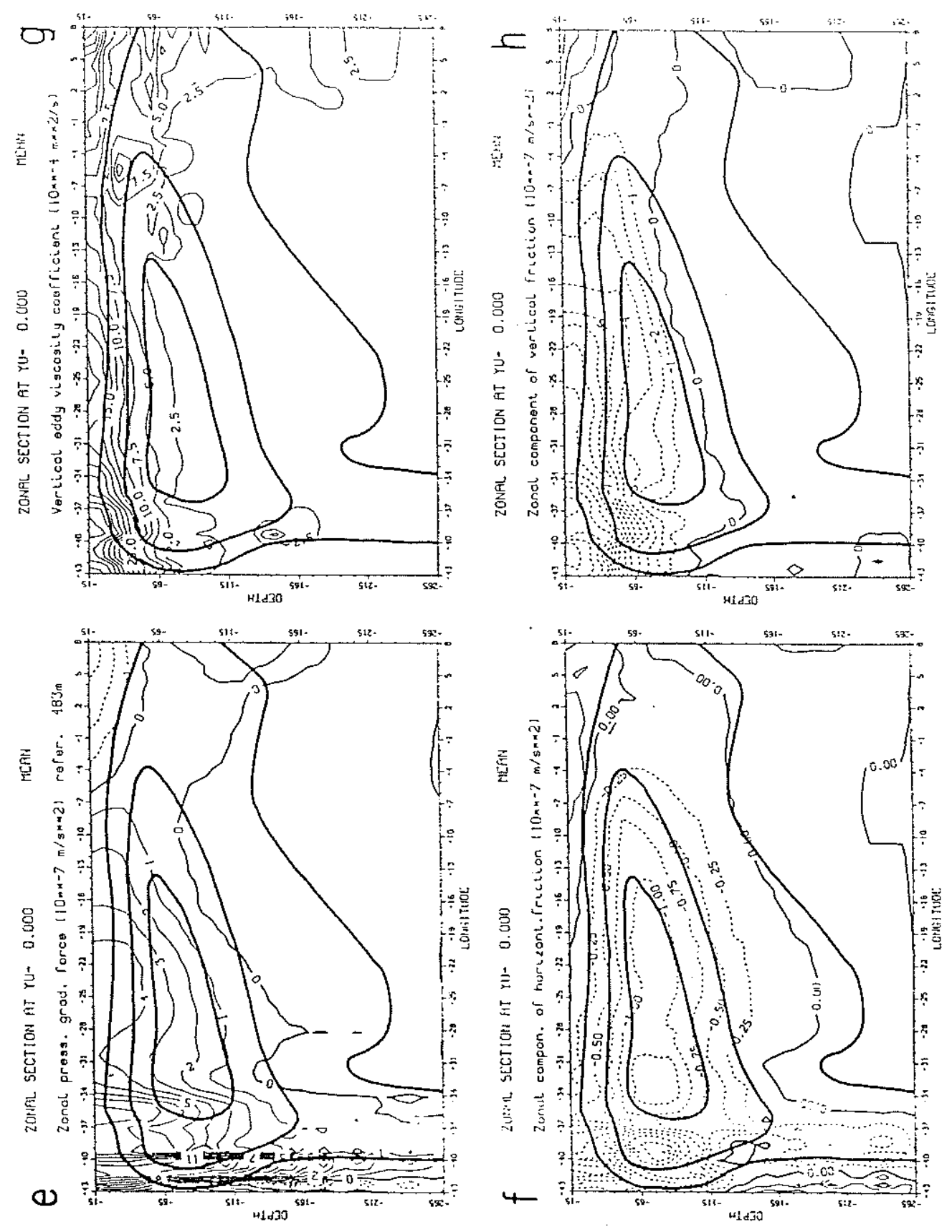

Figure 72 (Continued) 


$$
\int_{-D^{*}}^{0}\left(p_{x} / \rho_{0}\right) d z=-\tau>0
$$

(definition of $D^{*}$ )

even though the vertical integral of $w u_{z}$ may not be zero.

In the west however [regions (1) and (2) of Figure 51] the vertical extent $D^{\prime}$ of $\left(-p_{x} / \rho_{b}\right.$ becomes larger as $\int_{-D^{\prime}}^{0}\left(p_{x} / \rho_{0}\right) d z$ balances not only $(-\tau)$ but also nonlinear accelerations whose vertical integral can no longer be neglected:

$$
\int_{-D^{\prime}}^{0}\left(-p_{x} / \rho_{0}\right) d z=-\tau+\underbrace{\int_{-D^{+}}^{0}(D u / D t) d z}_{>0} \text { (definition of } D^{\prime})
$$

For simplicity we can decompose the new western depth scale $D^{\prime}$ into $\left[D^{*}+\left(D^{\prime}-D^{*}\right)\right]$, define:

$$
\begin{aligned}
& \int_{-D^{*}}^{0}\left(-p_{x} / \rho_{0}\right) d z=-\tau, \\
& \int_{-D^{\prime}}^{-D^{*}}\left(-p_{x} / \rho_{0}\right) d z=\int_{-D^{\prime}}^{-D^{*}}(D u / D t) d z
\end{aligned}
$$

assuming: $\int_{-D^{\star}}^{0}(D u / D t) d z \sim 0$,

and identify the lower region $-D^{\prime}<z<-D^{*}$ with Pedlosky's inertial undercurrent and with region (2) of Figure 51. The question is now to justify the 1 imited zonal extent of that region in the GOM.

Let us consider as in Pediosky's model that the structure of the deep western equatorial thermocline observed in the GCM is caused by a meridionally convergent flow which advects towards the equator an off-equatorial density structure and veers eastwards at the equator. Since the zonal structure of the observed wind stress $\tau$ is not such as to produce a zonal discontinuity in the off-equatorial 
thermocline depth (a function of $\int_{x}^{x_{E}} \tau d x$, where $x_{E}$ is the longitude of the eastern boundary), one should not find a zonal discontinuity in the deep equatorial density structure either. That in fact there is a discontinuity indicates that some other process constrains the deep thermal structure independently.

I believe that what constrains the deep thermal structure and cuts short the zonal extent of region (2) is heat convergence from the deep westward return flow below the mid-basin undercurrent. Reexamining Figure 72b, we can see that indeed deep isotachs and isotherms are shaped in such a way that both regions west and east of about $33^{\circ} \mathrm{W}$ correspond to negative $\mathrm{TT}_{X}$. For example, at about the level of the $13^{\circ} \mathrm{C}$-isotherm, $u$ is positive between $40^{\circ} \mathrm{W}$ and $33^{\circ} \mathrm{W}$ where $T_{x}$ is negative, while $u$ is negative east of $33^{\circ} \mathrm{W}$ where $T_{x}$ has become positive since the $13^{\circ} \mathrm{C}-i$ sotherm has reversed its zonal slope. [That the deep westward flow would advect warmer water makes sense since it appears to return some of the extra water from the overlying undercurrent (section 3.2.1)]. In the deep western region, the heat convergence produces a strong upwelling (Figure 72d) which advects most of the zonal momentum into the shallower regime characterized by $D^{*}$. [The vertical extent of $w u_{z}$ (not shown) has the same zonal pattern as that of $w(d)]$. Some of the zonal momentum however remains at levels deeper than $z=-D^{*}$ and constitutes the deep EUC layers of region (4) (see Figure 51 and section 5.4).

\subsection{Conceptual model of an $x$-dependent upper undercurrent}

In this section, we show that the dynamics of region (3) of the model (Figures 51 and 60) can be anticipated from scale analysis, and we solve a simple conceptual model of the upper EUC zonal variation. We only consider the domain bounded in the west by the longitude at which the inertial undercurrent emerges from the western acceleration region described in 5.2, as a more quantitative analysis of the western region lies beyond the scope of this dissertation. 
The main idea can be summarized as follows. Only in the west can a distinct inertially accelerated regime exist below a frictional sublayer. With increasing distance eastwards, the depth scale relevant to the problem ( $D^{*}$, introduced in section 5.2 ) becomes smaller, and inertial and frictional regimes merge into a single decelerated regime.

\subsubsection{Input from_scale_analysis}

Let us start our analysis by assuming the existence of a subsurface inertially accelerated flow à la Pedlosky (1987) in the west of our domain, and investigate the possible zonal and vertical dimensions of such a regime.

Since baroclinic adjustment brings the zonal pressure gradient force from a maximum at the surface to a negligible value near the bottom of the thermocline, one can define a conceptual correspondance between the continuous stratification and a reduced gravity layer of depth $D^{*}$, where $D^{*}$ represents a depth scale for baroclinic adjustment (see section 5.2). Thus:

$$
\frac{D u}{D t}=\frac{-p_{x}}{\rho_{0}}=-g^{\prime} D_{x}^{*} \quad ; \quad g^{\prime}=g \frac{\Delta \rho}{\rho_{0}}
$$

One expects that, at least in terms of scales, the vertical integral of the ZPG force (down to a depth of negligible vertical stress such as $D^{*}$ ) balances the surface wind forcing, yielding:

$$
D^{*}\left[-p_{x} / \rho_{0}\right]=-\tau_{0}
$$

with $\tau_{0}$ a scale for the wind stress per unit mass. Near the western end of our domain, i.e. close to the western boundary, estimates of $D^{*}$ and $U$ can thus be derived as:

$$
\begin{aligned}
& \frac{-\tau_{0}}{D^{*}}=\frac{g^{\prime} D^{*}}{x_{E}} \Rightarrow D^{*}=\left(\frac{-\tau_{0} x_{E}}{g^{\prime}}\right)^{1 / 2} \\
& \frac{U^{2}}{L}=\frac{-\tau_{0}}{D^{\star}}=\left(\frac{-g^{\prime} \tau_{0}}{x_{E}}\right)^{1 / 2}=\frac{\left(-g^{\prime} \tau_{0} x_{E}\right)^{1 / 2}}{x_{E}} \Rightarrow U=\left(\frac{L}{x_{E}}\right)^{1 / 2}\left(-g^{\prime} \tau_{0} x_{E}\right)^{1 / 4}
\end{aligned}
$$


where $L$ is an a priori unknown length scale $\left(L \leq x_{E}\right)$. For $L=x_{E}$, one recovers Pedlosky's inertial scaling, and scales for $v, w$ and $\ell$ can be derived using continuity $\left(U / L=V / \ell=W / D^{*}\right)$ and $\ell=(U / B)^{1 / 2}$ [consistent with a geostrophic balance in the meridional direction].

In order to justify the existence of our inertial regime, we now need to check that, for the scales derived above, the terms of vertical and horizontal friction are indeed negligible. We can write:

$$
\begin{aligned}
& {\left[A \nabla^{2} u\right]=\left[A u_{y y}\right]=\frac{A U}{l^{2}}=B A} \\
& {\left[\left(v u_{z}\right)_{z}\right]=\frac{\nu_{0} U}{D^{*^{2}}}}
\end{aligned}
$$

so that:

$$
\begin{aligned}
& R_{H}=\frac{\left[A \nabla^{2} u\right]}{\left[-p_{x} / \rho_{0}\right]}=B A\left(\frac{x_{E}}{-g^{\prime} \tau_{0}}\right) 1 / 2 \\
& R_{V}=\frac{\left[\left(\nu u_{z}\right)_{z}\right]}{\left[-p_{x} / \rho_{0}\right]}=\frac{\nu_{0} U}{-\tau_{0} D^{*}}=\frac{\nu_{0} g^{13 / 4} x_{E}}{\left(-\tau_{0} x_{E}\right)^{5 / 4}}\left(\frac{L}{x_{E}}\right)^{1 / 2}
\end{aligned}
$$

Using the following values for the equatorial Atlantic:

$$
\begin{aligned}
& x_{E}=55 \times 10^{5} \mathrm{~m} \\
& \tau_{0}=-0.5 \times 10^{-4} \mathrm{~m}^{2} \mathrm{~s}^{-2} \\
& \text { (so that: } \tau_{0} x_{E}=-275 \mathrm{~m}^{3} \mathrm{~s}^{-2} \text { ) } \\
& B=2.3 \times 10^{-11} \mathrm{~m}^{-1} \mathrm{~s}^{-1} \\
& g^{\prime}=2 \times 10^{-2} \mathrm{~m} \mathrm{~s}^{-2} \\
& A=2 \times 10^{3} \mathrm{~m}^{2} \mathrm{~s}^{-1} \\
& \nu_{O}=15 \times 10^{-4} \mathrm{~m}^{2} \mathrm{~s}^{-1}
\end{aligned}
$$

(the values for $A$ and $\nu_{0}$ being inspired by the GOM simulation), one obtains: 


$$
\begin{aligned}
& D^{*} \sim 120 \mathrm{~m} \\
& U \sim 1.5\left(\mathrm{~L} / \mathrm{x}_{E}\right)^{1 / 2} \leq 1.5 \mathrm{~m} \mathrm{~s}^{-1} \\
& R_{H} \sim 0.1 \\
& R_{V} \sim 0.4\left(L / x_{E}\right)^{1 / 2} \leq 0.4
\end{aligned}
$$

One can thus easily justify the neglect of horizontal friction, but less easily that of vertical friction, unless $\nu_{0}$ has been overestimated or $L$ is considerably smaller than $x_{E}$ (or both). For instance, reducing $v_{0}$ by a factor 3 or having $L / x_{E}=1 / 8$ would bring $R_{v}$ below 0.15 . On the other hand, multiplying $g^{\prime}$ by 2 reduces $D^{*}$ to $85 \mathrm{~m}$, and brings $U$ to $1.8 \mathrm{~m} \mathrm{~s}^{-1}, R_{H}$ to 0.07 and $\mathrm{R}_{\mathrm{V}}$ to 0.7 .

There is no doubt that vertical friction should enter the problem at some point, since it constitutes the mechanism by which the wind energy penetrates into the upper ocean. The question is how deep it penetrates and thus whether there is room left in the thermocline for the inertial regime that we are investigating. An estimate of the depth of penetration $D$ of vertical mixing effects can be obtained by setting $R_{v}$ equal to 1 :

$$
\frac{\nu_{0} U}{D^{2}} \frac{D^{*}}{-\tau_{0}}=1 \Rightarrow \frac{D}{D^{\star}}=\left(\frac{\nu_{0}^{U}}{-\tau_{0} D^{D^{*}}}\right)^{1 / 2}=\frac{\nu_{0}^{1 / 2} g^{3 / 8} x_{E}{ }^{1 / 2}}{\left(-\tau_{0} x_{E}\right)^{5 / 8}}\left(\frac{L}{x_{E}}\right)^{1 / 4}
$$

For the values used above, one gets:

$$
\frac{D}{D^{\star}}=0.5\left(\frac{L}{x_{E}}\right)^{1 / 4}
$$

Reducing $\nu_{0}$ by a factor 3 or having $L / x_{E}=1 / 8$ only brings $D$ down to about $D^{*} / 3$. This suggests that the upper frictional sublayer will occupy a substantial fraction of our original inertial region for realistic values of the parameters.

While this scaling argument cannot yield a precise vertical scale for the upper frictional regime, it does make the point that the two regimes are difficult to separate on the basis of scale analysis, even in the region close to the western boundary. 
As the thermocline slopes upwards to the east, $D^{*}$ decreases with distance eastwards and the vertical separation between inertial and frictional regimes is likely to become even more difficult. The possibility thus exists of a merging of the upper frictional and underlying inertial western regimes into a single nonlinear frictional regime past some transitional longitude.

5.3.2 Simulation_of a zonal transition_between_regimes_under_zonally uniform easterly_wind forcing

Let us consider a uniform easterly wind stress $\tau_{0}$ acting over an equatorial basin of zonal dimension $x_{E}$. And let us as above approximate the continuous stratification by a reduced gravity layer of depth $D^{*}$. $D^{*}$ thus represents the depth at which baroclinic adjustment has reduced the surface zonal pressure gradient to a negligible value. We are not however insisting that $z=D^{*}$ be a solid boundary for the flow above. In fact it needs to be somewhat permeable to justify the existence of the deep EUC 1ayers (section 5.4).

In order to simulate a zonal transition between regimes, our problem needs to be $x$-dependent, even for zonally uniform wind forcing. We can achieve this by introducing an explicit $x$-dependence of the depth $D^{*}$ as follows:

$$
\begin{aligned}
& g^{\prime} D^{*}=\frac{\tau_{0}}{D^{*}} \quad \Rightarrow \quad\left(D^{*}\right)_{x}=\frac{2 \tau_{0}}{g^{\top}} \\
& \text { or: } D *^{2}\left(x^{\prime}\right)=D *^{2}\left(x_{E}\right)-\frac{2 \tau_{0} x_{E}}{g}\left(1-x^{\prime}\right) \text {, }
\end{aligned}
$$

taking the origin of the $x$-axis at the western end of our domain, i.e. for practical purposes at the western boundary, and defining $x^{\prime}=x / x_{E}$. Taking $D^{*}\left(x_{E}\right)=0$ for simplicity, one recovers for $D^{*}$ near the western boundary a depth of the same order of magnitude as the depth scale introduced in the previous section:

$$
D *(0)=\left(\frac{-2 \tau_{0} x_{E}}{g^{\prime}}\right)^{1 / 2}=\sqrt{2}\left(\frac{-\tau_{0} x_{E}}{g^{\prime}}\right)^{1 / 2}
$$


In reality, the thermocline depth does not go to zero in the east: mixed layer turbulence imposes a minimum depth of about $20 \mathrm{~m}$ to the surface mixed layer. So in the following we will use the definition:

$$
D *\left(x^{\prime}\right)=\left(\frac{-2 \tau_{0} x_{E}}{g^{\prime}}\right)^{1 / 2}\left(1-x^{\prime}\right)^{1 / 2}
$$

but we will ignore results relative to the easternmost region where $D^{*}$ becomes less than about $20 \mathrm{~m}$.

We now define $U$ and $P^{*}$ as the vertically averaged zonal velocity and zonal pressure gradient per unit mass for our region of vertical extent $D^{*}$, set the value of $U$ at the western end of the region according to the scaling of section 5.3.1 and solve explicitiy for their zonal variation, using the relations:

$$
\begin{aligned}
& U(0)=\left(\frac{-g^{\prime} \tau_{0} x_{E}}{2}\right)^{1 / 4} \quad\left[\text { consistent with } D^{*}(0)\right] \\
& \frac{\partial}{\partial x}\left(\frac{U^{2}}{2}\right)=P^{*}=\frac{-\tau_{0}}{D^{*}}=\left(\frac{-g^{\prime} \tau_{0}}{2 x_{E}}\right)^{1 / 2} \frac{1}{\left(1-x^{\prime}\right)^{1 / 2}} .
\end{aligned}
$$

The following expression obtains for $U$ :

$$
U\left(x^{\prime}\right)=\left(\frac{-g^{\prime} \tau_{0} x_{E}}{2}\right)^{1 / 4}\left[5-4\left(1-x^{\prime}\right)^{1 / 2}\right]^{1 / 2} .
$$

The dimensionless number $R_{v}$ introduced in section 5.3.1 which measures the importance of vertical friction relative to the ZPG force can be written as a function of longitude as follows:

$$
R_{v}=\frac{\nu_{0} U}{-\tau_{0} D^{\star}}=\left(\frac{g^{13} v_{0}^{4}}{-2^{3} x_{E} \tau_{0}^{5}}\right)^{1 / 4}\left[\frac{5-4\left(1-x^{\prime}\right)^{1 / 2}}{\left(1-x^{\prime}\right)}\right]^{1 / 2} \text {. }
$$

The expression for $U$ derived above from an inertial balance is thus valid only up to the longitude $x^{\prime}{ }_{c}$ at which $R_{v}$ equals $1 . \quad x^{\prime}{ }_{c}$ is defined by: 


$$
\left[\frac{5-4\left(1-x_{c}^{1}\right)^{1 / 2}}{1-x_{c}^{1 / 2}}\right]=\left(\frac{-2^{3} x_{E} \tau_{0}^{5}}{g^{13} v_{0}^{4}}\right)^{1 / 4} \sim 4.3
$$

for the parameter values introduced in section 5.3.1. Setting $y=$ $\left(1-x^{\prime}\right)^{1 / 2}$, one obtains a simple quadratic equation in $y$. Its solutions yield a value of about 0.8 for the dimensionless longitude $x^{\prime}{ }_{c}$ at which $R_{v}$ first equals 1 . At that longitude, $U$ can be rewritten using $R_{v}\left(x^{\prime}{ }_{c}\right)=1$ :

$$
U\left(x^{\prime}{ }_{c}\right)=\left(\frac{-2 x_{E} \tau_{0}^{3}}{g^{\prime} v_{0}{ }^{2}}\right)^{1 / 2}\left(1-x^{\prime}{ }_{c}\right)^{1 / 2} .
$$

Past the 1ongitude $x^{\prime}{ }_{c}$, vertical friction remains of the same order of magnitude as the ZPG force, and an analytical expression for $U$ can be obtained by setting:

or

$$
R_{v}=\frac{\nu_{0} U}{-\tau_{0} D^{*}}=1 \Rightarrow U\left(x^{\prime}\right)=\frac{-\tau_{0} D^{*}\left(x^{\prime}\right)}{\nu_{0}},
$$

$$
U\left(x^{\prime}\right)=\left(\frac{-2 x_{E} \tau_{0}^{3}}{g^{\prime} \nu_{0}^{2}}\right)^{1 / 2}\left(1-x^{\prime}\right)^{1 / 2} \text { for } x^{\prime} \geq x^{\prime}{ }_{c}
$$

By construction, the two functions match at $x^{\prime}=x^{\prime} c^{\circ}$

The results from this simple analytical model are shown on Figure 73 (thick lines). Compared to the GCM simulation (Figure 60), the longitude $x^{\prime}{ }_{c}$ of transition between inertial accelerated regime west of $x^{\prime}{ }_{c}$ and frictional decelerated regime east of $x^{\prime}{ }_{c}$ tends to be located too far east. This should not be of much concern given the crudeness of our approximations, the fact that we ignore the eastern region of wind reversal, etc. The point of Figure 73 is to provide a visual illustration of the effect on $U$ of the transition between regimes. West of $x^{\prime}{ }_{c}, U$ increases slowly eastwards along with $p^{*}$. East of $x^{\prime}{ }_{c}, U$ decreases abruptly while on the contrary $p *$ continues to increase. 

$\tau\left(10^{-4} \mathrm{~m}^{2} \mathrm{~s}^{-2}\right)$
$\mathrm{P}^{*}\left(10^{-7} \mathrm{~ms}^{-2}\right)$
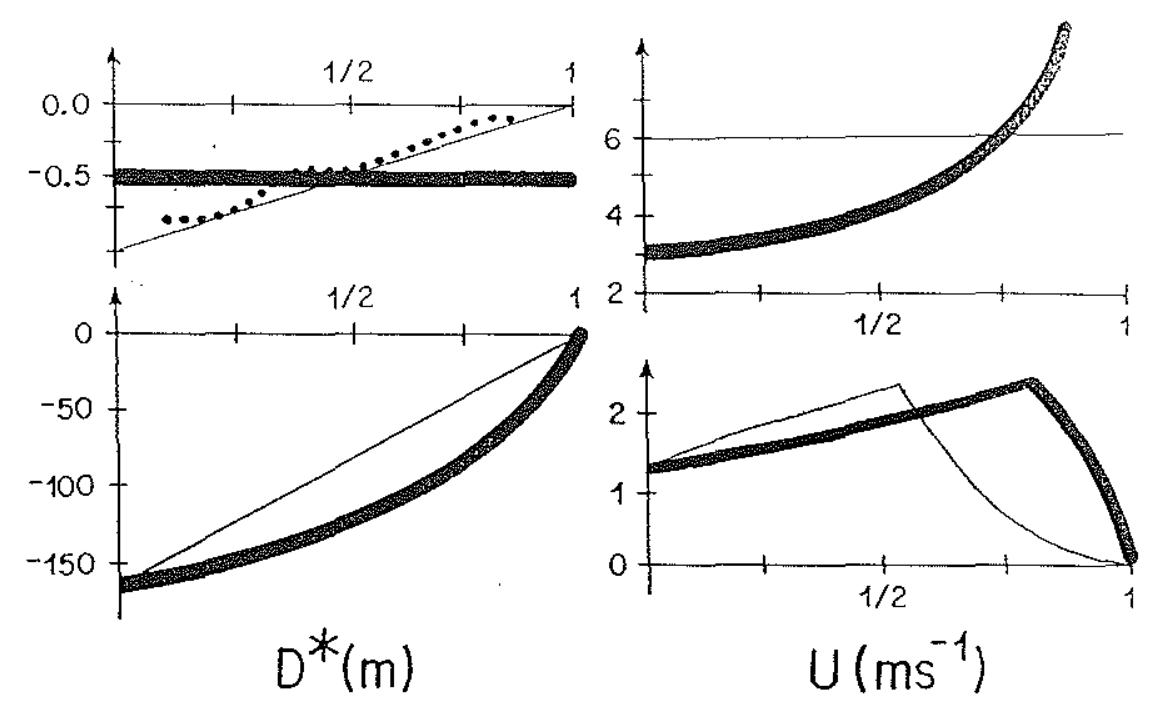

Figure 73: Results from a simple conceptual model of the upper undercurrent for zonally uniform (thick curves) and for zonally decreasing (thin curves) wind forcing. The dotted line represents the mean annual zonal wind stress at the equator. As a function of the dimensionless longitude $x^{\prime}$, and using the parameters of section 5.3.1, the following functions are plotted:

$$
\begin{aligned}
& D^{*}\left(x^{\prime}\right)=\left(\frac{-2 \tau_{0} x_{E}}{g^{\top}}\right)^{1 / 2} d\left(x^{\prime}\right) \sim 165 d\left(x^{\prime}\right) \\
& P^{*}\left(x^{\prime}\right)=\left(\frac{-g^{\prime} \tau_{0}}{2 x_{E}}\right)^{1 / 2} p\left(x^{\prime}\right) \sim 3 \times 10^{-7} p\left(x^{\prime}\right) \\
& 0 \leq x^{\prime} \leq x_{C}^{\prime}: U\left(x^{\prime}\right)=\left(\frac{-g^{\prime} \tau_{0} x_{E}}{2}\right)^{1 / 4} u_{w}\left(x^{\prime}\right) \sim 1.3 u_{w}\left(x^{\prime}\right) \\
& x_{C}^{\prime} \leq x^{\prime} \leq 1: U\left(x^{\prime}\right)=\left(\frac{-2 x_{E} \tau_{0}^{3}}{g^{\prime} v_{0}{ }^{2}}\right) 1 / 2 u_{e}\left(x^{\prime}\right) \sim 5.5 u_{e}\left(x^{\prime}\right)
\end{aligned}
$$

\begin{tabular}{|c|c|c|}
\hline & Thick curves & Thin curves \\
\hline $\begin{array}{l}\tau \\
d\left(x^{i}\right) \\
p\left(x_{i}^{i}\right) \\
u_{w}\left(x^{i}\right) \\
u_{p}\left(x^{i}\right) \\
\left.x_{c}{ }_{c}\right)\end{array}$ & $\begin{array}{c}\left.\tau_{0}\right) 1 / 2 \\
\left(1-x^{0}\right) 1 / 2 \\
\left(1-x^{0}\right)-1 / 2 \\
{\left[\begin{array}{c}\left.4\left(1-x^{0}\right)^{1 / 2}\right]^{1 / 2} \\
\left(1-x^{1}\right) 1 / 2 \\
0.8\end{array}\right.}\end{array}$ & $\begin{array}{c}2 \tau_{0}\left(1-x^{+}\right) \\
1-x^{1} \\
2 \\
\left(1+4 x^{1}\right) 1 / 2 \\
2\left(1-x^{1}\right)^{2} \\
0.5\end{array}$ \\
\hline
\end{tabular}


The infinite increase of $p *$ at the eastern boundary is somewhat artificial since it is forced by our letting $D^{*}$ go to zero. This can be fixed if the same model is forced by a more realistic wind of the form $\left[2 \tau_{0}\left(1-x^{\prime}\right)\right]$ (Figure 73 , thin curves): the zonal profile of $D^{*}$ becomes linear and $P^{*}$ becomes a constant throughout the basin. $U$ again increases west of $X^{\prime}{ }_{c}$ and decreases more sharply east of $x^{\prime} c^{\prime}$. Both cases thus illustrate the decorrelation between $U$ and $p *$ in the east.

Finally, it is worth noting that, with the zonal integral of the wind stress kept identical when going from a constant wind in the first case to a linearly decreasing wind in the second case, the location of $x^{\prime} c$ is found farther west in the second than in the first case, improving the comparison with the GCM simulation.

These results were obtained for the idealized case of constant $v_{0}$. They hold if one assumes that the depth of vertical mixing is a weaker function of longitude than the depth of baroclinic adjustment $D^{*}$. This is true in the GCM where the Richardson numberdependent vertical friction depends more on the vertical shear than on the stratification in regions of deep thermocline. We believe that it is a reasonable assumption for the real ocean.

\subsection{Justification for a deep EUC in the simulation}

As stressed in section 4.4, the deep eastward flow simulated by the GCM is of prime interest to this dissertation since it constitutes the undercurrent which "terminates" in the east. In this section we briefly review how to justify the existence and the dynamics of such a deep inertial flow dissipated by lateral friction.

We mentioned in section 5.2 how some of the accelerated inertial flow upwelled in the west as a result of heat convergence can remain at levels deeper than $z=-D^{*}$ and later be found in region (4) of the GOM simulation (Figure 51). [The stratification is not an obstacle to transfer of mass between regions (2) and (4) since the zonal slope of the deep isotherms from west to east is either flat or downwards east of the acceleration region.] 
Another possible source of eastward momentum for the deep flow are the lower layers of the overlying eastward flow in region (3). Through geostrophy, eastward flow in the lower thermocline corresponds to a bowing down of the isotherms at the equator. Under the action of lateral diffusion, this in turn permits a transfer of zonal momentum towards deeper levels since the flow can cross isotherms according to:

$$
u T_{x}+w T_{z}=A_{T} T_{y y}<0 \Rightarrow w / u<-T_{x} / T_{z}
$$

where $A_{T}$ is an eddy coefficient of lateral diffusion. Some downwelling across deep isopycnals was indeed described in section 3.2.1 (Figure 45d).

In section 5.3, we considered the region of substantial zonal pressure gradient (which we identified as the region above the base of the thermocline), and accordingly compared the magnitude of various dynamical terms to that of the ZPG force. We concluded that lateral friction was negligible at first order. Below, say, the middle of the thermocline however, the various dynamical terms become increasingly small in the continuously stratified case. Assuming that an inertial scaling $\ell=(U / \beta)^{1 / 2}$ is still relevant for the remaining eastward flow, the term of lateral friction $\mathrm{Au}$ yy continues to be scaled by the constant product $B A$. One may therefore anticipate that there exists a range of depths below the middle of the thermocline for which lateral friction becomes an order 1 term of the dynamical balance.

That is probably what happens in region (4) of the GCM simulation, where the annually averaged ZMB was seen in section 3.3 to reduce to:

$$
\overline{u u_{x}}+\overline{w u_{z}}=\overline{A \nabla^{2} u}
$$


CONCLUS ION

The main result of this dissertation is the novel picture of equatorial undercurrent dynamics which emerges from the analysis of Philander and Pacanowski's general circulation model. Being nonlinear and stratified, the GCM permits a much richer range of dynamical regimes than previous simpler models. At the equator one can identify several regions in which different approximations of the zonal momentum balance hold, as summarized below:

1) In the west, one finds an accelerated inertial regime below an accelerated inertio-frictional regime. The positive zonal inertial acceleration corresponds to an excess of eastward zonal pressure gradient force over vertical friction. Water originates at higher latitudes and is deflected eastwards and upwards at the equator.

2) Farther east, the depth scale appropriate for the accelerated inertial regime shrinks. (This is also the depth scale for the bottom of the thermocline below which baroclinic adjustment becomes negligible). East of a critical longitude, the whole eastward flow above the base of the thermocline becomes a noninear frictional regime. The inertial deceleration is mostly vertical advection of zonal momentum and is due to the excess of vertical friction over eastward ZPG force. Water comes from the west and from higher latitudes, is deflected eastwards and upwards, crosses isopycnals, and is recirculated westwards and polewards in the surface layer.

3) Below the thermocline in the central and eastern basin both ZPG and vertical stress become negligible. Here one finds an inertial zonal flow mostly fed by the deep western accelerated region and retarded by lateral friction.

The accelerated inertial regime is similar to Pedlosky's (1987), the nonlinear frictional regime to Charney's (1960) and Charney and Spiegel's (1971). No regime similar to the inertial regime found 
below the GCM thermocline has been previousiy described in the 1 iterature.

The above description of coexisting regimes is very likely to apply at least qualitatively to the EUC observed in the real ocean because it is consistent with two observations that have received little attention in the past: the existence of eastward flow considerably below the depth at which zonal pressure gradients become negligible, and the location of the bulk of the eastern EUC below the eastern thermocline (rather than above or within). These best support the concept defended in this dissertation of two distinct regimes in the vertical with negligible interaction and different retarding mechanisms (the upper mechanism being more efficient at retarding the flow than the lower one).

A related result is that the eastern termination of the model EUC is really the termination of the lower inertial flow. In agreement with Lukas'(1981) description of the eastern Pacific undercurrent, the final weakening of the subsurface eastward flow is insensitive to the reversal of the surface pressure gradient because the flow lies below the depth of baroclinic adjustment. The terminating undercurrent should therefore have the character of an inertial flow impinging onto a wall. That the GCM underestimates the longitude of penetration and the strength of the simulated EUC in the east may be caused by too large a coefficient for horizontal mixing. By contrast, the upper levels of the mid-basin EUC are retarded by vertical frictional exchanges with the overlying westward surface flow. They are directly influenced by the local winds and by the fact that these winds progressively lose their intensity eastwards. The remaining eastward momentum of these upper levels is destroyed by the action of the reversal of the surface ZPG force in the east. Given the considerable decrease in zonal transport between the mid-basin and the eastern undercurrents, it can be said that most (about 95 percent) of the EUC terminates in the overlying westward flow rather than at the eastern coast. 
The GCM analysis also briefly addresses the seasonal variation of the equatorial circulation. It explains the apparent deepening of the EUC core in response to an increase in the local wind forcing by a frictional deceleration of the upper levels concomitant with an inertial acceleration of the lower levels.

A new scale analysis of the equatorial circulation was able to rationalize to some extent the existence of a zonal transition between the upper regimes on the basis of an $x$-dependent depth scale for baroclinic adjustment, which shrinks to the east. The considerably larger values of that depth scale in the west were attributed to heat convergence by the opposing deep westward return flow. The argument was however purely qualitative and the western region deserves more attention in the future since it may be crucial in determining the ultimate speed of the EUC by acting as a Bernoulli head.

Observational contributions of this thesis include a review of ZPG measurements and their comparison with simultaneous estimates of the EUC speed in all equatorial oceans. Despite unsatisfactory spatial and temporal resolution, the Atlantic and Pacific data suggest that the main mechanism for changing the zonal eastward transport on a seasonal basis is downhill acceleration of the surface flow in the spring when the easterlies weaken and temporarily fail to balance the still eastward ZPG force; changes in the ZPG itself appear of secondary importance. On interannual time scales however, changes in the ZPG do seem to directly influence the EUC strength.

A review of the current meter measurements available east of $5^{\circ} \mathrm{W}$ in the Gulf of Guinea, and of the ambiguities still remaining in the description of the seasonal modulation of the eastern Atlantic EUC is also presented. It is suggested that part of the experimental scatter is due to aliasing by interannual variations. Finally, evidence is offered for the existence, between 0 and $5^{\circ} \mathrm{S}$ in the Gulf of Guinea, of a coastal undercurrent similar to the Peru-Chile undercurrent in the eastern Pacific, and only reported sporadically in 
the past south of $5^{\circ} \mathrm{S}$. The observations are not inconsistent with Lukas'(1981) hypothesis of a seasonal surge of the undercurrent to the coast and a concomitant seasonal branching of EUC waters into the coastal southeastward undercurrents. However, in neither termination region do the observations conclusively relate the coastal undercurrents to the equatorial circulation. 


\section{REFERENCES}

Arnault, S., 1984. Variation saisonnière de 1a topographie dynamique et de 1 a circulation superficielle de 1'océan Atlantique tropical. Thèse de doctorat 3ème cycle, Université $P$. et $M$. Curie, Museum National di'Histoire Naturelle de Paris.

Arthur, R. S., 1960. A review of the calculation of ocean currents at the equator. Deep-Sea Research, 6 , 287-297.

Brink, K.H., D. Halpern, A. Huyer, and R.L. Smith, 1983. The physical environment of the peruvian upwelling system. Progress in Oceanography, 12, 285-305.

Brockmann, C., E. Fahrbach, and A. Huyer, 1980. The poleward undercurrent along the Peru coast: 5 to $15^{\mathrm{S}} \mathrm{S}$. Deep-Sea Research, 27A, 847-856.

Bryan, K., 1969. A numerical method for the study of the world ocean. Journal of Computational Physics, 4, 347-376.

Bryan, K., and M. D. Cox, 1972. An approximate equation of state for numerical models of ocean circulation. Journal of Physical Oceanography, $2,510-514$.

Bryden, H. L., and E. C. Brady, 1985. Diagnostic model of the threedimensional circulation in the upper equatorial Pacific ocean. Journal of Physical Oceanography, 15, 1255-1273.

Bryden, H. L., E. C. Brady, and D. Halpern, 1986. Lateral mixing in the equatorial Pacific 0cean. U.S. TOGA Workshop on the dynamics of the equatorial oceans, Hawaii.

Busalacchi, A.J., and J. Picaut, 1983. Seasonal variability form a model of the Tropical Atlantic 0cean. Journal of Physical Oceanography, $13,1564-1588$.

Cane, M. A., 1979a. The response of an equatorial ocean to simple wind-stress patterns: I. Model formulation and analytic results. Journal of Marine Research, 37, 233-252.

Cane, M. A., 1979b. The response of an equatorial ocean to simple wind stress patterns: II. Numerical results. Journal of Marine Research, 37, 253-299.

Cane, M. A., 1980. On the dynamics of equatorial currents, with application to the Indian 0cean. Deep-Sea Research, 27A, 525-544.

Cane, M. A., and R. J. Patton, 1984. A numerical model for lowfrequency equatorial dynamics. Journal of Physical Oceanography, 14, $1853-1863$. 
Cane, M. A., and E. S. Sarachik, 1977. Forced baroclinic ocean motions: The linear equatorial bounded case. Journal of Marine Research, 35, 395-432.

Cane, M. A., and E. S. Sarachik, 1983. Equatorial oceanography. Reviews of Geophysics and Space Physics, 21, 1137-1148.

Cardone, V., C. Greenwood, Y. Tourre, and P. Chavy, 1988. High frequency surface wind fields during SEQUAL/FOCAL 1982-1984. To be submitted.

Charney, J. G., 1960. Non-1 inear theory of a wind-driven homogeneous layer near the Equator. Deep-Sea Research, 6, 303-310.

Charney, J. G., and S. L. Spiegel, 1971. Structure of wind-driven equatorial currents in homogeneous oceans. Journal of Physical Oceanography, $\underline{1}, 149-160$.

Cox, M. D., 1984. A primitive equation, three-dimensional model of the ocean. GFDL Ocean Group Technical Report No.1, Aug. 30, 1984.

Cromwel1, T., 1953. Circulation in a meridional plane in the central equatorial Pacific. Journal of Marine Research, 12, 196-213.

Dillon, T. M., J. N. Moum, T. K. Chereskin, and D. R. Caldwell, 1988. on the zonal momentum balance at the equator. Journal of Physical Oceanography, submitted.

Duing, W., P. Hisard, E. Katz, J. Meincke, L. Miller, K. V. Moroshkin, G. Philander, A. A. Ribnikov, K. Voigt, and R. Weisberg, 1975. Meanders and 1ong waves in the equatorial Atlantic. Nature, 257, 280-284.

Duing, W., and D. Johnson, 1972. High resolution current profiling in the Straits of Florida. Deep-Sea Research, 19, 259-274.

Eriksen, C. C., 1979. An equatorial transect of the Indian Ocean. Journal of Marine Research, 37, 215-232.

Eriksen, C. C., and E. J. Katz, 1987. Equatorial dynamics. Reviews of Geophysics and Space Physics, 21, 217-226.

Fiadeiro, M. E., and G. Veronis, 1984. Obtaining velocities from tracer distributions. Journal of Physical Oceanography, 14, 1734-1746.

Firing, E., R. Lukas, J. Sades, and K. Wyrtki, 1983. Equatorial undercurrent disappears during 1982-83 El Niño. Science, 222, 1121-1123. 
Fofonoff, N. P., and R. B. Montgomery, 1955. The Equatorial Undercurrent in the light of the Vorticity Equation. Tellus, VII, 518-521.

Gallardo, Y., 1981. Ockanographie physique. In: Milieu marin et resources hal ieutiques de la République Populaíre du Congo, Travaux et documents de 1T0.R.S.T.0.M., 138, 0.R.S.T.O.M., Paris.

Gerard, R., R. Sexton, and P. Mazeika, 1965. Parachute drogue measurements in the eastern tropical Atlantic in September 1964. Journal of Geophysical Research, 70, 5696-5698.

Gi11, A. E., 1971. The equatorial current in a homogeneous ocean. Deep-Sea Research, 18, 421-431.

Gi11, A. E., 1975. Models of equatorial currents. Procedures of Symposium on Numerical Models of Ocean Circulation, NationaT Academy of Science, Durham, Oc tober 1972, 181-203.

Guillerm, J. M., 1981. Contribution à l'océanographie physique du golfe de Guinée: hydrologie et circulation saisonniere sur une radiale au large de Pointe-Noire (Congo). Thèse de doctorat d'Université de Bretagne Occidentale, faculté des Sciences et Techniques.

Gunther, E.R., 1936. A report on oceanographical investigations in the Peru coasta1 current. Discovery Reports, 13, 107-276.

Halpern, D., 1980. A Pacific equatorial temperature section from $172^{\circ} \mathrm{E}$ to $110^{\circ} \mathrm{W}$ during winter and spring 1979. Deep-Sea Research, 27, 931-940.

Halpern, D., 1984. Upper ocean current and temperature observations along the equator west of the Galapagos Islands before and during the 1982-83 ENSO event. El Niño/Southern Oscillation Worskhop, Climate Res. Comm., Nat1. Res. Counc., Miami, Florida.

Halpern, D., 1987a. Anomalous circulation in the equatorial Pacific during the 1982-83 E1 Niño. In: Further Progress in Equatorial Oceanography. A report of the U.S. TOGA workshop on the dynamics of the equatorial ocean, Honolulu, Hawai i, August 11-15, 1986. E. J. Katz and J. M. Witte, editors.

Halpern, D., 1987b. Observations of annual and interannual (E1 Niño) thermal and flow variations along the equator in the eastern Pacific Ocean during 1980-1985. Journal of Geophysical Research, 92, 8197-8212.

Halpern, D., and H. P. Freitag, 1987. Vertical motion in the upper ocean at the equator in the eastern Pacific. Oceanologica Acta, submitted. 
Harrison, D. E., and V. Cardone, 1984. Tropical Atlantic wind field variations during SEQUAL: preliminary results. Geophysical Research Letters 11,722-725.

Hayes, S. P., 1982. A comparison of geostrophic and measured velocities in the EUC. Journal of Marine Research, 40 (Supplement), 219-229.

Hellerman, S., and M. Rosenstein, 1983. Normal monthly wind-stresses over the world ocean with error estimates. Journal of Physical Oceanography, 13, 1093-1104.

Hénin, C., P. Hisard, and B. Piton, 1986. Observations hydrologiques dans 1'océan Atlantique équatorial (juillet 1982-août 1984). FOCAL Volume 1, Editions de 1'O.R.S.T.0.M.

Hide, R., 1969. Dynamics of the atmospheres of the major planets with an appendix on the viscous boundary layer at the rigid boundary surface of an electrically conducting rotating fluid in the presence of a magnetic field. Journal of Atmospheric Sciences, 26 , 841-853.

Hisard, P., 1980. Observation de reponses de type "E1 Niño" dans 11. Atlantique tropical oriental Golfe de Guinée. Oceanologica Acta, 3, 69-78.

Hisard, P., F. Citeau, and A. Morlière, 1975. Le courant de Lomonosov et la formation de la zone frontale du cap Lopez (Baie de Biafra, Golfe de Guinée). Cahiers O.R.S.T.0.M., série Océanographie, XIII, $107-116$.

Hisard, P., F. Citeau, and A. Morlière, 1976. Le système des contrecourants équatoriaux subsuperficiels. Permanence et extension de, 1a branche sud dans 1'océan At lantique. Cahiers 0.R.S.T.O.M., série Océanographie, XIV, 209-220.

Hisard, P., and C. Hénin, 1984. Zonal pressure gradient, velocity and transport in the Atlantic EUC from FOCAL cruises [July 82-

Feb 84). Geophysical Research Letters, 11, 761-764.

Hisard, P., and C. Hénin, 1987. Response of the equatorial Atlantic ocean to the 1983-84 wind from the FOCAL cruises data set. Journal of Geophysical Research, 92, 3759-3768.

Hisard, P., C. Hénin, R. Houghton, B. Piton, and P. Rual, 1986. Oceanic conditions in the tropical Atlantic during 1983 and 1984. Nature, 322, 243-245. 
Hisard, P., and A. Morlière, 1973. La terminaison du contre-courant equatorial subsuperficiel Atlantique (courant de Lomonosov) dans le Golfe de Guinée. Cahiers O.R.S.T.O.M., série Océanographie, $11,455-464$.

Hogg, N. G., 1987. A least-squares fit of the advective-diffusive equations to the Levitus Atlas data set. Journal of Marine Research, 45, 347-375.

Jarrige, F., and P. Rual, 1981. Measurements in the equatorial currents of the Atlantic and Pacific oceans. In: Recent Progress in Equatorial Oceanography. A report of the finat meeting of SCOR working group 47 in Venice, Italy, April 27-30, 1981. J. P. McCreary, D. W. Moore and J. M. Witte, editors, pp. 111-120.

Joyce, T. M., 1988a. On large-scale cross-equatorial flow in the Pacific Ocean. Journal of Physical Oceanography, in press.

Joyce, T. M., 1988b. On the wind-driven cross equatorial flow in the Atlantic Ocean. Journal of Physical Oceanography, in press.

Joyce, T., R. Lukas, and E. Firing, 1988. On the hydrostatic balance and equatorial geostrophy. Deep-Sea Research, submitted.

Katz, E., 1985. Further thoughts on the occurrence of very saline water in the eastern Gulf of Guinea. Tropical Ocean-Atmosphere Newsletter, 33, 10-11.

Katz, E., R. Belevitsch, J. Bruce, V. Bubnov, J. Cochrane, W. Duing, P. Hisard, H. U. Lass, J. Meincke, A. deMesquita, L. Miller, A. Rybnikov, 1977. Zonal pressure gradient along the equatorial Atlantic. Journal of Marine Research, 35, 293-307.

Katz, E. J., J. G. Bruce, and B. A. Petrie, 1979. Salt and mass flux in the Atlantic EUC. Deep-Sea Research, 26 (supplement 2), 137-160.

Katz, E. J., and S. Garzoli, 1982. Response of the western equatorial Atlantic ocean to an annual wind cycle. Journal of Marine Research, Supplement to $40,307-327$.

Katz, E. J., P. Hisard, J. M. Verstraete, and S. L. Garzoli, 1986. Annual change of sea surface slope along the Equator of the Atlantic ocean in 1983 and 1984. Nature, 322, 245-247.

Katz, E. J., R. L. Molinari, D. E. Cartwright, P. Hisard, H. U. Lass, and $A$. deMesquita, 1981. The seasonal transport of the equatorial undercurrent in the western Atlantic (during the Global Weather Experiment). Oceanologica Acta, 4, 445-450. 
Khanaichenko, H. K., 1974. The system of equatorial countercurrents in the ocean. A. D. Dobrovol'skii, editor; Gidrometeoizdat publishers, Leningrad; American translation, 1980, Amerind Publication Company, New Delhi.

Knauss, J. A., 1966. Further measurements and observations on the Cromwell current. Journal of Marine Research, 24, 205-240.

Knox, R. A., 1976. On a long series of measurement of Indian ocean equatorial currents near Addu Atol1. Deep-Sea Research, 23, 211-221.

Knox, R. A., and D. L. T. Anderson, 1985. Recent advances in the study of the low-latitude ocean circulation. Progress in 0ceanography, 14, 259-317.

Kolesnikov, A. G., S. G. Boguslavskiy, G. N. Kukiin, V. A. Shirey, and V. G. Kiryukhin, 1971. Lomonosov current in the Gulf of Guinea. (Academy of Sciences of USSR). Oceanology, 11, 311-315.

Lass, H. U., V. Bubnov, J. M. Huthnance, E. J. Katz, J. Meincke, A. deMesquita, F. Ostapoff, B. Voituriez, 1983. Seasonal changes of the zonal pressure gradient in the equatorial Atlantic during the FGGE year. Oceanologica Acta, 6, 3-11.

Leetmaa, A., and P. F. Spain, 1981. Results from a velocity transect along the equator from $125^{\circ}$ to $159^{\circ} \mathrm{W}$. Journal of Physical Oceanography, $11,1030-1033$.

Leetmaa, A., J. P. McCreary, and D. W. Moore, 1981. Equatorial currents: observations and theory. In: Evolution of Physical Oceanography, Scientific Surveys in Honor of Henry Stomme1; B. A. Warren and $\bar{C}$. Wunsch, editors; The MIT Press, Cambridge, Massachusetts, pp. 184-197.

Leetmaa, A., and D. Wilson, 1985. Characteristics of near surface circulation patterns in the eastern equatorial Pacific. Progress in Oceanography, Swallow volume, 14, 339-352.

Le Floch, J., 1970. La circulation des eaux d'origine subtropicale dans la partie orientale de 1'Atlantique équatorial étudiée en relation avec les mesures faîtes à bord du $N$. 0 . Jean Charcot en mai 68. Cahiers 0.R.S.T.0.M., série Océanographie, $8,77-113$.

Lemasson, L., 1975. Note sur la circulation dans 1:Atlantique tropical le long de $10^{\circ} \mathrm{W}$. Le contre-courant sud équatorial. Cahiers 0.R.S.T.0.M., série 0céanographie, 13, 339-343.

Lemasson, L., and B. Piton, 1968. Anomalie dynamique de la surface de la mer le long de 1 'équateur dans 1 'océan Pacifique. Cahiers 0.R.S.T.0.M., série Océanographie, 6 , 39-45. 
Lemasson, L., and J. P. Rebert, 1973a. Circulation dans la partie orientale de 1'Atlantique sud. Document Scientifique du Centre de Recherche 0céanographique diAbidjan, 4 , 91-124.

Lemasson, L., and J. P. Rebert, 1973b. Circulation dans le Golfe de Guinee. Etude de 1a region d'origine du sous-courant ivoirien. Cahiers 0.R.S.T.0.M., série Océanographie, 11, 303-316.

Lukas, R., 1981. The termination of the EUC in the eastern Pacific. $\mathrm{Ph.D}$. thesis, University of Hawaii.

Lukas, R., 1986. The termination of the EUC in the eastern Pacific. Progress in Oceanography, 16, 63-90.

Lukas, R., and E. Firing, 1984. The geostrophic balance of the Pacific equatorial undercurrent. Deep-Sea Research, 31, 61-66.

Mangum, L. J., and S. P. Hayes, 1984. The vertical structure of the ZPG in the eastern equatorial Pacific. Journal of Geophysical Research, 89, 10441-10449.

Mangum, L. J., S. P. Hayes, and J. M. Toole, 1986. Eastern Pacific Ocean circulation near the onset of the 1982/83 El Niño. Journal of Geophysical Research, 91, 8428-8436.

McCreary, J. P., 1981. A linear stratified ocean model of the equatorial undercurrent. Philosophical Transactions of the Royal Society of London, 298, 603-635.

McCreary, J. P., 1981. A linear stratified ocean model of the coastal undercurrent. Philosophical Transactions of the Royal Society of London, 302, 385-413.

McKee, W. D., 1970. Some topics in dynamical oceanography. Ph.D. thesis, University of Cambridge.

McPhaden, M., 1986. The equatorial undercurrent: 100 years of discovery. EOS, 67, 762-765.

Merle, J., 1980. Variabilité thermique annuelle et interannuelle de 1'océan Atlantique équatorial Est. L'hypothèse d'un "El Niño" Atlantique. Oceanologica Acta, 3 , 209-220.

Merle, J., and S. Arnault, 1985. Seasonal variability of the surface dynamic topography in the tropical Atlantic ocean. Journal of Marine Research, 43, 267-288.

Meyers, G., 1979. Annual variation in the slope of the $14^{\circ} \mathrm{C}$ isotherm along the equator in the Pacific 0cean. Journal of Physical Oceanography, 9, 885-891. 
Meyers, G., 1980. Do Sverdrup transports account for the Pacific North Equatorial Countercurrent? Journal of Geophysical Research, 85, 1073-1075.

Molinari, R.L., B. Voituriez, and P. Duncan, 1981. Observations in the subthermocline undercurrent of the equatorial South Atlantic ocean: 1978-1980. Oceanologica Acta, 4, 451-456.

Montgomery, R. B., 1962. Equatorial undercurrent observations in review. Journal of the Oceanographic Society of Japan, 20, 487-498.

Montgomery, R. B., and E. Palmen, 1940. Contribution to the question of the Equatorial Countercurrent. Journal of Marine Research, 3, $112-133$.

Moore, D. W., and S. G. H. Philander, 1977. Modeling of the tropical oceanic circulation. From: The Sea, Volume 6, 319-361. Goldberg, McCave, O'Brien, Steele, Editors; John Wiley and Sons.

Morlière, A., P. Hisard, and J. Citeau, 1974. Le courant de Lomonosov dans le fond du Golfe de Guinée en mai 1973. Document Scientifique du Centre de Recherche Océanographique dïAbidjan, $\underline{5}, 85-102$.

Moum, J. N., and D. R. Caldwe11, 1985. Local influences on shear-flow turbulence in the equatorial ocean. Science, 230, 315-316.

Neumann, G., W. H. Beatty, and E. Escowitz, 1975. Seasonal changes of oceanographic and marine-climatological conditions in the equatorial Atlantic. Final report of the Office of Naval Research contract NR083-307.

O'Brien, J. J., 1979. Equatorial oceanography. Reviews of Geophysics and Space Physics, 17, 1569-1575.

Pacanowski, R. C., and S. G. H. Philander, 1981. Parameterization of vertical mixing in numerical models of tropical oceans. Journal of Physical Oceanography, 11, 1443-1451.

Pedlosky, J., 1987. An inertial theory of the equatorial undercurrent. Journal of Physical Oceanography, 17, 1978-1985. A. Gill Memorial Issue.

Philander, S. G. H., 1971. The equatorial dynamics of a shallow homogeneous ocean. Geophysical Fluid Dynamics, 2, 219-245.

Philander, S. G. H., 1973a. The equatorial undercurrent: measurements and theories. Reviews of Geophysics and Space Physics, 11, 513-570. 
Philander, S. G. H., 1973b. The equatorial thermocline. Deep-Sea Research. 20, 69-86.

Philander, S. G. H., 1979. Variability of the tropical oceans. Dynamics of Atmospheres and Oceans, $3,191-208$.

Philander, S. G. H., 1981. The response of equatorial oceans to a relaxation of the trade winds. Journal of Physical Oceanography, 11, 176-189.

Philander, S. G. H., 1986. Unusual conditions in the tropical Atlantic 0cean in 1984. Nature, 322, 236-238.

Philander, S.G.H., and P. Delecluse, 1983. Coastal currents in low latitudes (with application to the Somali and El Niño currents). Deep-Sea Research, 30, 887-902.

Philander, S.G.H., W.J. Hurl in, and R.C. Pacanowski, 1986. Properties of long equatorial waves in models of the seasonal cycle in the tropical Atlantic and Pacific Oceans. Journal of Geophysical Research, 91, 14207-14211.

Philander, S. G. H., and R. C. Pacanowski, 1980. The generation of equatorial currents. Journal of Geophysical Research, $\underline{85}$, $1123-1136$.

Philander, S. G. H., and R. C. Pacanowski, 1981. Response of equatorial oceans to periodic forcing. Journal of Geophysical Research, 86, $1903-1916$.

Philander, S. G. H., and R. C. Pacanowski, 1986a. A model of the seasonal cycle in the tropical At7 antic ocean. Journal of Geophysical Research, 91, 14192-14206.

Philander, S. G. H., and R. C. Pacanowski, 1986b. The mass and heat budget in a model of the tropical Atlantic ocean. Journal of Geophysical Research, $91,14212-14220$.

Philander, S. G. H., and R. C. Pacanowski, 1987. Nonlinear effects in the seasonal cycle of the tropical Atlantic ocean. Deep Sea Research, 34, 123-137.

Philander, S. G. H., and A. D. Seige1, 1985. Simulation of El Niño of 1982-83. Chapter 33 in: Coupled Ocean-Atmosphere models, J. C. J. Nihoul, editor.

Picaut, J., J. Servain, A. Busalacchi, and M. Seva, 1984. Interannual variability versus seasonal variability in the tropical Atlantic. Geophysical Research Letters, 11, 787-790. 
Picaut, J., J. Servain, P. Lecomte, M. Seva, S. Lukas, and G. Rougier, 1985. Climatic atlas of the tropical Atlantic wind stress and sea surface temperature 1964-1979. Université de Bretagne occidentale and University of Hawaii.

Pickart, R. S., 1987. The entrainment and homogenization of tracers within the cyclonic Gulf Stream recirculation gyre. Ph.D. Thesis, Massachusetts Institute of Technology/Woods Hole Oceanographic Institution.

Piton, B., M. Besson, and P. Esposito, 1978. Compte-rendu de 1a participation du N. O. André Nizery à 1 'opération CIPREA (juill-août-sept 78). Centre 0.R.S.T.0.M. de Pointe-Noire, Océanographie, Doc. 625 S. R.

Piton, B., Y. Monte1, and J. P. Gausi, 1978. Compte-rendu des campagnes effectuées par 1e N.0. Nizery de Mars à Sept. 1977 dans le sud-est du Golfe de Guinée. Centre 0.R.S.T.0.M. de PointeNoire, Océanographie, Doc. 623.

Piton, B., and S. Wacongne, 1985. Unusual amounts of very saline subsurface water in the eastern Gulf of Guinea in May 1984. Tropical Ocean-Atmosphere Newsletter, 32, 5-8.

Rebert, J. P., J. R. Donguy, G. Eldin, and K. Wyrtki, 1985. Relations between sea level, thermocline depth, heat content, and dynamic height in the tropical Pacific Ocean. Journal of Geophysical Research, 90, 11719-11725.

Richardson, P. L., and T. K. McKee, 1984. Average seasonal variation of the Atlantic equatorial currents from historical ship drifts. Journal of Physical Oceanography, 14, 1226-1238.

Richardson, P. L., and K. Mooney, 1975. The Mediterranean outflow. A simple advection-diffusion model. Journal of Physical Oceanography, $5,476-482$.

Richardson, P. L., and S. G. H. Philander, 1987. The seasonal variations of surface currents in the tropical Atlantic 0cean: a comparison of ship drift data with results from a general circu1ation mode1. Journal of Geophysical Research, 92, 715-724.

Richardson, P. L., and G. Reverdin, 1987. Seasonal cycle of velocity in the Atlantic North Equatorial Countercurrent as measured by surface drifters, current meters, and ship drifts. Journal of Geophysical Research, 92, 3691-3708.

Rinke1, M. 0., P. Sund, and G. Neumann, 1966. The location of the termination area of the equatorial undercurrent in the Gulf of Guinea based on observations during EQUALANT III. Journal of Geophysical Research, 71, 3893-3901. 
Robinson, A. R., 1960. The general thermal circulation in the equatorial regions. Deep Sea Research, 6, 311-317.

Schopf, P. S., and M. A. Cane, 1983. On equatorial dynamics, mixed layer physics and sea surface temperature. Journal of Physical Oceanography, 13, 917-935.

Semtner, A. J., 1974. An oceanic general circulation model with bottom topography. UCLA Department of Meteorology, Technical Report No. 9,31 December 1974.

Smith, R.L., 1983. Peru coastal currents during El Niño: 1976 and 1982. Science, 221, 1397-1399.

Stomme1, H. M., 1960. Wind-drift near the Equator. Deep-Sea Research, $6,298-302$.

Taft, B. A., and J. A. Knauss, 1967. The equatorial undercurrent of the Indian 0cean as observed by the Lusiad expedition. Bulletin of Scripps Institution of Oceanography, $9,1-163$.

Tréguier, A. M., and Y. du Penhoat, 1983. Réponse basse fréquence d'un modèle numérique de l'Atlantique équatorial. Antenne 0.R.S.T.0.M. COB Brest, doc. tech. BC n 27, 0ctobre 83.

Tsuchiya, M., 1968. Upper waters of the intertropical Pacific Ocean. The Johns Hopkins Oceanographic Studies, No. 4. The Johns Hopkins Press, Baltimore, Maryland.

Tsuchiya, M., 1979. Seasonal variation of the equatorial zonal geopotential gradient in the eastern Pacific Ocean. Journal of Marine Research, 37, 399-407.

Van Bennekom, A.J., and G.W. Berger, 1984. Hydrography and silica budget of the Angola Basin. Netherlands Journal of Sea Research, 17, 149-200.

Veronis, G., 1960. An approximate theoretical analysis of the equatorial undercurrent. Deep-Sea Research, 6 , 318-327.

Voituriez, B., 1980a. Campagnes CIPREA. L'upwelling equatorial du Golfe de Guinée, juin-septembre 1978. Pub1. du CNEXO, Resultats des campagnes à 1 a mer No. 19.

Voituriez, B., 1980b. Equatorial upwelling in the eastern Atlantic: problems and paradoxes. In: Coastal Upwelling, F. A. Richards, editor, Coastal and Estuarine Sciences, 1, American Geophysical Union, Washington, D.C., pp. 95-106. 
Voituriez, B., 1981. The equatorial upwelling in the eastern Atlantic ocean. In: Recent progress in equatorial oceanography. A report of the finaT meeting of SCOR working group 47 in venice, Italy, April 27-30, 1981. J. P. McCreary, D. W. Moore and J. M. Witte, editors, pp. 229-247.

Voituriez, B., 1983. Les variations saisonnières des courants équatoriaux à $4^{\circ}$ W et 1'upwelling équatorial du Golfe de Guinée. 1. Le sous-courant équatorial, 2. Le courant équatorial sud. Océanographie tropicale, 18, 1. 163-183, 2. 185-199.

Wauthy, B., 1977. Révision de la classification des eaux de surface du Golfe de Guinée (Berrit 1961). Cahiers 0.R.S.T.0.M., série Océanographie, 15, 279-295.

Weisberg, R., 1984. Instability waves observed on the equator in the Atlantic ocean during 1983. Geophysical Research Letters, 11, 753-756.

Weisberg, R., and C. Colin, 1986. Equatorial Atlantic ocean temperature and current variations during 1983 and 1984 . Letters to Na ture, 322, 240-243.

Weisberg, R. H., J. H. Hickman, T. Y. Tang, and T. J. Weingartner, 1987. Velocity and temperature observations during the SEQUAL experiment at $0^{\circ} 28^{\circ} \mathrm{W}$. Journal of Geophysical Research, 92, 5061- 5075 .

Weisberg, R. W., and A. M. Horigan, 1981. Low-frequency variability in the equatorial Atlantic. Journal of Physical Oceanography, 11, 913-920.

Weisberg, R. H., and T. J. Weingartner, 1986. On the baroclinic adjustment of the zonal pressure gradient in the equatorial Atlantic Ocean. Journal of Geophysical Research, 91, 11717-11725.

Wunsch, C., 1985. Can a tracer field be inverted for velocity Journal of Physical Oceanography, 15, 1521-1531.

Wyrtki, K., 1966. Oceanography of the eastern equatorial Pacific ocean. Oceanography and Marine Biology Annual Review, 4, 33-68, Harold Barnes, editor.

Wyrtki, K., 1967. Circulation and water masses in the eastern equatorial Pacific 0cean. International Journal of Oceanology and Limnology, 1, 117-147.

Wyrtki, K., 1973. An equatorial jet in the Indian Ocean. Science, $181,262-264$. 
Wyrtki, K., 1975. El Niño. The dynamic response of the equatorial Pacific 0cean to atmospheric forcing. Journal of Physical Oceanography, $\underline{5}, 572-584$.

Wyrtki, K., 1981. An estimate of equatorial upwelling in the Pacific. Journal of Physical Oceanography, 11, 1205-1214.

Wyrtki, K., 1983. An attempt to monitor the equatorial undercurrent. Journal of Geophysical Research, 88, 775-777.

Wyrtki, K., 1984. The slope of sea level along the equator during the 1982-1983 El Niño. Journal of Geophysical Research, 89, $10419-10424$.

Wyrtki, K., and G. Meyers, 1976. The trade wind field over the Pacific Ocean. Journal of Applied Meteorology, 15, 698-704.

Yoshida, K., 1959. A theory of the Cromwell current (the EUC) and of the equatorial upwelling -- an interpretation in a similarity to a coastal circulation. Journal of the Oceanographic Society of Japan, 15, 149-170.

Yoshida, K., 1967. Circulation in the eastern tropical oceans with special references to upwelling and undercurrents. Japan Journal of Geophysics, $4,1-75$. 


\section{Appendix I: MERIDIONAL STRUCTURE OF THE FLOW \\ AND THE ZONAL MOMENTUM BALANCE SIMULATED \\ BY THE GENERAL CIRCULATION MODEL}

In order to look in more detail at how the flow and the ZMB change with latitude in the upper and lower EUC in turn, Figures 74 and 75 were prepared for the regions above and below $100 \mathrm{~m}$ respectively, at $25^{\circ} \mathrm{W}$. This presentation allows us to adopt different scales in each region and thus better distinguish terms within the weak lower regime. Above $100 \mathrm{~m}$ at $1^{\circ} \mathrm{S}$ and $2^{\circ} \mathrm{S}$, the $Z P G$ force is eastwards and counteracted by vertical friction as at $0^{\circ} \mathrm{N}$ (Figure $74 \mathrm{~h}, \mathrm{i}$ ). But the net resulting force (f) which at $0^{\circ} \mathrm{N}$ was balanced by the inertial accelerations $\left(\overrightarrow{v u_{y}}+\overrightarrow{w u_{z}}\right)(g)$ is by $2^{\circ} \mathrm{S}$ mostiy balanced by the Coriolis acceleration $(\overrightarrow{f v})$, as both $\overrightarrow{v u}_{y}$ and $\overrightarrow{w u}_{z}$ become small $(1, \mathrm{~m})$. Accordingly, $\vec{v}$ at $2^{\circ} \mathrm{S}$ is polewards within the range of depths where $\left.\overline{\left(-p_{X} / \rho_{0}\right.}+\overrightarrow{\left(v u_{z}\right)_{z}}\right)$ is negative, and equatorwards below where the net force is positive $(c, f)$. Closer to the equator, the vertical profile of $\vec{v}$ is dominated by the influence of the meridional wind stress (a) and the meridional pressure gradient force which opposes it: $\vec{v}$ is northwards near the surface, southwards below. North of the equator, this reinforces the subsurface "zonally" forced equatorward flow just described, but south of the equator that equatorward flow tends to be cancelled. The meridional structure of $\overline{v u_{y}}$ reflects that asymmetry (1). Based on the southward evolution of the upper $100 \mathrm{~m}$-profiles at $25^{\circ} \mathrm{W}$ then, the transition between inertially accelerated flow at the equator and linearly accelerated flow off the equator occurs between $1^{\circ} \mathrm{S}$ and $2^{\circ} \mathrm{S}(k, 1, \mathrm{~m}, \mathrm{n})$. (One still cannot talk about a purely linear off-equatorial regime since the term of vertical friction remains nonlinear).

Let us now turn to the part of the EUC below $100 \mathrm{~m}$, where vertical friction has become negligible (Figure 75). Surface effects are no longer important, and in particular no longer force such a N-S asymmetry in the dynamics as in the region described above. off the 
equator, the ZPG force is now westwards over most of the domain ( $h$ ). At $2^{\circ} \mathrm{N}$ and $2^{\circ} \mathrm{S}$, it is balanced by the coriolis force $(n)$ and thus corresponds to a poleward geostrophic flow (c), too weak however to cause a substantial lateral flux of zonal momentum away from the lower EUC (1). At the equator, the main balance is between $\overleftarrow{u u_{x}}$ and $\overline{A \nabla^{2} u}$, at least below $120 \mathrm{~m}$. Again, it is between $1^{\circ}$, and $2^{\circ}$ of $f$ the equator that the inertial terms become negligible compared to the Coriolis acceleration $(k, 1, m, n)$.

The above description leaves out the intermediate depth range $90-120 \mathrm{~m}$ in which, on the annual mean, the term of vertical friction is already negligible but the ZPG force is still eastwards (Figure $76 \mathrm{~h}, \mathrm{i}$ ). That $30 \mathrm{~m}$-thick region is thus already isolated from surface effects but still accelerated by the ZPG force and by lateral influx of zonal momentum. $\vec{v}$ is equatorwards at $\pm 1^{\circ}$ and $\pm 2^{\circ}$ latitude (c) and causes a $\overline{v u}$ which does contribute substantially to the ZMB at $1^{\circ} \mathrm{S}$ and $1^{\circ} \mathrm{N}$ (1). Compared to the dynamics above $90 \mathrm{~m}$, the dynamics within the 90-120 $\mathrm{m}$ domain are, as for the dynamics below $120 \mathrm{~m}$, much more symmetric about the equator, and $\overline{\mathrm{vu}_{\mathrm{y}}}$ drops to zero at $0^{\circ} \mathrm{N}$. The balance at $0^{\circ} \mathrm{N}$ can be written:

$$
\overline{u u_{x}}+\overline{w u_{z}}=\overline{-p_{x} / \rho_{0}}+\overline{A \nabla^{2} u} \quad 0 \quad(h, j, k, m)
$$

and includes no signature of the meridional circulation. The righthand side represents a zero net force, since $\overline{-p_{x} / \rho_{0}}$ is roughly balanced by lateral dissipation ( $f$ ). The left-hand side therefore vanishes too $(\mathrm{g})$ and behaves 1 ike a free inertial jet flowing eastwards and upwards. As in the underlying regime, the ZMB is linear and geostrophic by $\pm 2^{\circ}$ latitude:

$$
-f \bar{v}=-\overline{p_{x} / \rho_{0}} \quad(h, n) .
$$


$2525 \mathrm{~W} \quad 1 \mathrm{~S} \quad \mathrm{ON} \quad 1 \mathrm{~N} \quad 2 \mathrm{~N} 25 \mathrm{~W}$
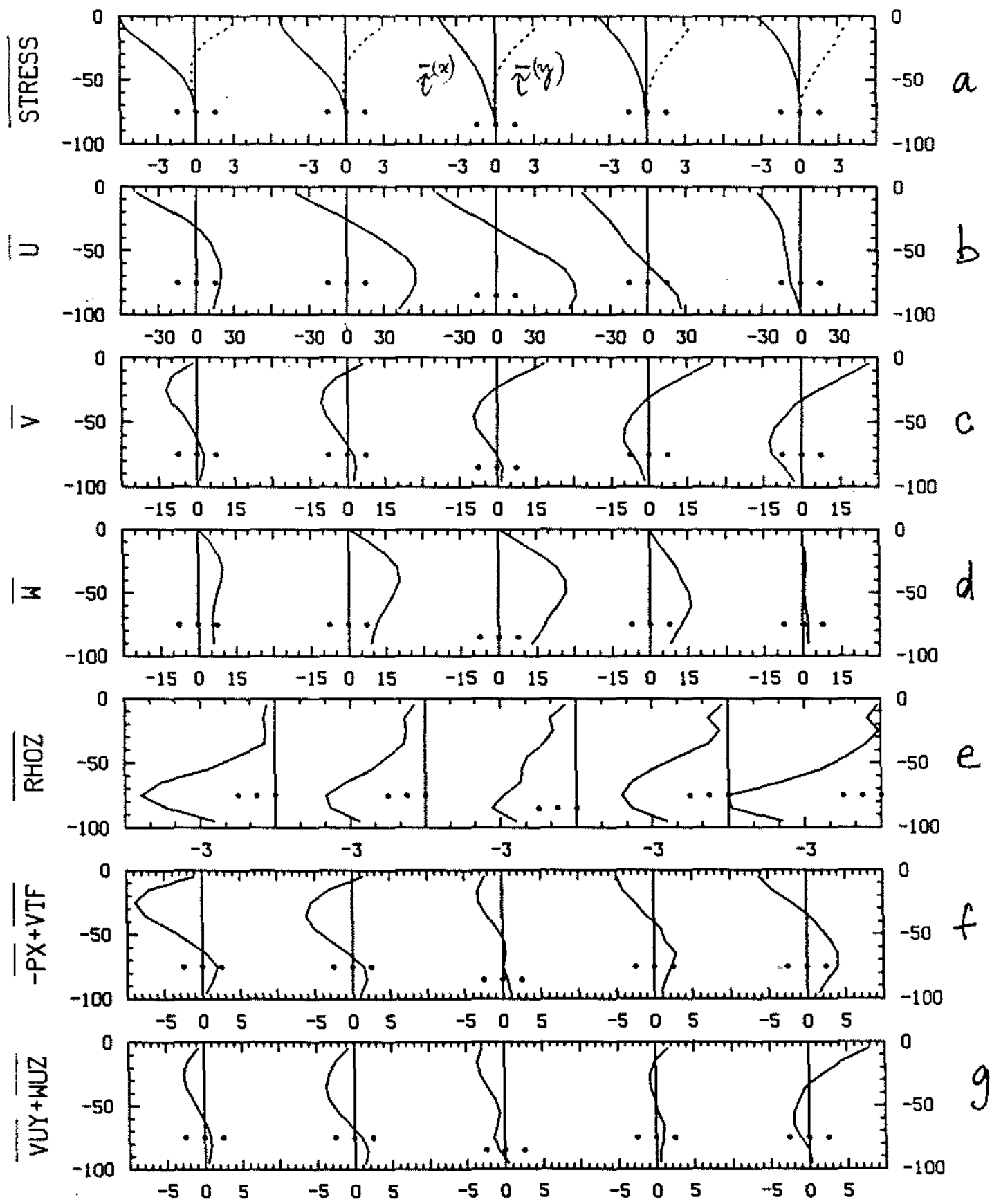

Figure 74: Vertical profiles of basic fields $(a, e)$ and zonal momentum balance terms $(h, n)$ simulated by the general circulation model at $25^{\circ} \mathrm{W}$ amd $2^{\circ} \mathrm{S}, 1^{\circ} \mathrm{S}, 0^{\circ} \mathrm{N}, 1^{\circ} \mathrm{N}$ and $2^{\circ} \mathrm{N}$ for the depth range $0-100 \mathrm{~m}$. 


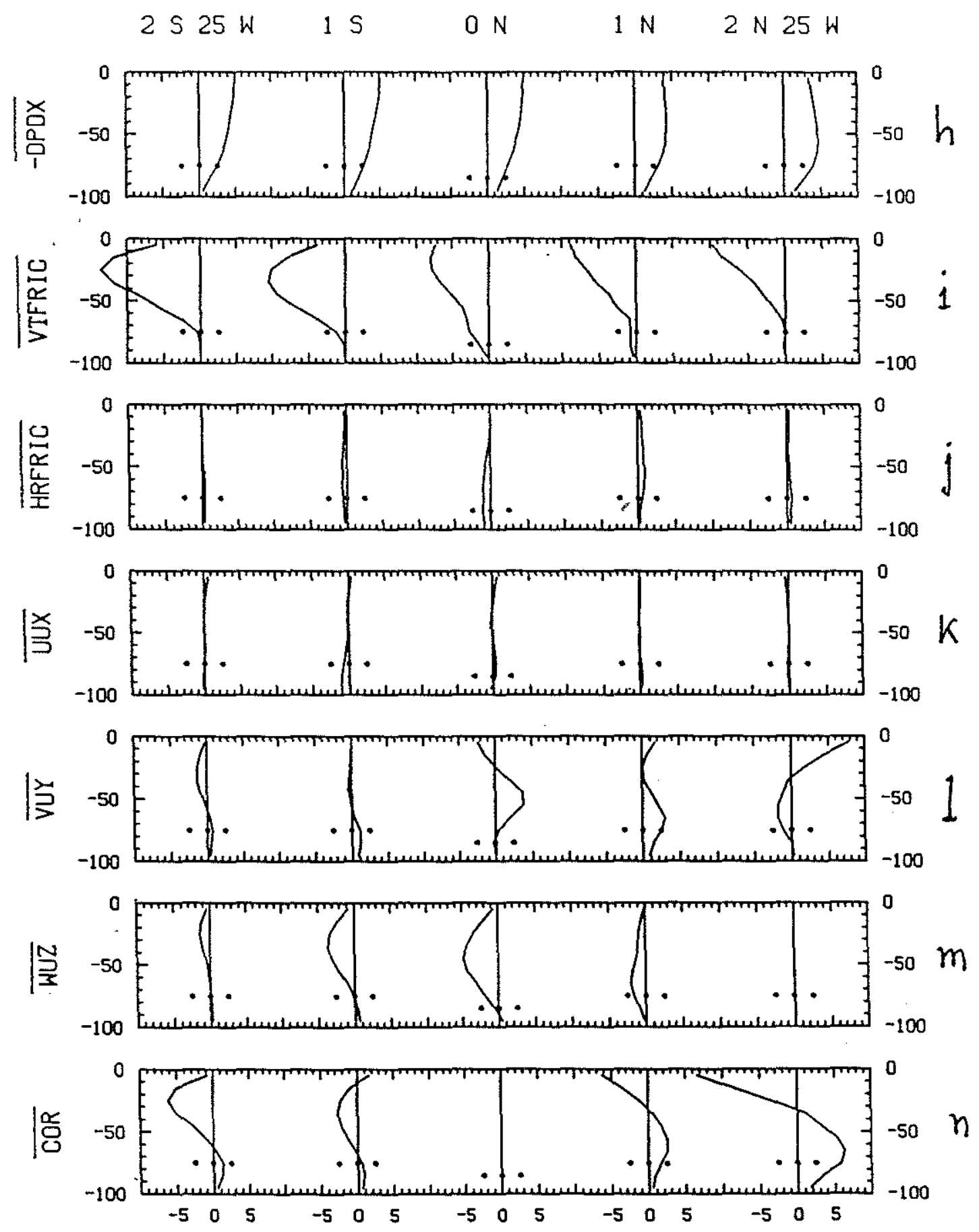

Figure 74 (Continued) 
$2 S 25 W \quad 1 S \quad O N \quad 1 N \quad 2 N 25 W$
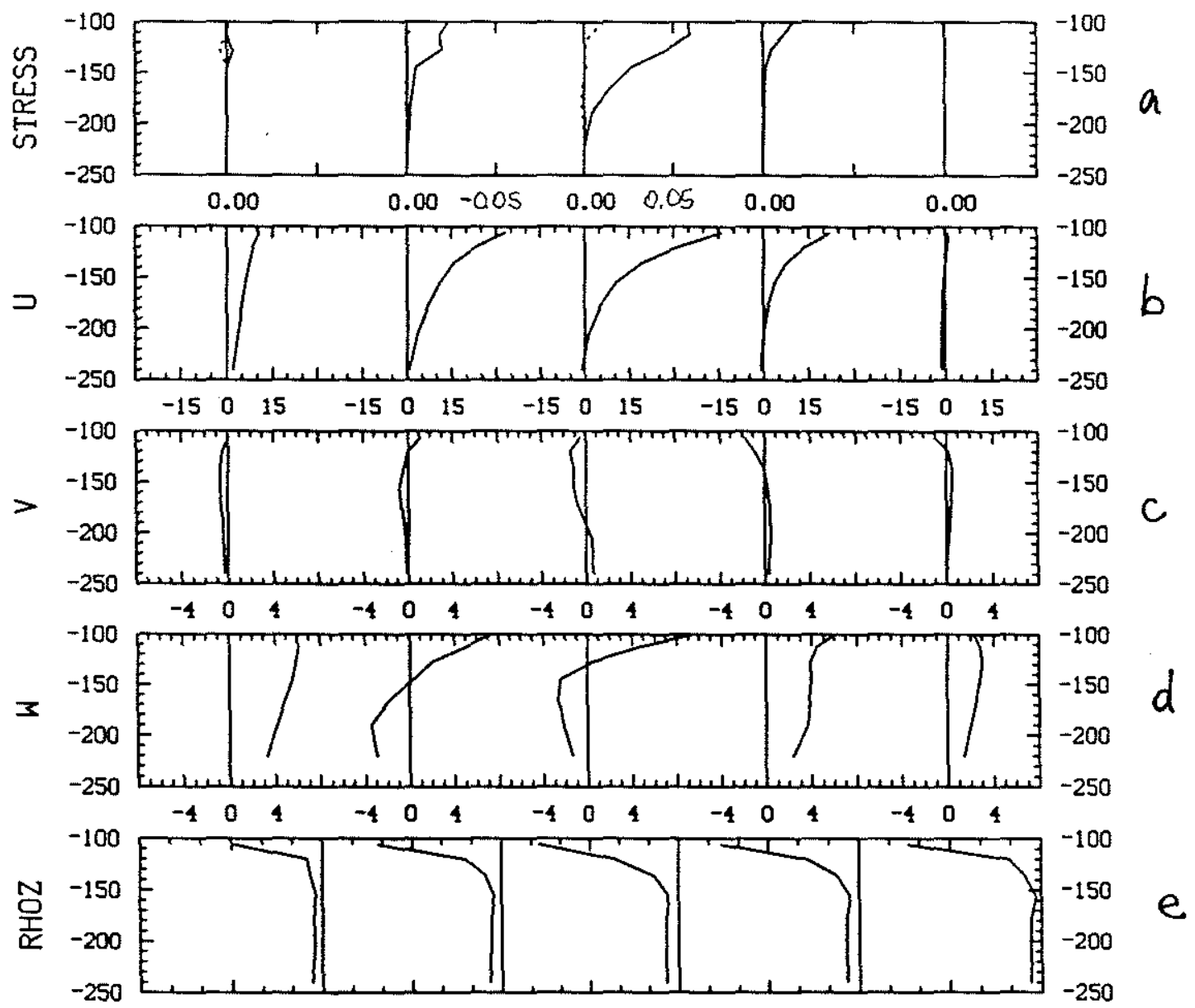

$d$

e

$a$

$b$

C

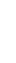


2 S. $25 \mathrm{~W} 1 \mathrm{~S} \quad 0 \mathrm{~N} \quad 1 \mathrm{~N} 2 \mathrm{~N} .25 \mathrm{~W}$
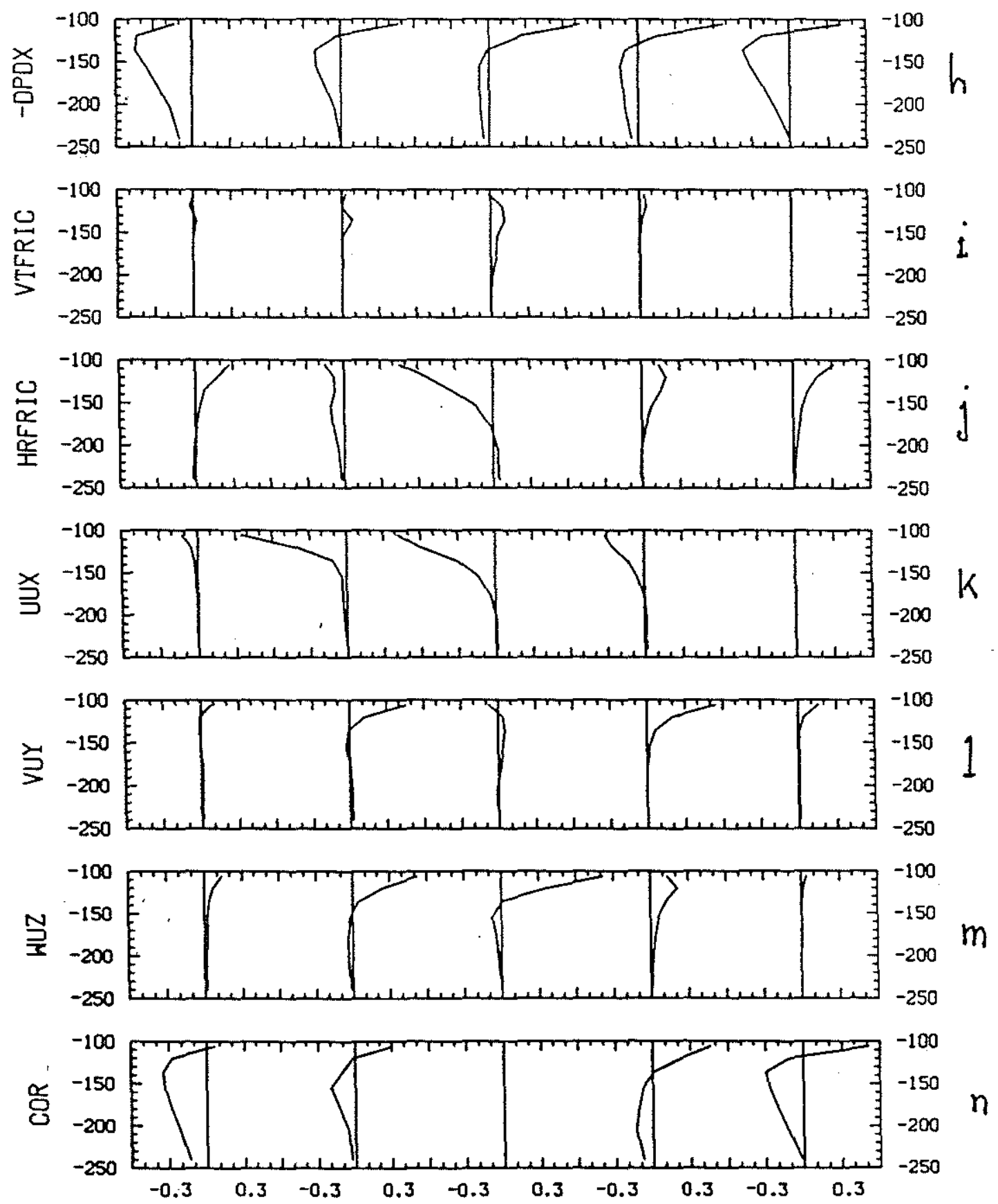

Figure 75 (Continued) 


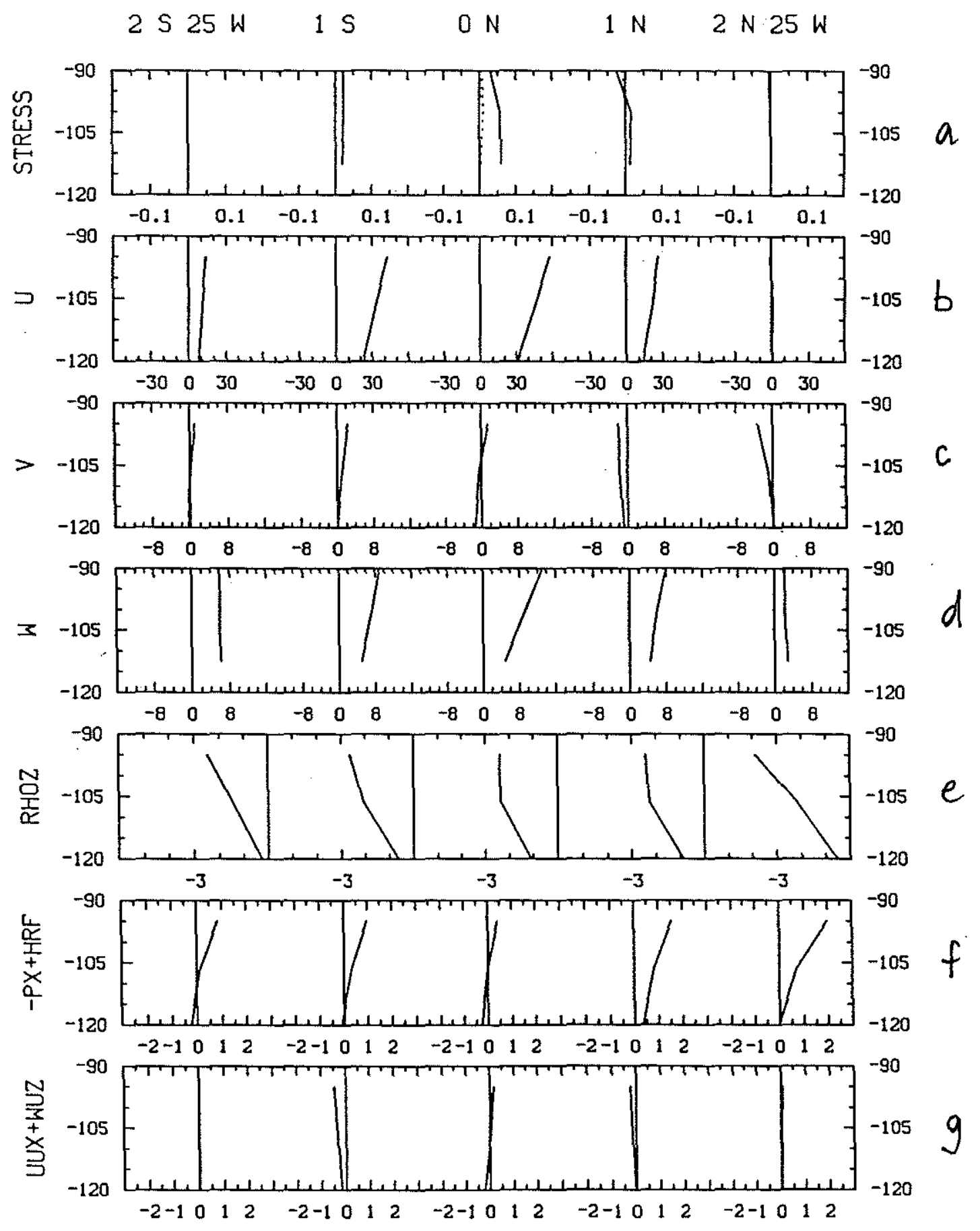

Figure 76: Same as Figure 74 for the range $90-120 \mathrm{~m}$. 


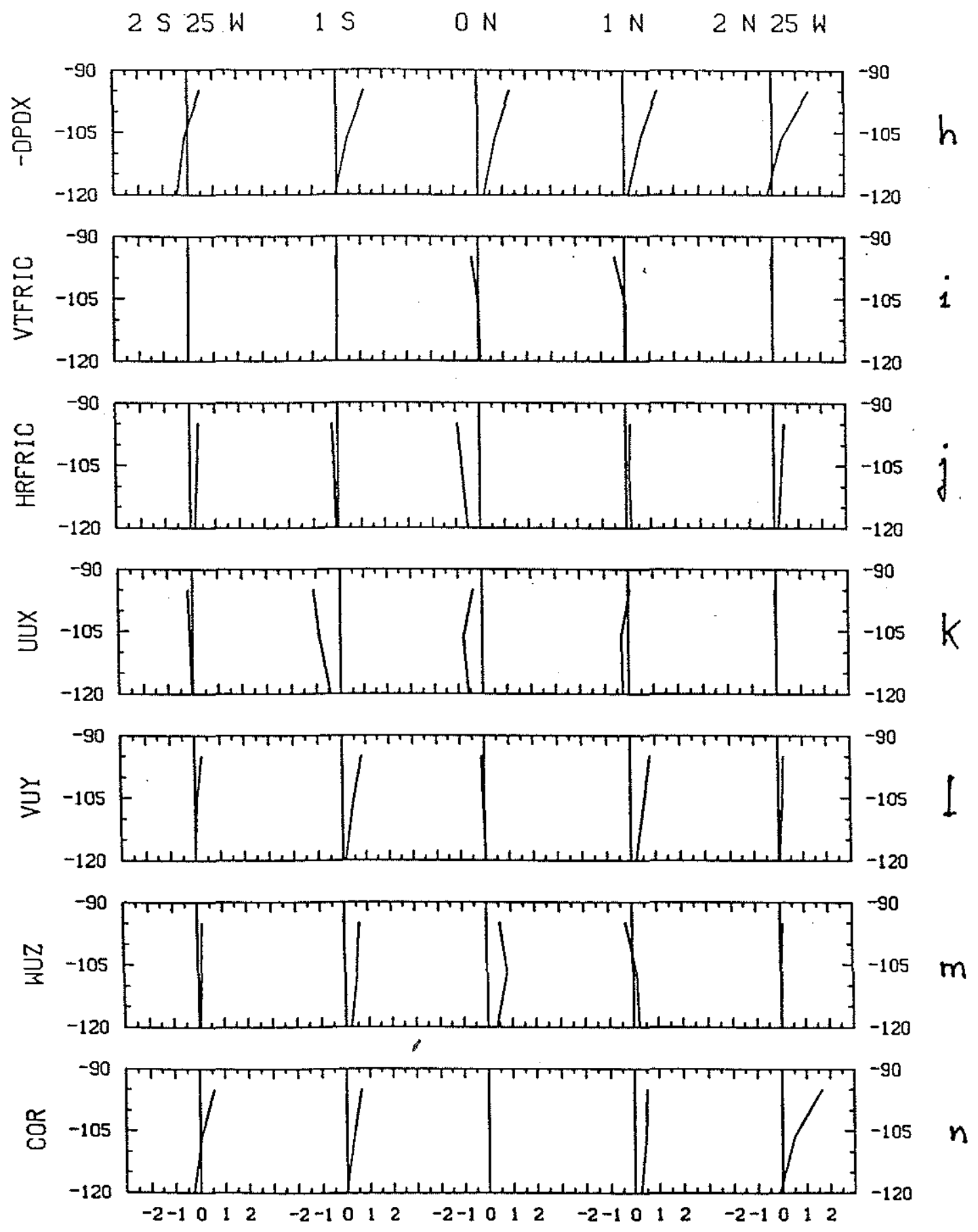

Figure 76 (Continued) 
